\title{
INFLUENCE OF CORROSION DAMAGE TOPOGRAPHY ON FATIGUE PROPERTIES IN LONGITUDINAL FUSELAGE LAP JOINTS
}

By

Jonathan Cook, B.Eng.

A thesis submitted to

the Faculty of Graduate Studies and Research

in partial fulfilment of

the requirements for the degree of

Master of Engineering

Department of Mechanical and Aerospace Engineering

Ottawa-Carleton Institute of

Mechanical and Aerospace Engineering

\author{
Carleton University \\ Ottawa, Ontario
}

April 2001

Work for this thesis was performed in conjunction with the NRC and performed under contract \#31184-9-7243/001/ST

Copyright (C) 2001 Her Majesty the Queen in right of Canada, as represented by the Minister of Industry 


$\begin{array}{ll}\begin{array}{l}\text { Library and } \\ \text { Archives Canada }\end{array} & \begin{array}{l}\text { Bibliothèque et } \\ \text { Archives Canada }\end{array} \\ \begin{array}{l}\text { Published Heritage } \\ \text { Branch }\end{array} & \begin{array}{l}\text { Direction du } \\ \text { Patrimoine de l'édition }\end{array} \\ \begin{array}{l}\text { 395 Wellington Street } \\ \text { Ottawa ON K1A 0N4 }\end{array} & \begin{array}{l}\text { 395, rue Wellington } \\ \text { Ottawa ON K1A ON4 } \\ \text { Canada }\end{array} \\ \end{array}$

Your file Votre référence ISBN: 0-612-97463-4 Ourfile Notre référence ISBN: 0-612-97463-4

The author has granted a nonexclusive license allowing the Library and Archives Canada to reproduce, loan, distribute or sell copies of this thesis in microform, paper or electronic formats.

The author retains ownership of the copyright in this thesis. Neither the thesis nor substantial extracts from it may be printed or otherwise reproduced without the author's permission.
L'auteur a accordé une licence non exclusive permettant à la Bibliothèque et Archives Canada de reproduire, prêter, distribuer ou vendre des copies de cette thèse sous la forme de microfiche/film, de reproduction sur papier ou sur format électronique.

L'auteur conserve la propriété du droit d'auteur qui protège cette thèse. $\mathrm{Ni}$ la thèse ni des extraits substantiels de celle-ci ne doivent être imprimés ou aturement reproduits sans son autorisation.
In compliance with the Canadian Privacy Act some supporting forms may have been removed from this thesis.

While these forms may be included in the document page count, their removal does not represent any loss of content from the thesis.
Conformément à la loi canadienne sur la protection de la vie privée, quelques formulaires secondaires ont été enlevés de cette thèse.

Bien que ces formulaires aient inclus dans la pagination, il n'y aura aucun contenu manquant. 


\begin{abstract}
The results of a parametric study assessing the effects of corrosion on fatigue characteristics in riveted fuselage joints are described. Using a uniaxial specimen, known to produce realistic multiple site damage (MSD), testing of seven specimens, four precorroded and three non-corroded, was completed. This work is part of the ageing aircraft research activities being conducted by Carleton University, in collaboration with the National research Council of Canada (NRC).
\end{abstract}

Corrosion pitting is known to play an important role in expediting fatigue crack nucleation in fuselage joints. However, corrosion-fatigue research incorporating the effects of corroded surface topography is limited. The work described herein, addresses this issue and develops an approach for quantifying corrosion pitting damage, suitable for use in fracture mechanics modelling. Measurement of corrosion topography is accomplished using digitised $\mathrm{x}$-ray (DXR) images of fuselage joint specimens. Using finite element modelling, a relationship has been established between corrosion pitting geometry and the corresponding stress concentration factor (SCF). A probabilistic approach was utilised for representing corrosion damage in fuselage joints. Therefore, probability distributions of pit depth and SCF have been developed, for varying levels of material thickness loss. 


\section{ACKNOWLEDGEMENTS}

This thesis, and all of my work, is dedicated to my mother, Carole Ann Cook. It is to the memory of her caring and guidance that I owe all of my success.

I would like to thank my thesis supervisor, Professor Paul Straznicky for the leadership, and friendship he provided throughout my research. I would also like to show my appreciation to Paul and my co-supervisor, Graeme Eastaugh, for providing me with such an interesting and challenging project.

I would like to express my sincerest thanks to the staff at the Institute for Aerospace Research for all of their help on this project.

- Expertise and advice on any ageing aircraft issue - Nick Bellinger, and Ron Gould

- NDI - Ted Chapman, Mike Brothers, David Forsyth, and Sylvain Giguere

- Strain Gauging - Michel Delannoy, and Michael Kennedy

- Fatigue Testing - Danielle Godin, and Tom Benak

- Fractography - Dr. Ali Merati, David Chow

- Technical Support - Jim Keller and Charles Wilson

- Image processing - David Forsyth, Sherri Sparling

- Wyko ${ }^{\circledR}$ optical profilometry - Sing Yick (NRC Innovation Centre, Vancouver)

- Confocal Microscopy - Robert Monette (NRC-Institute for Biological Sciences)

Special thanks go to Danielle Godin for her invaluable help in fatigue testing and posttest analysis.

I would like to thank my family who gave me nothing but support, love and encouragement, and Denielle, for her caring, patience and understanding throughout these past several years. 


\section{TABLE OF CONTENTS}

NOMENCLATURE XVII

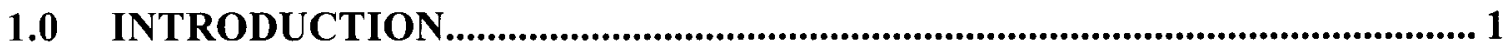

\subsection{STRUCTURES SUSCEPTIBLE TO MSD .............................................. 6}

2.1 Evolution of Aircraft Design CRiteria ................................................. 6

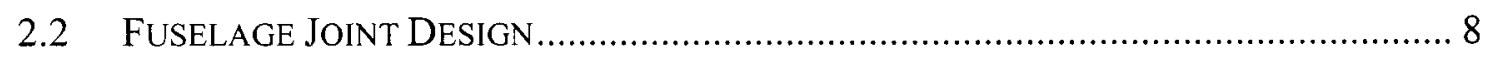

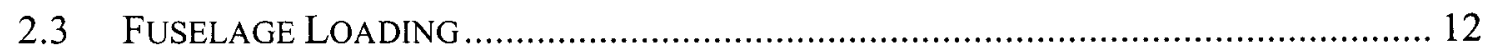

2.3.1 Longitudinal Fuselage Joint Loads .................................................. 13

2.3.2 Load Transfer in Longitudinal Fuselage Joints ...................................... 16

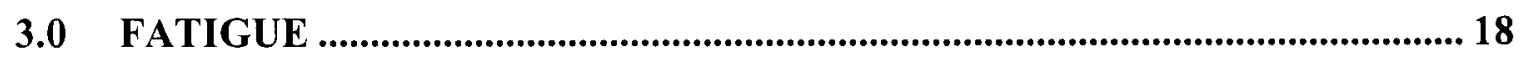

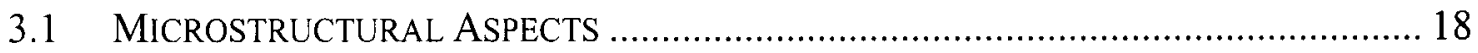

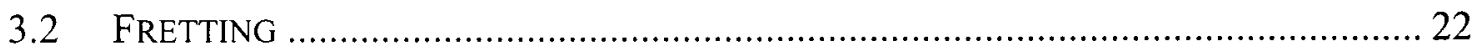

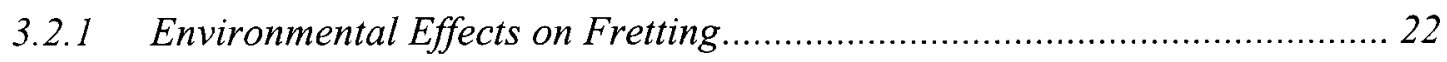

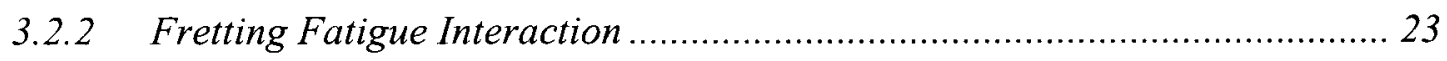

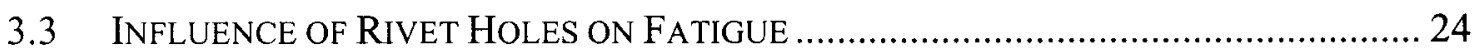

3.3.1 Cracking Beneath Rivet Heads ............................................................. 24

3.3.2 Crack Growth Beyond Rivet Heads ................................................. 26

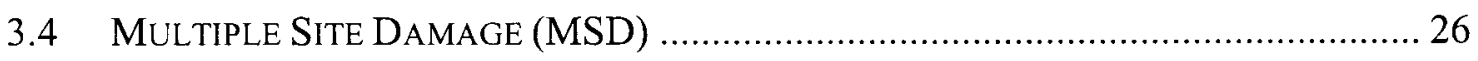

3.4.1 Interaction of Multiple Fatigue Cracks ................................................. 27

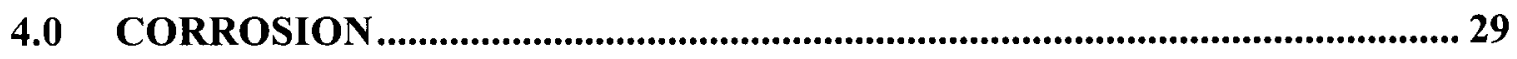

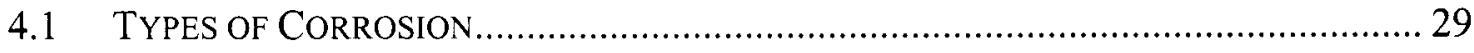

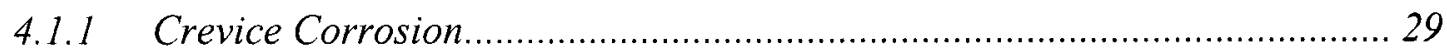

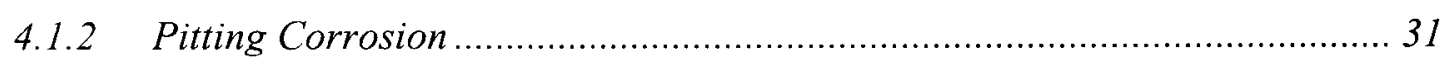

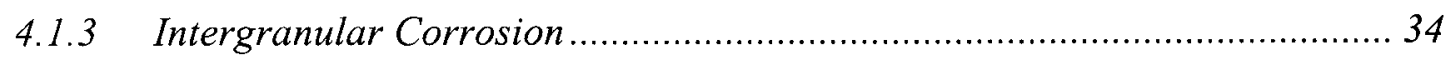

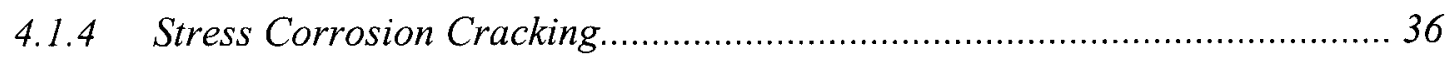

4.2 Corrosive ATTACK IN FuSELAGE LAP JoINTS ............................................. 37

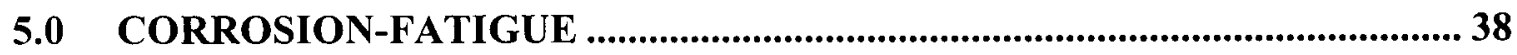




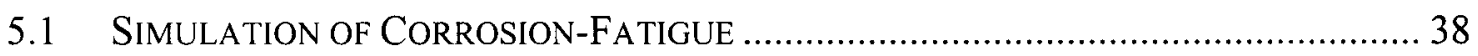

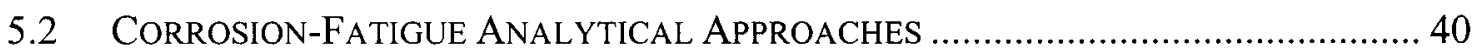

5.2.1 Proposed Corrosion-Fatigue Models ..................................................... 41

5.3 General Methodology (AdDresSED IN THIS THESIS) ................................. 45

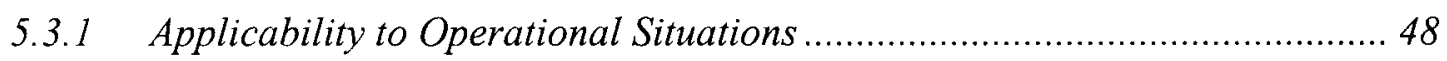

5.4 Influence of Corroded Surface Topography on CORRosion-Fatigue

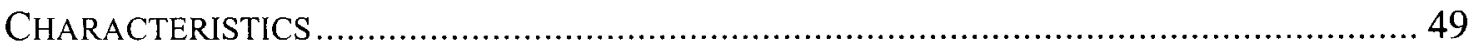

5.4.1 Previous Research Into Corrosion Topography Quantification.................. 49

\subsection{PROJECT DEFINITION}

6.1 Corrosion-Fatigue Testing (USING MSD SPECIMENS) ................................ 53

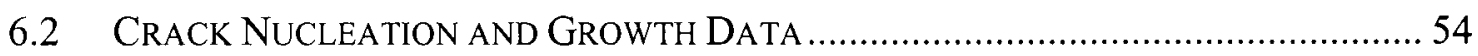

6.3 Forensic ANALYSIS OF CORRODED StRUCTURE (USING MSD SPECIMENS) ....... 54

6.3.1 Refinement of Existing Digitised Radiography Techniques........................ 54

6.4 CORROSION TOPOGRAPHY QUANTIFICATION ................................................. 54

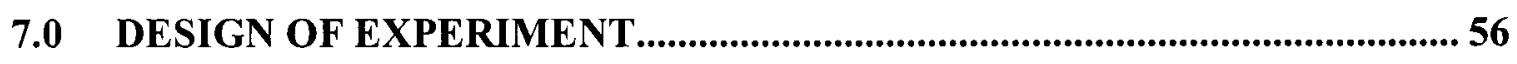

7.1 ReVIEW Of PREVIOUS EXPERIMENTAL DESIGN .............................................. 57

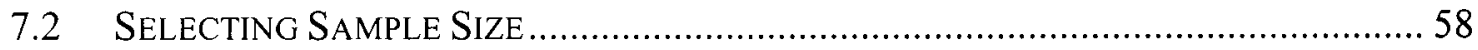

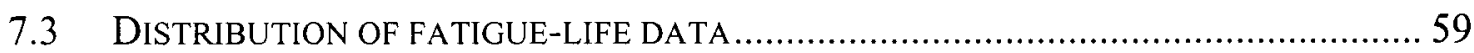

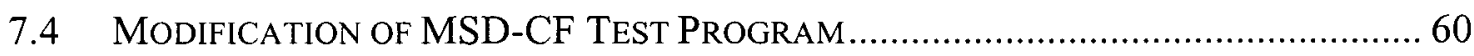

7.4.1 Statistical Analysis of Revised Test Program .............................................61

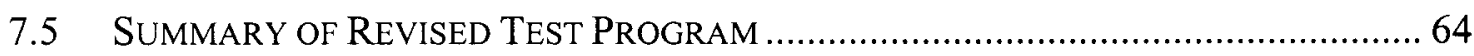

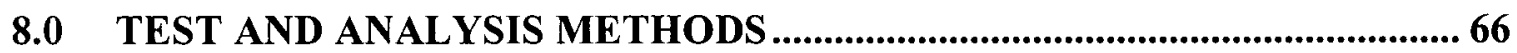

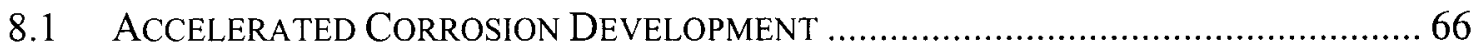

8.1.1 Monitoring of Corrosion Development ....................................................6 68

8.1.2 Inspection of Bonded Side-strap Region................................................ 70

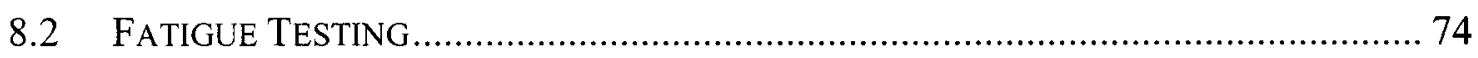

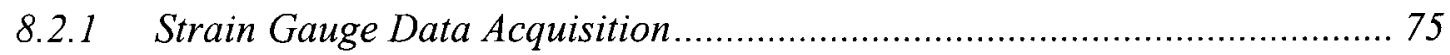

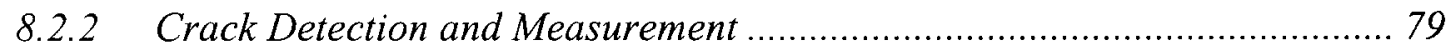

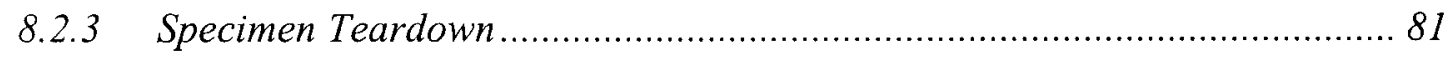




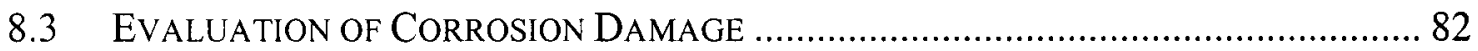

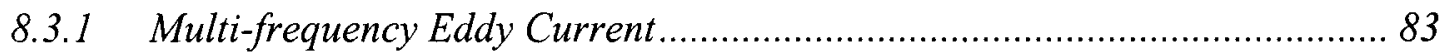

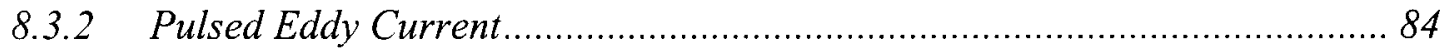

8.3.3 Digitised X-Radiography (DXR) Technique ...................................... 84

8.3.4 Pillowing-to-Thickness-Loss (PTL) Ratio................................................ 88

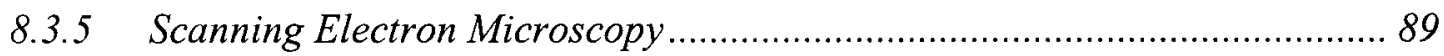

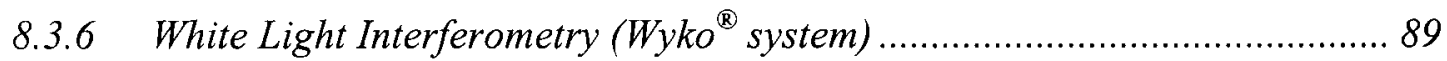

\subsection{TEST PROGRAM AND RESULTS …..............................................................90}

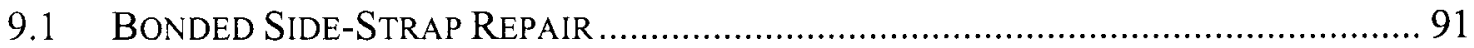

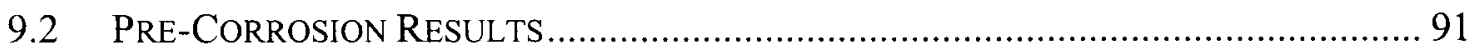

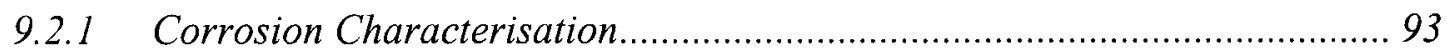

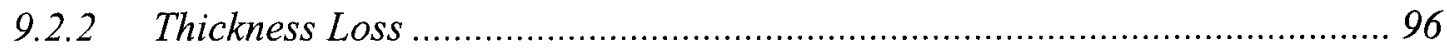

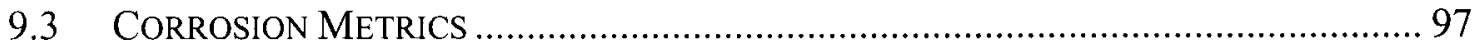

9.3.1 Pillowing-to-Thickness Loss (PTL) Ratio............................................ 97

9.3.2 Conventional and Pulsed Eddy Current ................................................ 99

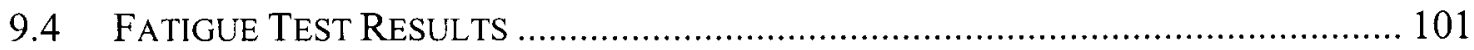

9.4.1 Non-Corroded Fatigue Test Results ...................................................... 101

9.4.2 Pre-Corrosion Fatigue Test Results ................................................... 107

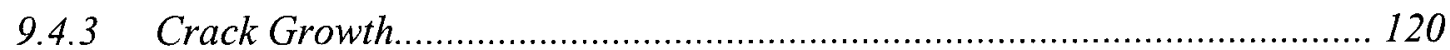

9.4.4 Influence of Repair on Corrosion-Fatigue Characteristics..................... 122

9.5 SUMMARY OF FATIGUE TEST RESULTS ....................................................... 123

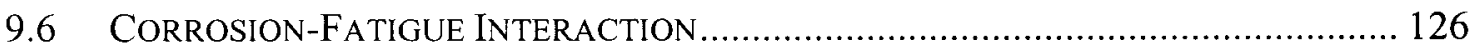

9.6.1 Changes in Visual Crack Detection Lives (VDL) ............................... 126

9.6.2 Changes in Membrane and Bending Stresses .................................... 127

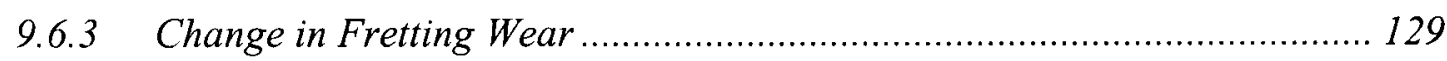

10.0 CORRODED SURFACE TOPOGRAPHY ANALYSIS ............................ 130

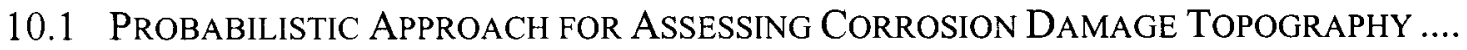

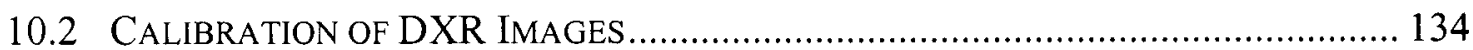

10.2.1 Thickness Calibration ......................................................................... 134 


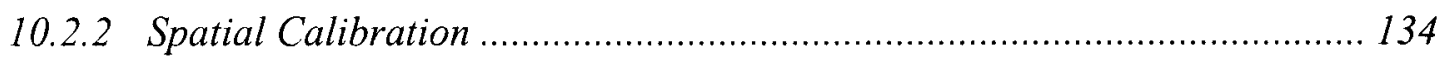

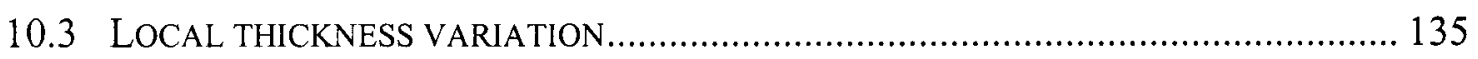

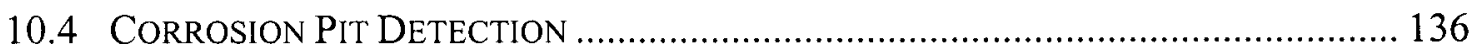

10.4.1 Corrosion Pit Detection Techniques..................................................... 136

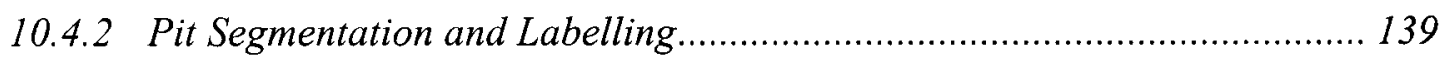

10.5 Measurement of Corrosion Pit Geometric Parameters........................... 142

10.5.1 Corrosion Pit Geometry Measurement Using Optical Microscopy .......... 142

10.5.2 Measurement of corrosion pit geometry using $I D L^{\circledR}$ analysis.................. 144

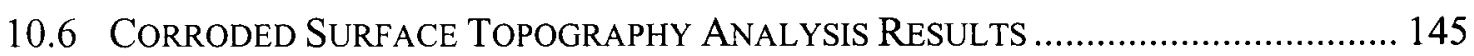

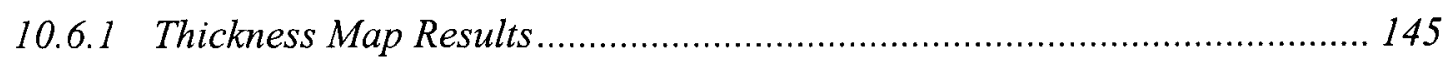

10.6.2 Corrosion Pit Analysis Results ........................................................ 146

10.6.3 Pit Geometry Validation ............................................................... 148

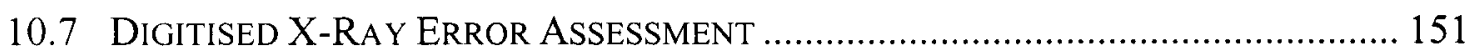

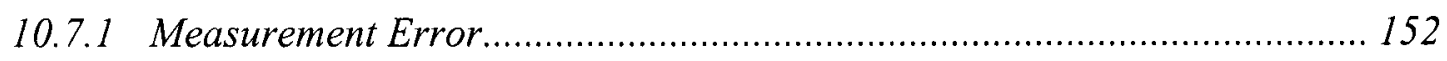

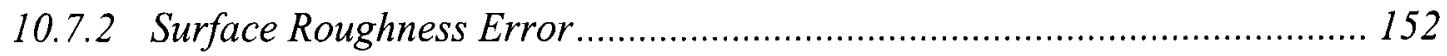

10.7.3 Radiographic Film Grain Variations ............................................ 152

10.7.4 X-Ray Beam Variation ........................................................... 152

10.7.5 Intensity Variations in the Processed X-Ray Film ................................. 153

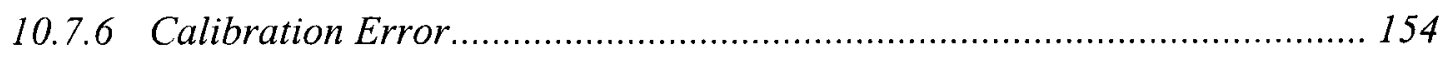

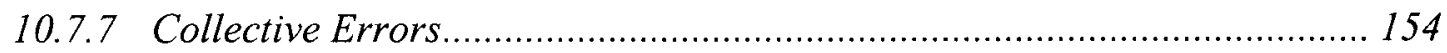

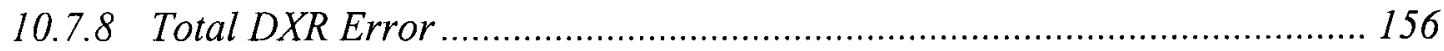

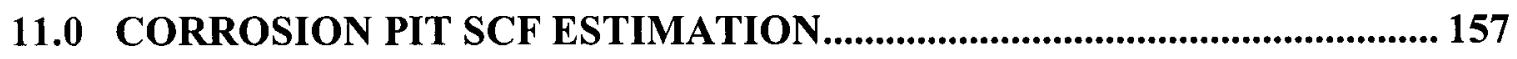

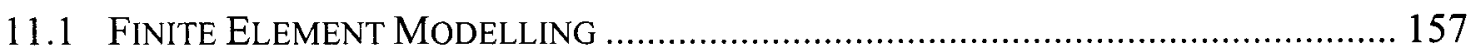

11.1.1 Finite Element Model Validation .................................................. 160

11.1 .2 Pit SCF Results ....................................................................... 161

11.2 Stress Concentration Factor Probability Distributions ....................... 164

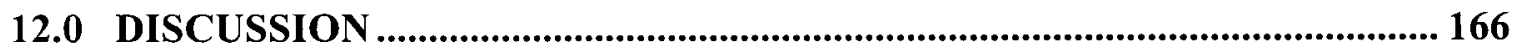

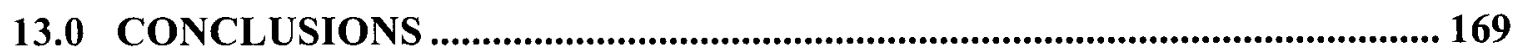

13.1 Corrosion-Fatigue Testing Using MSD SPECIMENS. ............................. 169 
13.2 FORENSIC ANALYSiS OF CORRODED MSD SPECIMENS

13.3 CORROSION TOPOGRAPHY QUANTIFICATION

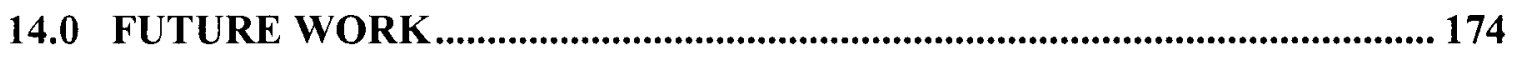

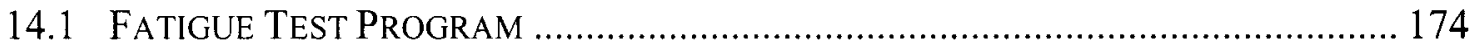

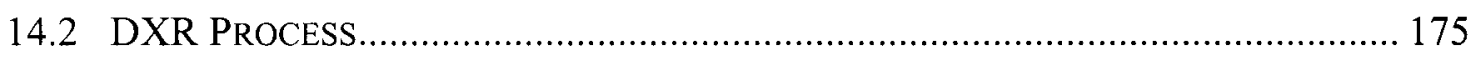

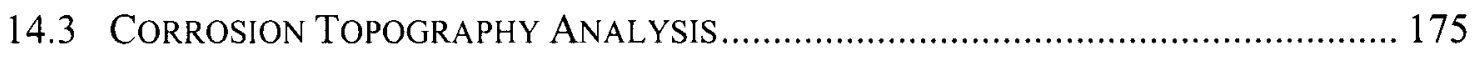

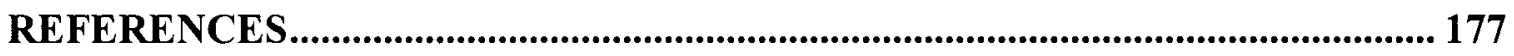

APPENDIX A: SIDE-STRAP REPAIR DRAWING ...................................... 184

APPENDIX B: INSPECTION RESULTS FOR PRE-CORRODED SPECIMENS

186

APPENDIX C: CORROSION TOPOGRAPHY DATA ..................................... 199 


\section{LIST OF TABLES}

TABLE 1-1: CURRENT FLEET STATUS OF JET AIRLINERS (EXCERPT FROM FLIGHT INTERNATIONAL'S

AgEING AirCRAFt Census 2000)

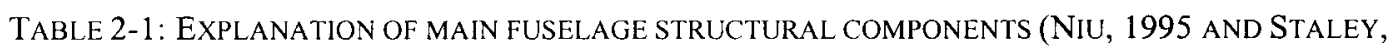
1995) 8

TABLE 3-1: ROUND ROBIN INSPECTION RESULTS FOR THE SPECIMEN IN FIGURE 3-8 CARRIED OUT IN LABORATORY CONDITIONS 25

Table 5-1: Summary of Pitting Corrosion-Fatigue Models (Hoeppner, 1999 and Wei, 1996)....... 42

TABLE 7-1: "Design Of EXPERIMENT" Definitions (LitTLE, 1975), (ASTM, 1991) ...................................56

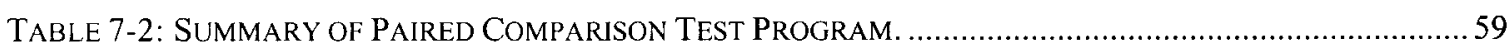

TABLE 7-3: REVISED TEST MATRIX MSD-DOE SPECIMEN TESTS. (HIGHLIGHTED REGION REPRESENTS

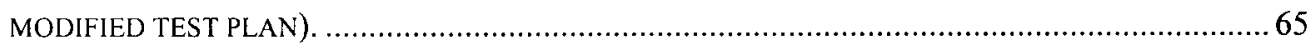

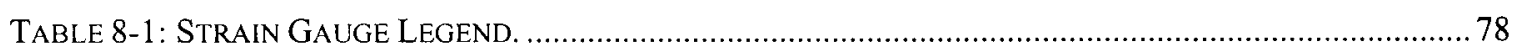

TABLE 8-2: EDDY CURRENT FREQUENCIES USED TO DETECT CORROSION IN MSD SPECIMENS..................... 83

TABLE 9-1: LENGTH OF PRE-CORROSION PROCESS (HIGHLIGHTED SPECIMENS HAVE BEEN TESTED AND REPORTED ON FOR THIS THESIS).

TABLE 9-2: SUMMARY OF MEAN THICKNESS LOSS OF PRE-CORRODED SPECIMENS, INCLUDING MSD-

DOE SPECIMENS TESTED BY KRIZAN (1999). NOTE: HIGHLIGHTED SPECIMENS WERE

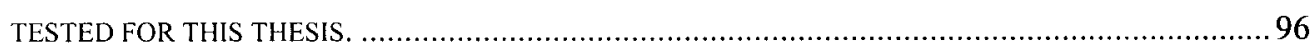

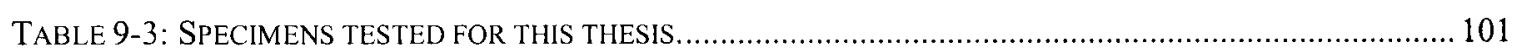

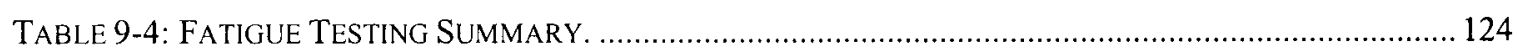

TABLE 10-1: POPULATION INFORMATION FOR PIT DEPTH PROBABILITY DENSITY DISTRIBUTIONS................. 147

TABLE 10-2: COMPARISON OF PIT MEASUREMENTS USING DXR TOPOGRAPHICAL ANALYSIS TO LOW-

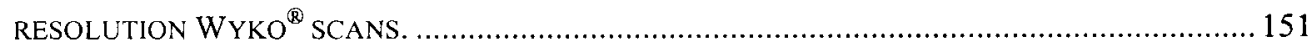

TABLE 11-1: COMPARISON OF SCF RESULTS TO THOSE PRODUCED BY REED AND WILCOX (1970)

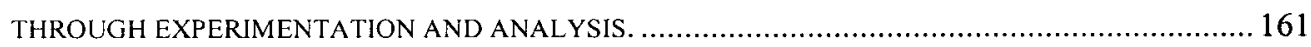

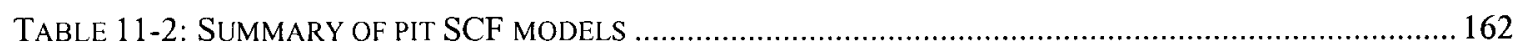

TABLE 11-3: POPULATION INFORMATION FOR SCF PROBABILITY DENSITY DISTRIBUTIONS ......................... 164 


\section{LIST OF FIGURES}

Figure 1-1: Aloha Airlines Flight 243 737-200 AfTER EXPLosive DeCOMPRESSION CAUSED SEPARATION OF AN 18 FT. SECTION OF THE FORWARD FUSELAGE AT 24000 FT (SEATS REMOVED) (EASTIN, 2000)

FiguRE 2-1: TYPICAL SEMI-MONOCOQUE FUSELAGE STRUCTURE ILLUSTRATING KEY STRUCTURES (NiU, 1995). 9

Figure 2-2: TYPiCAL LONGITUdinal BUtT JoINT DESIGN (HART-SMITH, 1995). 10

FIGURE 2-3: TYPICAL RIVETED SINGLE LAP JOINT CONSTRUCTION FOR A BOEING 727 (EASTIN, 2000) 11

FIGURE 2-4: BOEING 737 LAP JOINT DESIGNS, (A) LINE NUMBERS 1-291, (B) LINE NUMBERS 292 AND AFTER (NTSB, 1989). 11

FIGURE 2-5: DOUGLAS LONGITUdINAL FUSELAGE BUTT JOINT DESIGN EMPLOYING FINGER DOUBLERS

(NIU, 1995). 12

Figure 2-6: Fatigue CRITICAL Locations IN RIVETED SINGLE LAP JOINTS (WAKEMAN, 1996) ................. 14

FIGURE 2-7: TYPICAL COUNTERSUNK RIVET INSTALLATION SHOWING A "KNIFE EDGE" CONDITION. 15

FIGURE 2-8: IDEALISED REPRESENTATION OF A RIVETED SINGLE LAP JOINT SHOWING SHEET LOAD TRANSFER FOR 2117-T4 RIVETS IN 0.040 IN. 2024-T3 SKIN (NIU, 1995). 16

Figure 3-1: EXTRUSION SCHEMATIC (SMALLMAN, 1985). 19

FIGURE 3-2: SEM MICROGRAPH OF INTRUSION/EXTRUSION IN 2024-T3 CLAD (COURTESY OF MERATI, NRC). 19

Figure 3-3: Schematic diagram Of CRACK NUCleation IN A PSB (SMallman, 1985). 20

FIGURE 3-4 CRACK NUCLEATION EMANATING FROM SECOND PHASE PARTICLE IN 2024-T3 SHEET A)

SEM MICROGRAPH AT LOW MAGNIFICATION SHOWING CRACK NUCLEATION SITE (WINDOW); B) HIGH MAGNIFICATION BACKSCATTER VIEW OF NUCLEATION SITE AT A CONSTITUENT PARTICLE (DASHED OUTLINE) (COURTESY OF MERATI, NRC). 21

FIGURE 3-5: TYPICAL FRETTING WEAR PATTERN AT A COUNTERSUNK RIVET HOLE IN A FUSELAGE JOINT SHOWING TYPICAL CRACK INITIATION PATTERN (WAKEMAN, 1996) 23

FIGURE 3-6: LOCATION OF FATIGUE CRACK NUCLEATION SITE WITHIN A HEAVILY FRETTED REGION (COURTESY OF KRIZAN, 1999). 24

Figure 3-7: CRACK GROWTH BENEATH COUNTERSUNK RIVET HEAD. DASHED LINE REPRESENTS THE CRACK FRONT.

FiguRE 3-8: DiAgRAM OF ROUND ROBIN NDI SPECIMEN. CRACK 1 IS THE UPPERMOST FLAW. NAS1097-AD5 (5/32 IN. SHANK DIAMETER) FLUSH RIVETS WERE USED (AAWG, 1999),.....25

FiguRE 3-9: PICTURES OF CRACK LINK-UP. (A) CRACK TIP LINK-UP WHERE THE LIGAMENT BETWEEN THE TWO CRACKS FRACTURES (SPECIMEN MSD511-061, (KRIZAN, 1999)). (B) OVERLAP OF CRACKS WHERE THE LIGAMENT DOES NOT FRACTURE, BUT NO LONGER CARRIES ANY LOAD (SPECIMEN MSD511-046, COURTESY OF D. KRIZAN). 
FIGURE 3-10: "TURTLE" DIAGRAM SHOWING AN UNFOLDED TOP VIEW OF THE B-727 FUSELAGE AREA AFFECTED BY MSD CRACK SCENARIO DESCRIBED ABOVE (BOEING, 1999). ......................28

FIGURE 4-1: FIGURE SHOWING ROUTES OF MOISTURE INGRESS INTO LAP JOINTS (WAKEMAN, 1996)...........30

FIGURE 4-2: MICROGRAPH SHOWING CATHODIC PARTICLE CORROSION WHERE THE MATRIX SURROUNDING THE PARTICLES HAS BEEN DISSOLVED (WEI, 1996)............................... 32

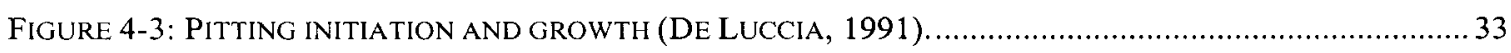

FIGURE 4-4: AUTOCATALYTIC CORROSION PIT GROWTH PROCESS (FONTANA, 1986) ...............................33

Figure 4-5: Corrosion PILlowing OF a B-747 FuSELAGE JOINT OBSERVED USING D-SIGHT (DOUBLE PASS RETRO-REFLECTION INSPECTION SYSTEM) (COURTESY OF RON GOULD, NRC). ............. 34

FIGURE 4-6: INTERGRANULAR CORROSION EXTENDING FROM CORROSION PITS IN A 727 LAP JOINT SPECIMEN. (A) INITIAL CORROSION PITTING, (B) COALESCENCE OF CORROSION PITS, (C) CREATION OF THINNED REGION AS A RESULT OF PIT COALESCENCE (BELLINGER, 2000)........ 35

FIGURE 4-7: STRESS-CORROSION CRACKING RESULTING IN A RIVET FAILURE. (A) MICROGRAPH OF RIVET FRACTURE SURFACE. (B) MICROGRAPH SHOWING INTERGRANULAR CORROSION OF RIVET FRACTURE SURFACE (KRIZAN, 1999). 37

FIGURE 4-8: CORRODED SHEET FROM FUSELAGE LAP JOINT OF A BOEING 727 FUSELAGE JOINT

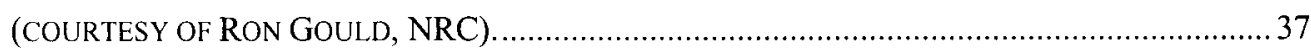

FIGURE 5-1: MSD TEST SPECIMEN DEVELOPED BY NRC AND CARLETON UNIVERSITY. 40

FIGURE 5-2: NUCLEATION AND EARLY CRACK GROWTH OF A FATIGUE CRACK FROM LOCALISED CORROSION PITTING IN 2024-T3 ALUMINUM ALLOY (WEI, 1996). 43

FIGURE 5-3: GENERAL FRACTURE MECHANICS APPROACH FOR ANALYSING CORROSION-FATIGUE OF AIRCRAFT STRUCTURES 47

FIGURE 5-4: 3-D VIEW OF CORROSION PIT SHOWN AS A 'MOUNTAIN' RATHER THAN A PIT, FOR CLARITY.

(A) ACTUAL PIT GEOMETRY MEASURED USING WHITE LIGHT INTERFERENCE MICROSCOPE. THE DIMENSIONS ARE 0.032 IN. X 0.032 IN. $(809 \mu \mathrm{M} \times 809 \mu \mathrm{M})$, AND THE MAXIMUM PIT DEPTH IS 0.0080 IN. $(203.82 \mu \mathrm{M})$. (B) WAVELET RECONSTRUCTED REPRESENTATION OF THE SAME PIT. A PIT DEPTH OF 0.0088 IN. $(223 \mu \mathrm{M})$ WAS DETERMINED (FRANTZISKONIS, 2000) 50

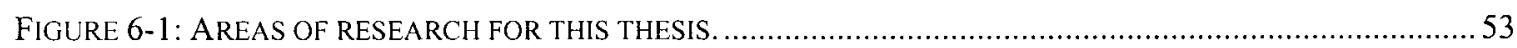

Figure 7-1: PAIRED COMPARISON TEST PROGRAM (PCTP) ORGANISATIONAL STRUCTURE .......................58

FIGURE 7-2: FATIGUE RESULTS FOR THE FIRST 10 DOE SPECIMENS (KRIZAN, 1999).............................61

Figure 7-3: PREDicted CONFIDENCE INTERVALS For MEAN VDL For the PREVIOUS TEST PLAN. THE

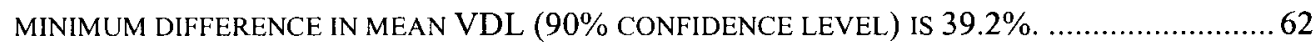

Figure 7-4: PREDICTED CONFIDENCE INTERVALS FOR MEAN VDL FOR THE REVISED TEST PLAN. THE MINIMUM DIFFERENCE IN MEAN VDL (90\% CONFIDENCE LEVEL) IS 39.6\% 63

FigURE 8-1: PAINTED MSD SPECIMEN, PRIOR TO EXPOSURE IN CORROSION CHAMBER............................66

Figure 8-2: PROTECTIVE BAGGING SYSTEM, OPENED LIP SHOWN SURROUNDED BY SEALANT. 67 
FIGURE 8-3: MSD SPECIMENS SUSPENDED IN CORROSION CHAMBER. 67

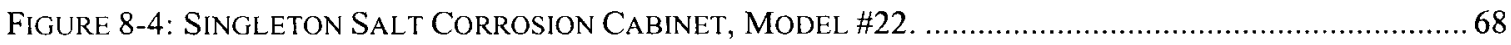

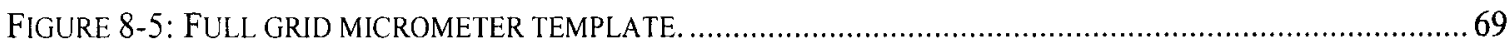

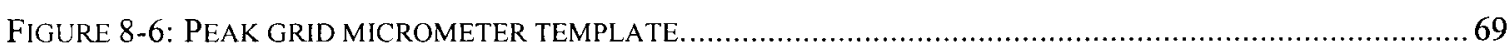

FIGURE 8-7: GEOMETRY OF BONDED JOINT AND SIDE-STRAP FOR THE MSD511 SPECIMEN (ALL GAPS BETWEEN SHEETS REPRESENT FM-73 BONDLINES) (NOT TO SCALE) ............................... 70

FIGURE 8-8: SIDE-STRAP INSPECTION GRID FOR MICROMETER AND ULTRASONIC MEASUREMENTS. .............71

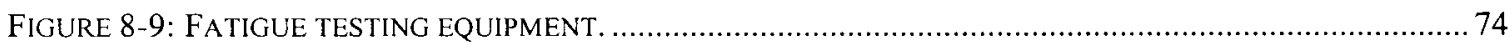

FIGURE 8-10: MSD SPECIMEN MOUNTED IN MTS LOAD FRAME ............................................... 75

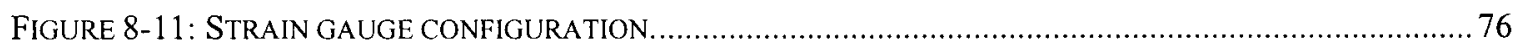

FIGURE 8-12: ILLUSTRATION OF VISIBLE CRACK DETECTION AT A TYPICAL RIVET (KRIZAN, 1999).............80

FIGURE 8-13: CRACK LENGTH MEASUREMENT DATUM, AND RIVET NUMBERING SCHEME. ..........................81

FIGURE 8-14: PHOTOGRAPH OF THE IAR/NRC EDDY CURRENT SYSTEM (LEPINE ET AL., 1999). ................84

FIGURE 8-15: CONFIGURATION OF ALUMINUM 2024-T3 DXR CALIBRATION WEDGE AND CALIBRATION STRIPS 85

FiguRE 8-16: GRAPH OF GREYSCALE VALUE VS. CALIBRATION WEDGE THICKNESS SHOWING THE RESULTING EXPONENTIAL CALIBRATION EQUATION. 87

FIGURE 8-17: DEFINITION AND NUMBERING OF PITCHES FOR DXR, PTL AND OTHER ANALYSIS. 88

FIGURE 9-1: MICROMETER MEASUREMENTS OF CORROSION PILLOWING FOR SPECIMEN \#037 AFTER PRECORROSION WITH THE PAINT REMOVED. ORIENTED AS ON AN AIRCRAFT, COUNTERSUNK SHEET FACING OUT, OUTER LIP OF JOINT FACING DOWN.

FIGURE 9-2: REGION OF LIGHT CORROSION (SPECIMEN 054 OUTER SHEET, CORROSION PRODUCT REMOVED). DASHED REGIONS SHOW INTACT CLAD LAYER WITH LITTLE PITTING CORROSION. 94

FIGURE 9-3: PHOTOGRAPH OF SPECIMEN 037 FAYING SURFACES AFTER CORROSION, WITH CORROSION PRODUCT INTACT, (A) OUTER SHEET (B) INNER SHEET. 94

FIGURE 9-4: PHOTOGRAPH OF SPECIMEN 037 FAYING SURFACES AFTER CORROSION, WITH CORROSION PRODUCT REMOVED, (A) OUTER SHEET (B) INNER SHEET 95

FIGURE 9-5: STAGES OF CORROSION OBSERVED IN MSD SPECIMENS (A) GENERAL ATTACK OF CLADDING (SCALLOPED APPEARANCE) (B) TRANSITION FROM GENERAL TO PITTING CORROSION OF CORE METAL (C) CORROSION PITTING IN CORE METAL . ..........................96

FIGURE 9-6: MEAN PTL RATIOS FOR EACH PITCH FOR 9 PRE-CORRODED MSD SPFCIMENS. ......................97

FIGURE 9-7: MEAN WET-PTL RATIO FOR 9 PRE-CORRODED MSD SPECIMENS. 98

FIGURE 9-8: COMPARISON OF EDDY CURRENT C-SCANS TO CALIBRATED DXR IMAGE FOR OUTER SHEET OF SPECIMENS 037. (A) EDDY CURRENT SCAN, 17 KHz, (B) PULSED EDDY CURRENT SCAN, (C) COLOURED AND CALIBRATED DXR IMAGE. DASHED LINES ARE AN EXAMPLES OF THE CORRELATION OF REGIONS WITH SEVERE CORROSION. 
Figure 9-9: CRACK GROWTH CURVES FOR NON-CORRODED MSD SPECIMENS, (A) LEGEND, (B) SPECIMEN 041, (C) SPECIMEN 042, (D) SPECIMEN 048.

FIGURE 9-10: CRACK GROWTH RATES FOR NON-CORRODED MSD SPECIMENS, (A) LEGEND, (B) SPECIMEN 041, (C) SPECIMEN 042, (D) SPECIMEN 048. 103

Figure 9-11: EXAMPLES OF CRACK LINK-UP. (A) OVERLAPPING CRACKS, (B) JOINING CRACK TIPS, (C) CRACK GROWTH INTO RIVET HOLE WITH NO VISIBLE CRACK INITIATION. 104

FIGURE 9-12: FIRST VISIBLY DETECTED CRACKS PHOTOGRAPHED SHORTLY AFTER DETECTION: (A) SPECIMEN 041 BOTH SIDES OF RIVET 5, (B) SPECIMEN 042, BOTH SIDES OF RIVET 5 (ARROWS SHOW LOCATION OF CRACK TIPS). 104

FIGURE 9-13: EXAMPLE OF FINAL CRACKING PATTERN FOR NON-CORRODED SPECIMEN (FAYING SURFACE OF COUNTERSUNK SHEET FOR SPECIMEN 041) 105

FIGURE 9-14: FAYING SURFACE PHOTOGRAPHS SHOWING CRACKS EMANATING FROM FRETTING REGIONS SURROUNDING THE RIVET (A) SPECIMEN 041 RIVET 5, (B) SPECIMEN 042 RIVET 5

FIGURE 9-15: MULTIPLE CRACK NUCLEATION SITES FOR SPECIMEN 041 AT THE FRETTED REGION ADJACENT TO RIVET 5. (A) CRACK NUCLEATION SITES ON THE FRACTURE SURFACE. (B) TILTED FRACTURE SURFACE REVEALING THE FRETTED REGION NEAR THE RIVET HOLE.......... 106

FIGURE 9-16: CRACK GROWTH CURVES FOR PRE-CORRODED MSD SPECIMENS, (A) LEGEND, (B) SPECIMEN 037, (C) SPECIMEN 049, (D) SPECIMEN 050 AND (E) SPECIMEN 054. 108

FIGURE 9-17: CRACK GROWTH CURVES FOR PRE-CORRODED MSD SPECIMENS, (A) LEGEND, (B) SPECIMEN 037, (C) SPECIMEN 049, (D) SPECIMEN 050 AND (E) SPECIMEN 054. 109

FIGURE 9-18: CRACK DETECTION FOR SPECIMEN 037 (PHOTOGRAPH TAKEN OF RIVET 3 AT 81000 CYCLES) 110

FIGURE 9-19: PHOTOGRAPH OF SPECIMEN 037 FAYING SURFACE SHOWING LARGE ELONGATED CORROSION DAMAGE REGION AT RIVET 3

FIGURE 9-20: MICROGRAPH OF CRACK NUCLEATION SITE FOR SPECIMEN 037 AT A CORROSION PIT ADJACENT TO RIVET 3. (A) CRACK NUCLEATION SITE ON THE FRACTURE SURFACE MARKED BY THE ARROW, (B) SHOWS THE TILTED FRACTURE SURFACE REVEALING CORROSION DAMAGE NEAR THE RIVET HOLE. 112

FIGURE 9-21: CRACK DETECTION FOR SPECIMEN 049, LEFT SIDE OF RIVET 8 (292 378 CYCLES). 113

FIGURE 9-22: SEM MICROGRAPH OF CRACK NUCLEATION SITES FOR SPECIMEN 049. (A) FRACTURE SURFACE (B) TILTED FRACTURE SURFACE SHOWING CORROSION PITTING AT NUCLEATION SITES.

FIGURE 9-23: PHOTOGRAPH AFTER VISIBLE CRACK DETECTION FOR SPECIMEN 050 (CYCLE 748 500) (A) CRACK ON THE LEFT SIDE OF RIVET 3 (B) CRACK TO THE RIGHT OF RIVET 5 
FIGURE 9-24: CRACK NUCLEATION SITE FOR RIVET 3 OF SPECIMEN 050 (A) FRACTURE SURFACE, (B) TILTED FRACTURE SURFACE SHOWING CRACK NUCLEATION SITE AND REGIONS OF LITTLE OR NO CORROSION DAMAGE NEAR RIVET HOLE.

FIGURE 9-25: CRACK NUCLEATION SITE FOR RIVET 5 OF SPECIMEN 050 (A) FRACTURE SURFACE, (B) TILTED FRACTURE SURFACE SHOWING CRACK NUCLEATION SITE AND REGIONS OF LIGHT CORROSION NEAR RIVET HOLE.

FIGURE 9-26: PHOTOGRAPH OF VISIBLE CRACK AT RIVET 4 ON SPECIMEN 054.

FIGURE 9-27: CRACK NUCLEATION SITE FOR THE RIGHT SIDE OF RIVET 4 OF SPECIMEN 054 (A) FRACTURE SURFACE, (B) TILTED FRACTURE SURFACE SHOWING CRACK NUCLEATION SITE AND REGIONS OF LIGHT CORROSION DAMAGE IN THE CLADDING.

FIGURE 9-28: AGGREGATE CRACK GROWTH CURVES 120

FIGURE 9-29: NORMALISED AGGREGATE CRACK GROWTH CURVES. THE CURVES FROM FIGURE 9-28 HAVE BEEN NORMALISED TO THE CYCLE AT WHICH THE CRACK LENGTHS EQUALLED THE CLD (0.150 IN. MEASURED LONGITUDINALLY FROM THE CENTRE OF THE RIVET).

FIGURE 9-30: AGGREGATE CRACK GROWTH CURVES FOR ALL MSD-DOE SPECIMENS TESTED TO DATE. ...121

FIGURE 9-31: COMPARISON OF AVERAGE NOMINAL STRESSES IN THE COUNTERSUNK SHEET FOR CORRODED MSD-DOE SPECIMENS WITH AND WITHOUT A SIDE-STRAP REPAIR. 123

FIGURE 9-32: VISUAL CRACK DETECTION LIFE, AND CRACK GROWTH SUMMARY. 125

FIGURE 9-33: TWO-SIDED CONFIDENCE INTERVAL FOR MEAN VDL USING SAMPLE SIZES OF 8 NONCORRODED AND 6 PRE-CORRODED. 126

FIGURE 9-34: AVERAGE NOMINAL LOCATION STRESSES FOR NON-CORRODED SPECIMENS. 127

FIGURE 9-35: AVERAGE NOMINAL LOCATION STRESSES FOR PRE-CORRODED SPECIMENS. 127

FIGURE 9-36: COMPARISON OF AVERAGE NOMINAL STRESSES. 128

FIGURE 9-37: GRAPH SHOWING THE RELATIONSHIP BETWEEN FAYING SURFACE STRESS AND VISIBLE CRACK DETECTION LIFE (CYCLE 100 AT 7219 LB.). 129

Figure 10-1: CORRosion Pit Geometry Terminology. 132

FIGURE 10-2: GENERAL APPROACH TO QUANTIFY CORROSION DAMAGE FOR MSD511-DOE SPECIMENS... 133

FIGURE 10-3: BOXCAR AVERAGING KERNEL (HIGHLIGHTED CELL IS $I^{T H}$ PIXEL). 135

FIGURE 10-4: ORIGINAL CORRODED SURFACE WITH CORRESPONDING SMOOTHED IMAGE (SPECIMEN MSD511-045). 136

FIGURE 10-5: CORROSION PIT MAP EXAMPLE (SECTION TAKEN FROM SPECIMEN MSD511-045). (A) ORIGINAL GREYSCALE DXR IMAGE, (B) PIT MAP OF THE CORRESPONDING REGION. 139

FIGURE 10-6: CORROSION PIT MAP FROM FIGURE 10-5 AFTER APPLICATION OF A MORPHOLOGICAL OPENING AND CLOSING OPERATION. 141

FiguRE 10-7: LABELLED CORROSION PIT MAP (SECTION TAKEN FROM SPECIMEN MSD511-045) 142

FigURE 10-8: SAMPLES OF POLISHED, CORRODED SECTIONS OF 2024-T3 ALUMINUM SPECIMENS (COURTESY OF BELLINGER AT NRCC) 
FIGURE 10-9: POSSIBLE SIMPLIFIED GEOMETRY USED TO MODEL CORROSION PITS (A) HYPERBOLOID (B)

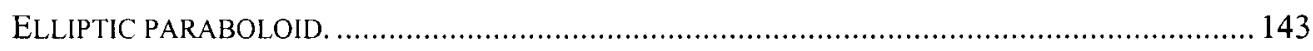

FIGURE 10-10: MAXIMUM AND MINIMUM PIT CO-ORDINATE DIAGRAM................................................... 144

FIGURE 10-11: COMPARISON OF LINE PROFILES FOR THICKNESS MAP AND EDDY CURRENT DATA BETWEEN THE MIDDLE AND LOWER RIVET ROWS SPECIMEN 037 ......................................... 146

FIGURE 10-12: PIT MAP IMAGE FOR OUTER SHEET OF SPECIMEN 050. WHITE REGIONS, EXCLUDING RIVET HOLES, REPRESENT CORROSION PITS. 146

FIGURE 10-13: LOGNORMAL PROBABILITY DENSITY FUNCTIONS OF PIT DEPTH FOR VARIOUS LEVELS OF LOCAL CORROSION THICKNESS LOSS.

FIGURE 10-14: COMPARISON OF CORROSION PIT GEOMETRY FOR SPECIMEN 050 CSK PIT 4 (A) DXR IMAGE (B) SEGMENTED PIT GEOMETRY FROM DXR IMAGE ANALYSIS (C) CONFOCAL MICROSCOPE (D) WYKO ${ }^{\circledR}$ OPTICAL PROFILER................................................................ 149

FIGURE 10-15: SAMPLE LINE PROFILE COMPARISONS OF DXR TO WYKO ${ }^{\circledR}$ LOW-RESOLUTION SCANS. ......... 150

FIGURE 10-16: LINE PROFILE OF CALIBRATION STRIP \#2 TAKEN FROM DXR IMAGE FOR MSD511-037

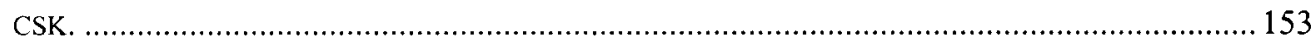

FIGURE 10-17: KODAK STEP TABLET OF VARYING OPTICAL DENSITIES.

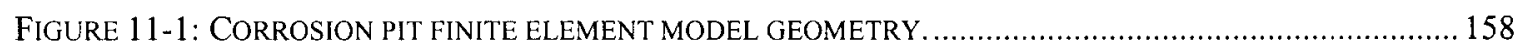

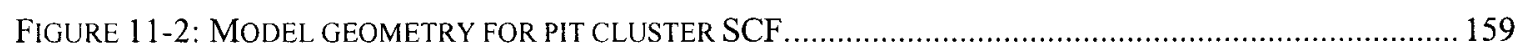

FIGURE 11-3: HYPERBOLOID CAVITY GEOMETRY INVESTIGATED BY REED AND WILCOX ............................. 160

FIGURE 11-4: ESTIMATED MAXIMUM PRINCIPAL STRESS DISTRIBUTION AT THE BOTTOM OF A

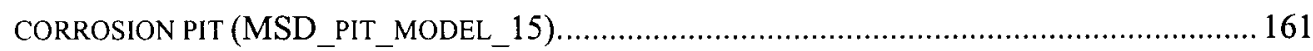

FIGURE 11-5: GRAPH OF SCF VS. PIT DEPTH FOR DIFFERENT PIT DIAMETERS.......................................... 163

FIGURE 11-6: LOGNORMAL PROBABILITY DENSITY FUNCTIONS OF PIT SCF FOR VARIOUS LEVELS OF

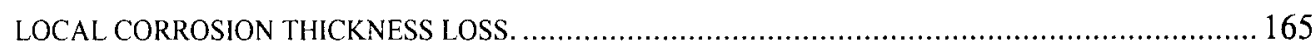

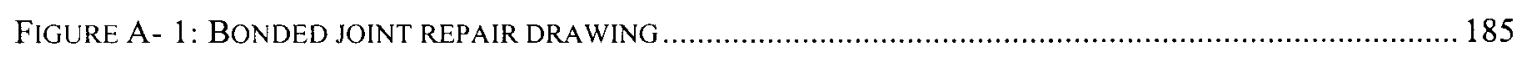

FIGURE B- 1: SPECIMEN 037 (A) D-SIGHT , (B) MICROMETER PILLOWING MEASUREMENTS .......................... 187

FIGURE B- 2: SPECIMEN 037 (A) EDDY CURRENT C-SCAN AT $5.5 \mathrm{KHZ}$, THICKNESS LOSS IN BOTH SHEETS.

(B) EDDY CURRENT C-SCAN AT 17 KHZ, THICKNESS LOSS IN OUTER SHEET ONLY. (C)

PULSED EDDY CURRENT C-SCAN, THICKNESS LOSS IN BOTH SHEETS................................... 188

FiguRe B- 3: SPECIMEN 037 CALIBRATED DXR IMAGES (A) OUTER SHEET, (B) INNER SHEET, (C)

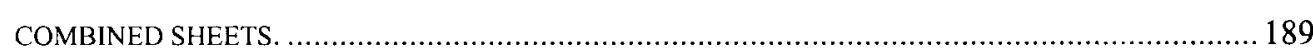

FIGURE B- 4: SPECIMEN 049 (A) D-SIGHT , (B) MiCROMETER PILLOWING MEASUREMENTS .......................... 190

FIGURE B- 5: SPECIMEN 049 (A) EdDY CURRENT C-SCAN AT $5.5 \mathrm{KHZ}$, THICKNESS LOSS IN BOTH SHEETS. (B) EDDY CURRENT C-SCAN AT $17 \mathrm{KHZ}$, THICKNESS LOSS IN OUTER SHEET ONLY. (C) PULSED EDDY CURRENT C-SCAN, THICKNESS LOSS IN BOTH SHEETS. 191

FIGURE B- 6: SPECIMEN 049 CALIBRATED DXR IMAGES (A) OUTER SHEET, (B) INNER SHEET, (C) COMBINED SHEETS. 
FIGURE B- 7: SPECIMEN 050 (A) D-SIGHT , (B) MICROMETER PILLOWING MEASUREMENTS. 193

FIGURE B- 8: SPECIMEN 050 (A) EDDY CURRENT C-SCAN AT $5.5 \mathrm{KHZ,} \mathrm{THICKNESS} \mathrm{LOSS} \mathrm{IN} \mathrm{BOTH}$ SHEETS. (B) EDDY CURRENT C-SCAN AT $17 \mathrm{kHZ}$, THICKNESS LOSS IN OUTER SHEET ONLY. (C) PULSED EDDY CURRENT C-SCAN, THICKNESS LOSS IN BOTH SHEETS. 194

FigurE B- 9: SPECIMEN 050 CALIBRATED DXR IMAGES (A) OUTER SHEET, (B) INNER SHEET, (C) COMBINED SHEETS 195

FIGURE B- 10: SPECIMEN 054 (A) D-SIGHT , (B) MICROMETER PILLOWING MEASUREMENTS 196

FIGURE B- 11: SPECIMEN 054 (A) EDDY CURRENT C-SCAN AT $5.5 \mathrm{KHZ}$, THICKNESS LOSS IN BOTH SHEETS. (B) EDDY CURRENT C-SCAN AT $17 \mathrm{KHZ}$, THICKNESS LOSS IN OUTER SHEET ONLY. (C) PULSED EDDY CURRENT C-SCAN, THICKNESS LOSS IN BOTH SHEETS. 197

Figure B- 12: SPECIMEN 054 CALIBRATED DXR images (A) OUTER SHEET, (B) INNER SHEET, (C) COMBINED SHEETS. 198

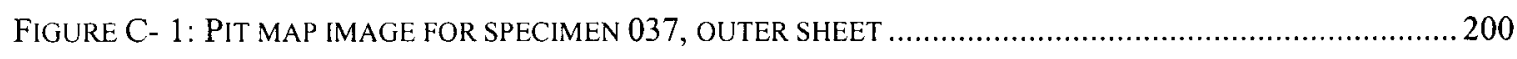

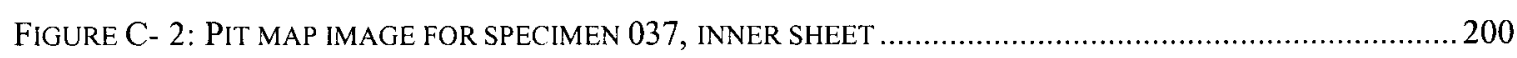

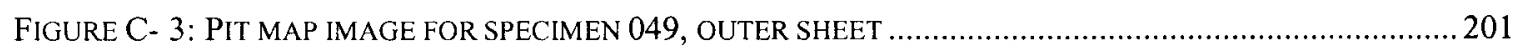

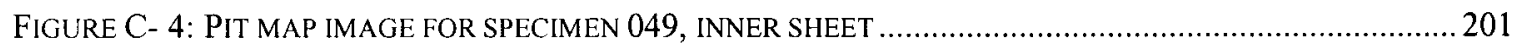

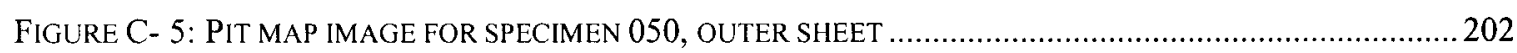

FIGURE C- 6: PIT MAP IMAGE FOR SPECIMEN 050, INNER SHEET ....................................................202

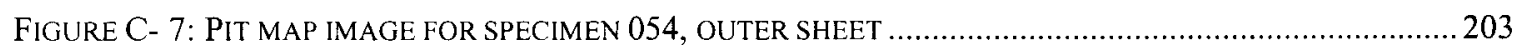

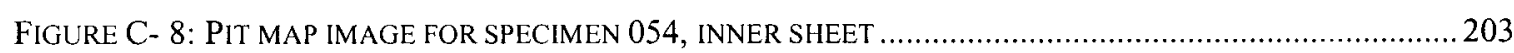

FIGURE C- 9: CORROSION PIT GEOMETRY FOR SPECIMEN 037CSK E PIT 3 (A) DXR IMAGE (B) SEGMENTED PIT GEOMETRY FROM DXR IMAGE ANALYSIS (C) CONFOCAL MICROSCOPE (D) WYKO ${ }^{\circledR}$ OPTICAL PROFILER. 204

FIGURE C- 10: HIGH-RESOLUTION CORROSION PIT GEOMETRY LINE PROFILES FOR SPECIMEN 037CSK E PIT 3. 205

FIGURE C- 11: LOW-RESOLUTION CORROSION PIT GEOMETRY LINE PROFILES FOR SPECIMEN 037CSK E PIT 3. 206

FIGURE C- 12: CORROSION PIT GEOMETRY FOR SPECIMEN 049CSK L PIT 2 (A) DXR IMAGE (B) SEgMENTED PIT GEOMETRY FROM DXR IMAGE ANALYSIS (C) CONFOCAL MICROSCOPE (D) WYKO ${ }^{\circledR}$ OPTICAL PROFILER. 207

Figure C- 13: High-RESOlution CORROSION PIT GEOMETRY LINE PROFILES FOR SPECIMEN 049CSK L PIT 2. 208

FIGURE C- 14: LOW-RESOLUTION CORROSION PIT GEOMETRY LINE PROFILES FOR SPECIMEN 049CSK L PIT 2. 209

Figure C- 15: CORROSION PIT GEOMETRY FOR SPECIMEN 049DRV L PIT 2 (A) DXR IMAGE (B) SEGMENTED PIT GEOMETRY FROM DXR IMAGE ANALYSIS (C) CONFOCAL MICROSCOPE (D) WYKO ${ }^{\circledR}$ OPTICAL PROFILER. 210 
FIGURE C- 16: HIGH-RESOLUTION CORROSION PIT GEOMETRY LINE PROFILES FOR SPECIMEN 049DRV L

PIT 2.

FIGURE C- 17: LOW-RESOLUTION CORROSION PIT GEOMETRY LINE PROFILES FOR SPECIMEN O49DRV L PIT 2 .

FIGURE C- 18: CORROSION PIT GEOMETRY FOR SPECIMEN 050CSK G PIT 1 (A) DXR IMAGE (B) SEGMENTED PIT GEOMETRY FROM DXR IMAGE ANALYSIS (C) CONFOCAL MICROSCOPE (D) WYKO ${ }^{\circledR}$ OPTICAL PROFILER. 213

FIGURE C- 19: HIGH-RESOLUTION CORROSION PIT GEOMETRY LINE PROFILES FOR SPECIMEN 050CSK G PIT 1. 214

FIGURE C- 20: LOW-RESOLUTION CORROSION PIT GEOMETRY LINE PROFILES FOR SPECIMEN 050CSK G PIT 1.

FiguRE C- 21: CORROSION PIT GEOMETRY FOR SPECIMEN 050CSK G PIT 4 (A) DXR IMAGE (B) SEGMENTED PIT GEOMETRY FROM DXR IMAGE ANALYSIS (C) CONFOCAL MICROSCOPE (D) WYKO ${ }^{\circledR}$ OPTICAL PROFILER. .216

FIGURE C- 22: HIGH-RESOLUTION CORROSION PIT GEOMETRY LINE PROFILES FOR SPECIMEN 050CSK G PIT 4. 217

FIGURE C- 23: LOW-RESOLUTION CORROSION PIT GEOMETRY LINE PROFILES FOR SPECIMEN 050CSK G PIT 4 . .218 


\section{NOMENCLATURE}

\begin{tabular}{|c|c|}
\hline AAWG & Airworthiness Assurance Working Group \\
\hline $\mathrm{AC}$ & Advisory Circular (manufacturer) \\
\hline $\mathrm{AD}$ & Airworthiness Directive (FAA) \\
\hline AGARD & Advisory Group for Aerospace Research and Development \\
\hline BS & $\begin{array}{l}\text { Body Station (datum system to specify longitudinal aircraft } \\
\text { locations) }\end{array}$ \\
\hline CASS & Copper-Accelerated acetic acid-Salt Spray testing method \\
\hline Corrosion-Fatigue & Sequential application of corrosion and fatigue \\
\hline $\mathrm{CPCP}$ & Corrosion Prevention and Control Program \\
\hline CRD & Completely Randomised Design \\
\hline DAIS & D-Sight aircraft Inspection System \\
\hline DADT & Durability And Damage Tolerance \\
\hline DOT & Department Of Transportation (U.S.) \\
\hline D Sight & Diffracto Sight \\
\hline DTA & Damage Tolerance Analysis \\
\hline DXR & Digitised X-Radiography \\
\hline $\mathrm{EAC}$ & Environmentally Assisted Cracking \\
\hline $\mathrm{ECD}$ & Equivalent Corrosion Damage \\
\hline ESF & Environmental Severity Factor \\
\hline FAA & Federal Aviation Administration (U.S.) \\
\hline FAR & Federal Airworthiness Regulations (U.S.) \\
\hline GTOW & Gross Takeoff Weight \\
\hline IAR & Institute for Aerospace Research \\
\hline IDS & Intrinsic Discontinuity State \\
\hline LEFM & Linear Elastic Fracture Mechanics \\
\hline MDS & Modified Discontinuity State \\
\hline MED & Multiple Element Damage \\
\hline MSD & Multiple Site Damage \\
\hline NDI & Non-Destructive Inspection \\
\hline
\end{tabular}


Pre-Corrosion Fatigue testing

PCTP

Paired Comparison Test Program

PSB

Persistent Slip Band(s)

PSE

Principal Structural Element

PTL

Peak Pillowing-to-Thickness-Loss ratio

$\mathrm{RCB}$

Randomised Complete Block

SB

Service Bulletin

$\mathrm{SCC}$

Stress Corrosion Cracking

SEM

Scanning Electron Microscope (Microscopy)

SFC

Salt Fog Chamber

SIF

Stress Intensity Factor

SSID

Supplemental Structural Inspection Document

SSIP

Supplemental Structural Inspection Program

TIFF

Tagged Image File Format

USAF

United States Air Force

WFD

Widespread Fatigue Damage

\section{UNITS}

This thesis uses English units to keep with the North American aerospace industry practice. The following conversion factors are provided to convert to S.I. units:

\begin{tabular}{|c|c|}
\hline English & Conversion Factor to \\
Unit & S.I. Unit \\
\hline & \\
in. & $25.40 \mathrm{~mm}$ \\
lb. & $4.45 \mathrm{~N}$ \\
ksi & $6.89 \mathrm{MPa}$ \\
\hline
\end{tabular}




\subsection{INTRODUCTION}

Given the high cost of replacing aircraft, operators are choosing to maintain ageing aircraft $^{l}$ rather than purchase new ones. This has increased the number of ageing aircraft in service to roughly $60 \%$ of the North American airline fleet (Flight International, 2000).

Based on Flight International's Ageing Airliner Census numerous aircraft are flying in excess of their original economic design lives. For example there are 1331 of the original 1831 Boeing 727 aircraft still in service. The fleet leader has nearly achieved twice the original design life, in years (Table 1-1).

Table 1-1: Current fleet status of jet airliners (excerpt from Flight International's Ageing Aircraft Census 2000).

\begin{tabular}{|c|c|c|c|c|c|c|c|c|c|}
\hline \multirow{2}{*}{$\begin{array}{l}\text { Aircralft } \\
\text { Model }\end{array}$} & \multirow[t]{2}{*}{ Units } & \multirow{2}{*}{$\begin{array}{l}\text { Service } \\
\text { Entry }\end{array}$} & \multicolumn{3}{|c|}{ Design Life } & \multicolumn{3}{|c|}{ Flect Leader } & \multirow{2}{*}{$\begin{array}{c}\text { Average Ige } \\
\text { (years) }\end{array}$} \\
\hline & & & Years & Hours & Cycles & Years & Hours & cycles & \\
\hline A300 & 213 & 1974 & 20 & 60000 & 35000 & 25 & 55174 & 35405 & 13 \\
\hline 707 & 138 & 1957 & 20 & 60000 & 20000 & 41 & 92466 & 51161 & 27 \\
\hline 727 & 1331 & 1964 & 20 & 50000 & 60000 & 37 & 85378 & 78564 & 26 \\
\hline $737-100 / 200$ & 880 & 1968 & 20 & 51000 & 75000 & 33 & 88457 & 96528 & 22 \\
\hline 747 & 480 & 1970 & 20 & 60000 & 20000 & 32 & 114823 & 34531 & 14 \\
\hline MD-80 & 268 & 1980 & 20 & 30000 & 25000 & 21 & 61645 & 45150 & 12 \\
\hline DC-9 & 744 & 1965 & 20 & 75000 & 105000 & 35 & 94580 & 100055 & 29 \\
\hline DC- 10 & 331 & 1971 & 20 & 60000 & 42000 & 30 & 110179 & 41979 & 23 \\
\hline L1011 & 173 & 1972 & 20 & 210000 & 115500 & 28 & 85416 & 37709 & 22 \\
\hline
\end{tabular}

As aircraft age they are susceptible to fatigue and corrosion damage. Both corrosion and fatigue reduce the residual strength ${ }^{2}$ of the affected structures, jeopardising aircraft safety.

\footnotetext{
${ }^{1}$ Several definitions exist for ageing aircraft. For the purposes of this research, an ageing aircraft is one which has reached $75 \%$ of the original design life. This number was selected based on the previous definition by Krizan (1999). Considering that most aircraft were designed for a 20 -year service life, $75 \%$ of the design service goal is 15 years, which coincides with the ageing aircraft definition used by Flight International (2000).

${ }^{2}$ Residual strength refers to the maximum load a component can withstand with damage (fatigue cracks, corrosion, etc.) present in the structure.
} 
In 1977 a Danair Boeing 707 crashed on landing at Lusaka due to a horizontal stabiliser fatigue failure. Following this accident, supplemental structural inspection programs (SSIP) and supplemental structural inspection documents (SSID) were developed to focus on the B-707 tail section. SSIP's were subsequently adopted to enhance existing maintenance programs for many ageing aircraft. In the 1970's, fifty principal structural elements (PSE) were selected for monitoring on each affected aircraft model. The PSE selection was based solely on the potential consequences to airworthiness of undetected cracking in these structures (Scott, 1997). These additional inspections were devised to detect fatigue and corrosion damage before the residual strength was compromised. This was the beginning of damage tolerant analysis of commercial aircraft structures.

A potential problem on aircraft is Widespread Fatigue Damage (WFD), a dangerous form of fatigue that can develop when cracks exist concurrently in several structural elements. This damage can affect the continued safe operation of the aircraft. Multiple Element Damage (MED), where numerous cracks exist in several structural elements, or Multiple Site Damage (MSD), where numerous cracks exist within the same structural element, are two forms of WFD. Both are dangerous because they can develop quickly from small, difficult to detect cracks into a critical WFD condition.

Corrosion can promote fatigue cracking by reducing section thickness, introducing stress concentrations (corrosion pits) and, for some materials, affecting the microstructure. These effects may influence the development of MSD, although this is not yet well understood. Aside from being detrimental to structural integrity, corrosion is a heavy burden on aircraft operators. The cost of corrosion to the United States airline industry is approximately $\$ 13$ billion per year. However, the safety concern far outweighs the financial burden as illustrated by the Aloha Airlines Flight 243 explosive fuselage decompression in 1988 (Figure 1-1). The primary culprits of this failure, as determined by the U.S. National Transportation Safety Board (NTSB) were MSD and corrosion (NTSB/AAR-89/03, 1989). 


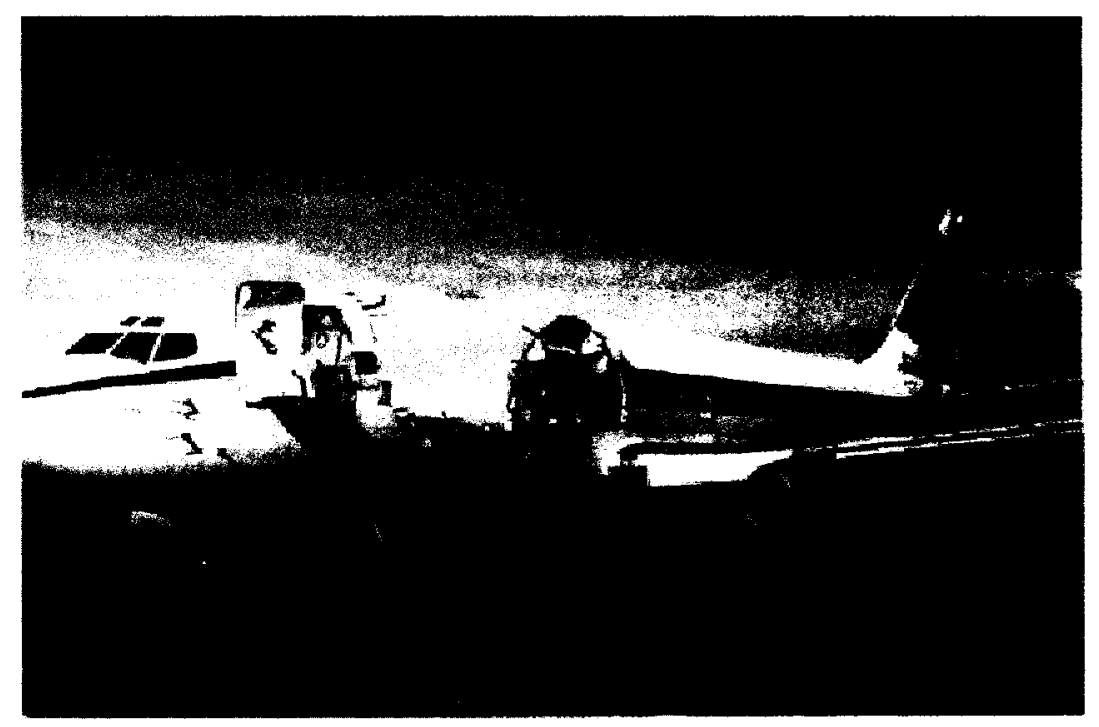

Figure 1-1: Aloha Airlines Flight 243 737-200 after explosive decompression caused separation of an $18 \mathrm{ft}$. section of the forward fuselage at $24000 \mathrm{ft}$ (seats removed) (Eastin, 2000).

After the Aloha incident, Boeing modified the existing SSID for the 727, 737, and 747 to include thin gauge fuselage structures and structures susceptible to MSD. The fallout from this accident also prompted significant research into the topic of WFD and MSD by manufacturers and independent research organisations ${ }^{3}$.

Carleton University in collaboration with the National Research Council of Canada (NRC) has responded, by investigating the corrosion-fatigue characteristics of riveted single-shear joint specimens. A test specimen, hereafter referred to as the MSD specimen, was designed to accurately simulate the multiple-site fatigue damage frequently experienced in longitudinal fuselage lap joints on aircraft (Eastaugh, 1993). A method for corroding the lap joint specimens at an accelerated rate has been developed by Komorowski et al. (1994). An investigation into the similarities between naturally corroded aircraft lap joints, and specimens undergoing accelerated corrosion concluded that, for the requirements of the current research, the corrosion damage was comparable (Eastaugh et al., 1998).

\footnotetext{
${ }^{3}$ Refer to Wakeman (1996) for an in depth discussion of the historical background pertaining to the Aloha airlines incident and the subsequent changes to the FAA ageing aircraft policies.
} 
This corrosion technique has been used to pre-corrode MSD specimens enabling Carleton University and the NRC to study the effects of corrosion on MSD development. Several Carleton University researchers have investigated the MSD/corrosion interaction.

- Wakeman (1996) performed fatigue testing on pre-corroded and non-corroded MSD specimens, adapted the accelerated pre-corrosion procedure for corrosionfatigue testing, developed techniques to quantify corrosion damage, and investigated corrosion-fatigue interactions.

- Scott (1997) performed further testing of pre-corroded and non-corroded MSD specimens, investigated the effect of alternating fatigue and corrosion on MSD development, and studied the effect of smaller rivet heads (smaller countersunk shear head rivets vs. countersunk tension head rivets) on fatigue. The role of secondary bending on crack development was also examined.

- Krizan (1999) developed a carefully designed experimental program to minimise nuisance fatigue failures and maximise the statistically valid corrosion-fatigue data produced. Metrics were developed to quantify corrosion development for an intact joint, including a relationship between corrosion pillowing and average thickness loss. Investigation into the effects of corrosion on fatigue crack development, growth and link-up was accomplished by further testing of MSD specimens.

The corroded lap joint specimens have produced a great deal of useful data pertaining to how fatigue characteristics are influenced by corrosion. Test results have provided insight into the changes of stress-state, failure mode, and fatigue life as compared to the noncorroded joints (Krizan, 1999). The increase of inner surface (faying) stresses near rivet holes related to corrosion pillowing have also been investigated and modelled in depth at the NRC (Bellinger, 1997).

In the near future, damage tolerance-based programs to preclude WFD in ageing aircraft fleets will be required for certain aircraft (AAWG, 1999 and FAA/DOT, 2000). However, 
the FAA will not require corrosion to be included in the analysis. The terms of these rules would be as follows (AAWG, 1999):

"... one year after the effective date of the rule (e.g. Dec. 31, 2002), no large transport airplane (>75 $000 \mathrm{lb}$. GTOW) may be operated beyond the flight cycle limits to be specified in the regulation unless an Aging Aircraft Program has been incorporated into the operators maintenance program.

... The program shall cover the necessary special inspections and modification actions for the prevention of Widespread Fatigue Damage (WFD), Structural Modifications, Supplemental Structural Inspection Programs (SSIP), Corrosion Prevention and Control Programs (CPCP) and structural repairs."

Recently, ageing aircraft research in the United States Air Force (USAF) has begun to focus on damage tolerance-based methods for analysing corrosion-fatigue. Carleton University in collaboration with the NRC has commenced research to develop a damage tolerance analysis methodology for corrosion-fatigue. Various aircraft structures prone to age degradation and WFD, including longitudinal fuselage lap joints, are being targeted in the early phases of this research.

One key issue in successfully developing a damage tolerance analysis is the need to understand the influence of corroded surface topography on the local stress-state, and resulting fatigue properties. Fatigue cracks tend to nucleate in local regions of highest stress. Thus, a relation linking the corroded surface topography to the corresponding stress concentration factors is required to perform corrosion-fatigue damage tolerance analysis.

This thesis attempts to establish such a relationship by examining the role of pitting on the corrosion-fatigue interaction in fuselage joints. The work builds on the prior research into MSD by Carleton University and the NRC, namely that performed by Krizan (1999), Scott (1997), Wakeman (1996), and Eastaugh (1993). The corrosion-fatigue test program developed by Krizan (1999) is continued, while improving testing and data reduction techniques. Efficient and accurate methods to assess corrosion damage topography have also been developed. 


\subsection{STRUCTURES SUSCEPTIBLE TO MSD}

The potential to develop MSD or MED requires similar structural details operating at similar stress levels, where the existence of multiple cracks could significantly degrade the load carrying capability. The AAWG has identified structures susceptible to MSD/MED based on industry experience. A selection of these structural elements with the potential to develop WFD is identified below (AAWG, 1999).

\section{Fuselage}

- Longitudinal skin joints, stringers and tear straps (MSD, MED)

- Stringer to frame attachments (MED)

- Circumferential joints (MSD, MED)

- Fuselage frames (MED)

- Aft pressure dome outer ring and dome web joints (MSD, MED)

- Window surround structure (MSD, MED)

$\underline{\text { Wing }}$

- Wing or empennage chordwise joints (MSD, MED)

Since this thesis focuses on fuselage joints, only the details of these structures will be examined here.

\subsection{Evolution of Aircraft Design Criteria}

Before describing the design features of fuselage joints, it is important to discuss the design philosophies used in past aircraft designs. As research and development progressed, so did the structural principles upon which the airframes were designed. The definitions below show the evolution of concepts to ensure adequate life, from the early 1950's to current aircraft design practices.

Safe-Life Design: In the 1950 's, aircraft were designed such that at no time during the design life should detectable cracks develop due to repeated variable loads. The 
estimations of service lives of structures were conservative to account for the scatter in test results. As a result, many components were prematurely retired from service, which was costly for commercial operations. Currently, only special structures are designed using safe-life guidelines, typically where multiple load paths are not feasible and high strength materials are used, such as landing gear and aircraft engine components.

Fail-Safe Design: In 1954, fatigue failures caused two deHavilland Comet crashes. The existence of fatigue cracks in the fuselage structure was not considered in the original safe-life design. The residual strength was insufficient to withstand the loads experienced, and the aircraft were lost.

It wasn't until 1967, 13 years after the Comet accidents, that the Federal Aviation Administration mandated all aircraft be certified to the fail-safe criteria (FAR 25.571 Pre amendment 45). This philosophy required that a catastrophic failure or excessive deformation that could adversely affect the aircraft's flight characteristics was not probable after failure of a single principal structural element.

To demonstrate a fail-safe airframe, damage is introduced into the structure. It must then be proven that the structure has sufficient residual static strength to withstand $100 \%$ of the design limit load. The required damage size is generally chosen to be easily detected prior to failure of the remaining structure.

In many past fuselage designs the fail-safe criterion was met considering only cabin pressurisation loads. The combination of flight loads and cabin pressure were not necessarily considered (AAWG, 1999).

Damage Tolerant Design: Damage tolerant designs must ensure that catastrophic failure or excessive structural deformation due to fatigue, corrosion, manufacturing defects, or accidental damage will be avoided throughout the aircraft's operational life. The evaluation includes a determination of the probable locations and types of damage. 
After several crashes of "fail-safe" aircraft, the United States Air Force (USAF) introduced damage tolerance requirements for all military aircraft in 1974. The CAA and FAA did not immediately follow suit. It wasn't until an AVRO 748 crashed in Argentina in 1976, as a result of MSD in the fail-safe wing structure and the Lusaka accident, that the two organisations decided to introduce damage tolerance requirements.

The U.S. Federal Aviation Regulations regarding fail-safe structure were changed in 1978 through FAR 25.571, amendment 45. This amendment introduced certification requirements using damage tolerance concepts. At the time, this was deemed a significant technological advance since pre-determined inspections were introduced to detect and repair damage before loss of structural integrity could occur.

\subsection{Fuselage Joint Design}

Conventional pressurised commercial aircraft fuselages are constructed of a thin metallic skin, typically using high strength aluminum alloys, supported longitudinally by stringers and circumferentially by fuselage frames and bulkheads (Table 2-1). This type of stiffened cylindrical structure is referred to as semi-monocoque construction (Figure 2-1).

Table 2-1: Explanation of main fuselage structural components (Niu, 1995 and Staley, 1995).

\begin{tabular}{|l|l|l|}
\hline Structure & \multicolumn{1}{|c|}{ Function } & \multicolumn{1}{c|}{ Comments } \\
\hline Frames & $\begin{array}{l}\text { Maintain fuselage shape and reduce } \\
\text { stringer column length providing } \\
\text { compressive stability }\end{array}$ & $\begin{array}{l}\text { Spacing: 18-20 in. (typical) } \\
\text { Materials used: 7075-T6, 7150- } \\
\text { T77 }\end{array}$ \\
\hline Bulkheads & $\begin{array}{l}\text { Transfer localised loads to surrounding } \\
\text { fuselage structure. Typically located at } \\
\text { wing, empennage, and landing gear } \\
\text { attachment points }\end{array}$ & $\begin{array}{l}\text { Materials used: 7050, 7075-T6 } \\
\text { Sometimes forgings are used in } \\
\text { cases of very high loads }\end{array}$ \\
\hline Stringers & $\begin{array}{l}\text { Support the fuselage skin, and carry } \\
\text { axial fuselage loads due to bending and } \\
\text { pressure }\end{array}$ & $\begin{array}{l}\text { Spacing: 6-10 in. (typical) } \\
\text { Materials used: 2024-T3, 2524- } \\
\text { T3, 7150-T77 }\end{array}$ \\
\hline Skin & $\begin{array}{l}\text { Supports shear loads, and to a lesser } \\
\text { extent, tensile and compressive loads } \\
\text { due to fuselage pressurisation, bending } \\
\text { and torsion. }\end{array}$ & $\begin{array}{l}\text { Sheet thickness: 0.036-0.087 in. } \\
\text { depending on aircraft. } \\
\text { Materials used: 2024-T3, 2524-T3 }\end{array}$ \\
\hline
\end{tabular}




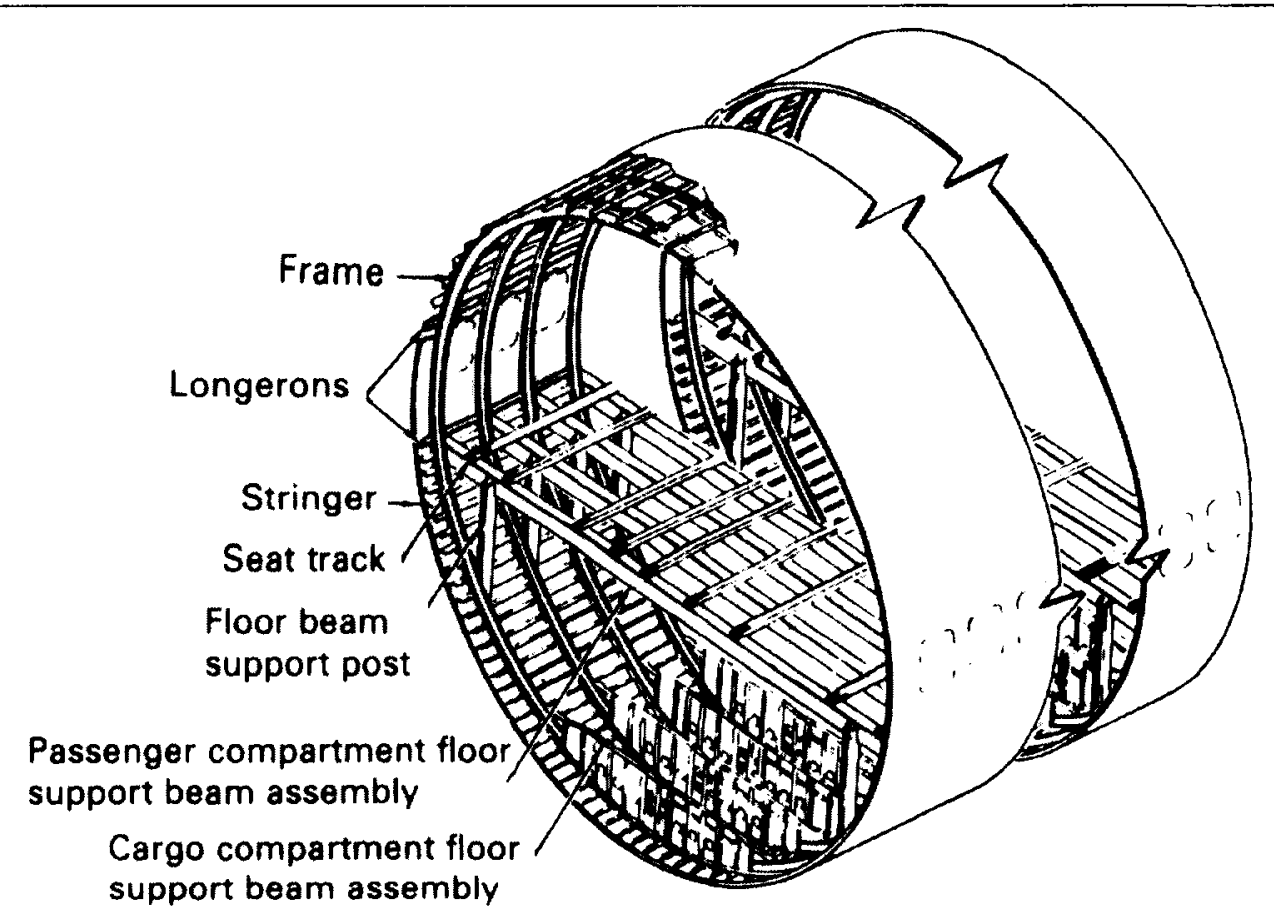

Figure 2-1: Typical semi-monocoque fuselage structure illustrating key structures (Niu, 1995).

Fuselage structures are designed using fail safe/damage tolerant principles according to FAA AC25.571-1A. This is accomplished using multiple load paths to provide fail safety in conjunction with damage tolerant materials and crack stopping features such as tear straps. Most aircraft structures utilise 2000 and 7000 series aluminum alloys for their high strength, low weight and fracture toughness properties (Table 2-1).

Fuselage skin panels are manufactured in rolled sheets that are typically $8 \mathrm{ft}$. by $12 \mathrm{ft}$. in size. Because of this size restriction there is a need to join numerous skin panels together both longitudinally and circumferentially to form the fuselage pressure boundary. Butt joints are commonly used for circumferential joints to limit the aerodynamic penalties. This joint may attach to an underlying frame (typical Boeing design) or midway between two frames (Douglas design).

Longitudinal fuselage joints can take several forms depending on the manufacturer, and the aircraft. Butt joints can be used with inner splice straps, similar to that shown in 
Figure 2-2. More typical, however is the single lap joint design where the upper skin panel is riveted to the lower panel in an overlap region using either two or three rows of rivets (Figure 2-3). The overlap region can vary in width depending on the number of fastener rows used, the sheet thickness and the fastener size used.

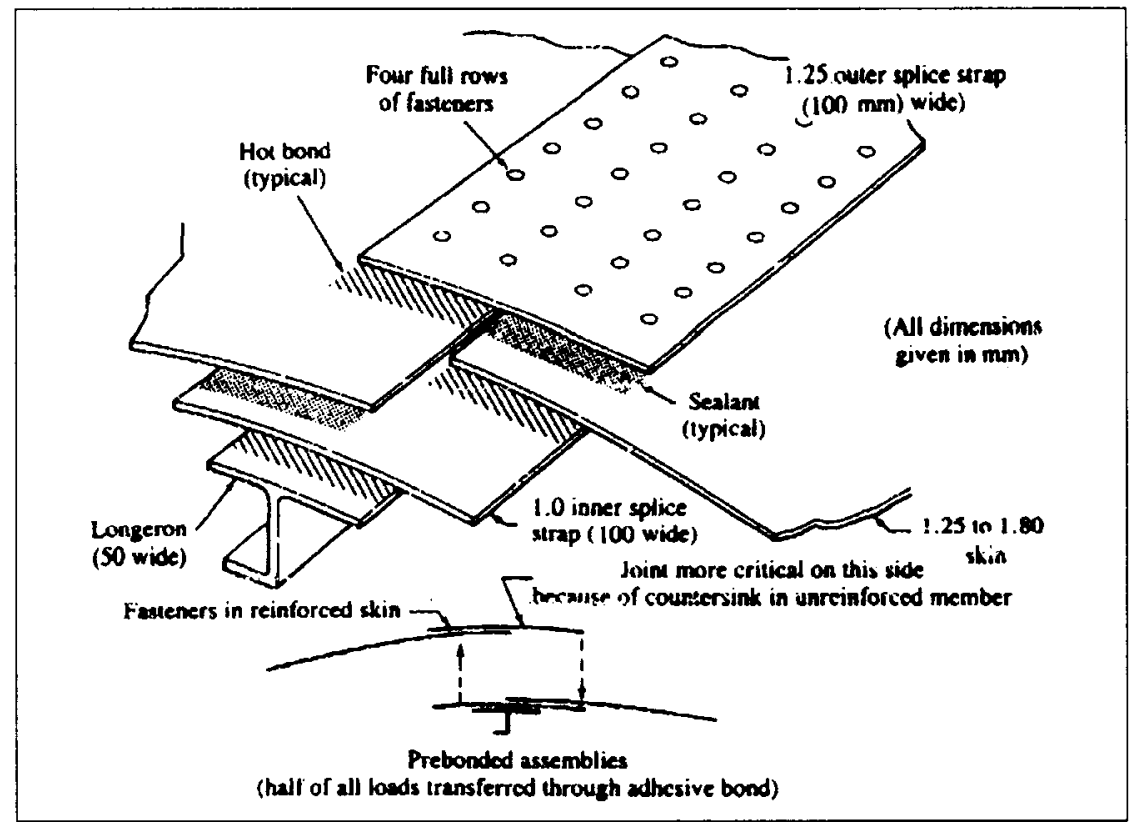

Figure 2-2: Typical longitudinal butt joint design (Hart-Smith, 1995).

Boeing uses riveted single lap joints almost exclusively for longitudinal fuselage joints. The typical Boeing 727 lap joint consists of 3 rows of rivets spaced 1 in. apart fastening two 0.040 in. aluminum 2024-T3 sheets together. Sandwiched between the skin sheets is a 0.020 in. doubler, hot bonded to the outer sheet (Line no. 850 and after). A top hat extruded stringer is riveted to the middle row of the joint (Figure 2-3).

In earlier designs of the Boeing 737 (line numbers 1-291) there was no doubler in the joint, and the two skin sheets were cold bonded and riveted together to form the lap joint. This created a condition referred to as a "knife-edge" countersink at the rivet holes (discussed further in Section 3.2) that reduced fatigue lives in these joints. Another problem with the design was the frequent failure of the bonded region due to manufacturing difficulties. The failed bond resulted in higher stresses near the rivet holes leading to premature fatigue cracking in numerous aircraft (NTSB, 1989). 


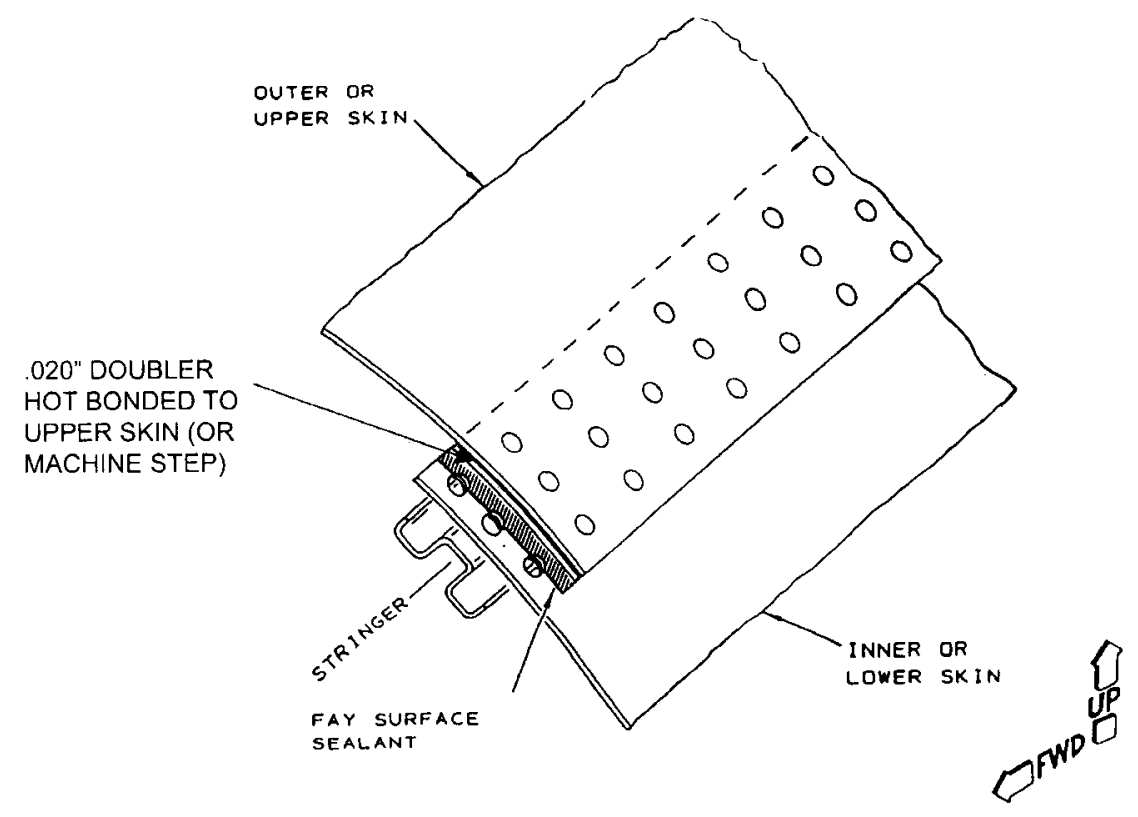

Figure 2-3: Typical riveted single lap joint construction for a Boeing 727 (Eastin, 2000).

This problem was addressed on Boeing 737 line number 292 and later by hot bonding a doubler to the outer skin sheet and adding faying surface sealants (Figure 2-4). The doubler increased the skin thickness removing the knife-edge countersink in the outer sheet.

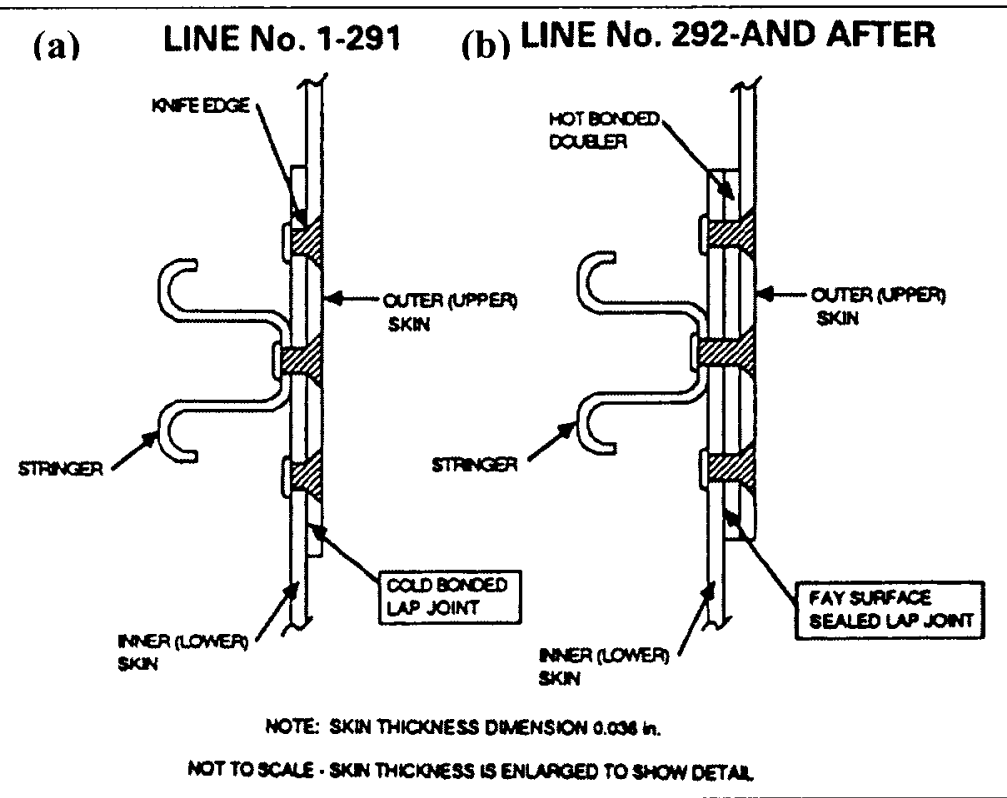

Figure 2-4: Boeing 737 lap joint designs, (a) line numbers 1-291, (b) line numbers 292 and after (NTSB, 1989). 
Other manufacturers use adaptations of the butt joint and the lap joint to best suit their designs. For example, Douglas was the only manufacturer to use finger, or scallopdoublers in its aircraft fuselage joints (Figure 2-5). This doubler is designed to reduce the load transfer at the first (critical) rivet row by lowering the local stiffness of the doubled structure. The load carried by a structure is proportional to the stiffness, EA, where E is the Young's modulus and $\mathrm{A}$ is the cross-sectional area. Reducing the doubler area near the critical rivet row decreases the load transfer at this location. This improves the fatigue performance, and crack detection qualities of the joint, at the cost of complexity and weight. Scott (1997) presents a more thorough investigation of fuselage joint design.

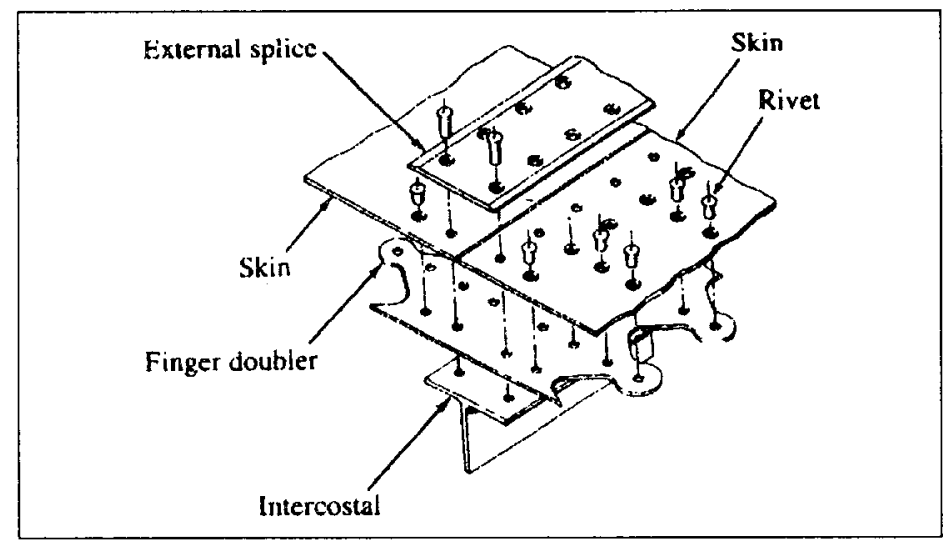

Figure 2-5: Douglas longitudinal fuselage butt joint design employing finger doublers (Niu, 1995).

\subsection{Fuselage Loading}

Aircraft fuselages are subjected to several types of loading during operation. A typical flight subjects the structure to ground loads (during taxi, take-off and landing), pressurisation loads, and flight loads. A major load condition for longitudinal fuselage joints is pressurisation of the cabin.

Flying at typical altitudes of 35000 to $45000 \mathrm{ft}$. commercial transport aircraft require cabin pressurisation. As the aircraft ascends the fuselage pressure is maintained at approximately $8000 \mathrm{ft}$. altitude. This creates a positive pressure differential $(\Delta \mathrm{p})$ between the aircraft and the external environment. Essentially, the fuselage is a cylindrical pressure vessel with the forward and aft pressure bulkheads acting as end caps. 
Longitudinal and circumferential ("hoop", or tangential) stresses are thus generated in the fuselage structure. For a thin shell, closed pressure vessel the equations of hoop stress $\left(\sigma_{t}\right)$ and axial stress $\left(\sigma_{1}\right)$ are:

$$
\begin{array}{ll}
\sigma_{\mathrm{t}}=\Delta \mathrm{pR} / \mathrm{t} & {[2-1]} \\
\sigma_{\mathrm{l}}=\Delta \mathrm{pR} / 2 \mathrm{t} & {[2-2]}
\end{array}
$$

In these equations, $R$ is the mean fuselage radius, and $t$ is the skin thickness. As the radius of the fuselage increases so does the stress, which is the reason widebody aircraft generally have thicker fuselage skin than narrow body aircraft. Typical pressurisation stresses for commercial jet transports ranges from $10.1 \mathrm{ksi}$ (DC-9, narrow body) to $16.2 \mathrm{ksi}$ for a B-747 (Niu, 1995).

The hoop stress component is twice as large as the axial stress component for an unstiffened cylindrical pressure vessel. Thus, the major stress in longitudinal fuselage joints is in the circumferential (hoop) direction, resulting from cabin pressurisation.

Structures such as frames and stringers carry a portion of the load, reducing the hoop stresses on the skin to $75-90 \%$ of the monocoque hoop stress $(\Delta \mathrm{pR} / \mathrm{t})$. This effect is more prominent near the frames and tear straps.

\subsubsection{Longitudinal Fuselage Joint Loads}

As previously discussed the primary load that longitudinal fuselage lap joints experience is tangential (hoop) loading from fuselage pressurisation. Other less obvious, but equally important stresses act on the joint such as secondary bending and rivet stress concentrations, briefly described below. In order to accommodate these stress raisers the nominal hoop stresses in fuselage skins are intentionally kept to $25-30 \%$ of the material yield stress to reduce the likelihood of fatigue cracking. For a more thorough discussion refer to Scott (1997). 
Secondary Bending: In a single lap joint an eccentricity of the load paths exists between the upper and lower sheets. This causes out of plane bending, which induces tensile stresses on the faying (mating) surfaces of the skin, see Figure 2-6.

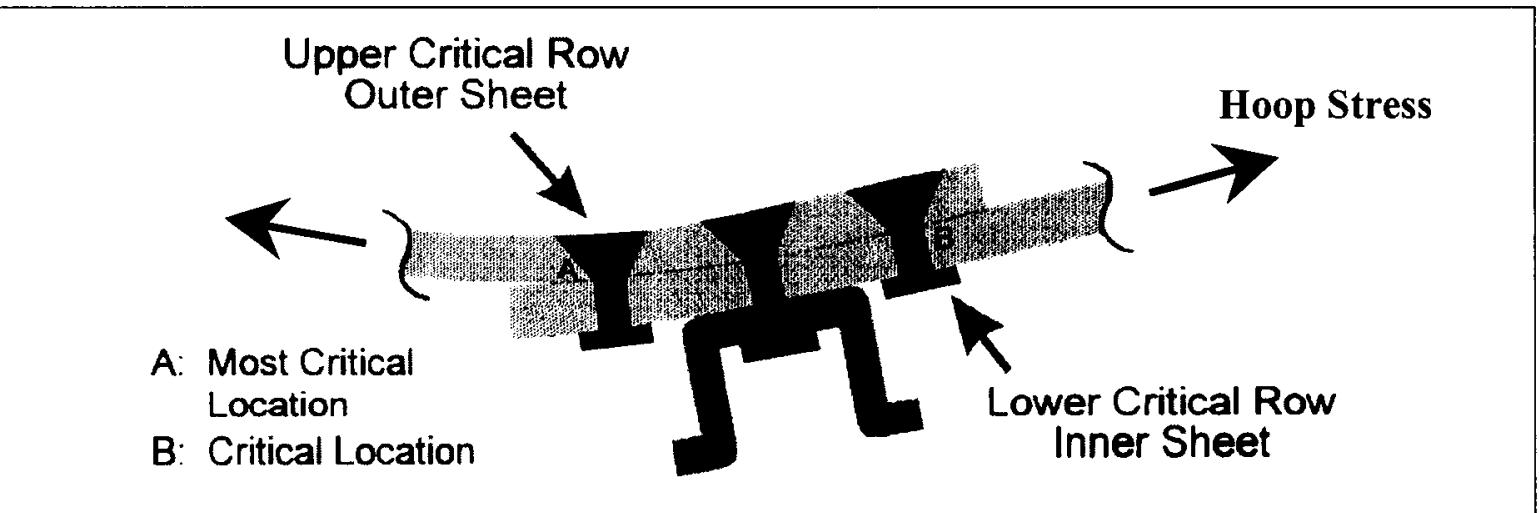

Figure 2-6: Fatigue critical locations in riveted single lap joints (Wakeman, 1996).

Secondary bending is difficult to accurately predict as it varies considerably depending on the particular joint design. The Secondary Bending Factor (SBF) is used to quantify the increased stress due to out of plane bending and is defined in Equation 2-3. If the remote membrane stress is unknown the local membrane stress ( $\left.\sigma_{\text {local membrane }}\right)$ often replaces $\sigma_{\text {remote membrane }}$ (Equation 2-4).

$$
\begin{aligned}
& S B F=\frac{\sigma_{\text {bending }}}{\sigma_{\text {remote membrane }}} \\
& S B R=\frac{\sigma_{\text {bending }}}{\sigma_{\text {local membrane }}}
\end{aligned}
$$

Measurements taken by Schütz and Lowak (1974) show that SBR can range from 0.2 to 1.8 for various Airbus skin joints. Previous testing of MSD specimens by Krizan (1999) showed that the SBF ranged from 0.10 for non-corroded specimens to 0.15 for corroded specimens at a location $1 \mathrm{in}$. above the critical rivet row. Installed rivets apply perpendicular forces to the sheets, constraining out of plane deflection. As a result, the bending stresses in the vicinity of the rivets are higher compared to the nominal location. Fatigue cracks usually nucleate on the inner surface of the joint. An increase in bending 
would result in higher faying surface stresses and would likely reduce the fatigue initiation life, as was the case for the corroded MSD specimens tested by Krizan (1999).

Rivet Stress Concentrations: Any hole or discontinuity in a structure introduces a stress concentration. A single, un-filled ${ }^{4}$, through-hole in a large, thin sheet subjected to inplane uniaxial stresses experiences a stress concentration factor (SCF) of 3.0. This high stress occurs at $90^{\circ}$ from the loading direction at the hole edge (Pilkey, 1997).

Since many aircraft structures require smooth surfaces for aerodynamic efficiency, countersunk fasteners are used extensively. The countersink in the skin panel reduces the sheet thickness in the region of highest stress surrounding the rivet. If the skin is too thin the countersink can penetrate the entire thickness creating a knife-edge condition (Figure 2-7). The stress concentration due to a countersunk rivet hole increases to approximately 4.0 if a knife-edge condition exists (Shivakumar, 1992). Again, the high stresses at the faying surface near fasteners can promote fatigue cracking.

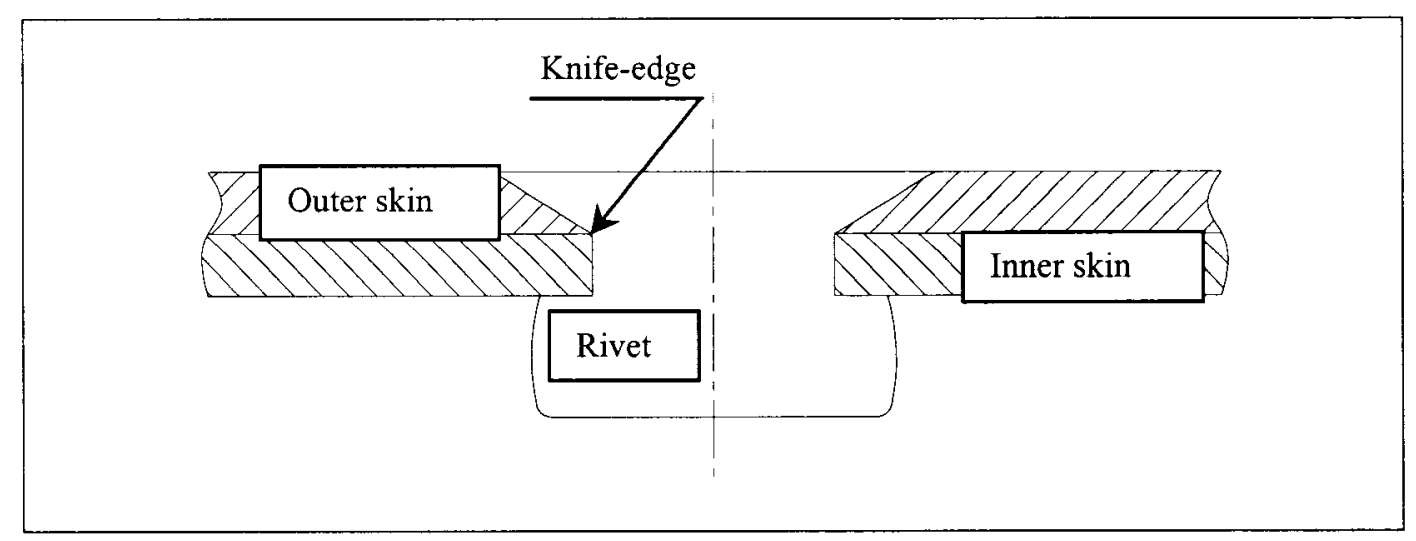

Figure 2-7: Typical countersunk rivet installation showing a "knife edge" condition.

\footnotetext{
${ }^{4}$ Installed solid rivets introduce compressive residual stresses at the edge of rivet holes. The rivet also acts to restrict the deformation of the hole further reducing the maximum stresses at the hole.
} 


\subsubsection{Load Transfer in Longitudinal Fuselage Joints}

Hoop loads generated by internal fuselage pressure must be transferred from the outer skin panel to the inner skin. This is accomplished in several ways. A portion of the total load is transferred through bearing on the rivet holes. The rest of the load is transferred by friction between the two sheets. This friction transfer is possible because the rivets apply a clamping force to the skin panels during installation.

Friction reduces the load transferred by fastener bearing, which serves to improve the fatigue life of the joint. Testing has shown that increasing the squeeze (or clamping) force of the rivet during installation can improve the fatigue life of riveted lap joints by up to $650 \%$ (Müller, 1995) ${ }^{5}$. The increased rivet squeeze provides two benefits; first, the frictional load transfer is increased, reducing rivet-bearing loads. The second benefit is that the increased rivet deformation during installation enlarges the compressive residual stress region around the rivet, further improving the fatigue life.

Load transfer is accomplished across all three rows of rivets (for a 3 row riveted lap joint). The amount of load transferred at each row of rivets depends on the type of materials being joined, the rivet material, and the size of the fasteners. An idealised depiction of a lap joint is shown in Figure 2-8. The rivets act as beams connecting the two sheets together. The flexural stiffness of these beams depends on the length, cross sectional area, and material of the rivets.

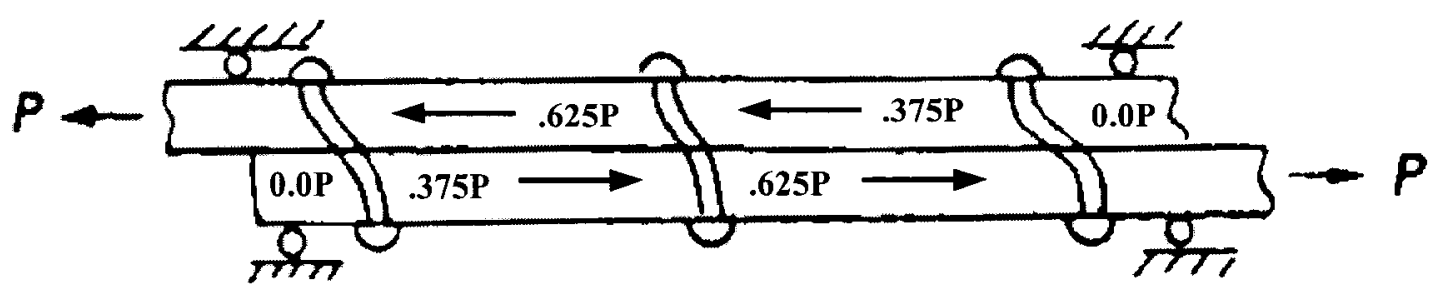

Figure 2-8: Idealised representation of a riveted single lap joint showing sheet load transfer for 2117-T4 rivets in 0.040 in. 2024-T3 skin (Niu, 1995).

\footnotetext{
${ }^{5}$ Results were for testing of a 2024-T3 single lap joint ( 0.050 in. sheet thickness) fastened using 3 rows of $5 / 32$ in. $\mathrm{AD}\left(2117-\mathrm{T} 3\right.$ ) rivets, $\sigma_{\max }=14.0 \mathrm{ksi}, \mathrm{R}=0.05$, using rivet squeeze forces ranging from $2140 \mathrm{lb}$.to $5000 \mathrm{lb}$.
} 
Based on extensive testing and analysis, the proportion of load transferred by each rivet row has been established (Figure 2-8). These values have been confirmed by the finite element modelling of Müller (1995) and experimentally by Swift (1991). 


\subsection{FATIGUE}

Ageing of aircraft structures is a result of corrosion, fatigue, or a combination of both. In many cases fatigue and corrosion interact in a synergistic manner diminishing the residual strength of the structure. Longitudinal fuselage joints contain thousands of fatigue sensitive details, such as rivets. As a result they are one of the most fatigue prone regions of a pressurised aircraft. This section explores the development of fatigue damage in longitudinal fuselage joints.

Fatigue occurs in two stages; nucleation and growth. Nucleation is the formation of a crack at the microstructural level. Crack growth describes subsequent extensions in length of the nucleated crack during each loading cycle. If undetected these cracks can grow to critical length causing failure of the structure.

\subsection{Microstructural Aspects}

Fatigue cracks develop in regions of the highest local stress near the surface of a material. Geometric discontinuities can give rise to stress concentrations, which provide ideal locations for fatigue damage to occur. At the microstructural level fatigue can be divided into four distinct stages:

1. Early stages, cyclic hardening or softening.

2. After $\sim 5 \%$ of the fatigue life, slip becomes localised, and persistent slip bands (PSB) appear.

3. Slip bands grow laterally, widen and cracks grow along the slip bands (Stage I crack growth). This phase can occupy $80-90 \%$ of the fatigue life.

4. Cracks grow normal to the applied loading (Stage II crack growth). 
In early stages of fatigue, the material is cyclically hardened ${ }^{6}$ by dislocation pile-up at grain edges, second phase particles, or other boundaries. As the stress is increased, slip occurs between primary and secondary slip systems, hindering further dislocation motion, hardening the material.

When the material has reached full cyclic hardness, persistent slip bands (PSB) form, which are softer regions in the material. The phenomena known as extrusion and intrusion form during loading and unloading of the material. As load is applied, the softer material in the persistent slip bands is forced outwards from the surface. During unloading cross slip occurs "pinning" the material in the PSB (Figure 3-1 and 3-2). The development of intrusions increases local material strains. These locations become probable locations for fatigue crack nucleation (Lynch, 1979).

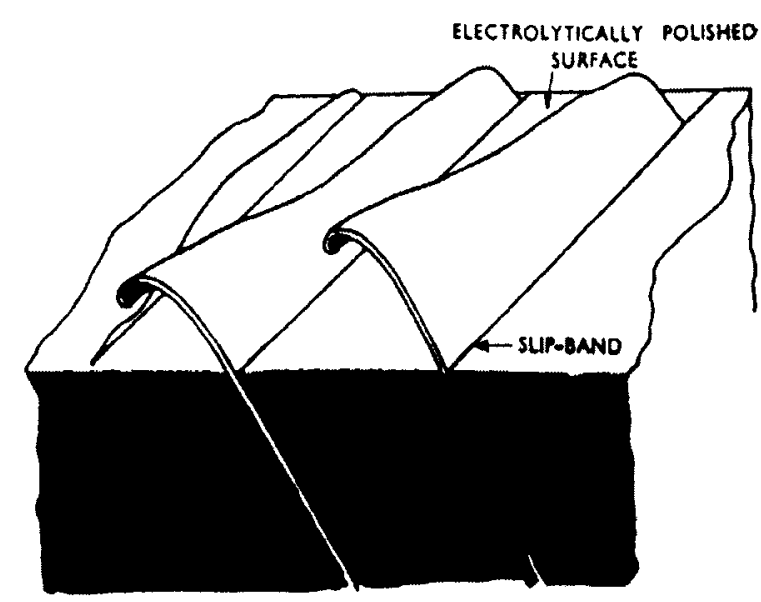

Figure 3-1: Extrusion schematic (Smallman, 1985).

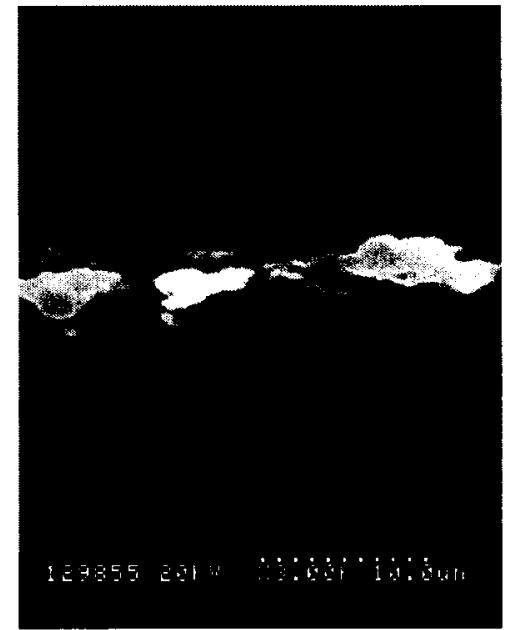

Figure 3-2: SEM micrograph of Intrusion/extrusion in 2024-T3 clad (Courtesy of Merati, NRC).

\footnotetext{
${ }^{6}$ Depending on the material processing cyclic softening, or hardening can occur. Since 2000- and 7000series aluminum alloys are precipitation age hardened, cyclic hardening occurs. For a more detailed description of the cyclic hardening (and softening) mechanisms refer to Smallman (1985).
} 
At a certain threshold stress intensity factor ${ }^{7}$ (SIF), $K_{\text {th }}$, a fatigue crack will nucleate in the PSB (Wilhelm, 1979). The crack then propagates into the softer material of the PSB, which increases length as the SIF at the crack tip increases (Figure 3-3). This is commonly referred to as Stage I crack growth.

At some point the stress required to further grow the crack within the PSB becomes large enough to activate Stage II fatigue crack growth. The crack now propagates perpendicular to the applied stress by alternating slip, which consists of repetitive blunting and sharpening of the crack tip. Fatigue striations are produced as a result of alternating slip, and are a feature of fatigued materials (Wilhelm, 1979).

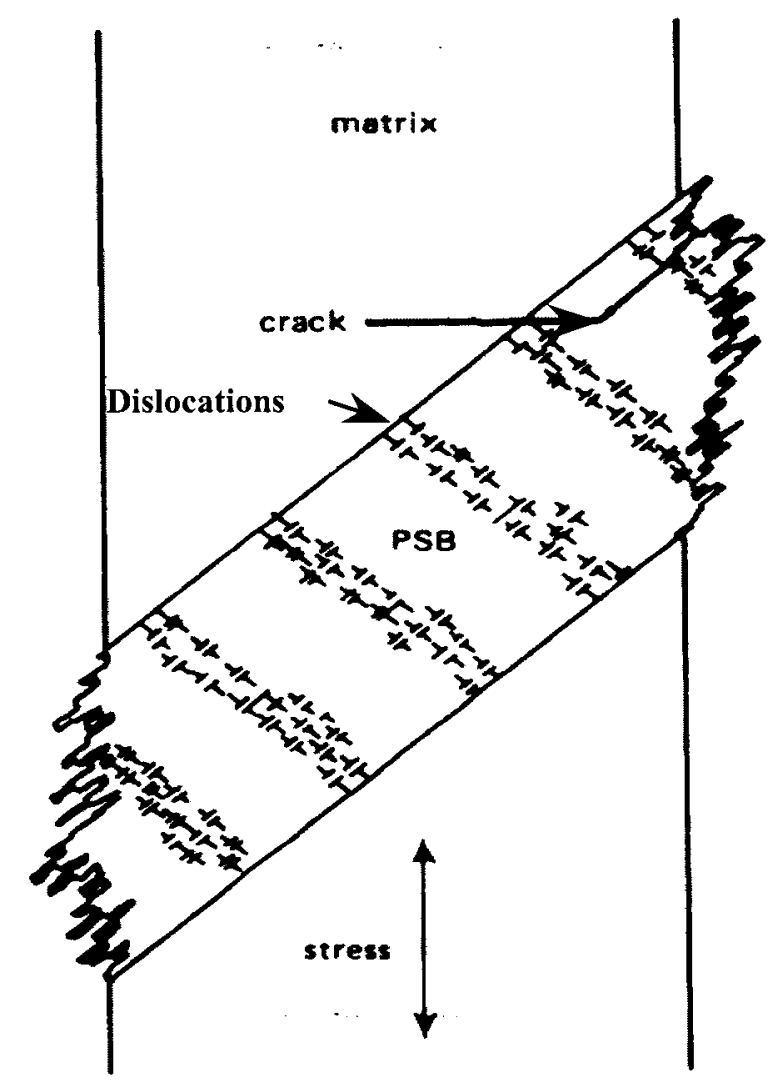

Figure 3-3: Schematic diagram of crack nucleation in a PSB (Smallman, 1985).

\footnotetext{
${ }^{7}$ Stress intensity factor is a measure of the magnitude of the crack-tip stress field and is governed by the applied stress and crack length. $\mathrm{K}=\mathrm{Q} \cdot \sigma(\pi \mathrm{a})^{1 / 2}$ (units of $\mathrm{ksi} \cdot \mathrm{in}^{1 / 2}$ ) where $\mathrm{Q}$ is a geometric factor, $\sigma$ is the applied stress, and a is the crack length.
} 
Nucleation is largely influenced by the presence of material inhomogeneities. The properties can vary significantly between particle and matrix, thus introducing a stress concentration within the material. These are often sites of fatigue crack nucleation (Figure 3-4). Newman et al. (1992) found fatigue cracks formed at inclusions and inclusion clusters in thin 2024-T3 aluminum. A semi-elliptical surface crack approximately the size of the inclusion was observed shortly after crack nucleation. The average observed inclusion size was 0.0001 in. $(3 \mu \mathrm{m})$ wide and 0.0005 in. $(12 \mu \mathrm{m})$ deep.

Estimated areas for the particles that nucleated fatigue cracks were all greater than $9 \times 10^{-5}$ in. $^{2}\left(58 \mu \mathrm{m}^{2}\right)$, and were likely $\mathrm{Al}_{7} \mathrm{Cu}_{2} \mathrm{Fe}$ (Newman et al., 1992). Particles in 2024$\mathrm{T} 3$ are generally comprised of $\mathrm{Al}-\mathrm{Cu}-\mathrm{Mn}-\mathrm{Fe}$, or $\mathrm{Al}-\mathrm{Cu}-\mathrm{Mg}\left(\mathrm{CuMgAl}_{2}\right)$. Particle sizes ranged from a cross-sectional area of $1.5 \times 10^{-4}$ in. $^{2}\left(100 \mu \mathrm{m}^{2}\right)$ to $2.3 \times 10^{-4}$ in. $^{2}\left(150 \mu \mathrm{m}^{2}\right)$ for moderate to large particles respectively (Laz, 1998 and DeBartolo, 1998).

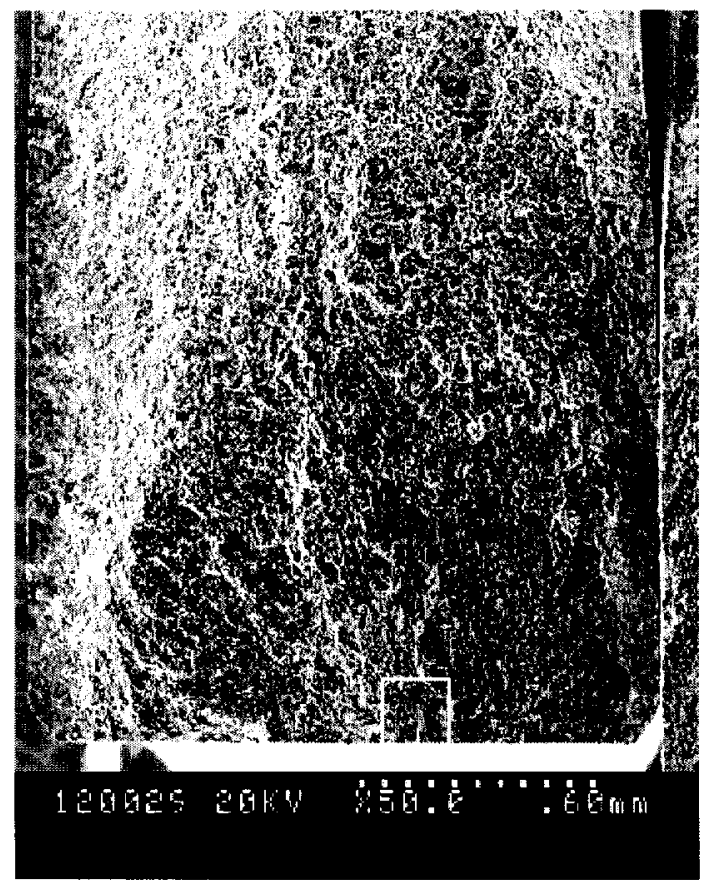

(a)

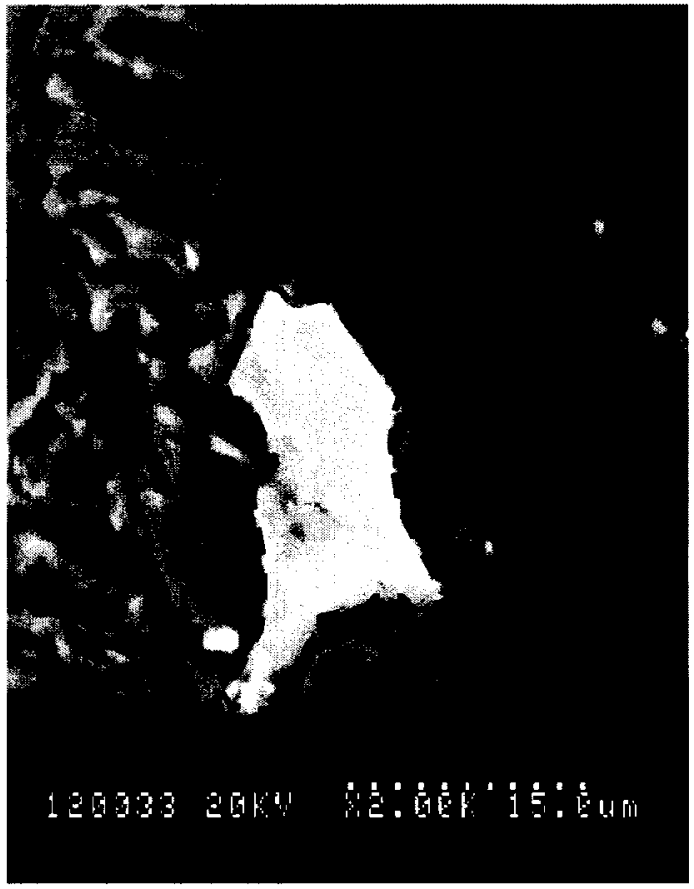

(b)

Figure 3-4 Crack nucleation emanating from second phase particle in 2024-T3 sheet a) SEM micrograph at low magnification showing crack nucleation site (window); b) high magnification backscatter view of nucleation site at a constituent particle (dashed outline) (Courtesy of Merati, NRC). 


\subsection{Fretting}

Fretting wear is a tribological, more specifically, a tribochemical process that involves small $(1-100 \mu \mathrm{m})$ oscillatory movement between 2 solid surfaces in contact. This motion often occurs between surfaces intended to be fixed relative to one another. For interference fit fastener installations (rivets, for example) a $1 \mu \mathrm{m}$ sliding motion can still occur, making them prone to fretting damage.

Tribochemical Wear is defined as rubbing contact between two surfaces that react with the environment. Repeated growth and fracture of the aluminum oxide layer between the two skin sheets produces fretting damage in joints. The wear debris for 2024-T3 produced by removing the oxide layer is typically $\gamma-\mathrm{Al}_{2} \mathrm{O}_{3}$, a very hard, black substance. Depending on the amplitude of surface oscillation, this debris is often retained within the contact region, further degrading the material.

\subsubsection{Environmental Effects on Fretting}

Fretting is strongly influenced by oxygen and moisture. Oxygen serves to increases wear rates as hard oxide particles form and cause abrasive wear on the material surface. A threefold increase in wear rate exists for dry air, when compared to dry nitrogen.

On the other hand, water vapour acts to reduce wear. The hydrated oxide debris is softer in humid air than in dry air. The surfaces can also be lubricated slightly by the presence of moisture, which decreases the surface friction, and hence the fretting wear rate.

When a corrosive environment is introduced, such as a $3.5 \% \mathrm{NaCl}$ solution, the wear rate is increased by up to 10 times compared to moisture alone. The reason for this is the synergistic interaction between electrochemical corrosion and fretting wear. Fretting wear increases the size of surface asperities (surface roughness), increasing the surface area on which corrosion can attack. 
In previous MSD specimen tests, the appearance of fretting in riveted lap joints was significantly reduced for corroded specimens (Krizan, 1999). This virtual disappearance of fretting in pre-corroded MSD specimens is thought to be due primarily to the separation of the faying surfaces by the accumulated corrosion product. Another possibility is that the corrosion product may act as a solid lubricant reducing friction around the rivet holes.

\subsubsection{Fretting Fatigue Interaction}

Fretting generally occurs on the faying surface in a region surrounding fasteners where the rivet clamping forces are the highest. When the joint is loaded the rivets tend to tilt within their holes, applying more pressure on the loaded side of the hole. This generates higher frictional forces, and thus, more fretting damage in that region. The resulting fretting pattern observed by Wakeman (1996), Scott (1997) and Krizan (1999) is shown in Figure 3-5.

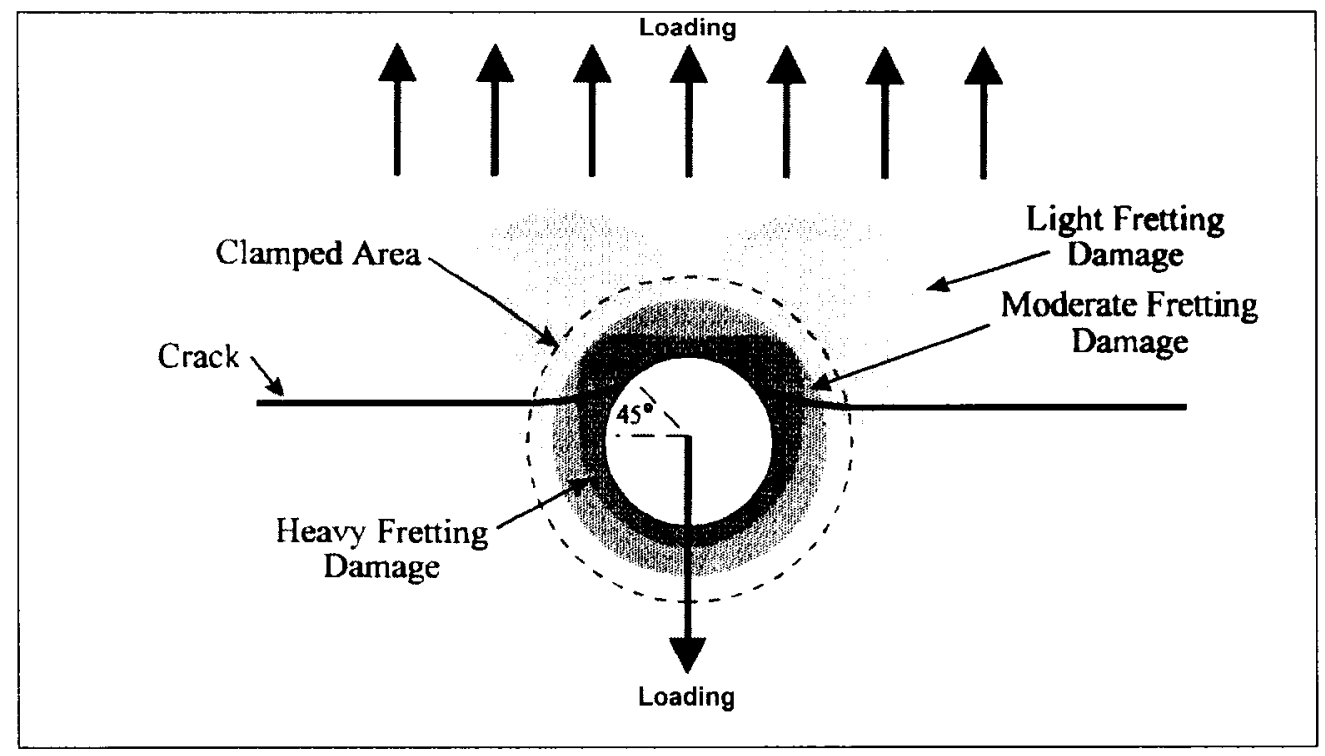

Figure 3-5: Typical fretting wear pattern at a countersunk rivet hole in a fuselage joint showing typical crack initiation pattern (Wakeman, 1996).

As a result of this damage, the faying surface has increased roughness, which can significantly decrease fatigue initiation life. Andrews and Sehitoglu (2000) have shown that fatigue life strongly depends on surface roughness. Testing has shown that fatigue 
cracks tend to nucleate in regions of heavy fretting damage surrounding countersunk rivets (Krizan, 1999). An example of this is presented in Figure 3-6.

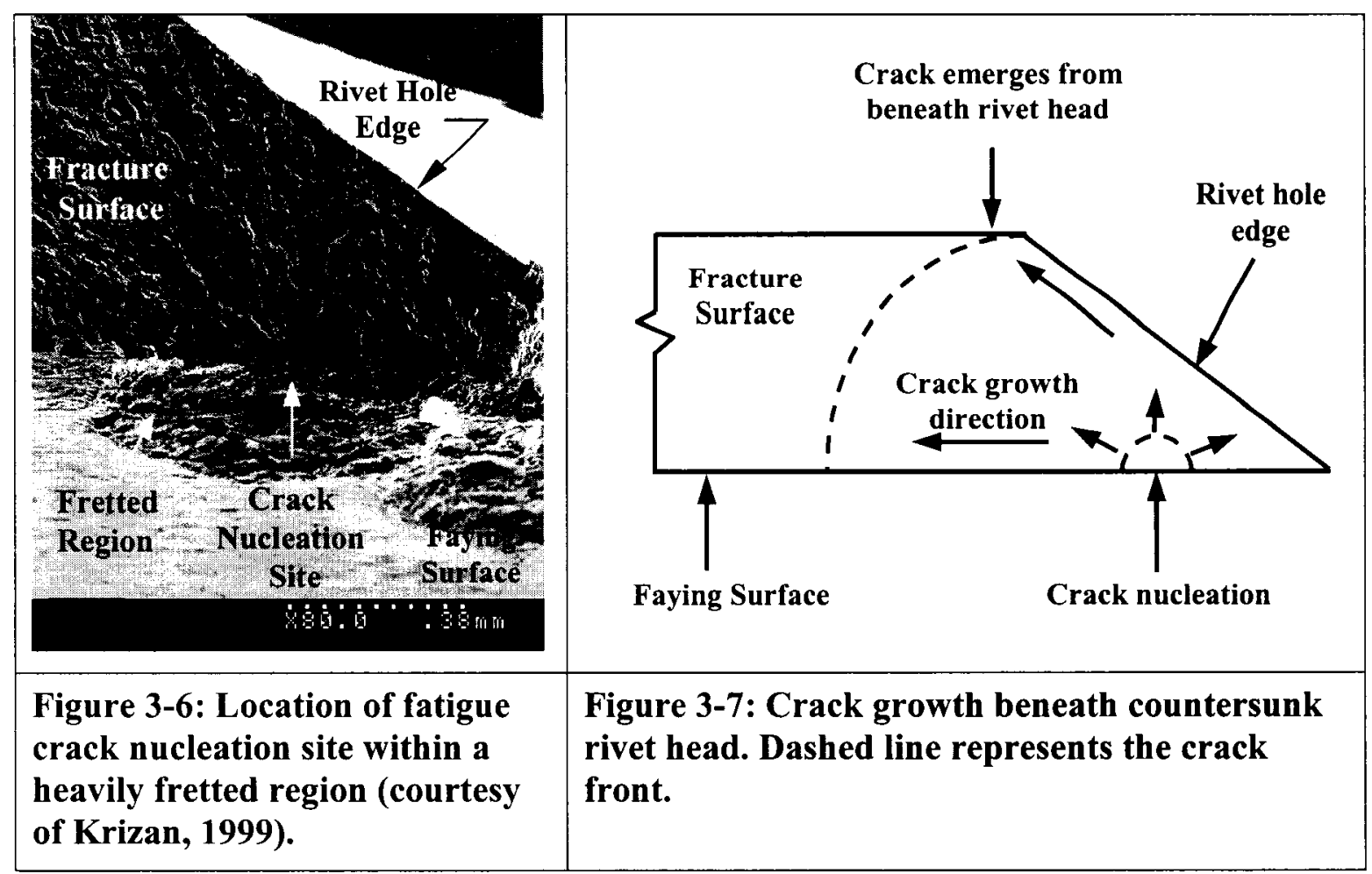

\subsection{Influence of Rivet Holes on Fatigue}

One region especially prone to fatigue cracking is at or near countersunk rivet holes in longitudinal lap joints. The combination of the countersunk hole stress concentration ( $\sim 4.0$ for a knife-edge countersink, Section 2.3.1), out-of-plane bending stress, rivet bearing loads, and faying surface fretting make rivet holes vulnerable to fatigue cracking.

\subsubsection{Cracking Beneath Rivet Heads}

Fatigue cracks generally initiate at the faying surface of the outer sheet beneath the rivet head. This also tends to correspond to the region of heaviest fretting damage (Figure 3-6). Due to secondary bending, the faying surface stresses are higher than on the outer surface of the upper sheet. As a result the "crack tunnelling" phenomenon occurs when cracks are close to the rivet (Figure 3-7). The crack front on the faying surface experiences a higher 
stress intensity factor (SIF) because of the higher bending stresses. The faying surface crack can lead the outer surface crack front by up to a sheet thickness, depending on the magnitude of bending stresses present (Eastaugh, 1993).

This early crack growth is significant since cracks, undetectable using in-service NDI, may exist beneath rivet heads. Flaws can often exist at the hole edge but are not detected by traditional NDI techniques (eddy current, ultrasonic, and even x-ray) because they are hidden by the rivet head. The inspection results using current state-of-the-art crack detection techniques for the configuration shown in Figure 3-8, are presented in Table 3-1. It is evident that first layer crack (crack 1) detection will reliably occur after the crack tip has grown beyond the rivet head. Based on these results, significant improvement in the current "state-of-the-art" in NDI technology is required to adequately support WFD inspections and aircraft audits (AAWG, 1999).

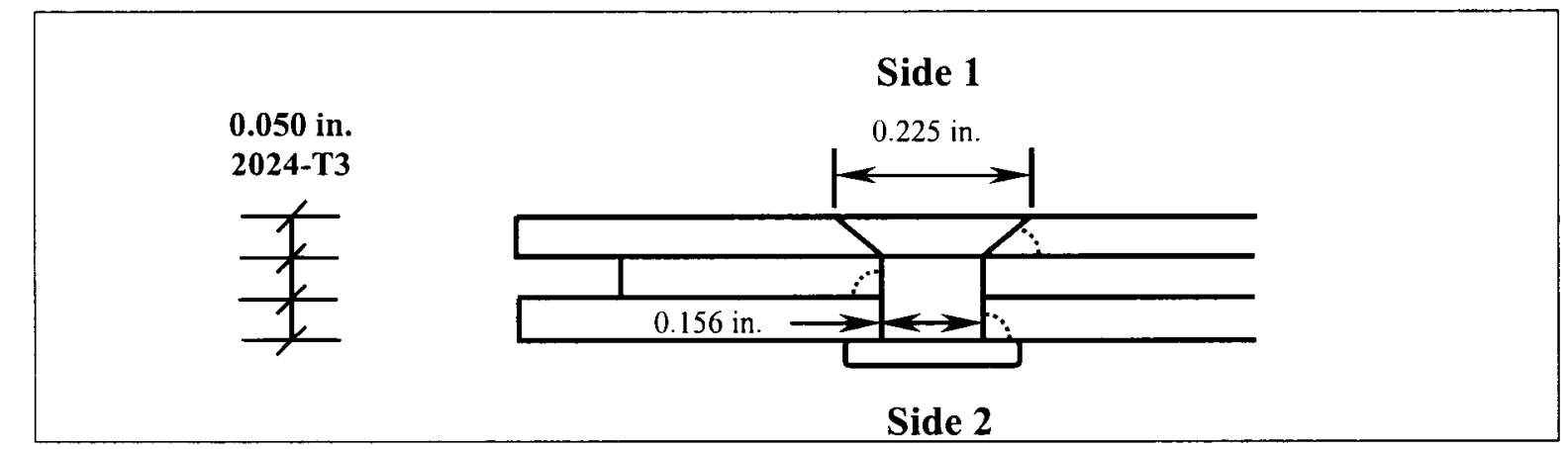

Figure 3-8: Diagram of round robin NDI specimen. Crack 1 is the uppermost flaw. NAS1097-AD5 (5/32 in. shank diameter) flush rivets were used (AAWG, 1999).

Table 3-1: Round robin inspection results for the specimen in Figure 3-8 carried out in laboratory conditions.

Note: Human factors have not been taken into account. Inspection performed from side 1. Cracks are labelled in ascending order from top to bottom (AAWG, 1999).

\begin{tabular}{|c|c|c|c|c|c|c|c|c|}
\hline & \multicolumn{2}{|c|}{ Boting } & \multicolumn{2}{|c|}{ Airbus Industrie } & \multicolumn{2}{|c|}{ Lockheed Martin } & \multicolumn{2}{|c|}{ FAA Tech Center } \\
\hline & in. & $\mathrm{mm}$ & in. & mm & in. & mm & in. & mm \\
\hline CRACK 1: & 0.05 & 1.3 & 0.08 & 2.0 & 0.05 & 1.3 & 0.05 & 1.3 \\
\hline CRACK 2: & 0.2 & 5.1 & 0.24 & 6.0 & 0.25 & 6.4 & - & - \\
\hline CRACK 3: & 0.3 & 7.6 & 0.31 & 8.0 & 0.3 & 7.6 & 0.24 & 6.1 \\
\hline
\end{tabular}




\subsubsection{Crack Growth Beyond Rivet Heads}

The influence of the clamping force, and secondary bending on the fatigue crack is reduced away from the rivet. According to St. Venant's principle, stress concentrations and other local effects are negligible at an approximate distance of one rivet diameter away from a rivet.

According to Boeing tests, crack growth rates for cracks up to 0.25 in. from the fastener edge, range from $5 \times 10^{-6}$ to $2 \times 10^{-5}$ in. per cycle depending on the type of airplane and the service conditions (Pelloux, 1991). Krizan (1999) found that early crack growth rates in MSD specimens, up to approximately 0.25 in. from the rivet hole edge, ranged from $1.0 \times 10^{-6}$ to $1.0 \times 10^{-5}$.

\subsection{Multiple Site Damage (MSD)}

When structures contain repeated details (such as holes, or notches) and are subjected to similar cyclic stresses, numerous cracks can develop simultaneously. Generally, when fatigue cracks in multiple structural details reach sufficient size and density, the structure can no longer meet its damage tolerance requirement, i.e. to maintain its required residual strength after partial structural failure (AAWG, 1999).

One source of widespread fatigue damage is multiple site damage (MSD). This phenomenon is characterised by the simultaneous presence of fatigue cracks in the same structural element. The major concern is that MSD can exist with the individual cracks being difficult to detect, but they may link up to form a single, large, crack in a relatively short period of time. If MSD exists ahead of a fatigue crack, the damage tolerance of that structural element may be drastically reduced.

Longitudinal fuselage joints contain thousands of fatigue sensitive details such as rivets, exposed to nearly uniform stresses. As such, they are particularly prone to the development of MSD. The characteristics of MSD in longitudinal fuselage joints are the main focus of this thesis. 


\subsubsection{Interaction of Multiple Fatigue Cracks}

Fatigue cracks in fuselage joints typically develop under the countersunk rivet heads, as described in Section 3.3.1. In the case of MSD, often there are two cracks growing within the same rivet pitch, from adjacent rivets. The interaction of cracks existing in the same rivet pitch is not significant until the crack tips grow to within $0.35-0.25$ in. of each other. At that point, the local stress fields of the two crack tips interact, and the crack growth rates increase up to approximately 0.004 in. per cycle (Krizan, 1999).

The stress in the ligament separating the two cracks increases until fracture of the ligament occurs. Crack link-up is defined as the joining of the two crack tips to form one larger crack, or when the two crack tips overlap (refer to Figure 3-9). Krizan (1999) has found that the period from the first visually detected crack to the first link-up is approximately $20 \%$ of the total fatigue life for non-corroded lap joint specimens. Similarly, Pelloux (1991) found that this same period was approximately $25 \%$ of the total fatigue life.

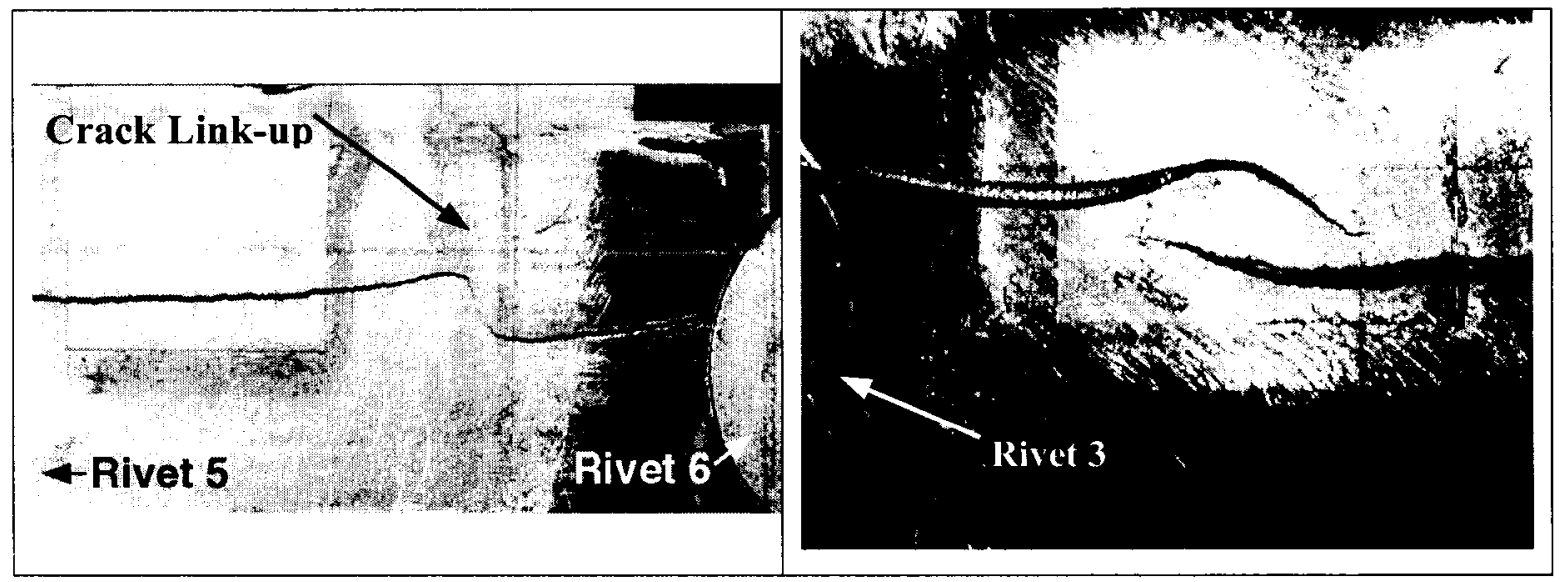

Figure 3-9: Pictures of crack link-up. (a) Crack tip link-up where the ligament between the two cracks fractures (Specimen MSD511-061, (Krizan, 1999)). (b) Overlap of cracks where the ligament does not fracture, but no longer carries any load (Specimen MSD511-046, Courtesy of D. Krizan).

After the first crack link-up has occurred, the longer crack dominates further crack growth. This dominant crack is referred to as the lead crack, as it exhibits the fastest crack growth rate in the specimen. A link-up of the lead crack and cracks emanating from the other rivets in the critical row will eventually occur. Both Scott (1997) and Krizan 
(1999) have reported that on several occasions, as the lead crack approached a rivet with no visible crack, a crack suddenly grew from the rivet, and linked up with the lead crack.

The time from first link-up to final failure ${ }^{8}$ of the lap joint is approximately $2 \%$ of the total life (Krizan, 1999). This is one of the very dangerous characteristics of MSD where several undetected cracks can quickly coalesce to form a large crack. In one case a Boeing 727 operator reported a 19 in. long crack in a fuselage lap joint located at S-26L between BS 540-560, which extended through 13 fastener holes. Subsequent inspections of S-26L revealed 22 additional cracks between stations 500-520, 580-600, 600-620 and 620-640 (Boeing, 1999). A "turtle" diagram of the cracked region on the B-727 is shown in Figure 3-10. The outlined area indicates the approximate region affected by this MSD scenario.

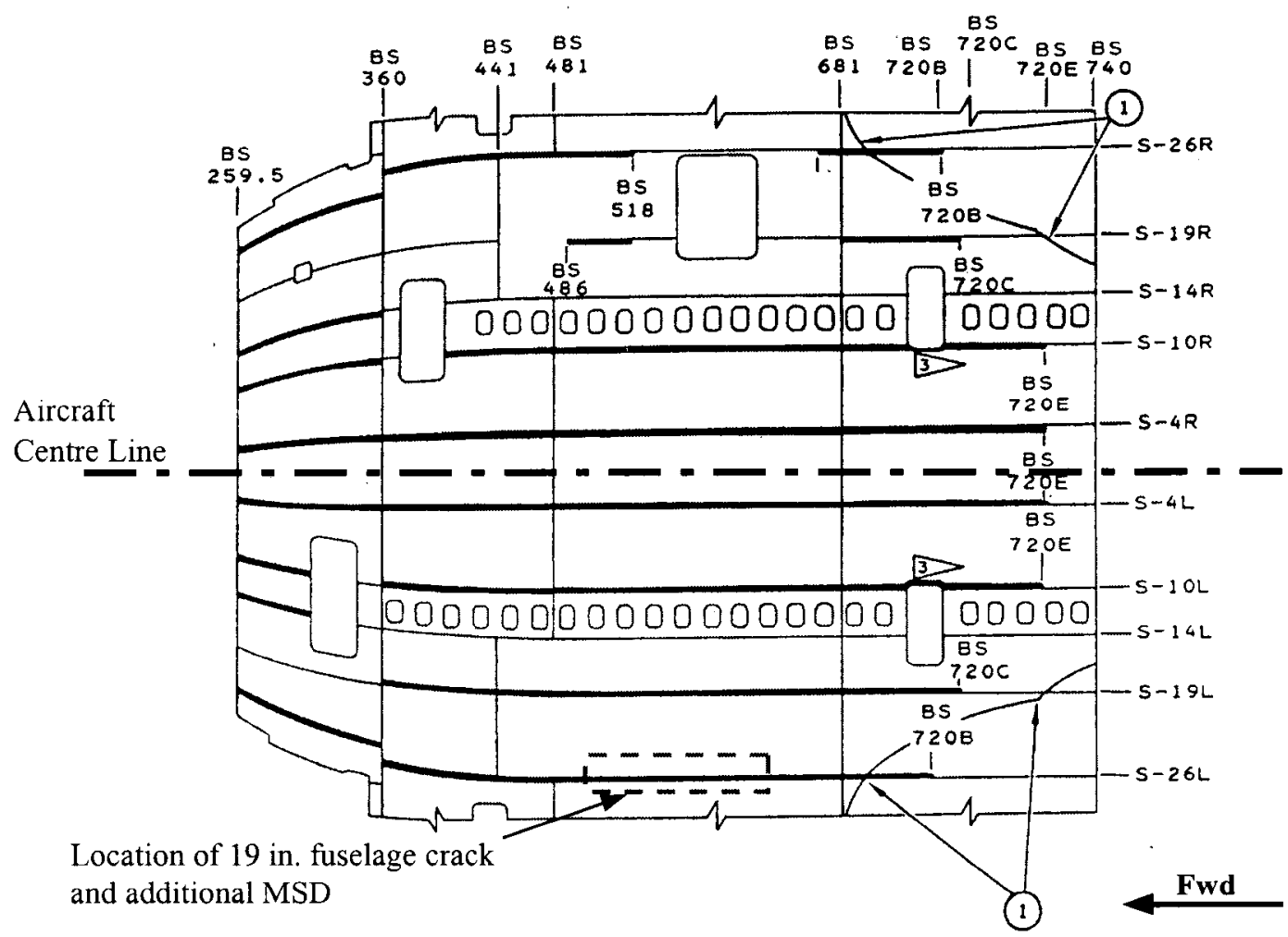

Figure 3-10: "Turtle" diagram showing an unfolded top view of the B-727 fuselage area affected by MSD crack scenario described above (Boeing, 1999).

\footnotetext{
${ }^{8}$ In this thesis, final failure is defined as the existence of a fatigue crack that spans all 8 rivets (approximately $7 \mathrm{in.} \mathrm{long} \mathrm{crack)} \mathrm{in} \mathrm{the} \mathrm{MSD} \mathrm{specimen.} \mathrm{This} \mathrm{would} \mathrm{simulate} \mathrm{a} \mathrm{single} \mathrm{bay} \mathrm{fuselage} \mathrm{crack} \mathrm{in}$ an actual aircraft.
} 


\subsection{CORROSION}

Most structures on commercial aircraft are manufactured from aluminum alloys. The fuselage joint material under consideration here, is Alclad 2024-T3 aluminum. For 0.040 in. thick sheet the cladding process deposits a thin, corrosion resistant, 0.0016 in. $(41 \mu \mathrm{m})$ layer of 1000 -series ( $99 \%$ pure) aluminum on both surfaces of the material. In addition, aluminum naturally forms a thin oxide barrier film when exposed to air. In order for corrosion to attack the underlying metal, the oxide and clad layers must first be breached either by physical or chemical means.

Once the base metal is exposed, various forms of corrosive attack can occur depending on the material properties, the corrosive environment, and the structural design. Aluminum 2024-T3 is susceptible to pitting corrosion, especially if subjected to chloride or sulphate rich aqueous solutions. Aircraft are often subjected to these types of aqueous environments, the most common being salt air and acid rain.

\subsection{Types of Corrosion}

The four main types of corrosive attack on aluminum alloys are crevice corrosion, pitting corrosion, intergranular and exfoliation corrosion and stress corrosion cracking (SCC). Crevice and pitting corrosion tend to be the most damaging forms of corrosion for lap joints. Each of these forms of corrosion is discussed in greater detail in the following sections.

\subsubsection{Crevice Corrosion}

Localised corrosive attack of the mating, or faying surfaces of a structure in the presence of corrosive media is referred to as crevice corrosion. Typically, crevice corrosion occurs when small volumes of corrosive solution ingress into a structure, and remain stagnant for a period of time. 
Lap joints are prime locations for crevice corrosion to occur. If the lip of the joint is not properly sealed moisture is able to wick into the joint. Often in aircraft, the inner lip of the joint is not sealed and is only painted with a primer coat, as it is not exposed to the external environment. However, for passenger aircraft the warm and humid internal environment poses a considerable threat of corrosion. Moisture can accumulate in the cabin from air conditioning systems and passengers. If this moisture accumulates along the inner lip of the joint it can easily enter the joint (refer to Figure 4-1).

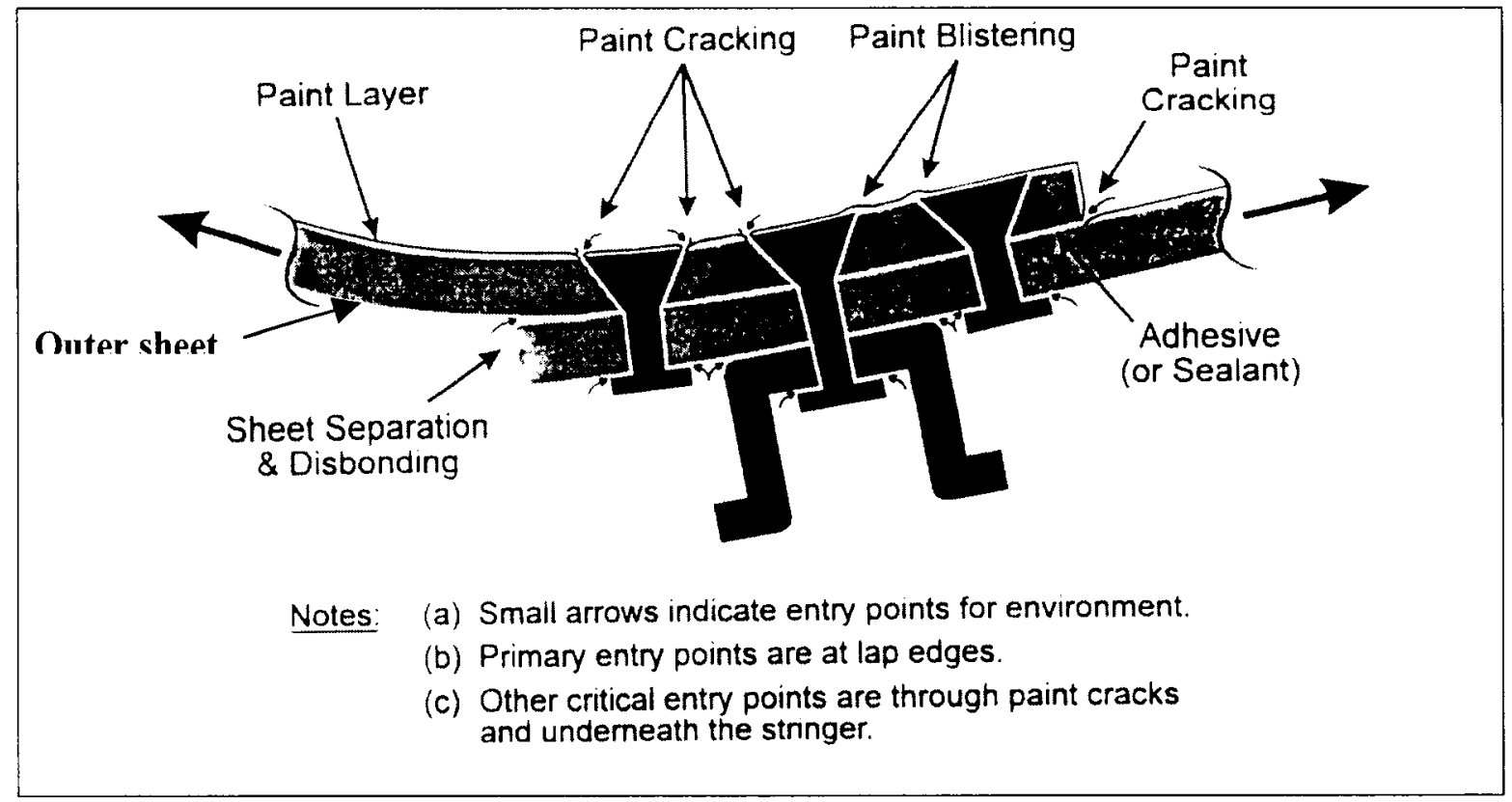

Figure 4-1: Figure showing routes of moisture ingress into lap joints (Wakeman, 1996).

The trapped solution contains varying concentrations of chloride and sulphide ions, corrosive agents (metallic salts) and dissolved oxygen. Initially, an oxidation and reduction reaction occurs producing hydroxides, and positively charged metallic ions $\left(\mathrm{M}^{+}\right)$(Equation 4-1 and 4-2) (Fontana, 1986).

$$
\begin{array}{ll}
\text { Oxidation: } & \mathrm{M} \rightarrow>\mathrm{M}^{+}+\mathrm{e} \\
\text { Reduction: } & \mathrm{O}_{2}+2 \mathrm{H}_{2} \mathrm{O}+4 \mathrm{e} \rightarrow 4 \mathrm{OH}^{-}
\end{array}
$$


Because of the lack of circulation within the crevice, oxygen is not replenished at the same rate it is being used. In a short period of time the oxygen supply is depleted. This oxygen deficiency arrests any further oxygen reduction reactions, although the dissolution of metal continues. An excess of positively charged ions $\left(\mathrm{M}^{+}\right)$develops, which is balanced by the migration of chloride ions into the crevice. This aqueous metal chloride solution dissociates into an insoluble hydroxide and a free acid (Equation 4-3) (Fontana, 1986).

$$
\mathrm{M}^{+} \mathrm{Cl}^{-}+\mathrm{H}_{2} \mathrm{O}=\mathrm{MOH}+\mathrm{H}^{+} \mathrm{Cl}^{-}
$$

The acid increases the dissolution rate of the metal, which in turn increases the migration of chloride ions. The fluid within the crevice has been found to contain 3 to 10 times the chloride content as the bulk solution, producing a $\mathrm{pH}$ level of 2-3. The result of this process is autocatalytic (self-sustained, accelerating) corrosion (Fontana, 1986).

Crevice corrosion generally leads to pitting corrosion on the faying surfaces, and intergranular and exfoliation corrosion at the rivet-hole interface.

\subsubsection{Pitting Corrosion}

As the corrosive environment breaks down the metal protective oxide layer, small regions of the underlying metal are exposed. These areas become sites of pitting corrosion. Pitting is one of the most destructive and vicious forms of corrosion because it is localised in nature, and is difficult to detect. It can penetrate quite deep into the material creating unwanted stress concentrations, increasing the probability for premature fatigue cracks to form.

Precipitates and constituent particles at or near the metal surface are the first regions attacked. They represent anodic and cathodic sites, depending on their composition. For 2024 there are two types of particles that are most aggressively attacked. The first are cathodic, Al-Cu-Mn-Fe particles, where the matrix surrounding the particle is dissolved (Figure 4-2). The other type are anodic particles comprised mainly of $\mathrm{Al}, \mathrm{Cu}$, and $\mathrm{Mg}$ 
(typically $\mathrm{CuMgAl}_{2}$ ). In the latter case the particles themselves are dissolved during corrosion.

An interesting fact of aluminum alloys is that as an anodic particle dissolves, in many cases, it becomes cathodic. This occurs as $\mathrm{Al}$, or $\mathrm{Mg}$ is selectively dissolved from the particle, leaving mainly $\mathrm{Cu}$. Most of the particles eventually form galvanic cells, which dissolve the surrounding matrix (Liao, 1998).

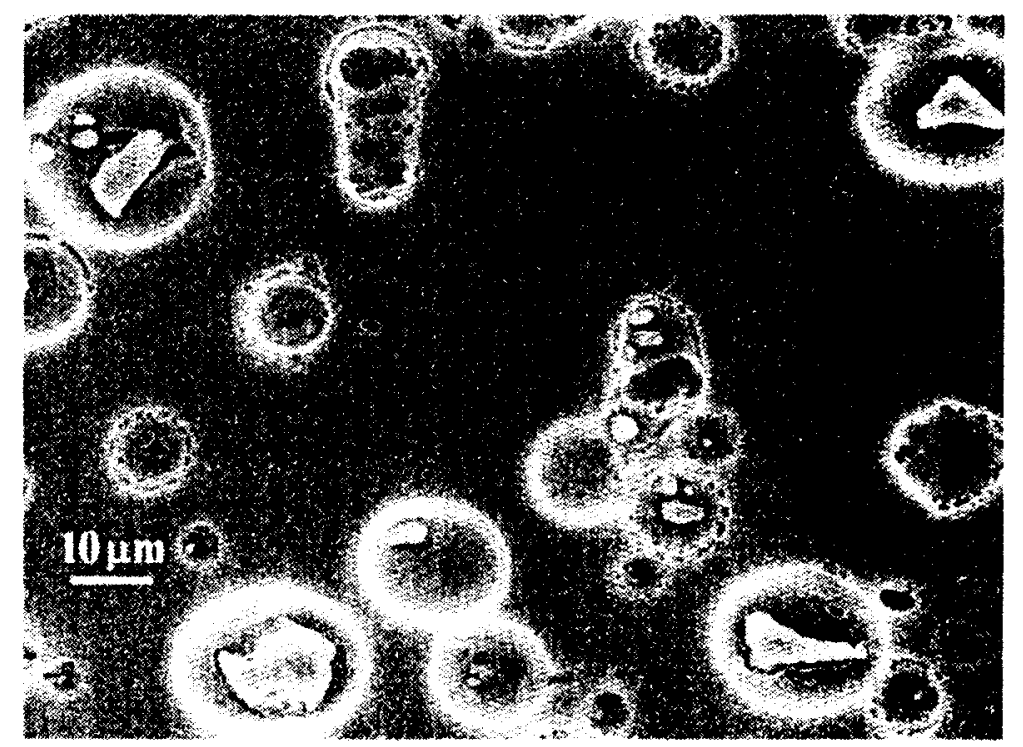

Figure 4-2: Micrograph showing cathodic particle corrosion where the matrix surrounding the particles has been dissolved (Wei, 1996).

Severe pitting occurs at particle clusters. These clusters are produced during the natural ageing process of the alloy, for the T-3 temper. The region with the highest density of particles, closest to the material surface will have the most severe pitting corrosion. This type of pitting corrosion is worse for two reasons. First, it produces numerous stress raisers in a small area. Secondly, the process occurs enclosed by a corrosion product dome (or bubble) (Liao, 1998). This creates a more aggressive environment, which accelerates the corrosion process (Figure 4-3).

Once a corrosion pit has formed, an environment conducive to accelerated pit growth is created. In the presence of an electrolyte (for example an aerated sodium chloride 
solution) a local electrochemical cell is created. Due to the dissociation reaction (Equation 4-3) hydrochloric acid forms in the pit and rapidly dissolves the base metal (Figure 4-4).

The autocatalytic nature allows the process to continue even if the electrolyte is stagnant, as in crevice corrosion. In fact, the longer the corrosive solution remains stagnant, the less oxygen reduction occurs, and the more aggressive the environment becomes.

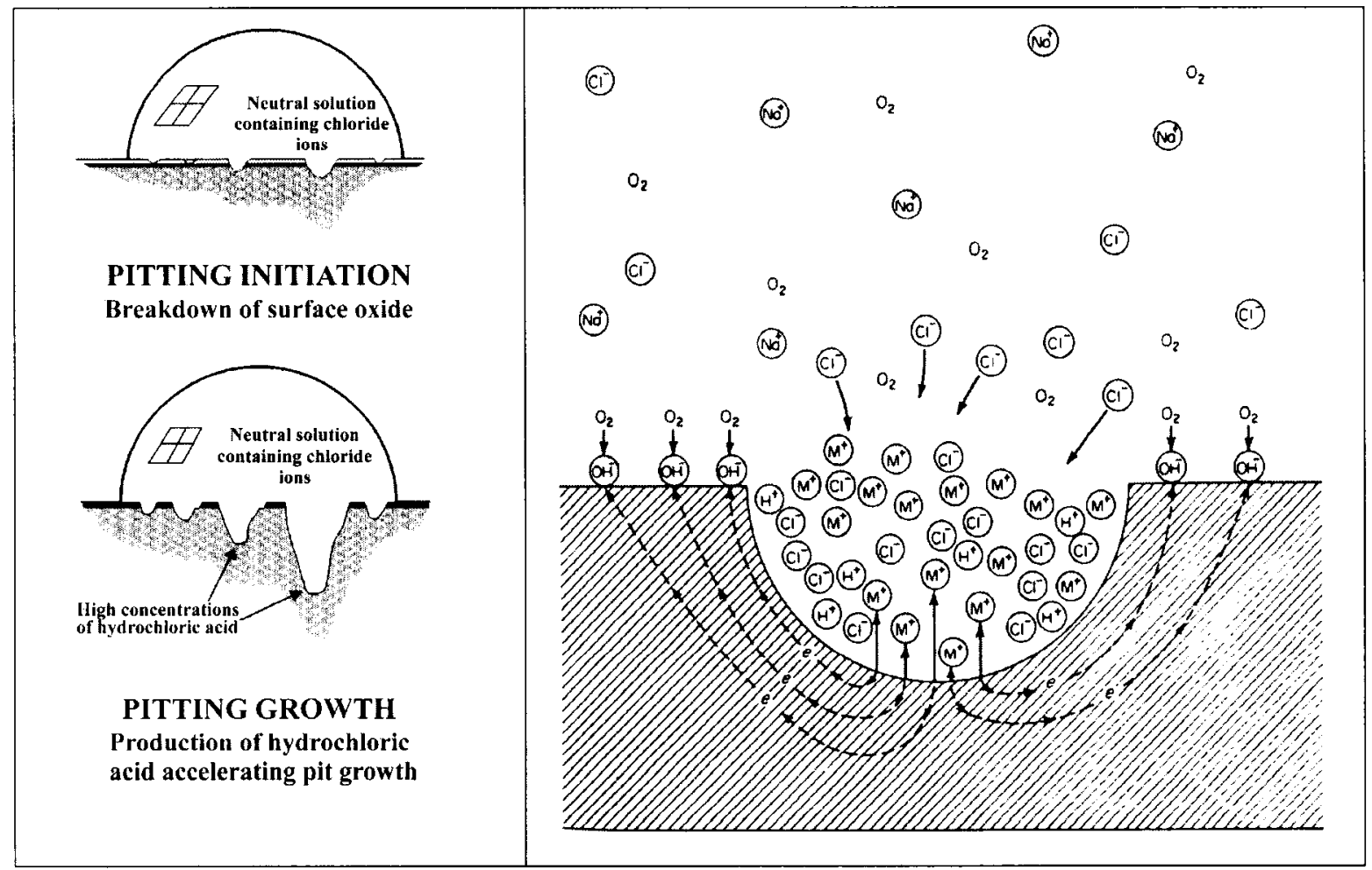

Figure 4-3: Pitting initiation and growth (De Luccia, 1991).

Figure 4-4: Autocatalytic corrosion pit growth process (Fontana, 1986).

The hydroxides formed during pitting or crevice corrosion become trapped within the joint. For 2024 aluminum, the corrosion products are comprised of amorphous aluminum hydroxide $\mathrm{Al}(\mathrm{OH})_{3}$ and hydrated aluminum oxides such as Bayerite $\left(\mathrm{Al}_{2} \mathrm{O}_{3} .3 \mathrm{H}_{2} \mathrm{O}\right)$ (Godard et al., 1967). These corrosion products have approximately 6.5 times the molecular volume of the removed metal (Bellinger et al., 1997). Thus the corrosion products cause out of plane deformation known as corrosion pillowing (Figure 4-5). This 
can significantly increase the faying surface stresses near rivets, increasing the risk of premature fatigue crack initiation.

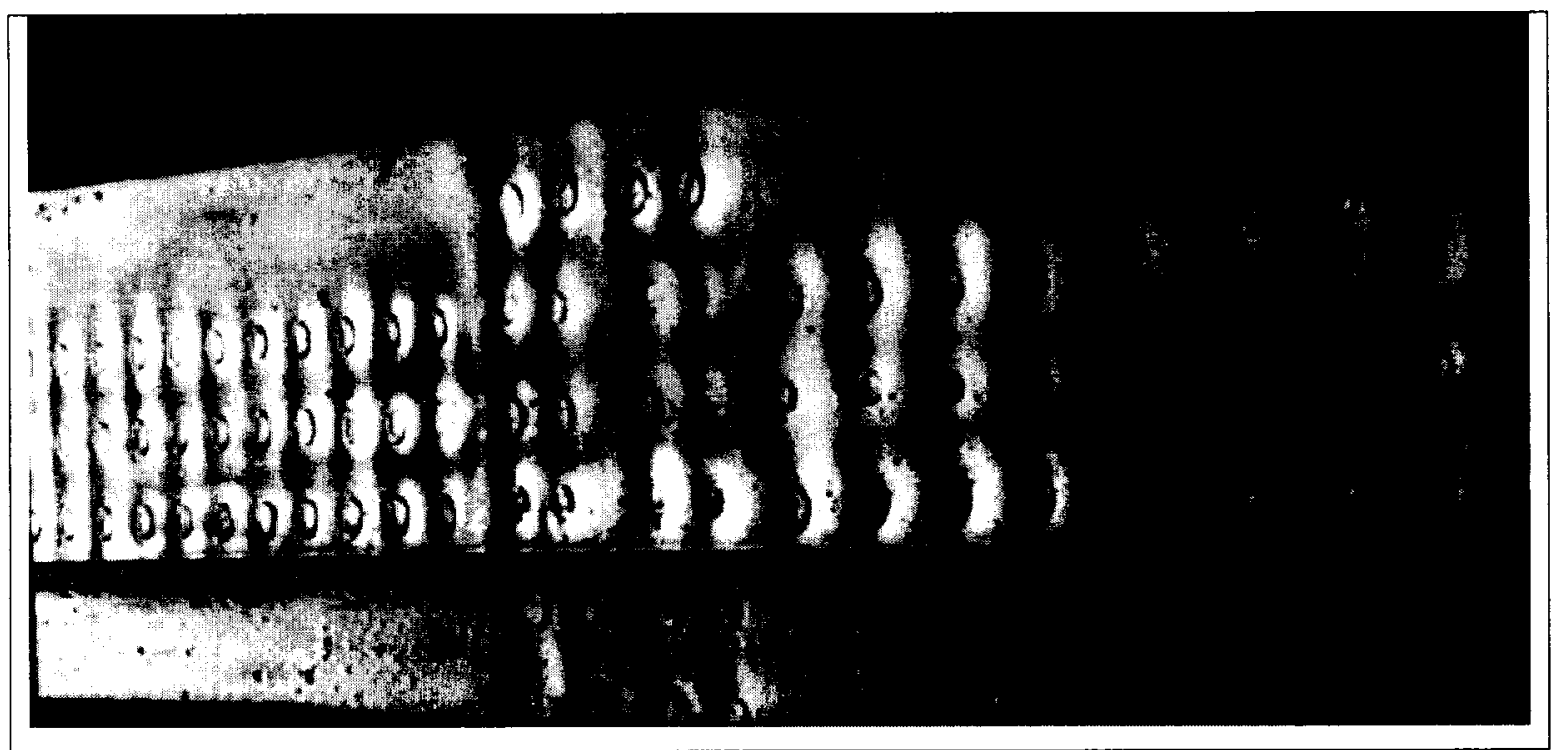

Figure 4-5: Corrosion pillowing of a B-747 fuselage joint observed using D-sight (double pass retro-reflection inspection system) (courtesy of Ron Gould, NRC).

\subsubsection{Intergranular Corrosion}

Intergranular corrosion is a form of localised, subsurface corrosion. Grain boundaries are preferentially attacked, creating narrow cracks in the material. This type of corrosion occurs mainly where the grain ends are exposed; at rivet holes, or corrosion pits for example.

The mechanism for intergranular corrosion is purely electrochemical dissolution of cells along grain boundaries. Second-phase particles within the grain boundaries have different electrical potentials than the grain boundaries and the surrounding matrix, thus forming anodic, or cathodic cells. Cathodic grain-boundary precipitates found in $\mathrm{Al}-\mathrm{Cu}$ alloys such as 2024 are comprised of copper and aluminum $\left(\mathrm{CuAl}_{2}\right)$. These particles stimulate corrosion of the surrounding grain boundary (Godard et al., 1967).

Intergranular corrosion emanating from corrosion pits in corroded Boeing 727 lap joints can be seen in Figure 4-6. This form of corrosion is also referred to as Environmentally 
Assisted Cracking (EAC), in which the environment promotes crack growth that would not occur without the presence of such conditions (Bellinger, 1999). Corrosion pits expose grain ends as they grow in the through-thickness direction, which are preferential sites for intergranular corrosion. Subsurface cracks extend along grain boundaries until another pit is encountered. The pits coalesce forming a thinner region with a smoother surface than the original pitted surface. It is thought that this process of pitting, intergranular corrosion and pit coalescence is repetitive in nature, although this has yet to be confirmed.

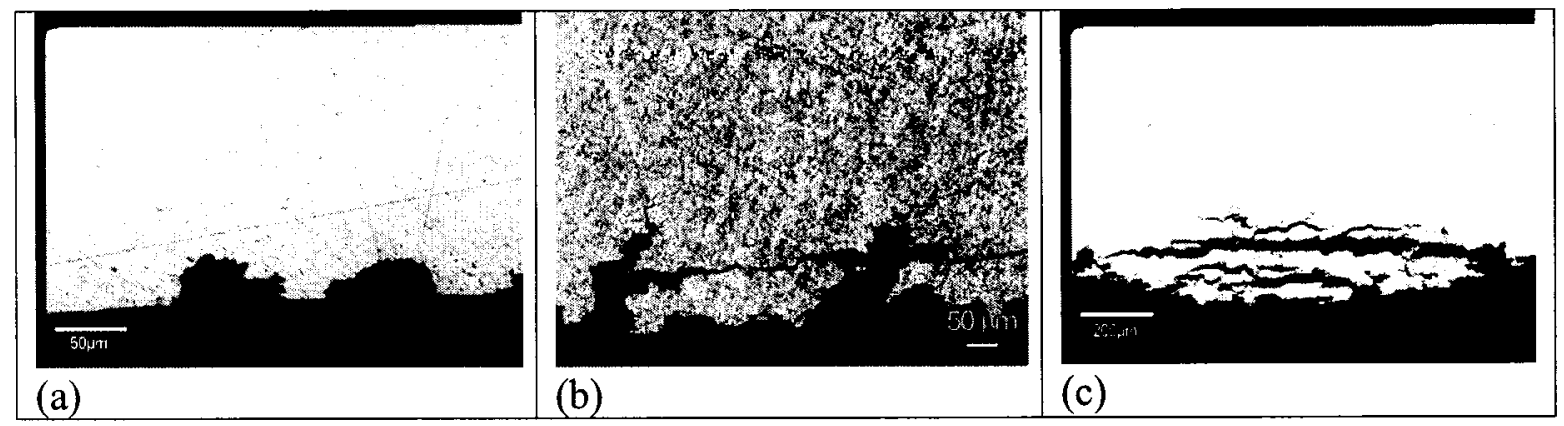

Figure 4-6: Intergranular corrosion extending from corrosion pits in a 727 lap joint specimen. (a) Initial corrosion pitting, (b) coalescence of corrosion pits, (c) creation of thinned region as a result of pit coalescence (Bellinger, 2000).

Exfoliation corrosion is a specific form of intergranular attack that proceeds along the grain boundaries parallel to the material surface. Corrosion products force these layers apart, causing the metal to swell, and blister (Godard et al., 1967). This type of corrosion is common in $\mathrm{Al}-\mathrm{Zn}-\mathrm{Mg}$ and $\mathrm{Al}-\mathrm{Cu}-\mathrm{MG}$ alloys. Sheared or machined edges, rivet holes for example, are more prone since the end grains are exposed.

It is believed that compressive loading may promote exfoliation corrosion, which is why it is often found on 7075-T6 upper wing skins, around fastener holes. In the past, this material was widely used and has become a serious corrosion problem for the ageing aircraft fleet. 


\subsubsection{Stress Corrosion Cracking}

The conditions required for stress-corrosion cracking are a simultaneous tensile load (either externally applied or internal residual stresses) and a specific corrosive medium. Higher strength aluminum alloys, such as 7075-T6, are more susceptible to this type of corrosion. However, in certain circumstances this form of corrosion is problematic for lap joints.

The most common example is the failure of rivets in a joint when subjected to a corrosive environment. During installation rivets develop residual tensile stresses. These stresses combined with an aggressive environment can produce intergranular cracks, weakening the rivet.

If at the same time crevice and/or pitting corrosion is occurring in the joint, corrosion pillowing will develop. The out of plane deformation increases tensile stresses in the rivets, exacerbating the situation. Eventually the rivet may fail across its section. In this situation, adjacent rivets experience increased loads, creating a risk of premature fatigue crack nucleation. An example of a rivet, which failed in this manner, is presented in Figure 4-7.

These cracks propagate along the grain boundaries of the material perpendicular to the applied loads. Both mechanical and electrochemical mechanisms are involved in crack propagation. In the first stage, local electrochemical cells produce subsurface intergranular fissures. A stress concentration develops at the root of the fissures promoting mechanical tearing, exposing fresh metal surfaces. This leads to further electrochemical activity, and the process repeats. Final failure of the rivet occurs by brittle fracture (Godard et al., 1967). 

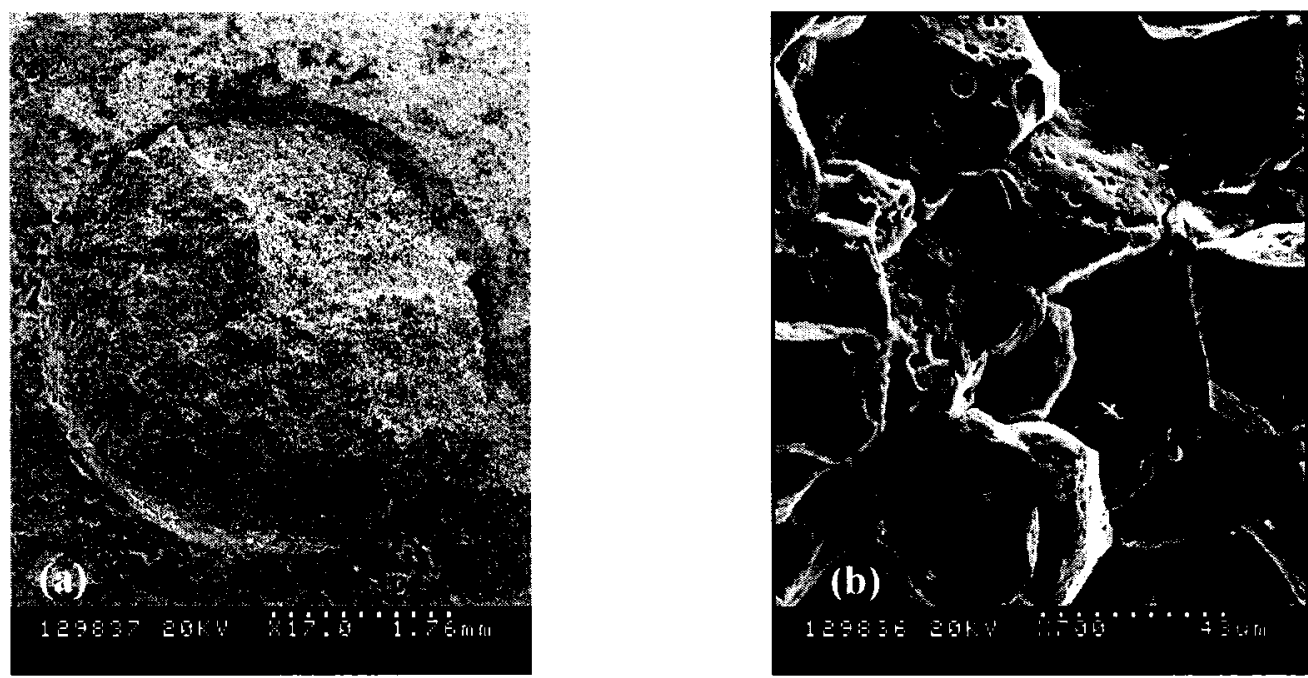

Figure 4-7: Stress-corrosion cracking resulting in a rivet failure. (a) Micrograph of rivet fracture surface. (b) Micrograph showing intergranular corrosion of rivet fracture surface (Krizan, 1999).

\subsection{Corrosive Attack in Fuselage Lap Joints}

Longitudinal fuselage lap joints are particularly vulnerable to corrosion. If exposed to a moist environment, moisture will wick into the joint, creating a sheltered corrosive environment. Sealants, and protectants used to prevent corrosive attack inside the joint can increase the susceptibility to corrosion if they are not properly applied. Figure 4-8 illustrates the degree of corrosion that can exist on ageing aircraft after the breakdown of the corrosion protection system, if not discovered during routine inspections.

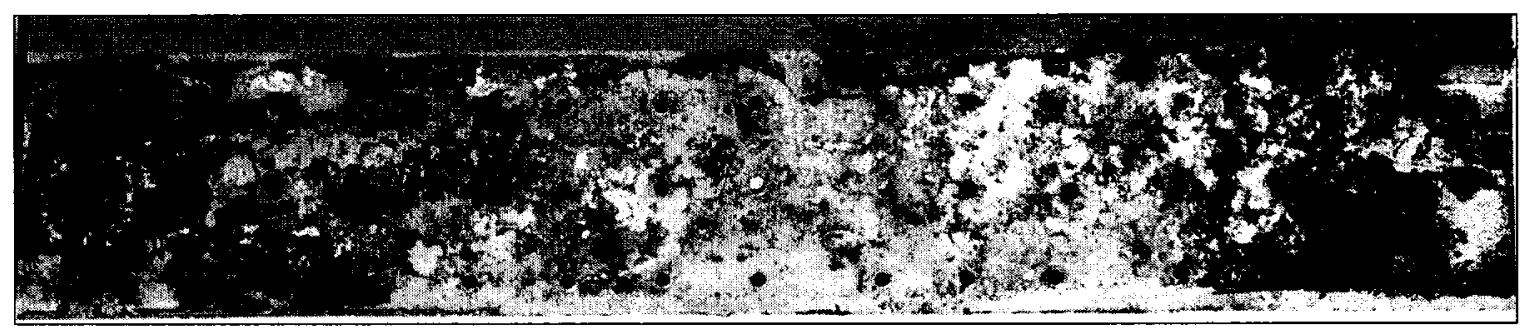

Figure 4-8: Corroded sheet from fuselage lap joint of a Boeing 727 fuselage joint (courtesy of Ron Gould, NRC). 


\subsection{CORROSION-FATIGUE}

Corrosion and fatigue often interact in a synergistic fashion. Exposure to a corrosive environment during the application of cyclic loading can facilitate corrosion damage accumulation. In turn, corrosion development can lead to lower fatigue nucleation lives and faster crack growth. Krizan (1999) found that the reduction in the number of cycles to first visible crack detection for specimens corroded to 5-6\% average thickness loss was approximately $50 \%$, compared to non-corroded specimens.

Aircraft fuselage structures, including lap joints, generally do not experience fatigue and corrosion simultaneously. During the typical load cycle, or GAG (Ground-Air-Ground) cycle, the fuselage is pressurised as the aircraft ascends, and is depressurised during descent before landing.

The environment during a GAG cycle ranges from cold/dry external air and warm humid air inside the fuselage during cruise, to ground-level atmospheric conditions. On the ground, the aircraft is often exposed to moisture containing various pollutants and corrosion agents for several hours, days or weeks at a time. During flight, it can be assumed that moisture trapped within a joint is quickly frozen, hindering further corrosion. Therefore, fatigue loading and corrosion act sequentially in fuselage joints.

This section deals with some of the general interactions between fatigue and corrosion, as well as some of the mechanisms believed to describe the adverse effects of corrosion on fatigue properties.

\subsection{Simulation of Corrosion-Fatigue}

Laboratory testing of full-scale fuselages is complex and expensive. Less costly specimens have been developed for studying the effects of corrosion on fatigue in lap joints. However, to obtain useful results, both the stress field and the corrosion damage in the specimen must be representative of actual aircraft conditions. Carleton University and 
the NRC have developed a test specimen that simulates multiple site damage development in narrow-body aircraft fuselage joints (Figure 5-1). A key feature of the specimen is the bonded straps on either side of the riveted joint. These simulate the load transfer to surrounding structure in an aircraft as fatigue cracks develop. Eastaugh (1993) provides an in depth discussion of the design and proof-of-concept testing of the MSD specimen.

The in-service environment of aircraft fuselage splices consists of alternating applications of corrosion and fatigue. For the current research a simplified approach was taken. The MSD specimen is initially corroded using an accelerated process (Section 8.1), dried and then fatigue tested. This technique simulates the interaction of pre-existing corrosion damage with fatigue crack initiation and growth.

A study was performed to compare the accelerated corrosion developed in the MSD specimens to naturally occurring corrosion on retired Boeing 727 and 747 joints (Eastaugh et al., 1998). Anecdotal evidence showing that significant corrosion damage can exist without the presence of fatigue cracks supports the use of the pre-corrosion fatigue testing performed on the MSD specimens. The appearance of corrosion damage was generally similar for the MSD specimens compared to the 727 joint corroded to roughly the same level of corrosion. The MSD specimens did, however lack the small intergranular cracks running laterally from pitting in the naturally corroded specimen. This might be insignificant in view of their orientation with respect to the primary loading direction (Eastaugh et al., 1998).

The major concern with the pre-corrosion fatigue approach is the lack of synergy between corrosion and fatigue. Interactions between fretting, corrosion and fatigue are not simulated. Fretting damage is drastically increased in the presence of aqueous $\mathrm{NaCl}$ solutions due to synergy between electrochemical corrosion and fretting wear. Sequential application of corrosion and fatigue, for MSD specimens, was tested by Scott (1997). However, due to the increased complexity, cost and duration of alternating corrosion- 
fatigue testing the simplified pre-corrosion approach was implemented for the work of Krizan (1999) and for this thesis.

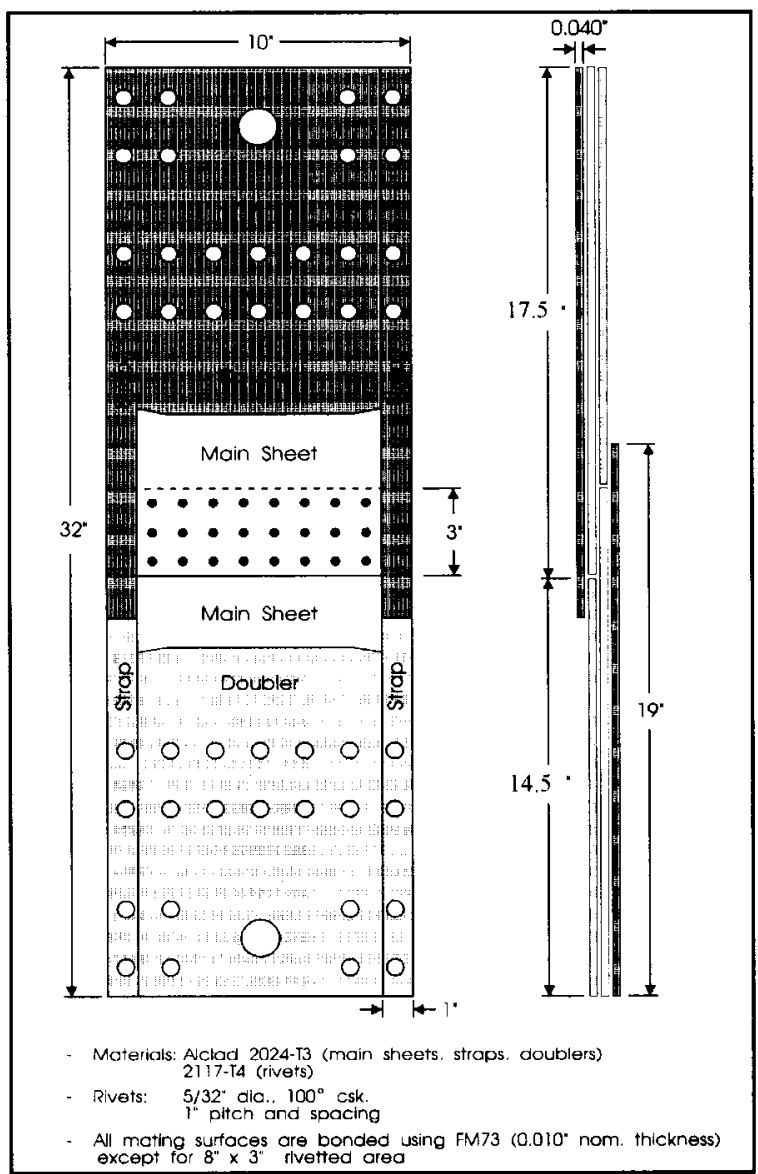

Figure 5-1: MSD test specimen developed by NRC and Carleton University.

\subsection{Corrosion-Fatigue Analytical Approaches}

Effective management of the an ageing aircraft fleet requires a methodology for defining suitable inspection intervals, mandating repairs and assessing the durability ${ }^{9}$ of airframe components. The methodology should include a quantitative understanding of the mechanisms of corrosion and fatigue damage and robust methods to characterise and model such damage.

\footnotetext{
${ }^{9}$ Durability refers to the ability of a material, or structure, to withstand cyclic loading without developing fatigue cracks.
} 
Generally, a linear elastic fracture mechanics (LEFM)-based approach is accepted as the most suitable in light of the current, and proposed, damage tolerance requirements for ageing aircraft. An example is the repair assessment guidelines (RAG) issued by the Federal Aviation Administration (FAA) in 2000. These guidelines establish damage tolerance-based supplementary inspection programs to detect damage in previously repaired regions of the "pressure boundary" for selected aircraft. Aircraft operators find themselves in a situation where maintaining older aircraft is becoming more costly due to the added inspections and repairs mandated. Pending modifications to the United States Federal Airworthiness Requirements (FAR) will require that MSD and WFD be taken into account for all repair designs, modifications, and new aircraft being developed (AAWG, 1999).

The impact of corrosion on fatigue is not mandated in the analysis required by these regulation changes. Yet, the occurrence of corrosion damage in aircraft structures is more widespread than was anticipated by manufacturers and operators. This has prompted research into methods to predict fatigue lives and residual strengths of corroded aircraft structures.

\subsubsection{Proposed Corrosion-Fatigue Models}

It is important to develop realistic models that can be used by designers and operators to assess the corrosion-fatigue life of aircraft structures. The overall methodology should consider the transition from corrosion pitting to fatigue crack growth, and the subsequent crack growth to failure.

In order to comprehend and predict the transition from pit growth to fatigue crack growth several models have been proposed by various researchers. All of these models are based upon LEFM principles, for cracks emanating from corrosion pits. A summary of these models is presented in Table 5-1. 
Table 5-1: Summary of Pitting Corrosion-Fatigue Models (Hoeppner, 1999 and Wei, 1996).

\begin{tabular}{|c|c|}
\hline Proposed By & Model Summary \\
\hline Kondo (1989) & $\begin{array}{l}\text { A competition model between corrosion pit growth } \\
\text { and fatigue crack growth with a criterion for pitting to } \\
\text { fatigue crack transition was proposed } \\
\text { Corrosion pits were modelled using an equivalent } \\
\text { semi-elliptical surface crack } \\
\text { Transition from pit growth to crack growth occurs } \\
\text { when the equivalent surface crack reaches the } \\
\text { threshold stress intensity factor }\left(\Delta \mathrm{K}_{\mathrm{th}}\right) \text { for fatigue } \\
\text { crack growth }\end{array}$ \\
\hline Wei and Harlow (1996) & $\begin{array}{l}\text { Very similar model to that proposed by Kondo } \\
\text { The major contrast was the addition of a growth rate } \\
\text { criterion based on findings that the pit-to-crack } \\
\text { transition size (crack nucleation size) depends on } \\
\text { cyclic-load frequency } \\
\text { The frequency dependence reflected the competition } \\
\text { between pitting corrosion and fatigue } \\
\text { Fatigue crack growth will only occur when the critical } \\
\text { pit size has been reached and the fatigue crack growth } \\
\text { rate exceeds the pit growth rate } \\
\text { The two transition criteria are: } \\
\text { - } \Delta \mathrm{K} \geqq \Delta \mathrm{K}_{\text {th }} \\
\text { - }(\mathrm{da} / \mathrm{dt})_{\text {crack }} \geqq(\mathrm{da} / \mathrm{dt})_{\text {pit }} \\
\text { Corrosion pits were modelled as ellipsoids }\end{array}$ \\
\hline Hoeppner (1999) & $\begin{array}{l}\text { Combined pit growth rate theory and fatigue crack } \\
\text { growth threshold for particular corrosive } \\
\text { environments to determine the critical pit depth to } \\
\text { nucleate a Mode I crack } \\
\text { Corrosion pits were assumed to be hemispherical } \\
\text { shape } \\
\text { Equivalent semi-circular (half penny shaped) crack } \\
\text { was used to simulate corrosion pits }\end{array}$ \\
\hline Lindley et al. (1982) & $\begin{array}{l}\text { Similar to Hoeppner, a method for determining the } \\
\text { threshold at which fatigue cracks would grow from } \\
\text { corrosion pits was proposed } \\
\text { Pits were considered semi-elliptical sharp cracks }\end{array}$ \\
\hline
\end{tabular}

The common assumption of all these models is that fatigue cracks nucleate at corrosion pits. This is a valid assumption supported by laboratory test results, as well as in-service evidence. Fatigue cracks will typically form at corrosion pits as they represent regions of 
high local stress. Evidence of fatigue crack nucleation and growth from a corrosion pit is observed in Figure 5-2.

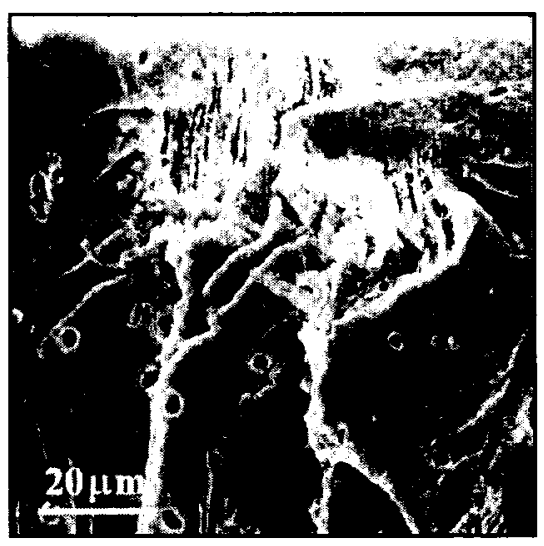

Figure 5-2: Nucleation and early crack growth of a fatigue crack from localised corrosion pitting in 2024-T3 aluminum alloy (Wei, 1996).

Recent research has focused on several methods to predict the corrosion-fatigue life of aircraft structures. One such approach to this problem is using an equivalent initial flaw size (EIFS) for the structure under examination. This method proposes that a certain size initial flaw exists in the component prior to any fatigue loading. This initial flaw grows under cyclic loading until failure of the component occurs. In the presence of corrosion, this flaw size is assumed to be larger, thus reducing fatigue life. This modified initial flaw size is referred to as equivalent corrosion damage (ECD) by some researchers.

The ECD is determined by testing corroded specimens to determine the fatigue life. Once the number of cycles to final failure is known for a test, back extrapolation using LEFM principles is used to determine the initial flaw size. Determination of the equivalent flaw for corroded specimens would require specimen testing for a wide range of corrosion levels, material, and structures as the EIFS varies with these parameters.

Another approach to corrosion-fatigue analysis has been proposed by Brooks et al. (1998) which treats corrosion damage as a change in surface geometry in a fracture mechanics analysis. For non-corroded structure fatigue crack growth, analysis starts from discontinuities in the material microstructure referred to as the intrinsic discontinuity 
state (IDS). The IDS is a function of material composition, microstructure, and the manufacturing process. Crack extensions occur from each IDS due to cyclic loading, as well as from time dependent environmental mechanisms (corrosion), until a dominant crack forms. The transition from corrosion pit growth to fatigue cracking is predicted using models similar to those described in Table 5-1

The generic fracture mechanics equation upon which this model is built is (Brooks et al., 1998):

$$
\Delta K_{l}=\beta \cdot \Delta \sigma_{c y} \sqrt{\frac{\pi \cdot a}{Q}}
$$

Where:

- $\Delta \mathrm{K}_{\mathrm{l}}$ is the stress intensity factor increment

- $\beta$ represents modifications to the cyclic stresses imposed by corrosion surface morphology, stress concentrations, corrosion pillowing etc.

- $\Delta \sigma_{c y}$ is the increment of nominal cyclic stress applied to the structure

- a represents the crack length

- Q represents the boundary conditions (crack shape parameter)

Corrosion damage is considered as a modification to the original geometry of the component. This modification to the surface geometry is applied in the model as stress multipliers ( $\beta$-factors). This methodology allows existing fracture mechanics equations (similar to Equation 5.1) to be used for modelling these complex interactions simply by amplifying the local stress-state.

The IDS model has been demonstrated for a fatigue-only situation. However, in order to utilise the method for corrosion-fatigue, data pertaining to the interactions of corrosion and fatigue are needed. 
Carleton University and the National Research Council of Canada are currently investigating the mechanisms of corrosion-fatigue in riveted fuselage joints. A major effort in this regard, and the primary topic of this thesis, is the influence of corrosion surface topography on the corrosion-fatigue properties of fuselage lap joints.

\subsection{General Methodology (Addressed in this Thesis)}

A fracture mechanics model for corrosion-fatigue could be used to predict the development of corrosion damage as a function of time, and determine the resulting change of durability and damage tolerance properties of the structural component. Such a tool could assess the current status of ageing aircraft fleets, and modify the inspection and maintenance schedules. By enabling a designer of a new airframe to predict the impact of corrosion on the fatigue characteristics of various structures, more corrosion-fatigue resistant designs could be developed. Safer and more cost effective inspection and maintenance programs could be developed for aircraft, both new and old. Figure 5-3 shows the general fracture mechanics-based analysis of corrosion-fatigue addressed in this thesis.

To minimise development costs and the complexity of this approach, structures prone to corrosion-fatigue must first be identified. This reduces the number of structures that must be analysed and corrosion-fatigue tested. Many of these structures have been identified by service experience.

The stress distributions for the selected structures must be determined using finite element modelling. The stress field is needed to determine the modified stress intensity factors for the corrosion damage.

In order to perform crack growth analysis, accurate crack nucleation and growth models are required. Corrosion-fatigue test data is required to determine crack nucleation sites, crack growth rates, and fatigue lives. Testing by research groups and manufacturers have been performed to obtain this type of data. 
In order to perform the fracture mechanics analysis of corrosion-fatigue a damage tolerance analysis (DTA) program must be developed. Brooks et al. (1999) are currently developing a corrosion damage tolerance analysis method. This program requires numerous inputs, which are described below.

Two main aspects of corrosion must be included in the corrosion DTA analysis. Firstly, quantification of the corroded surface topography is needed. This is obtained through forensic analysis of corroded aircraft structure. The topography can be measured using techniques such as digitised $\mathrm{x}$-radiography (DXR) and optical surface profiling (Wyko ${ }^{\mathbb{B}}$ ). The topography modifies the stress distribution in the structure, using $\beta$-factors. Secondly, corrosion pillowing must be considered in the stress distribution. Through finite element modelling the changes in stress are determined. Corrosion pillowing in fuselage joints has been researched extensively by Bellinger et al. (1994 and 1997).

The $\beta$-factors calculated for corrosion effects are used to develop modified stress intensity factors using Equation 6.1. These can then be incorporated into the corrosion DTA calculation program.

The final input to the DTA program is the time dependent corrosion parameter. The environmental severity factor (ESF) is a measure of the relative severity of the environment in different locations and can be used to help model the corrosion growth rate. The USAF is developing a database of corrosion rates based on deployment locations at approximately 40 bases around the world (Kinzie and Peeler, 1999). 


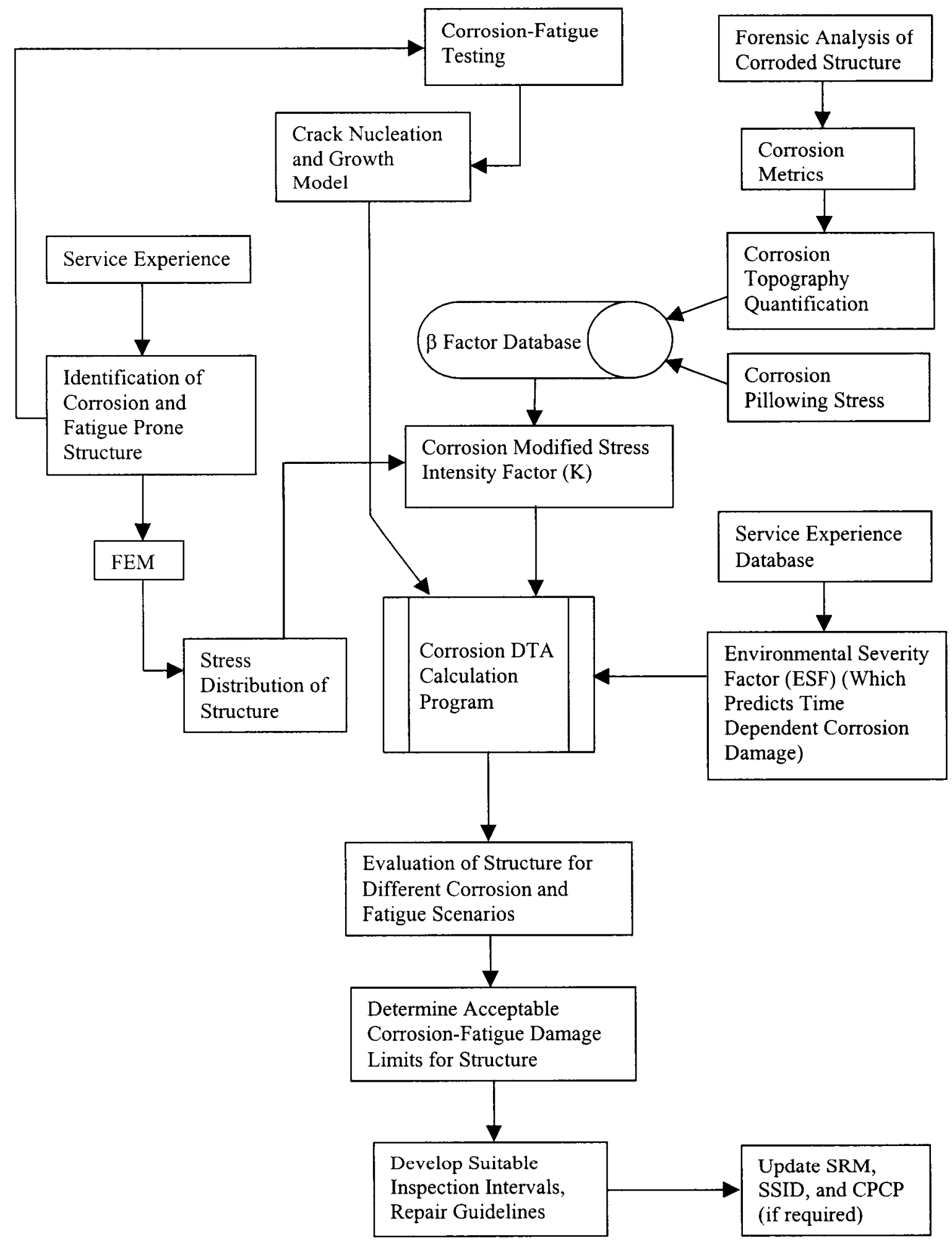

Figure 5-3: General fracture mechanics approach for analysing corrosion-fatigue of aircraft structures. 


\subsubsection{Applicability to Operational Situations}

Applying fracture mechanics analysis (Figure 5-3) to every occurrence of corrosionfatigue damage in a fleet, not included in the structural repair manual (SRM), would be a daunting and costly task. The more likely scenario is that the manufacturer would perform a thorough analysis of selected corrosion-fatigue prone structures. The analysis should consider varying levels of corrosion damage likely to occur in service. The results of this analysis would provide acceptable corrosion and fatigue damage limits for each structure. Using these limits the existing inspection intervals could be modified, as well as the current maintenance and repair guidelines. These modifications could take the form of SRM, SSID and CPCP updates or issuance of service bulletins by the manufacturers.

In the event that corrosion-fatigue damage is detected in structure not previously analysed, or the damage is manifested differently than specified by the revised maintenance documents, a special analysis could be performed by the manufacturer. A description of the damage and sufficient data to design the repair would be sent to the manufacturer, where an appropriate repair would be developed and certified. This repair would then issued to the operators for implementation.

In an operational environment, NDI results for a corrosion-fatigue sensitive structure could be used to determine its condition. The appropriate repair action (if any) would be performed according to the modified maintenance guidelines. If the damage fell outside the set limits, the damage tolerance analysis could be performed and recommendations to rectify the problem could be proposed. The SRM could then be updated to reflect this new analysis. 


\subsection{Influence of Corroded Surface Topography on Corrosion-Fatigue Characteristics}

Topography describes the features of a particular surface, including peaks and valleys. In relation to corrosive attack of a metallic surface, the topography refers to the various pits and any other asperities that exist.

As described in Section 4.0, corrosion can modify the surface geometry of a metal through dissolution and pitting. The modified surface is typically rougher than the original, increasing the local stresses at or near the surface. One study into the effects of surface roughness on fatigue properties of 4340 steel has shown an order of magnitude reduction in fatigue life for an average asperity size increase from $3.4 \times 10^{-6}$ in to $4.3 \times 10^{-5}$ in. $(0.1 \mu \mathrm{m}$ to $11 \mu \mathrm{m})$ (Andrews, 2000).

Fatigue cracks will nucleate at the location of highest local stress, which tend to be at pit locations for corroded metals. Thus, in order to model and predict corrosion-fatigue in aircraft structures the surface topography must be quantified. Limited research into corrosion topography quantification has been performed to-date. Many of these studies have used coupons that do not represent the corrosion damage that occurs in actual aircraft structures. This section discusses the previous research into this topic.

\subsubsection{Previous Research Into Corrosion Topography Quantification}

Frantziskonis et al. (2000) have characterised pitting corrosion damage in 2024-T3 using white light interference microscopy and multiscale image analysis. Their objective was to identify properties of two-dimensional images of pitting corrosion to enable a complete characterisation of the damage morphology. They concluded that three-dimensional pit geometry could be determined using wavelet analysis of the two-dimensional microscope images (Figure 5-4).

White light interference microscopes can typically achieve resolutions of $7.9 \times 10^{-6}$ in. $(0.2$ $\mu \mathrm{m})$ spatially and $3.9 \times 10^{-8}(1 \mathrm{~nm})$ vertically. The limitations of such a system are the 
current size restrictions for the specimen being analysed, and computer memory required to process large data sets.

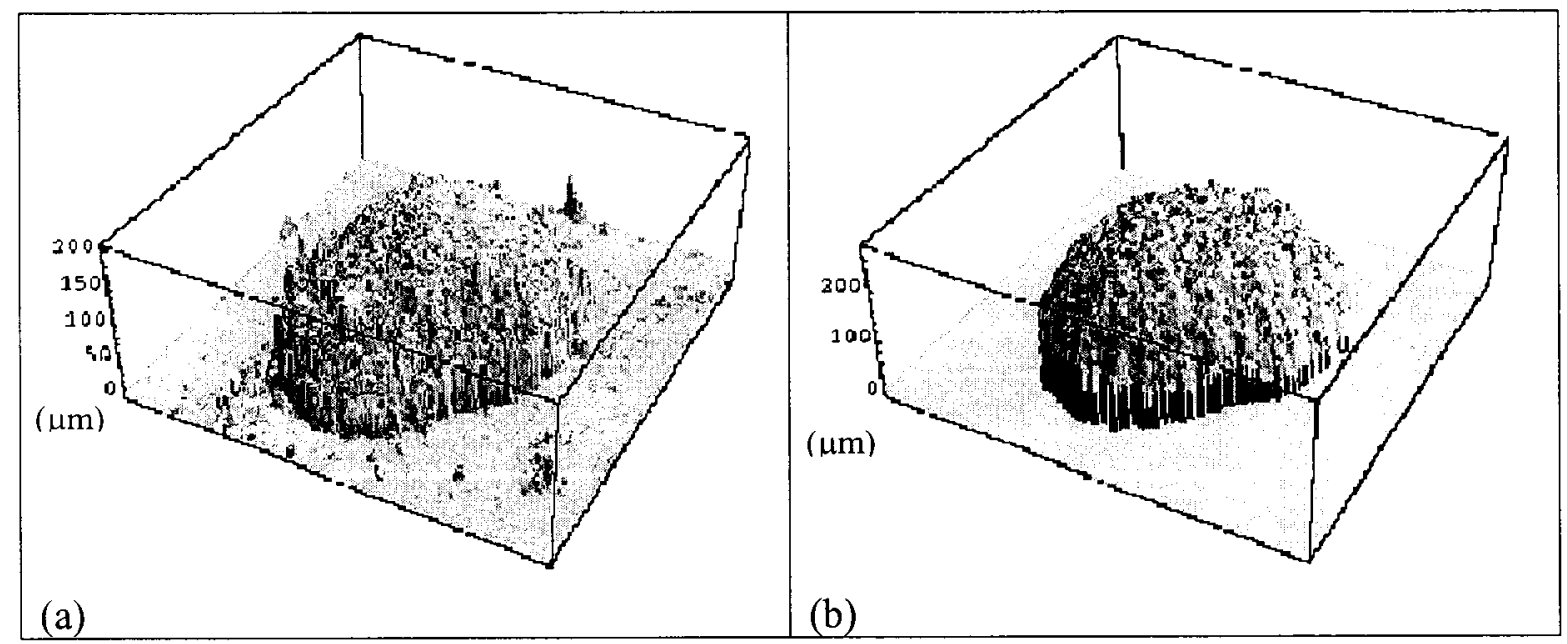

Figure 5-4: 3-D view of corrosion pit shown as a 'mountain' rather than a pit, for clarity. (a) Actual pit geometry measured using white light interference microscope. The dimensions are 0.032 in. $x 0.032$ in. $(809 \mu \mathrm{m} \times 809 \mu \mathrm{m})$, and the maximum pit depth is $0.0080 \mathrm{in}$. $(203.82 \mu \mathrm{m})$. (b) Wavelet reconstructed representation of the same pit. A pit depth of 0.0088 in. $(223 \mu \mathrm{m})$ was determined (Frantziskonis, 2000).

Brown and Newton (1994) used laser scanning confocal microscopy to quantify the surface texture of pitted aluminum specimens. High resolution (depth and spatially) data can be obtained for small sections only, due to size limitations of the microscope.

Another technique for smaller specimens was investigated by Liao, et al. (1996). This involved taking epoxy replicas of the pitting corrosion on the surface of 2024-T3 aluminum alloy. Replication was accomplished by infiltrating an epoxy resin into the corrosion pits using a vacuum casting technique. The corrosion replicas were examined by SEM. The corrosion pits exhibited an elongated shape along the material rolling direction, and were larger (in both width and length) than the surface opening. The time involved for specimen preparation and creation of the replicas makes this method inefficient and costly. 
The corrosion morphology quantification methods proposed by Frantziskonis et al. (2000), Brown and Newton (1994) and Liao, et al. (1996) are not efficient for characterising large regions of corrosion damage in a timely fashion. They are however, useful techniques for validating corrosion pit geometry determined using other, more practical methods. 


\subsection{PROJECT DEFINITION}

Krizan (1999) identified the important role of corrosion topography, in particular corrosion pitting, on the fatigue properties of fuselage lap joints. The need for an effective means to measure corrosion topography has become apparent in developing damage tolerance analysis of corrosion-fatigue. Thus, a major focus of this thesis is the development of techniques to quantify pitting corrosion damage in riveted fuselage joints.

Test results from an ongoing study of corrosion effects on fatigue characteristics of fuselage lap joints, currently being investigated by Carleton University and the National Research Council Canada (NRC), will be used to develop a methodology for quantifying corrosion topography. Specimens previously developed at Carleton University and the NRC for simulation of corrosion-fatigue of fuselage joints will be used to assess the role of corrosion pits on fatigue characteristics. These tests will also contribute to an NRC project that has already collected statistically valid results for ten MSD specimens.

Figure 6-1 illustrates the areas of research covered in this thesis. Each topic is covered in more detail in the following sections. 


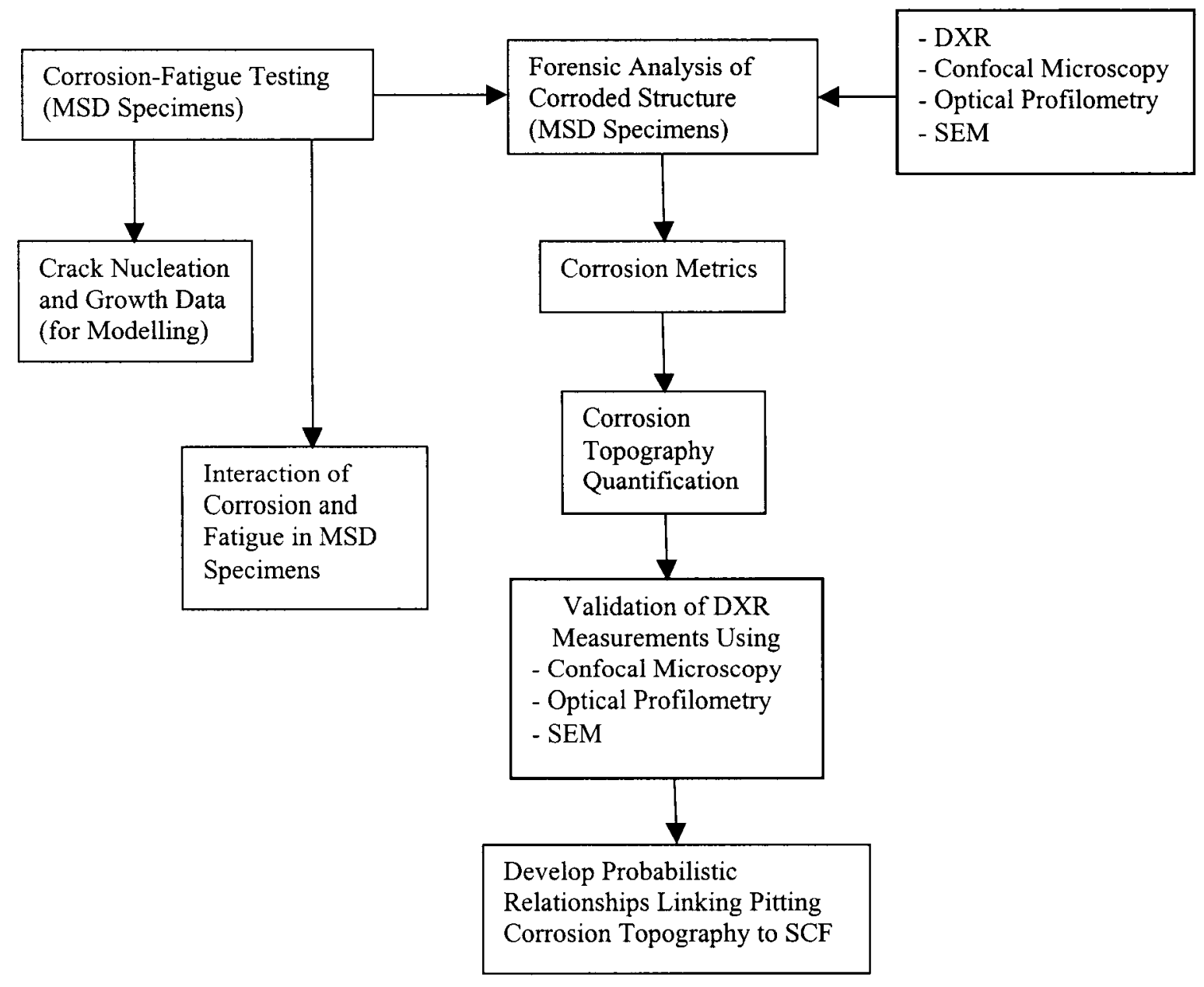

Figure 6-1: Areas of research for this thesis.

Note: Highlighted topics are taken from Figure 5-3 and represent major research areas of this thesis.

\subsection{Corrosion-Fatigue Testing (Using MSD Specimens)}

Since 1993, Carleton University and the NRC have developed methods for corroding and fatigue testing MSD specimens. In this phase, fatigue testing of 4 pre-corroded and 3 non-corroded MSD specimens will be performed. This will increase total number of carefully manufactured MSD (DOE) panels tested to 9 pre-corroded and 8 non-corroded. In addition, the existing test and analysis methods will be improved upon. 


\subsection{Crack Nucleation and Growth Data}

Crack nucleation, growth and link-up data will be obtained for pre-corroded and noncorroded MSD specimens. By doing so the interaction of corrosion and fatigue will be investigated. The reduction of visual crack detection life (VDL), and the difference in membrane and bending stresses for corroded specimens in relation to non-corroded specimens reported by Krizan (1999) will be further investigated.

\subsection{Forensic Analysis of Corroded Structure (Using MSD Specimens)}

Forensic analysis of pre-corroded MSD specimens will be performed, after fatigue testing is completed to investigate the mechanisms of crack nucleation. Digitised x-radiography (DXR), SEM, optical profilometry, and confocal microscopy will be used to analyse the corrosion damage.

\subsubsection{Refinement of Existing Digitised Radiography Techniques}

Sheet thickness in corroded specimens can be measured by digitising radiographic films of the corroded specimen. For use in fracture mechanics modelling, significantly higher precision than that previously demonstrated will be developed by refining the existing DXR process.

Problems with the previous DXR process include thickness variations and inaccuracies due to film processing, film scanning, and insufficient calibration. Each of these topics as well as an evaluation of the overall accuracy of the process will be investigated in this thesis.

\subsection{Corrosion Topography Quantification}

The main focus of this thesis is to develop methods to accurately quantify pitting corrosion topography in riveted fuselage lap joints using digitised $\mathrm{x}$-rays of disassembled (and cleaned), corroded MSD specimens. The objectives of this work are threefold: 
1. Develop image analysis techniques, using $\mathrm{IDL}^{\circledR}$ software, to accurately quantify three-dimensional corrosion topography using two-dimensional DXR greyscale images. The primary focus is the detection and measurement of corrosion pits, both important in the context of damage tolerant analysis of fuselage joints. IDL ${ }^{\circledR}$ was selected for its efficient manipulation of large data arrays and image processing routines.

2. Through FEM of common corrosion pit geometries, develop relationships between pit geometry and stress concentration factors (SCF or $\mathrm{K}_{\mathrm{t}}$ ).

3. Develop probability distributions of pit depth and SCF for various levels of thickness loss due to corrosion.

Validation of the surface topography and pit geometry measured using DXR will be accomplished using white light interferometry (Wyko ${ }^{\mathbb{B}}$ ) surface mapping and confocal microscopy analysis of corroded surfaces. 


\subsection{DESIGN OF EXPERIMENT}

The data being collected and analysed for the MSD-CF project at NRC will be used to develop statistically valid relations between corrosion and fatigue. A comprehensive "Design Of Experiment" (DOE) for the MSD-CF project was completed by Krizan (1999). DOE is a statistically based methodology used to encourage a systematic approach in planning and carrying out experiments (Little, 1975). In the following section, the process that was used and the resulting corrosion-fatigue test program will be reviewed. Following this review, the modification to this experimental program will be described. The DOE terminology is described in Table 7-1.

Table 7-1: "Design Of Experiment" definitions (Little, 1975), (ASTM, 1991).

\begin{tabular}{|c|c|c|}
\hline Term & Definition & Example \\
\hline Block & $\begin{array}{l}\text { A group of experimental units that may or may not be } \\
\text { more homogeneous than other groupings of } \\
\text { experimental units }\end{array}$ & $\begin{array}{l}\text { Three MSD specimens (two } \\
\text { pre-corroded \& one non- } \\
\text { corroded) }\end{array}$ \\
\hline $\begin{array}{l}\text { Experimental } \\
\text { Units }\end{array}$ & Individual specimens & MSD specimen \\
\hline Randomisation & $\begin{array}{l}\text { A procedure in which random numbers are used to } \\
\text { assign treatments and testing sequences to the } \\
\text { experimental units }\end{array}$ & $\begin{array}{l}\text { Random number generator } \\
\text { on Microsoft Excel }\end{array}$ \\
\hline $\begin{array}{l}\text { Nuisance } \\
\text { Variable }\end{array}$ & $\begin{array}{l}\text { Any variable that may affect test results but is not the } \\
\text { object of the experiment }\end{array}$ & $\begin{array}{l}\text { Drift in the load applied by } \\
\text { the fatigue-testing machine }\end{array}$ \\
\hline $\begin{array}{l}\text { Organisational } \\
\text { structure }\end{array}$ & $\begin{array}{l}\text { The overview of the test program. This includes test } \\
\text { order, inter-relation of variables, and the statistical } \\
\text { tools used in analysing the data }\end{array}$ & $\begin{array}{l}\text { Paired Comparison Test } \\
\text { Program (Section 7.1) }\end{array}$ \\
\hline Replicate & $\begin{array}{l}\text { The complete collection of observations comprising } \\
\text { one observation on each of the treatments }\end{array}$ & $\begin{array}{l}\text { One group of MSD } \\
\text { specimens (two pre- } \\
\text { corroded and one non- } \\
\text { corroded) }\end{array}$ \\
\hline Replication & The total number of replicates in the test program & $\begin{array}{l}5 \text { pairs, } 4 \text { groups of three } \\
\text { specimens, and one spare } \\
\text { (for a total of } 23 \mathrm{MSD} \\
\text { specimens) }\end{array}$ \\
\hline Treatment & The major variable to be studied & Pre-corrosion \\
\hline Treatment level & $\begin{array}{l}\text { The range of discrete or continuous values of the } \\
\text { treatment. These values may be quantitative and } \\
\text { qualitative }\end{array}$ & $\begin{array}{l}\text { Level of corrosion damage } \\
\text { (for the current testing; } \\
\text { average thickness loss over } \\
\text { the riveted joint region of } \\
\text { the MSD specimen) }\end{array}$ \\
\hline $\begin{array}{l}\text { Treatment effect } \\
\text { estimates }\end{array}$ & $\begin{array}{l}\text { The net positive or negative incremental effect on all } \\
\text { experimental units receiving the same treatment(s) }\end{array}$ & $\begin{array}{l}\text { Change in fatigue } \\
\text { characteristics due to } \\
\text { corrosion }\end{array}$ \\
\hline
\end{tabular}




\subsection{Review of Previous Experimental Design}

This section briefly describes the methodology used to develop the existing fatigue test program, by Krizan (1999). Several different organisational structures were considered for the test program such as, Completely Randomised Design (CRD), Randomised Complete Block (RCB), and the Paired Comparison Test Program (PCTP). The advantages and disadvantages of each method were compared and the PCTP was chosen as the most suitable method for the current test objectives.

A benefit of using the PCTP is that the number of pairs can be increased during testing if, for example, the variability is higher than expected. On the other hand the PCTP requires the testing be conducted on the same test machine under the same conditions and load spectrum. This was not a problem since the load frame being used was dedicated to this project. The PCTP also complied with the following criteria:

- Clearly defined experimental units and treatment(s), for this test program, the experimental units are the MSD coupons and the treatment is pre-corrosion.

- Ability to perform statistical analysis and comparison of results after testing.

- Accurate representation of the test population must be achieved through randomisation of the treatment application to the experimental units, as well as the testing order.

- Nuisance variables are reduced or eliminated by organising units into blocks so that the treatment effect can be estimated.

- Replication is sufficient to achieve required significance in results.

The Paired Comparison Test Program (also called a Paired $t$ Test Program) is a special case of the randomised complete block program with one treatment and one control (or non-treatment) per block. In the PCTP shown in Figure 7-1, $2 n$ specimens are randomly distributed into $n$ pairs. A treatment, pre-corrosion in the case of this experiment, is randomly applied to one specimen in each pair. The test order of specimens within each pair is randomised, and then the test order of each pair is randomised. As with the CRD, 
the specimens should come from the same batch of material and undergo the same manufacturing procedure and conditions (Little, 1975).

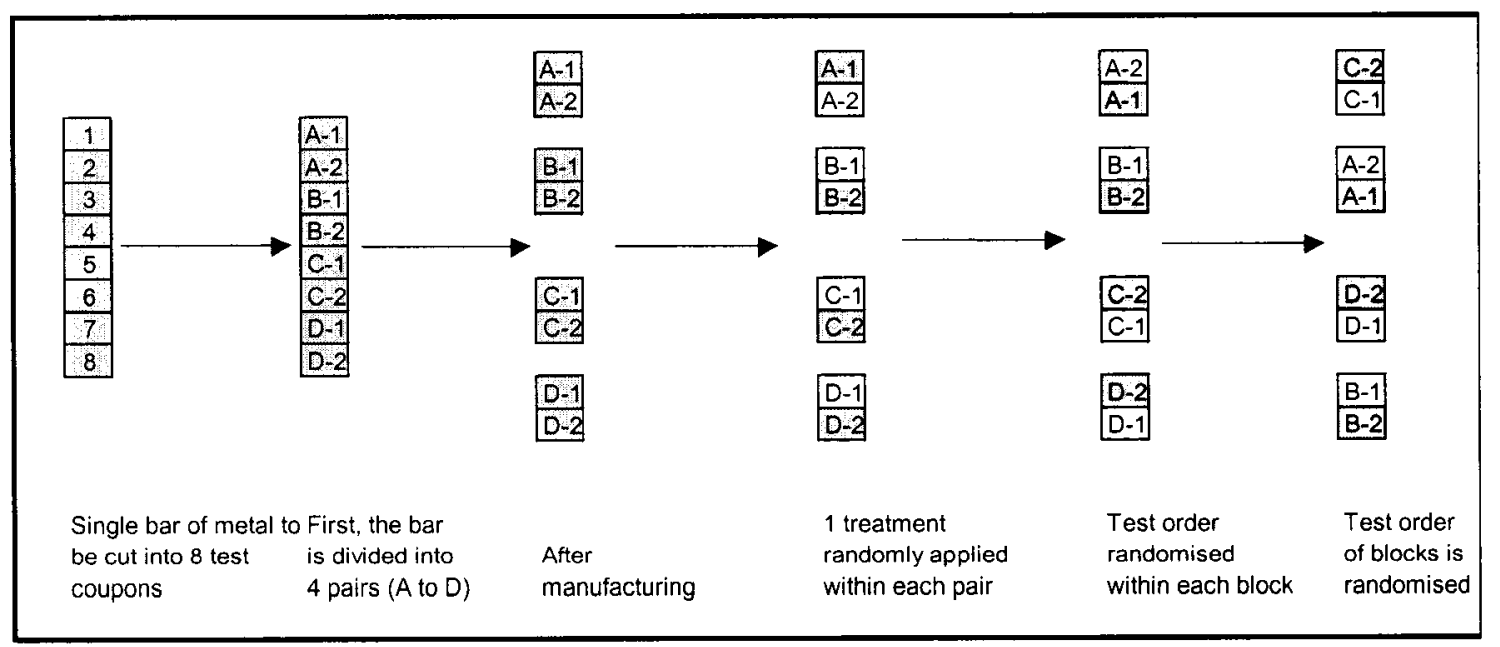

Figure 7-1: Paired Comparison Test Program (PCTP) organisational structure

\subsection{Selecting Sample Size}

Determining the sample size for a test program requires knowledge of the expected distribution of resulting data. This aspect is discussed in Section 7.3. It is useful to note that NRC manufactured 23 specimens in one batch, which met the required tolerances. Based on an in-depth statistical analysis by Krizan (1999), it was determined that a useful comparison of the mean visual crack detection lives of corroded and non-corroded specimens could be achieved using ten specimens per treatment. The PCTP developed by Krizan included 11 corroded and 11 non-corroded specimens with one randomly selected spare. Table 7-2 presents the test order and specimen treatment for the test program originally developed for this project. 
Table 7-2: Summary of Paired Comparison Test Program.

Note: The results of the first ten tests were presented by Krizan (1999).

\begin{tabular}{|c|c|c|c|}
\hline $\begin{array}{l}\text { Test } \\
\text { Order }\end{array}$ & Block/Pair & $\begin{array}{l}\text { Experimental } \\
\text { linit }\end{array}$ & Treatment \\
\hline $1^{\text {st }}$ test & $\mathrm{E}$ & MSD511-047 & PCF \\
\hline $2^{\text {nd }}$ test & $\mathrm{E}$ & MSD511-060 & $\mathrm{F}$ \\
\hline $3^{\text {rd }}$ test & $\mathrm{H}$ & MSD511-034 & PCF \\
\hline $4^{\text {th }}$ test & $\mathrm{H}$ & MSD511-038 & $\mathrm{F}$ \\
\hline $5^{\text {th }}$ test & $\mathrm{C}$ & MSD511-045 & PCF \\
\hline $6^{\text {th }}$ test & $\mathrm{C}$ & MSD511-051 & $\mathrm{F}$ \\
\hline $7^{\text {th }}$ test & $\mathrm{F}$ & MSD511-058 & PCF \\
\hline $8^{\text {th }}$ test & $\mathrm{F}$ & MSD511-046 & $\mathrm{F}$ \\
\hline $9^{\text {th }}$ test & I & MSD511-061 & F \\
\hline 10th test & I & MSD511-043 & PCF \\
\hline 11 th test & K & MSD511-042 & $\mathrm{F}$ \\
\hline 12 th test & $\mathrm{K}$ & MSD511-044 & PCF \\
\hline 13th test & $\mathrm{D}$ & MSD511-037 & PCF \\
\hline 14th test & $\mathrm{D}$ & MSD511-048 & $F$ \\
\hline 15 th test & G & MSD511-054 & PCF \\
\hline 16 th test & G & MSD511-056 & $\mathrm{F}$ \\
\hline 17 th test & A & MSD511-041 & $\mathrm{F}$ \\
\hline 18 th test & A & MSD511-050 & PCF \\
\hline 19th test & B & MSD511-059 & $\mathrm{F}$ \\
\hline 20 th test & B & MSD511-049 & PCF \\
\hline $21 \mathrm{st}$ test & $\mathrm{J}$ & MSD511-035 & PCF \\
\hline 22 nd test & $\mathrm{J}$ & MSD511-036 & $\mathrm{F}$ \\
\hline 23 rd test & $\mathrm{L}$ & MSD511-057 & PCF \\
\hline
\end{tabular}

\subsection{Distribution of fatigue-life data}

The distribution of fatigue lives in aircraft, in terms of cycles or flights to failure, is generally considered to follow a lognormal or Weibull distribution. A multitude of studies have been carried out by the United States Air Force, aircraft manufacturers, and research establishments to determine the distribution of fatigue lives, with varied results. Walker (1997) presented test results of Whittaker and Besuner for aluminum alloys with different configurations and for fatigue lives of $1 \times 10^{2}$ to $1 \times 10^{6}$ cycles (monolithic 
notched specimens, simple structural representations and full-scale structures). The results were that the distribution was not influenced by:

- Material alloy type

- Specimen geometry

- The fatigue-testing machine

- Fatigue life

The conclusions drawn were that, for most aluminum structural applications, approximate Weibull shape parameter and log standard deviation are 4.0 and 0.14 (base 10).

Schijve (1994) concluded there are no indications that any statistical distribution function has a general applicability to the results of fatigue test series.

ASTM Standard E 739-91 (1998) states that if the distribution is unknown, such as in an exploratory test program, then a lognormal distribution should be assumed. Since this test program is essentially an exploratory program, a lognormal distribution was assumed for the MSD fatigue-life data (Krizan, 1999).

\subsection{Modification of MSD-CF Test Program}

In previous DOE testing several failure modes were observed for the PCF specimens. In three of the specimens a single crack initiated and propagated without developing MSD. However, on one of these specimens the bonded strap fractured, leading to limited crack growth data. Two other specimens had cracks nucleate in the driven sheet (back-side) of the joint. Of the five PCF specimens, only specimens MSD511-045, and -058 produced crack propagation and failure in the critical rivet row. In view of the variability in failure mode, it would be useful to increase the sample size of PCF specimens.

After reviewing the results and recommendations made by Krizan (1999), a change to the existing test program was developed. The motivation for this change is the small scatter 
involved with the first five DOE, fatigue-only specimens (Figure 7-2), and relatively large scatter, and variability of failure mode of the PCF specimens.

The change to the existing MSD511 DOE test program involves using two of the remaining fatigue-only specimens as pre-corrosion fatigue (PCF) specimens. This will provide 9 fatigue-only and 14 pre-corroded specimens for the test program (if the additional specimen MSD511-057 is included as a PCF specimen).

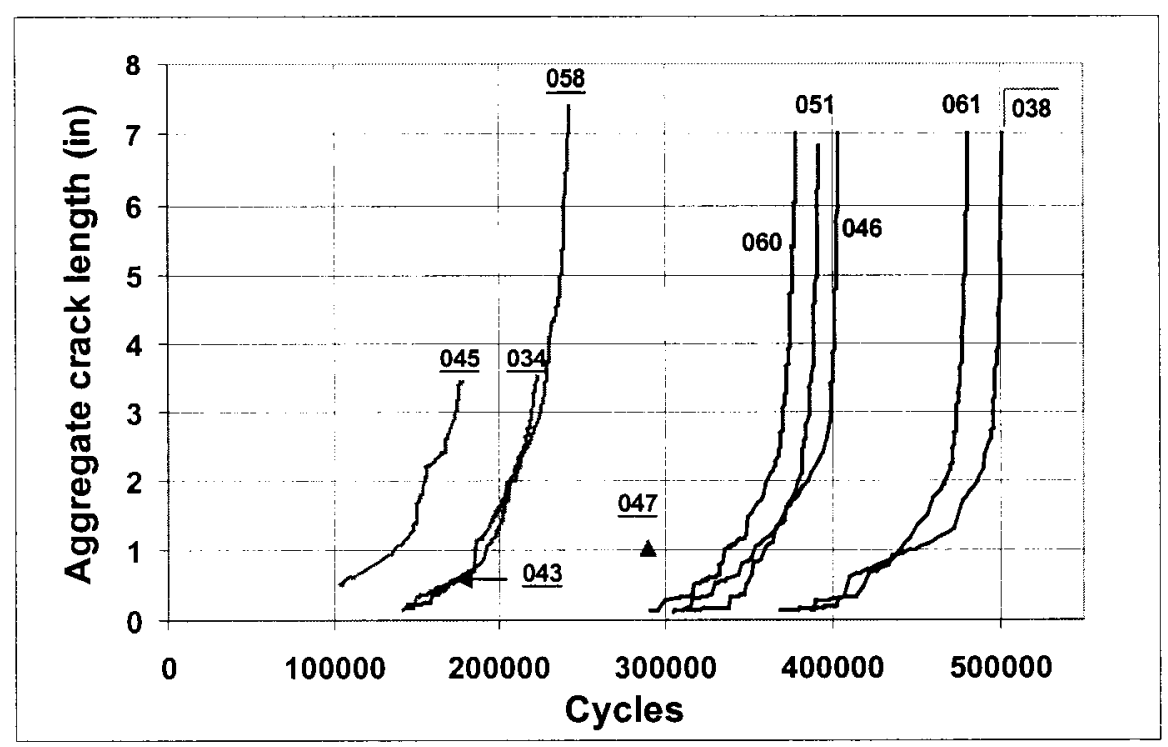

Figure 7-2: Fatigue results for the first 10 DOE specimens (Krizan, 1999).

Note: The underlined numbers identify pre-corroded specimens, the others are noncorroded specimens.

By testing more PCF specimens with the same level of corrosion, a better understanding of the behaviour of these corrosion-fatigue specimens could be gained. Ideally, this would lead to a more thorough understanding of the effects of corrosion on fatigue in fuselage single lap joints.

\subsubsection{Statistical Analysis of Revised Test Program}

The statistical validity of the proposed change to the test program must be ensured. The first consideration is that all specimens belong to the same statistical population. To accomplish this, the remaining PCF specimens would have to be corroded to the same 
level as the previous five DOE-PCF specimens. The pillowing-to-thickness-loss (PTL) ratio developed previously was utilised to predict this corrosion level. In conjunction with this metric, current pillowing measurements will be compared against measurements for the first five DOE specimens. This will provide a correlation between the pillow development in the new specimens with those tested previously. This comparison will determine whether the new specimens are pillowing, and corroding at the same rate as the previous specimens.

A statistical analysis of test results obtained for the first ten specimens was also performed. The standard deviation and the sample mean of the visible crack detection life (VDL) for the remaining 13 specimens were assumed equal to the values determined for the previous 10 DOE tests. These sample means were 5.519 and 5.199 (Log cycles) for F and PCF samples respectively. The log-standard deviations were 0.055 and 0.163 for F and PCF respectively. Using these values, a two-sided normal test was used to predict, and compare the confidence intervals for the existing DOE test plan and the proposed change to this plan. The results of this analysis are presented in Figures 7-3 and 7-4.

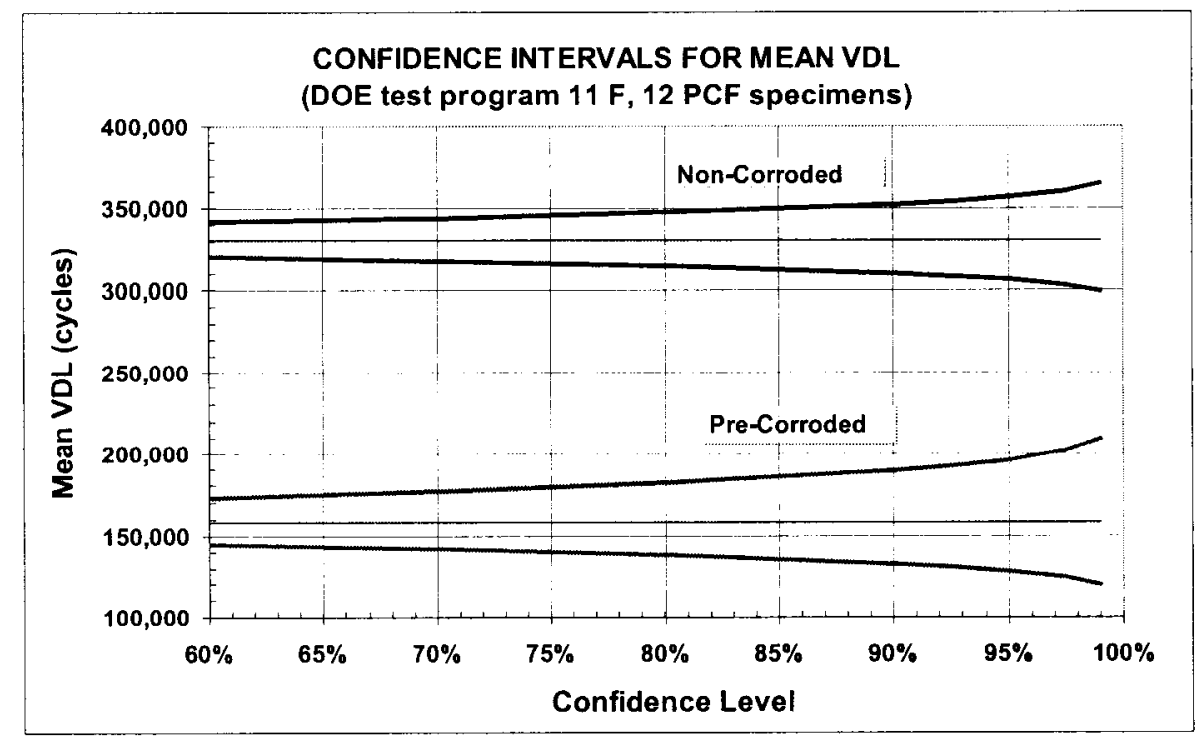

Figure 7-3: Predicted confidence intervals for mean VDL for the previous test plan. The minimum difference in mean VDL (90\% confidence level) is $39.2 \%$. 


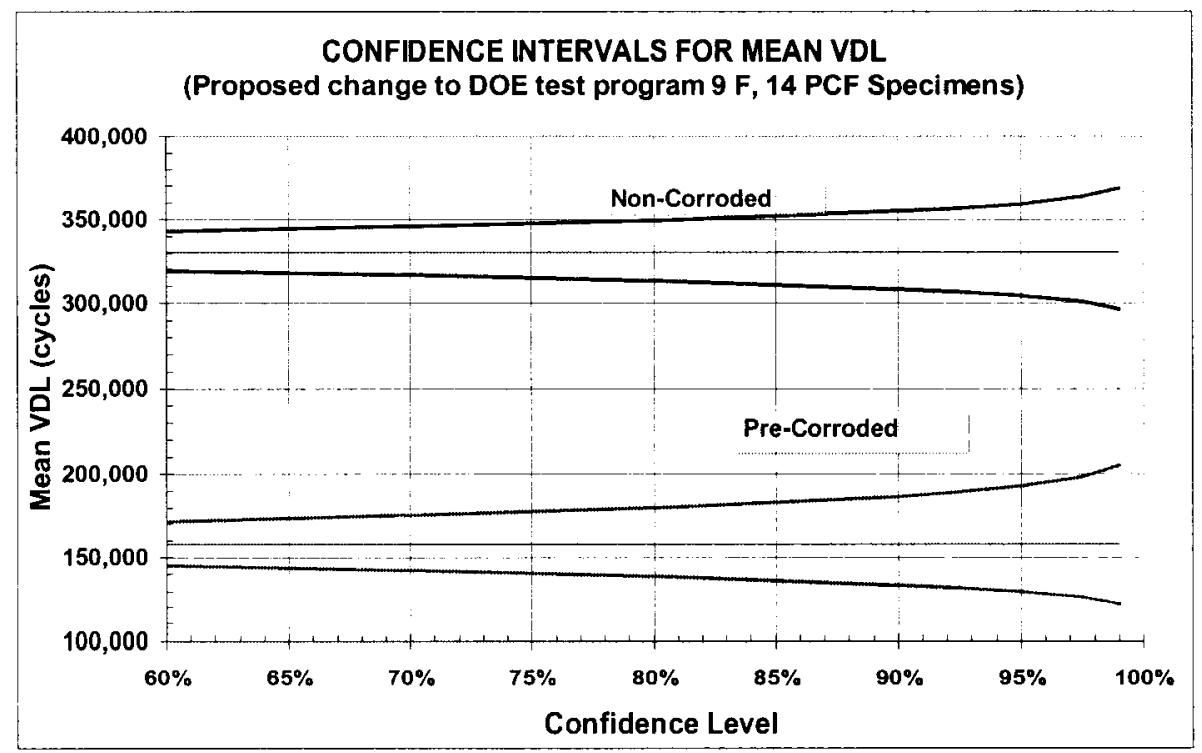

Figure 7-4: Predicted confidence intervals for mean VDL for the revised test plan. The minimum difference in mean VDL ( $90 \%$ confidence level) is $39.6 \%$.

The purpose of this statistical analysis was to determine whether the proposed change in test program would reduce the confidence in the results. As would be expected, the confidence intervals increase slightly for the non-corroded specimens and decrease slightly for the corroded specimens. The change in the test plan does not significantly affect the confidence levels. By modifying the original test plan, more results for the corroded specimens can be obtained without reducing the confidence level.

In order to utilise the PCF specimens currently being corroded a proper randomisation procedure was performed according to STP 588 (Little, 1975). The steps for determining the test matrix were as follows:

1. Randomly select 2 of the fatigue only specimens to undergo pre-corrosion

2. Add these 2 specimens to the PCF set of experimental units ( 8 in total)

Note: Specimen MSD511-057 was still considered to be an additional specimen, and was not considered in the randomisation process.

3. Randomly assign treatments to all PCF experimental units 
Note: Assign treatment 1 and treatment 2 to all PCF specimens. In actuality treatment 1 and treatment 2 are identical, namely, apply pre-corrosion to these specimens.

4. Randomly allocate all PCF experimental units into 4 blocks of 2 specimens

5. Randomly allocate all $F$ experimental units into the 4 blocks of step 4

6. Randomly determine the testing order within blocks

7. Randomly determine the order of testing the blocks

\subsection{Summary of Revised Test Program}

The proposed change in the test program gives a total of $9 \mathrm{~F}$ and $14 \mathrm{PCF}$ specimens. The proposed test order is given in Table 7-3.

By implementing the modified test plan no significant change in confidence in the mean VDL is observed. However, testing more PCF specimens could provide further insight into corrosion-fatigue mechanisms in the MSD specimens. 
Table 7-3: Revised test matrix MSD-DOE specimen tests. (Highlighted region represents modified test plan).

\begin{tabular}{|c|c|c|c|c|}
\hline TEST ORDER & BLOCK & $\begin{array}{l}\text { EXP. UNIT } \\
\text { MSD } \\
\text { COUPON }\end{array}$ & TREATMENT & $\begin{array}{l}\text { TESTED } \\
\text { BY }\end{array}$ \\
\hline $1^{\text {st }}$ test & $\mathrm{E}$ & MSD511-047 & PCF & D. V. Krizan \\
\hline $2^{\text {nd }}$ test & $\mathrm{E}$ & MSD511-060 & $\mathrm{F}$ & D. V. Krizan \\
\hline $3^{\text {rd }}$ test & $\mathrm{H}$ & MSD511-034 & PCF & D. V. Krizan \\
\hline $4^{\text {th }}$ test & $\mathrm{H}$ & MSD511-038 & $\mathrm{F}$ & D. V. Krizan \\
\hline $5^{\text {th }}$ test & $\mathrm{C}$ & MSD511-045 & PCF & D. V. Krizan \\
\hline $6^{\text {th }}$ test & $\mathrm{C}$ & MSD511-051 & $\mathrm{F}$ & D. V. Krizan \\
\hline $7^{\text {th }}$ test & $\mathrm{F}$ & MSD511-058 & $\mathrm{PCF}$ & D. V. Krizan \\
\hline $8^{\text {th }}$ test & $\bar{F}$ & MSD511-046 & $\mathrm{F}$ & D. V. Krizan \\
\hline $9^{\text {th }}$ test & $\mathrm{I}$ & MSD511-061 & $\mathrm{F}$ & D. V. Krizan \\
\hline 10 th test & $\mathrm{I}$ & MSD511-043 & PCF & D. V. Krizan \\
\hline $\begin{array}{l}\text { 11th test } \\
\text { 12th test } \\
\text { 13th test }\end{array}$ & $\mathrm{C}-2$ & $\begin{array}{l}\text { MSD511-037 } \\
\text { MSD511-041 } \\
\text { MSD511-054 }\end{array}$ & $\begin{array}{l}\text { PCF } \\
\text { F } \\
\text { PCF }\end{array}$ & J. C. Cook \\
\hline $\begin{array}{l}14 \text { th test } \\
15 \text { th test } \\
\text { 16th test }\end{array}$ & D-2 & $\begin{array}{l}\text { MSD511-049 } \\
\text { MSD511-050 } \\
\text { MSD511-042 }\end{array}$ & $\begin{array}{c}\text { PCF } \\
\text { PCF } \\
\text { F } \\
\end{array}$ & J. C. Cook \\
\hline $\begin{array}{l}17 \text { th test } \\
18 \text { th test } \\
19 \text { th test }\end{array}$ & A-2 & $\begin{array}{l}\text { MSD511-048 } \\
\text { MSD511-044 } \\
\text { MSD511-056 }\end{array}$ & $\begin{array}{l}\text { F } \\
\text { PCF } \\
\text { PCF }\end{array}$ & $\begin{array}{l}\text { Tested by the IAR (T. Benak) } \\
\text { To be tested by the IAR }\end{array}$ \\
\hline $\begin{array}{l}20 \text { th test } \\
21 \text { st test } \\
22 \text { nd test }\end{array}$ & B-2 & $\begin{array}{l}\text { MSD511-059 } \\
\text { MSD511-036 } \\
\text { MSD511-035 }\end{array}$ & $\begin{array}{l}\text { PCF } \\
\text { F } \\
\text { PCF }\end{array}$ & To be tested by the IAR \\
\hline 23 rd test & Spare & MSD511-057 & PCF & To be tested by the IAR \\
\hline
\end{tabular}




\subsection{TEST AND ANALYSIS METHODS}

Numerous experimental methods used for this MSD testing and analysis have been developed at the NRC. Several of the procedures discussed in this section were generated during the course of this research. The existing procedures have all been improved upon in an attempt to enhance the testing and analysis capabilities at the NRC.

\subsection{Accelerated Corrosion Development}

The objective of the accelerated corrosion process was to corrode only the faying surfaces of the lap joint. To prevent corrosive attack to the rest of the MSD specimen protective measures were implemented.

The entire specimen was first painted to provide a strong protective layer from the acidified salt solution used in the corrosion process (Figure 8-1). Careful attention was paid to ensure full coverage of the specimens while avoiding excessive pooling of paint at the lip of the joint. Prior to exposure, any paint covering both lips of the specimen was cut using a fine blade to allow ingress of the corrosion solution into the joint.

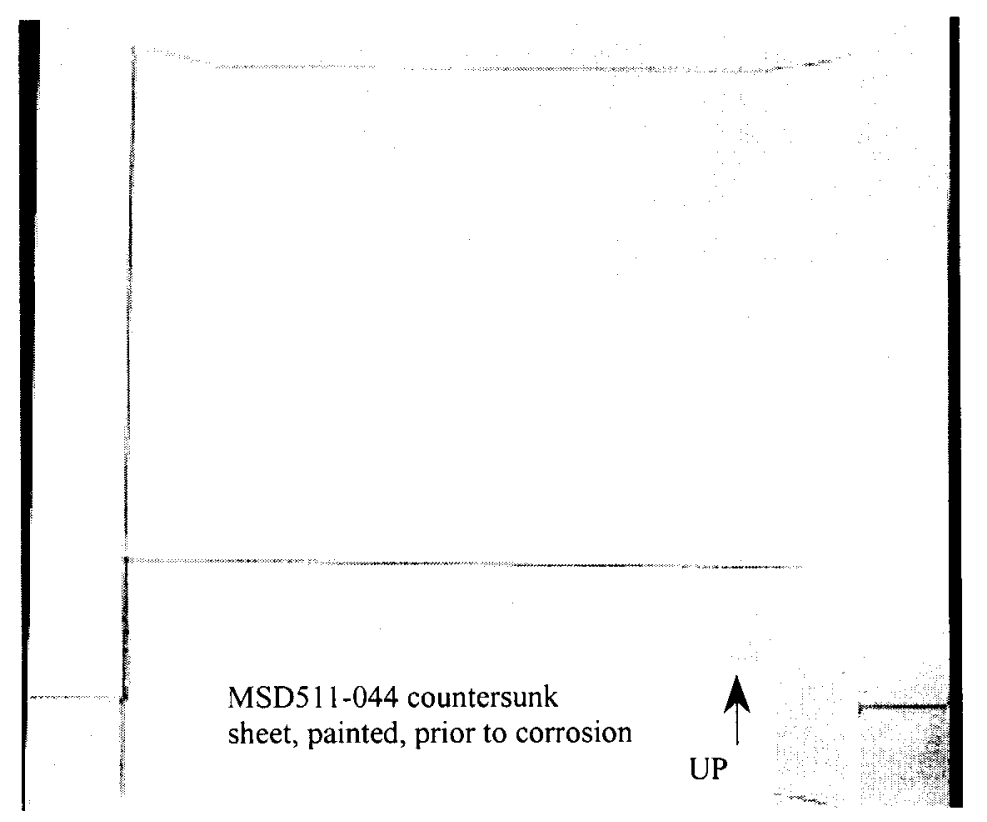

Figure 8-1: Painted MSD specimen, prior to exposure in corrosion chamber. 
Before the painted specimens were placed in the corrosion chamber they were inserted into plastic bags. To reduce probability of bag seal leakage, the edges were sealed using a heat sealer. An opening was created in the bag at both lips of the joint to allow penetration of the salt fog spray (Figure 8-2). The specimens were then hung vertically in the corrosion chamber using two plastic ties, through the heat sealed region at the top of the bag (Figure 8-3).

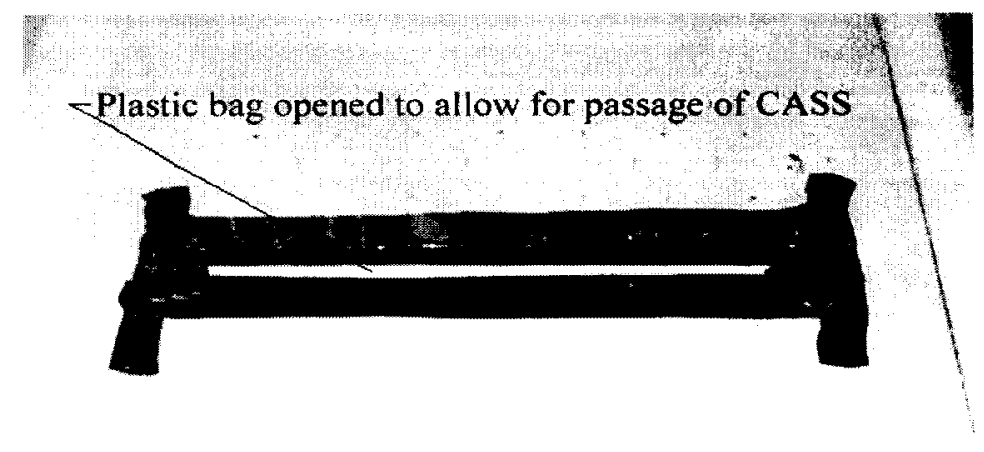

Figure 8-2: Protective bagging system, opened lip shown surrounded by sealant.

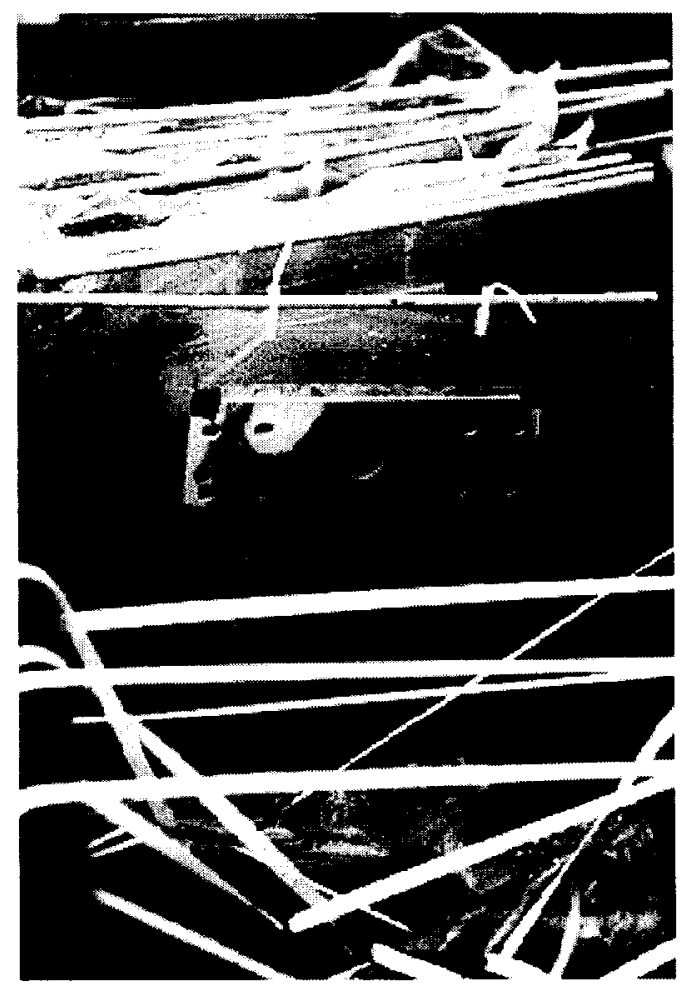

Figure 8-3: MSD specimens suspended in corrosion chamber. 
Corrosion of the specimens was accomplished using a modified ASTM B368 accelerated corrosion process developed by Komorowski et al. (1994). Specimens were suspended in the Singleton Salt Corrosion Cabinet (Figure 8-4) as shown in Figure 8-3. An acidified salt solution containing cupric chloride is atomised to create a dense fog, which surrounds and condenses on the specimens. The condensed salt-solution penetrates the joint through gravity, and capillary action at the lap edges. To ensure the integrity of the specimens during corrosion they were frequently inspected and cleaned. The protective bags were mended or replaced, and any damage to the paint was also repaired when required.

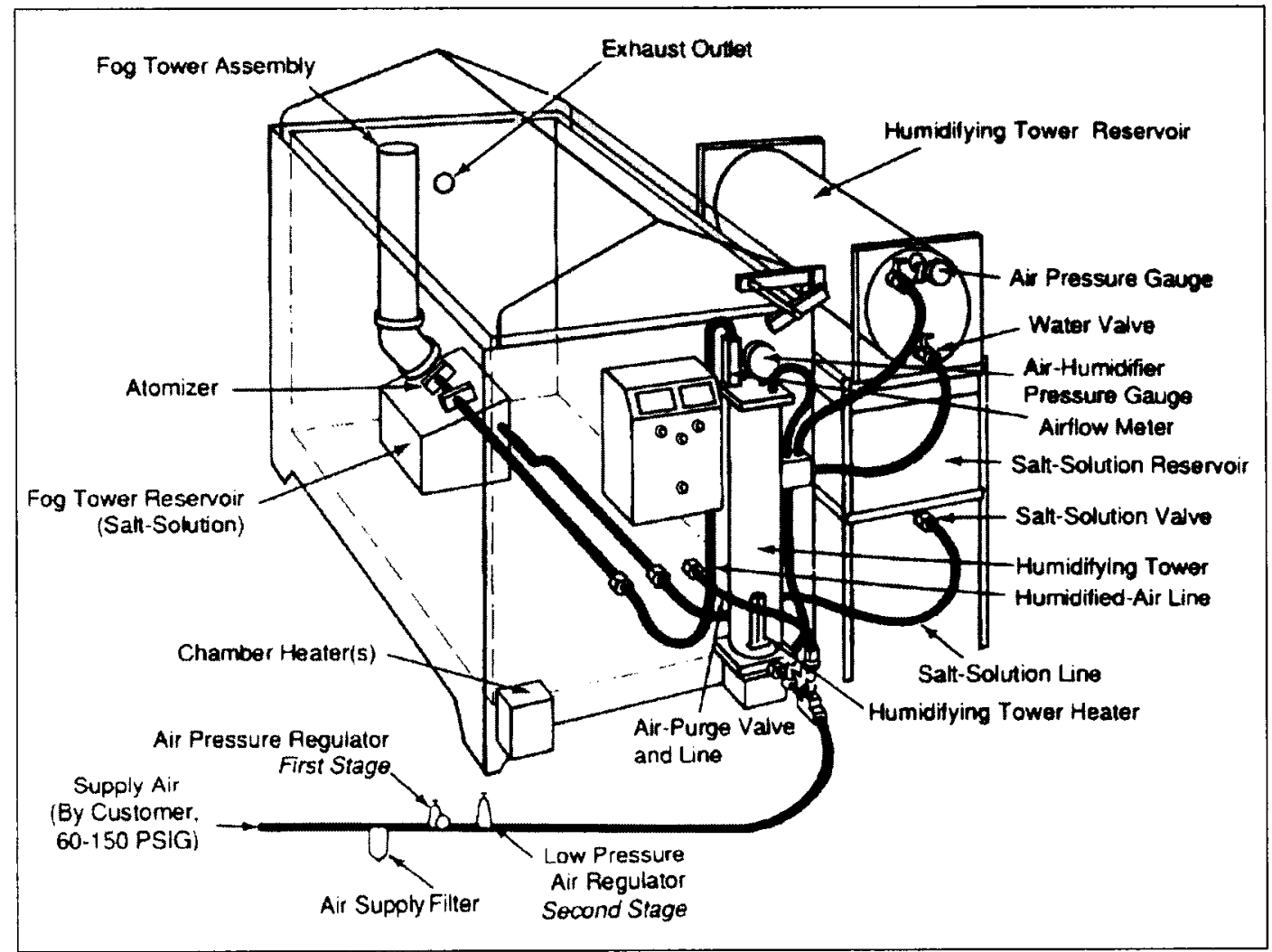

Figure 8-4: Singleton Salt Corrosion Cabinet, Model \#22.

\subsubsection{Monitoring of Corrosion Development}

Pillowing between fasteners in aircraft lap joints is the prime indicator of corrosion. This pillowing occurs when the corrosion product accumulates within the lap joint. Pillowing was evaluated using micrometer thickness measurements and D-Sight inspections. 
Micrometer Thickness Measurements

A metric for estimating the extent of average corrosion thickness loss over the entire joint was developed by Krizan (1999). The average thickness loss for the joint was related to the average corrosion pillowing over the same region after the joint was removed from the corrosion chamber, and dried.

This pillowing-to-thickness-loss (PTL) ratio, developed by Krizan (1999), was adjusted to account for the added pillowing due to moisture within the joint. An analysis of corroding joints revealed that the peak pillowing was larger when the interior of the joint was wet (i.e. during corrosion) as compared to a fully dried joint (i.e. after corrosion has been completed).

The "wet"-PTL ratio was used to monitor corrosion development in the MSD specimens. Pillowing measurements taken during corrosion were compared to the baseline readings to determine the magnitude of corrosion product build-up. The full grid measurement locations for the baseline readings and the peak grid locations used during corrosion are presented in Figure 8-5 and Figure 8-6 respectively. The simplified grid used periodically during the corrosion process measures maximum pillowing locations. These readings were used in conjunction with the wet-PTL ratio to estimate the level of thickness loss due to corrosion in the joint.

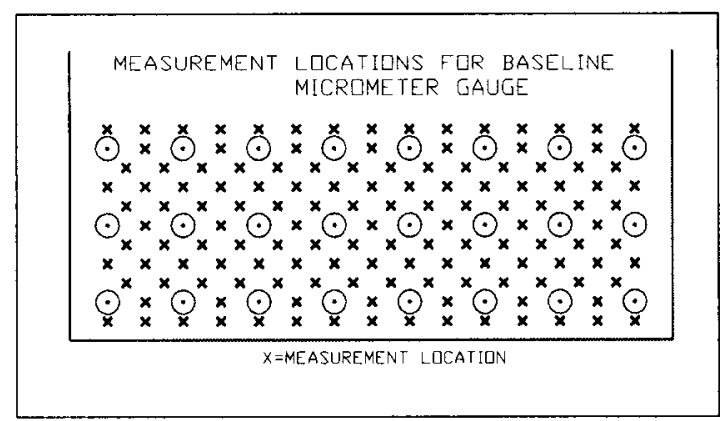

Figure 8-5: Full grid micrometer template.

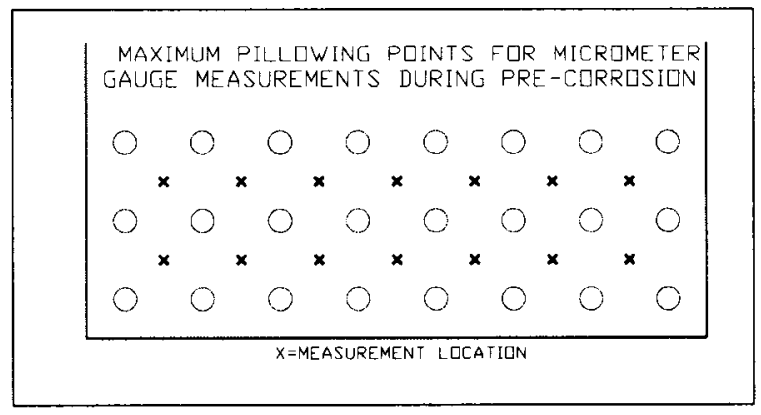

Figure 8-6: Peak grid micrometer template. 
$\underline{\text { D-Sight Inspections }}$

Upon completion of pre-corrosion, D-Sight was used to assess the extent of corrosion damage. D-Sight is a double pass retroreflection optical inspection method able of detecting small surface perturbations (Komorowski et al., 1994). This technique highlights changes of surface slope and acquires a qualitative pillowing image. The NRC is currently developing a method to quantify these images.

\subsubsection{Inspection of Bonded Side-strap Region}

To determine whether the bonded section of the joint, in the side-strap region (Figure 8-7), remained intact after pre-corrosion, several inspection techniques were employed. Corrosive attack in this region has, in the past (specimen MSD511-043 (Krizan, 1999)), destroyed the bond causing a nuisance fatigue failure in the side-strap. This resulted in a premature end to the fatigue test and loss of valuable crack growth data. By inspecting the straps after the corrosion process any specimens containing disbonds would be identified and repaired prior to fatigue testing (refer to Section 9.1 for a description of the repair procedure).

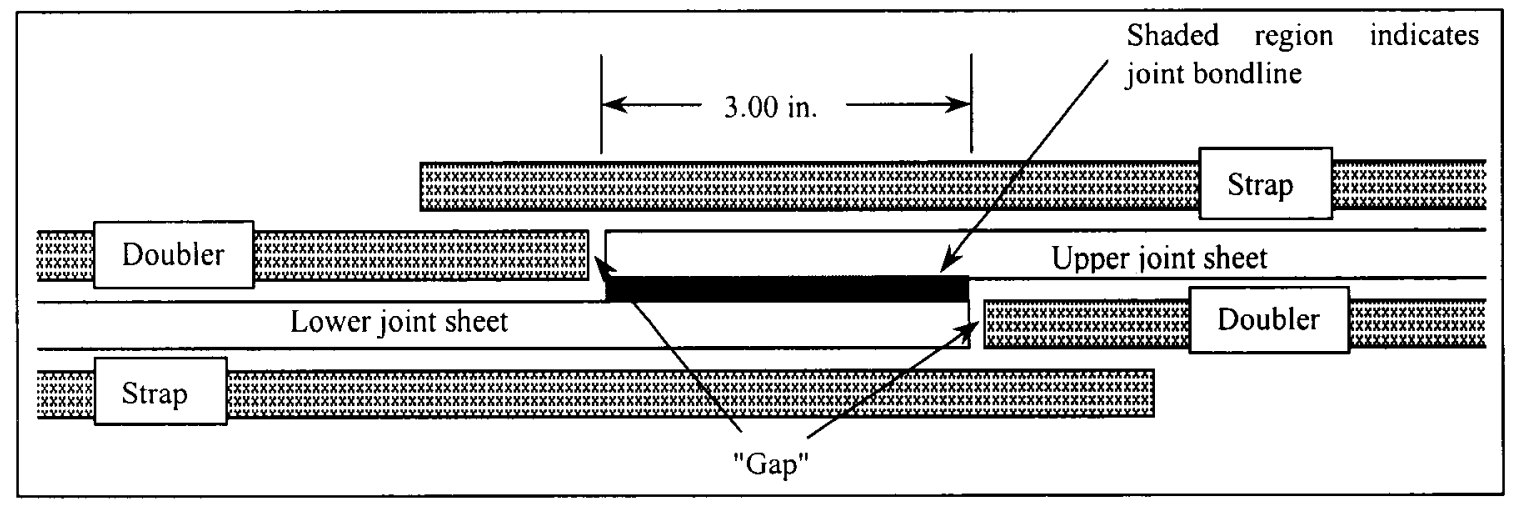

Figure 8-7: Geometry of bonded joint and side-strap for the MSD511 specimen (all gaps between sheets represent FM-73 bondlines) (Not to scale).

\section{Micrometer Thickness Measurements}

Micrometer thickness measurements of the side-straps were attempted during the corrosion process. This proved to be difficult, as the protective bagging arrangement did not allow clear access to this region. As a result, the protective layer was removed and a 
set of measurements were taken according to the grid pattern illustrated in Figure 8-8. These measurements recorded any pillowing present in the straps due to the build up of corrosion product. From these readings the affected area could be estimated.

This approach was not planned at the outset of the corrosion process, but was in response to a disbond of the side-straps that was noticed on specimen MSD511-054. Thus baseline thickness measurements were not obtained. This led to measurement uncertainties due to unknown variations in paint thickness, and possible variations in epoxy thickness in the bond lines.

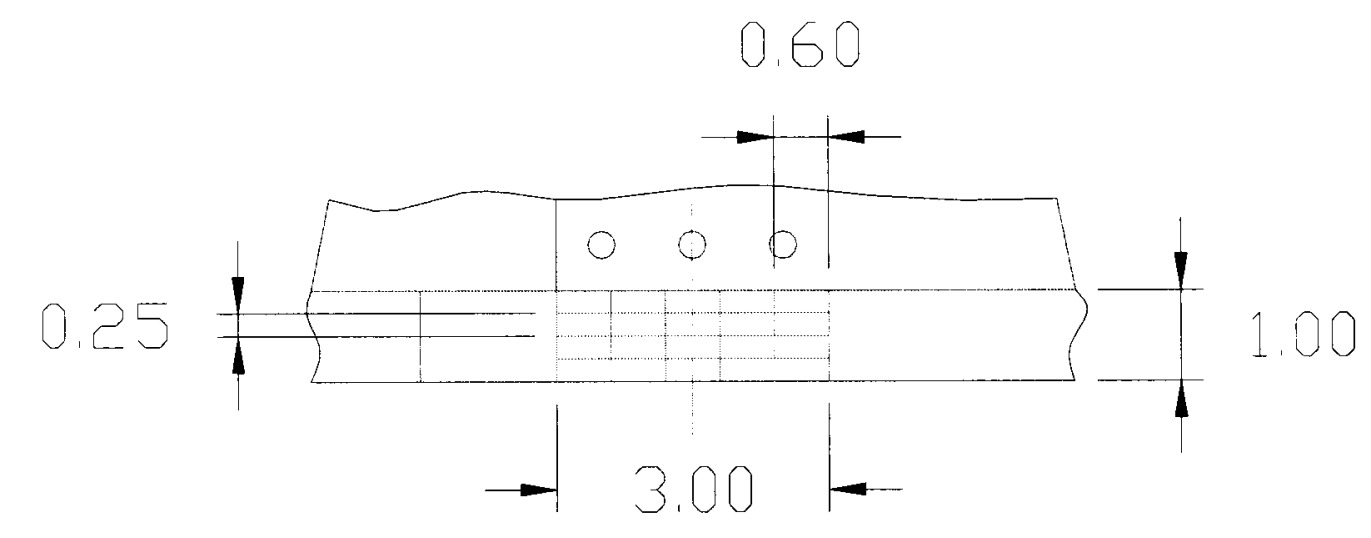

Figure 8-8: Side-strap inspection grid for micrometer and ultrasonic measurements.

Once the paint had been removed and the specimens were thoroughly dried, the micrometer measurements were repeated. This provided a clear picture of the deformation in the strap region caused by disbonding of the joint. The variations due to paint were eliminated, leaving only the slight variations in bond thickness as sources of error.

\section{Digitised X-Ray of the Side-straps}

Another form of inspection performed was digitised $\mathrm{x}$-ray. The specimens were first $\mathrm{x}-$ rayed with the paint intact, which provided no conclusive evidence of corrosion, or 
disbond in the region of interest. This may have been due to the layer of paint masking the useful data from the $\mathrm{x}$-rays. The relative variation in thickness or corrosion product build up, with respect to the total thickness of the specimens at that location, may have also masked the damage in the disbonded joint.

The $\mathrm{x}$-ray inspection was repeated once the paint had been removed and the specimens dried. Again, no conclusive evidence of corrosion or disbond in the side-straps was observed. This method was not useful for monitoring the integrity of the side-straps during the accelerated corrosion process.

\section{Pulsed Eddy Current Inspection of the Straps}

Another NDI technique employed for the side-strap inspections was pulsed eddy current (PEC). Details of this method are provided in Section 8.3 .2 and by Lepine et al. (1999). Two pieces of information were obtained from these inspections:

1. An estimation of the width of the air gap, or disbond.

2. An estimate of the variation of lift-off, which is interpreted as a measurement of the surface curvature. The amount of probe lift-off from the surface is proportional to the severity of surface curvature.

Using PEC to scan the side-straps, the location and size of a disbonded region can be estimated.

\section{$\underline{\text { Ultrasonic Inspection }}$}

The final NDI method used to detect side-strap disbonding was dual probe ultrasonic inspection. Using a Sonatest UFD7A ultrasonic inspection system at $2.25 \mathrm{MHz}$, with both a transmitting and receiving probe, the straps were inspected for disbonds. The inspection grid used is illustrated in Figure 8-8.

The concept is quite simple. Successful transmission through the strap into the receiver

probe indicates a solid bond. In the case of a disbonded strap, no signal is received. The 
major advantage of this method, besides being quick, was that it could be applied to painted specimens during the corrosion process.

When compared to the other NDI techniques used, this method proved to be the most effective for detecting disbonds in the side-strap region of the specimen. An estimate of the size of the disbonded region could also be acquired which was useful in assessing the need for a repair. 


\subsection{Fatigue Testing}

Cycling of the MSD specimens was performed using sinusoidal loading at $4 \mathrm{~Hz}$ between $144 \pm 10 \mathrm{lb}$. and $7219 \pm 10 \mathrm{lb}$. $(\mathrm{R}=0.02)$. Loading was applied using an MTS Model 305.03 load frame, and was controlled using MTS TestStar II ${ }^{\mathrm{TM}}$ control system and TestWare$\mathrm{SX}^{\mathrm{TM}}$ testing software (Figure 8-9). The test was operated under load control to simulate an aircraft loading environment.

Load was transferred from the load frame to the specimen through 1.125 in. diameter, upper and lower loading pins. These pins were inserted through the steel grips and the 0.050 in. thick steel plates that were bolted to the specimen (Figure 8-10). In this configuration the load is distributed relatively evenly across the specimen.

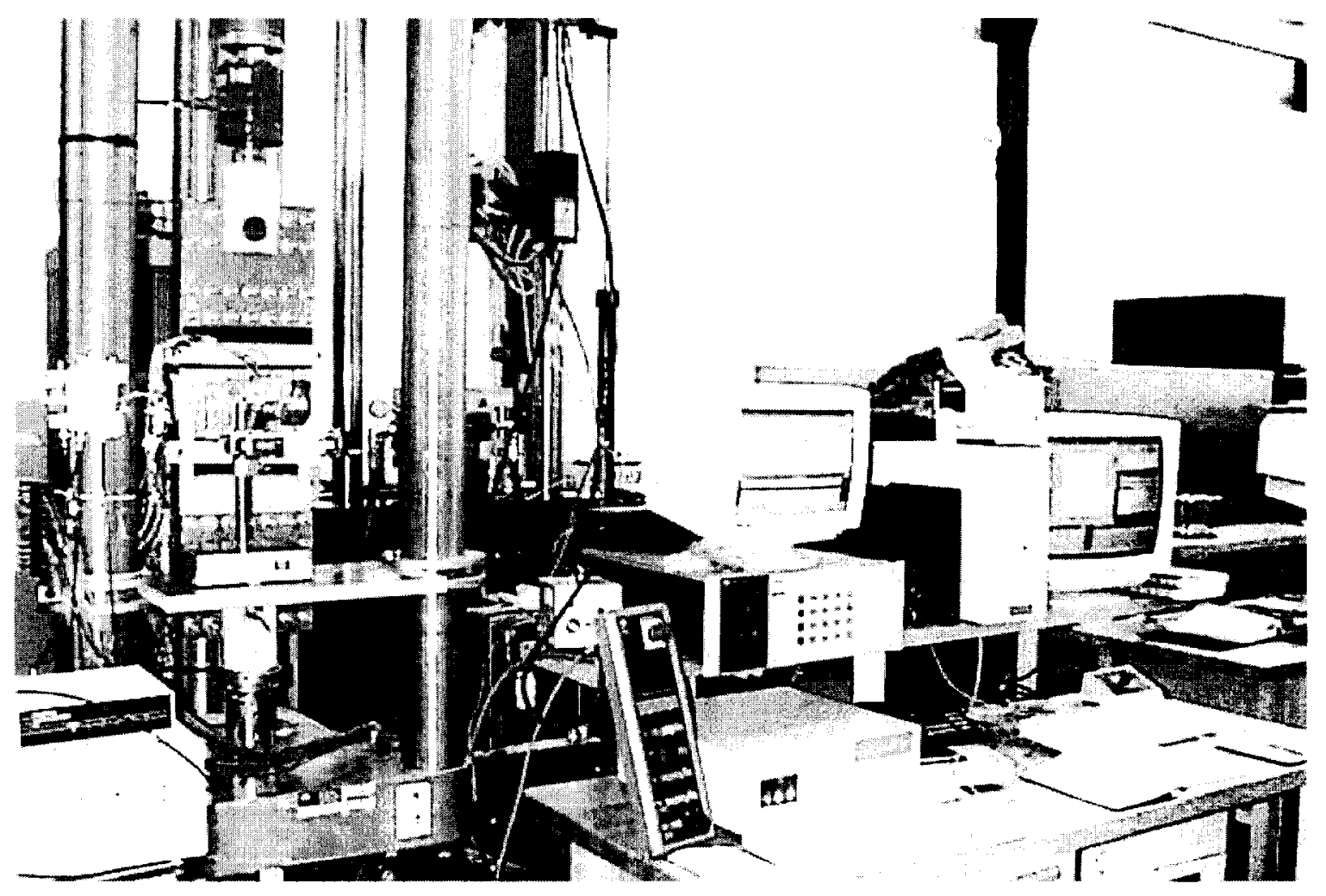

Figure 8-9: Fatigue testing equipment. 


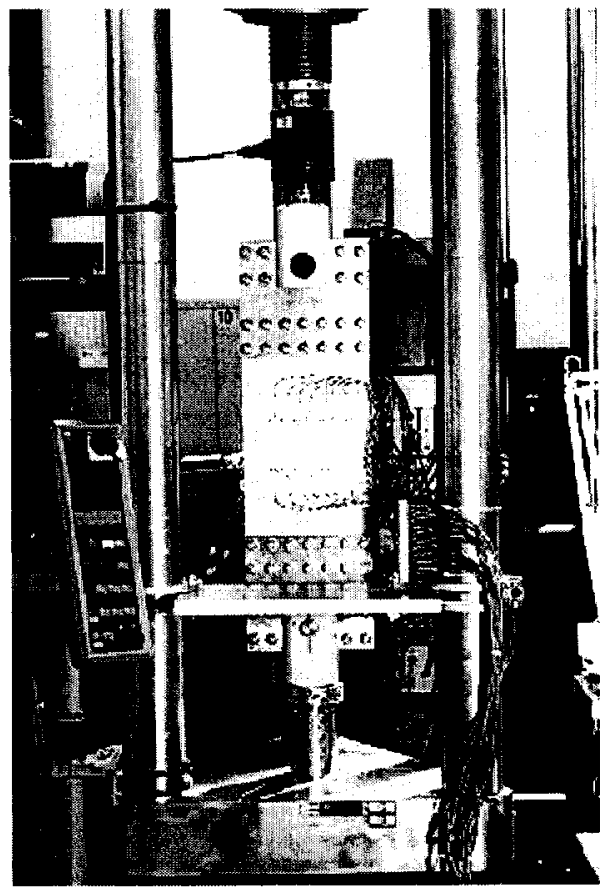

Figure 8-10: MSD specimen mounted in MTS load frame.

\subsubsection{Strain Gauge Data Acquisition}

The Data Acquisition System (DAS) used for all tests consisted of the following equipment:

1) Strain gauges installed on the specimen ( $120 \Omega$ and $350 \Omega$ gauges were used)

2) Hewlett Packard 3497A Data Acquisition/Control Unit ${ }^{\mathrm{TM}}$ to acquire the strain gauge readings via the following - quarter bridge circuit-internal cards:

a) one card with 8 channels for $350 \Omega$ strain gauges, 2 channels for $120 \Omega$ gauges

b) one card with 10 channels for $350 \Omega$ strain gauges

c) one card with 14 channels for $350 \Omega$ strain gauges 6 channels for $120 \Omega$ gauges

3) Lambda Electronics Corp. Precision Power Source Model LS511 ${ }^{\mathrm{TM}}$ to supply an excitation of $5.00 \mathrm{~V}$ to the quarter bridge circuits

4) 486-based PC loaded with a customised program developed by IAR to calculate strains from strain gauge output voltages. The program had the following features: 
a) Any combination of channels from the Hewlett Packard 3497A Data Acquisition/Control Unit ${ }^{\mathrm{TM}}$ could be selected and then automatically zeroed

b) Multiple readings could be taken and averaged for each channel to reduce experimental error; 10 readings per channel were taken for all tests

c) Data could be exported to a spreadsheet program for further analysis

Strain gauges are coded as follows:

$$
\text { Number-X/Y }-\Omega-\text { face }
$$

Where: Number : Strain gauge identification number (Refer to Figure 8-11 for strain gauge configuration)

$\mathrm{X} / \mathrm{Y} \quad$ : Axis that the strain gauge is oriented along

$\Omega \quad$ : Strain gauge resistance in Ohms

face : Indicates to which face a strain gauges is attached to (faying, outer, or inner) when the strain gauges is paired with another strain gauge on the opposite face of the sheet at the same location

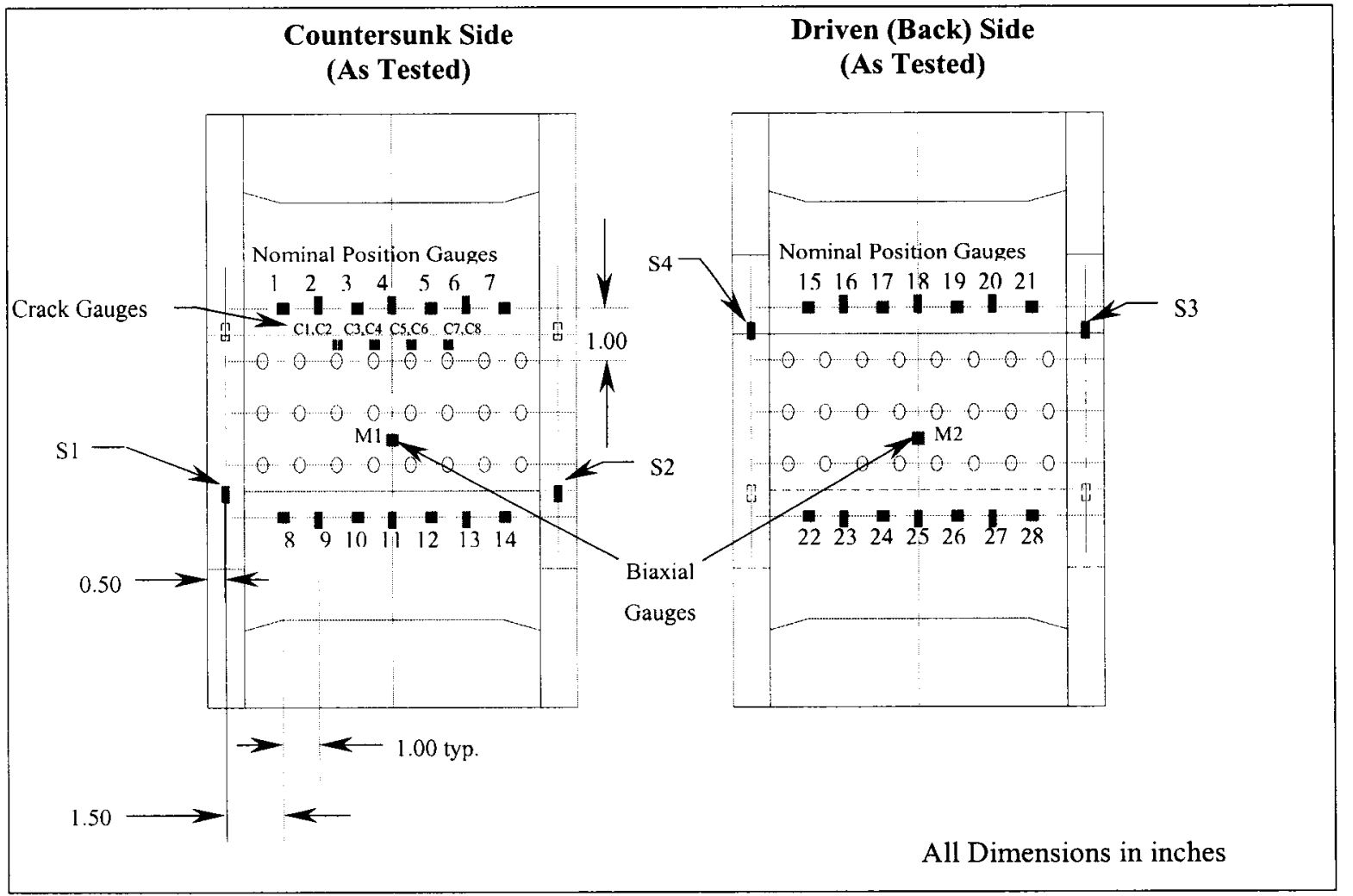

Figure 8-11: Strain gauge configuration. 
The strain gauges shown in Figure 8-11 can be classified into four functional categories. These categories are described below, and are summarised in Table 8-1.

1. Nominal Position Strain Gauges: These strain gauges are further classified as countersunk nominal pair strain gauges $(C N P)$ and driven nominal pair strain gauges $(D N P)$. They are located along a line one inch from the outer rivet rows. This position is close to the joint but away from the regions of high stress gradients. The function of these gauges is the following:

- Observe changes in nominal position strains

- Determine hysteresis of the specimens by plotting load versus gauge, and membrane stress

- Determine if differences in strain readings and settling time exist between specimens

- Verify that membrane and bending stresses fall within acceptable limits, and that no loading asymmetry exists

2. Crack Detection Strain Gauges: These gauges are located in close proximity to the four centre rivets in the critical rivet row, namely rivets $3,4,5$, and 6 . Two strain gauges are installed above each of these rivets, on either side of the rivet centre line. For simplicity these will be referred to as $31,3 \mathrm{r}$, and so forth. The purpose of these gauges is to monitor any small variations in strain from one side of the rivets to the other, which would indicate hidden cracks.

3. Side-Strap Strain Gauges: There are four side-strap gauges present on each specimen. These gauges were added to monitor the strains in the side-straps.

4. Biaxial Strain Gauges: Biaxial strain gauges were installed along the vertical centre line of the specimen, between the middle and lower rivet rows on both the inner and outer sheets. The purpose of these gauges was to determine the strains in these locations for comparison with finite element models, and photoelastic images. 
Table 8-1: Strain Gauge Legend.

\begin{tabular}{|c|c|c|c|}
\hline Category and Strain Cauge Yumber & $\begin{array}{c}\text { DAS } \\
\text { C'hannels }\end{array}$ & $\begin{array}{l}\text { Ciauge } \\
\text { Resistance } \\
\text { (()hms) }\end{array}$ & Strain Cauge C odes \\
\hline \multicolumn{4}{|l|}{ Countersunk Nominal Gauges (CNP) } \\
\hline CNP 1 & 64,46 & 350 & $1-Y-350$-outer, $21-Y-350$-faying \\
\hline CNP 2 & 65,45 & 350 & 2-X-350-outer, 20-X-350-faying \\
\hline CNP 3 & 66,44 & 350 & 3-Y-350-outer, 19-Y-350-faying \\
\hline CNP 4 & 67,43 & 350 & 4-X-350-outer, 18-X-350-faying \\
\hline CNP 5 & 68,42 & 350 & $5-Y-350$-outer, $17-Y-350$-faying \\
\hline CNP 6 & 69,41 & 350 & $6-X-350$-outer, 16-X-350-faying \\
\hline CNP 7 & 80,40 & 350 & 7-Y-350-outer, 15-Y-350-faying \\
\hline \multicolumn{4}{|l|}{ Driven Nominal Gauges (CNP) } \\
\hline DNP 1 & 81,53 & 350 & 28-Y-350-outer, 8-Y-350-faying \\
\hline DNP 2 & 82,52 & 350 & 27-X-350-outer, $9-X-350$ - faying \\
\hline DNP 3 & 83,51 & 350 & 26-X-350-outer, $10-Y-350$ - faying \\
\hline DNP 4 & 84,50 & 350 & 25-X-350-outer, 11-X-350-faying \\
\hline DNP 5 & 85,49 & 350 & 25-X-350-outer, $12-Y-350$ - faying \\
\hline DNP 6 & 86,48 & 350 & 24-X-350-outer, $13-X-350$ - faying \\
\hline DNP 7 & 87,47 & 350 & 23-X-350-outer, 14-Y-350- faying \\
\hline \multicolumn{4}{|l|}{ Crack Detection Gauges } \\
\hline $\mathrm{Cl}$ & 60 & 120 & C1-X-120-outer \\
\hline $\mathrm{C} 2$ & 61 & 120 & C2-X-120-outer \\
\hline $\mathrm{C} 3$ & 54 & 120 & C3-X-120-outer \\
\hline C.4 & 55 & 120 & C4-X-120-outer \\
\hline $\mathrm{C} 5$ & 56 & 120 & C5-X-120-outer \\
\hline C6 & 57 & 120 & C6-X-120-outer \\
\hline $\mathrm{C} 7$ & 58 & 120 & C7-X-120-outer \\
\hline $\mathrm{C} 8$ & 59 & 120 & C8-X-120-outer \\
\hline \multicolumn{4}{|l|}{ Side-strap Gauges } \\
\hline $\mathrm{S}]$ & 88 & 350 & $\mathrm{~S} 1-\mathrm{X}-350$-outer \\
\hline $\mathrm{S} 2$ & 89 & 350 & $\mathrm{~S} 2-\mathrm{X}-350$-outer \\
\hline S3 & 63 & 350 & S3-X-350-outer \\
\hline S4 & 62 & 350 & S4-X-350-outer \\
\hline \multicolumn{4}{|l|}{ Biaxial Gauges } \\
\hline $\mathrm{M} 1-\mathrm{X}$ & External & 350 & M1-X-350-outer \\
\hline $\mathrm{M} 1-\mathrm{Y}$ & External & 350 & M1-Y-350-outer \\
\hline$M 2-X$ & External & 350 & M2-X-350-outer \\
\hline $\mathrm{M} 2-\mathrm{Y}$ & External & 350 & M2-Y-350-outer \\
\hline
\end{tabular}




\subsubsection{Crack Detection and Measurement}

Detection of fatigue cracks before they attain a visible length of $0.010 \mathrm{in}$. is required for MSD fatigue testing. This was accomplished using visual inspections, eddy current inspections, as well as crack detector gauges (for non-corroded specimens). All inspections were carried out at $90 \%$ load (6497 lb.) to aid in crack detection.

Visual inspections required proper lighting to observe any plastic zone preceding a crack. The optimum lighting was found to be indirect fibre optic light. Under these conditions cracks were routinely detected at a visible length (refer to Figure 8-12) of $0.010 \mathrm{in}$. or less.

In addition to visual inspections, eddy current inspections were also utilised. A MIZ-17 eddy current system with a $50-500 \mathrm{kHz}$ EC/NDT plastic tipped probe was used. The coated probe allowed direct contact with the aluminum without scratching the surface. This technique can detect cracks just prior to breaking the surface, and will confirm cracks that have just become visible (approximately 0.010 in. in length).

The crack detector gauges assisted in early detection of cracks at the four central rivets. These gauges could detect cracks up to 20000 cycles prior to being visible. This was accomplished by plotting the variations in stress from one side of a rivet to the other during the test. If a crack developed to the right of a rivet, the right side crack gauge would experience a reduction in stress, while the left gauge would report an increase in stress. The technique was first demonstrated by Scott (1997), and was refined to its present form by Krizan (1999). 


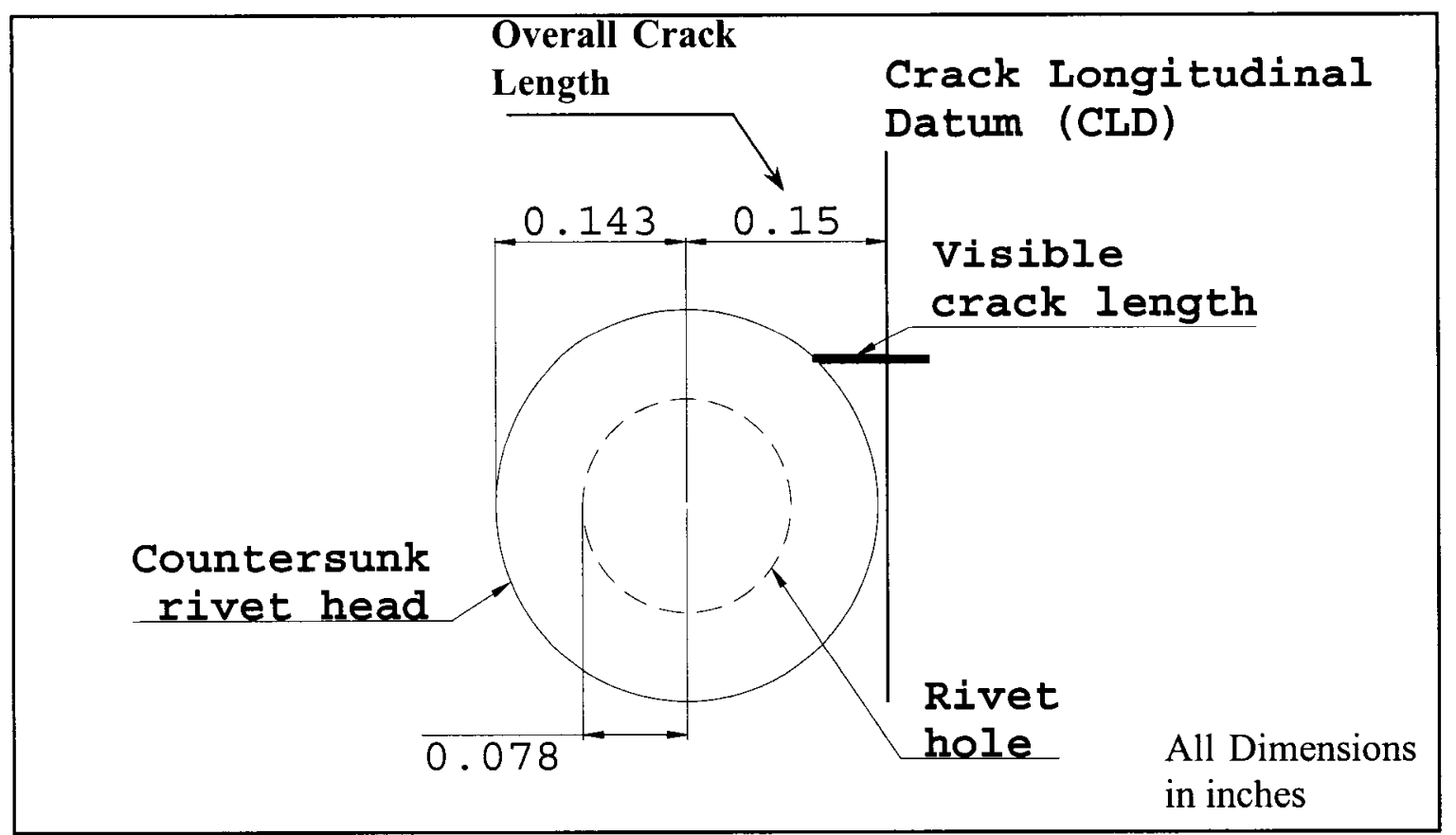

Figure 8-12: Illustration of visible crack detection at a typical rivet (Krizan, 1999).

In this thesis the length of a crack on either side of a rivet was measured from the centre of the rivet. The Visual Crack Detection Life (VDL) is defined as cycles to visual detection of the first crack in the specimen. In order to compare aggregate crack growth curves for different specimens, a common datum was established by Krizan (1999). The Crack Longitudinal Datum (CLD) was set at a horizontal distance of $0.150 \mathrm{in}$. from the rivet centre (Figure 8-12). The cycle at which the crack reached the CLD was estimated using linear interpolation. In cases where the crack length at visible detection was longer than the CLD, the crack lengths were extrapolated backwards to the CLD using a power function curve fit.

Once a crack was detected, the horizontal crack tip position was measured relative to the centre of the rivet (marked by manufactured dimple) using a travelling microscope. The crack tip positions were translated into a common set of longitudinal co-ordinates with the origin as shown in Figure 8-13. The measurement error for longer well-developed cracks was estimated to be \pm 0.002 in. based on repeated measurements of a known length. Cracks shorter than 0.2 in. were more difficult to measure, therefore the error is 
potentially larger. Frequent crack length measurements (after each 0.010-0.030 in. crack extension) were recorded to minimise this error (Krizan, 1999).

Crack growth monitoring was implemented to obtain a sufficient number of data points to construct smooth crack growth curves, and be able to accurately calculate the instantaneous crack growth rate at any point. The crack growth rate was determined using the secant method, one of the recommended techniques found in ASTM E-647-93 (1999). To accomplish this, crack length measurements were taken after each 0.010 to 0.030 in. of crack growth in the fastest growing crack. To monitor crack growth during the test, aggregate crack growth curves were constructed by summing the lengths of each individual crack.

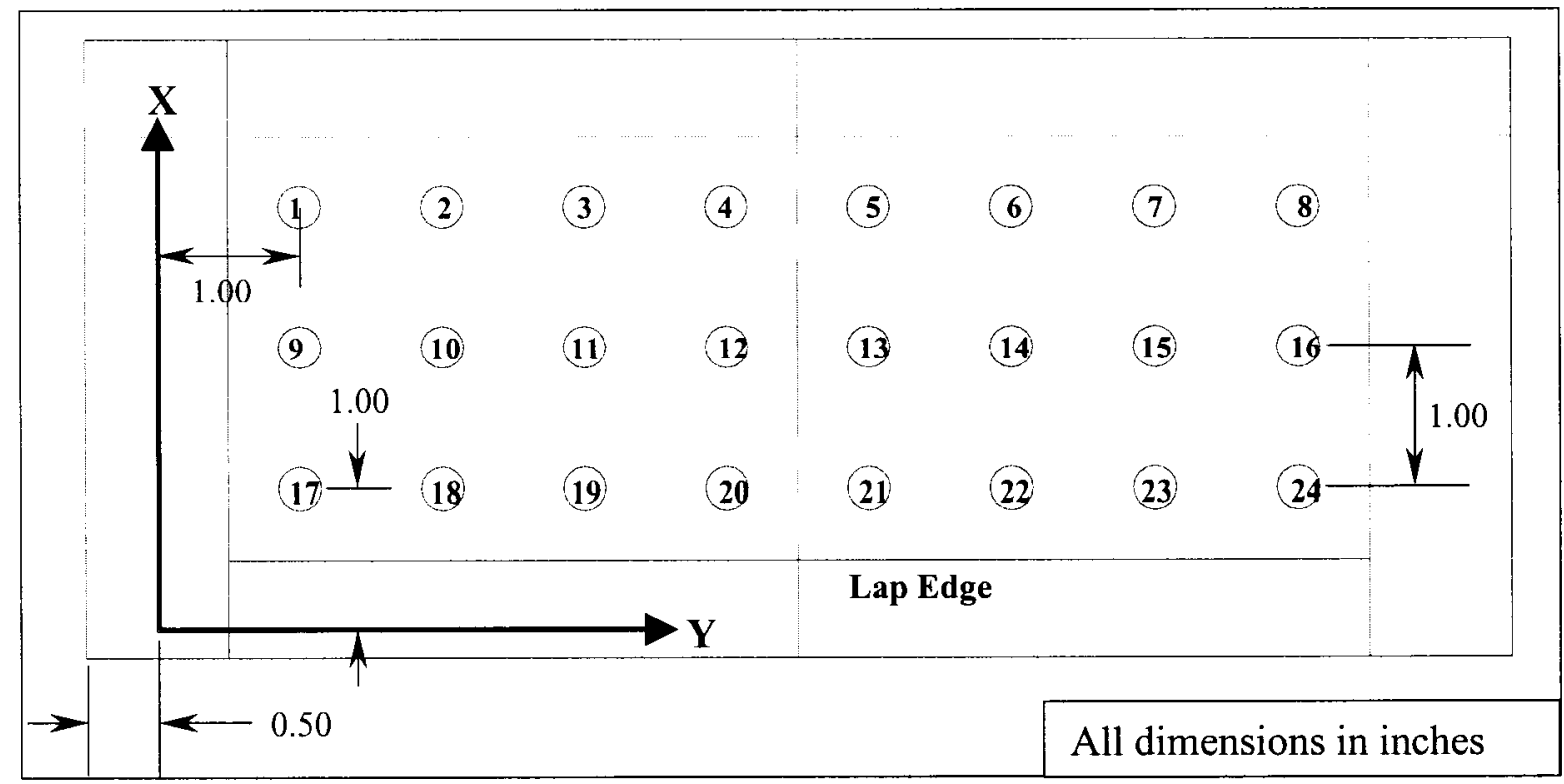

Figure 8-13: Crack length measurement datum, and rivet numbering scheme.

Note: Countersunk (outer) sheet shown as tested (outer lap edge down).

\subsubsection{Specimen Teardown}

Following the fatigue test the riveted joint region was cut from the rest of the MSD coupon. Next, the rivets were removed by drilling and shearing the driven head. The countersunk heads were labelled and retained for further analysis. 
The inner and outer sheets were then pried apart. Care was taken not to disturb any corrosion or fretting product on the faying surfaces. The condition of the faying surfaces for both corroded and non-corroded specimens were recorded using a Canon ${ }^{\mathrm{TM}} \mathrm{F}-1$ $35 \mathrm{~mm}$ SLR camera with a Tamron ${ }^{\mathrm{TM}} 90 \mathrm{~mm}$ F/2.8 macro lens and Kenko ${ }^{\mathrm{TM}}$ automatic extension tubes. One photograph of each rivet ( 24 in total), providing some overlap of images, and one general picture of the entire faying surface for both the inner and outer sheets were taken.

The corrosion product was then removed using a proprietary procedure developed at the NRC by Merati (2000). This process is based on repeated immersions in a chemical bath and an ultrasonic cleaner. The procedure has been proven to remove the corrosion products without damaging the base metal, or aluminum cladding. After corrosion removal, another set of macro photographs was taken of the faying surfaces. Once all photographs, measurements, and inspections have been performed, the specimen was cut into small samples for scanning electron microscope (SEM) analysis.

\subsection{Evaluation of Corrosion Damage}

One of the important objectives of this research is to correlate NDI results to actual corrosion damage. Most current techniques used for aircraft inspection are poor at best for quantifying hidden corrosion damage. Inspection data for corroded lap joints is generated using the corroded MSD specimens. This is an attempt to improve existing techniques (ultrasonic and eddy current), as well as validate newer technologies such as pulsed eddy current (PEC). Since the coupons are dismantled and the corrosion damage for each sheet quantified, using digitised $x$-ray (DXR), calibration of various NDI methods would be possible. Each inspection method employed is described in the following sections. All NDI results are presented in Appendix B, while selected results are discussed in Section 9.3.1. A calibration of these NDI techniques using DXR was not attempted in this thesis. 


\subsubsection{Multi-frequency Eddy Current}

Eddy current is widely used in the aerospace industry to inspect for cracks and more recently for hidden corrosion damage. For this research the IAR/NRC eddy current system (shown in Figure 8-14) was used. The apparatus consists of a custom-built scanning table, a MIZ 40 eddy current instrument, and proprietary probes designed by the IAR/NRC and RDTech for corrosion NDI, all controlled using the Winspect software package. The specimens were scanned using a sliding, absolute probe at the four frequencies, and the corresponding nominal signal penetration depths are listed in Table 8-2.

Table 8-2: Eddy current frequencies used to detect corrosion in MSD specimens.

\begin{tabular}{|c|c|l|}
\hline \multicolumn{2}{|c}{$\begin{array}{c}\text { Probe } \\
\text { Frequency }\end{array}$} & \multicolumn{1}{c|}{$\begin{array}{c}\text { Nominal Signal Penetration } \\
\text { Depth (in.) }\end{array}$} \\
\hline $30 \mathrm{kHz}$ & 0.026 & $\begin{array}{l}\text { Relevance for MSD Specimen } \\
\text { Insection } \\
\text { corrosion }\end{array}$ \\
\hline $17 \mathrm{kHz}$ & 0.035 & $\begin{array}{l}\text { Majority of first layer corrosion } \\
\text { detected }\end{array}$ \\
\hline $8 \mathrm{kHz}$ & 0.050 & $\begin{array}{l}\text { Detection of first and second layer } \\
\text { corrosion (unreliable results) }\end{array}$ \\
\hline $5.5 \mathrm{kHz}$ & 0.060 & $\begin{array}{l}\text { Detection of first and second layer } \\
\text { corrosion (unreliable results) }\end{array}$ \\
\hline
\end{tabular}




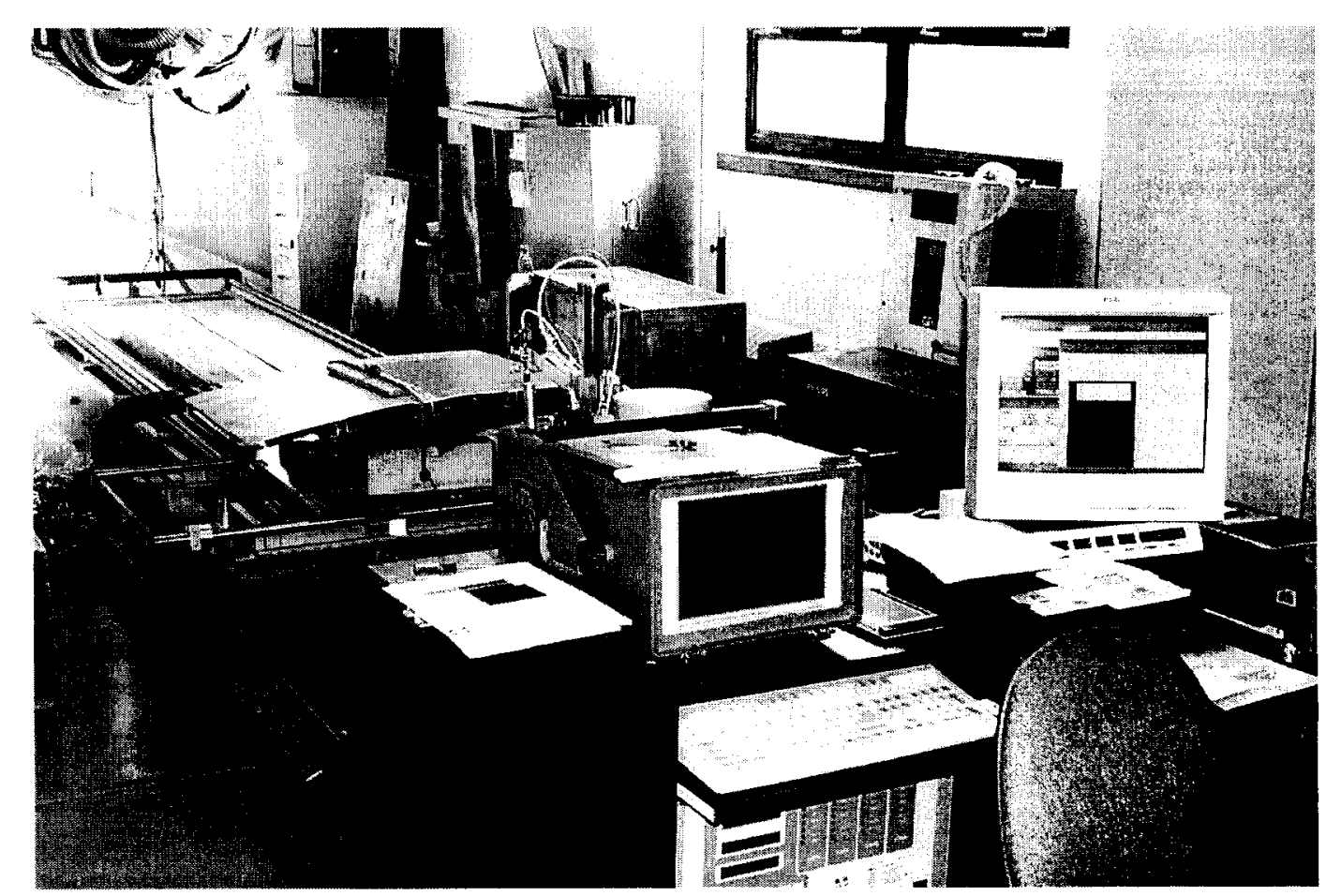

Figure 8-14: Photograph of the IAR/NRC eddy current system (Lepine et al., 1999).

\subsubsection{Pulsed Eddy Current}

An inspection technique currently under development at the IAR/NRC is Pulsed Eddy Current (PEC). It differs from conventional eddy current by using a step function rather than a continuous sinusoidal signal to excite the driver coil. A concentric pick-up coil acts as a sensor to measure the voltage induced by the time varying magnetic field. After processing the data, the results are displayed as C-scan images of the entire test piece. A C-scan represents one feature such as maximum amplitude, time-to-zero-crossing, and lift-off intersection point. For a more thorough description of pulsed eddy current refer to Lepine et al. (1999).

\subsubsection{Digitised X-Radiography (DXR) Technique}

DXR was used to quantify corrosion damage in the MSD specimens after teardown and cleaning. Each sheet of the joint was $\mathrm{x}$-rayed separately using radiographic settings to obtain a consistent optical density range for each film. For 0.040 in. thick 2024 Aluminum an optical density of $0.70 \pm 0.05$ was desired for the developed film. 
The corrosion damage was captured on high resolution, and high contrast $\mathrm{x}$-ray films. These film images were then digitised using an Epson Expression 386XL ${ }^{\mathrm{TM}}$ transparency scanner, generating $800 \mathrm{dpi}$ (dots per inch) 12-bit greyscale images.

In order to calibrate these images, a calibration wedge and calibration strips were included in the initial $x$-ray. The strips were 0.040 in. thick, pristine aluminum 2024-T3 clad coupons. The calibration wedge was a 0.25 in. thick aluminum 2024-T3 sheet with a sloping, milled groove down the centre (Figure 8-15). The wedge thickness decreased from $0.0528 \mathrm{in}$. to $0.0122 \mathrm{in}$. with a slope of roughly $0.004 \mathrm{in} . / \mathrm{in}$. A $32 \mu \mathrm{in}$. surface finish was applied to the sloped-groove to reduce the thickness variations in the wedge itself.

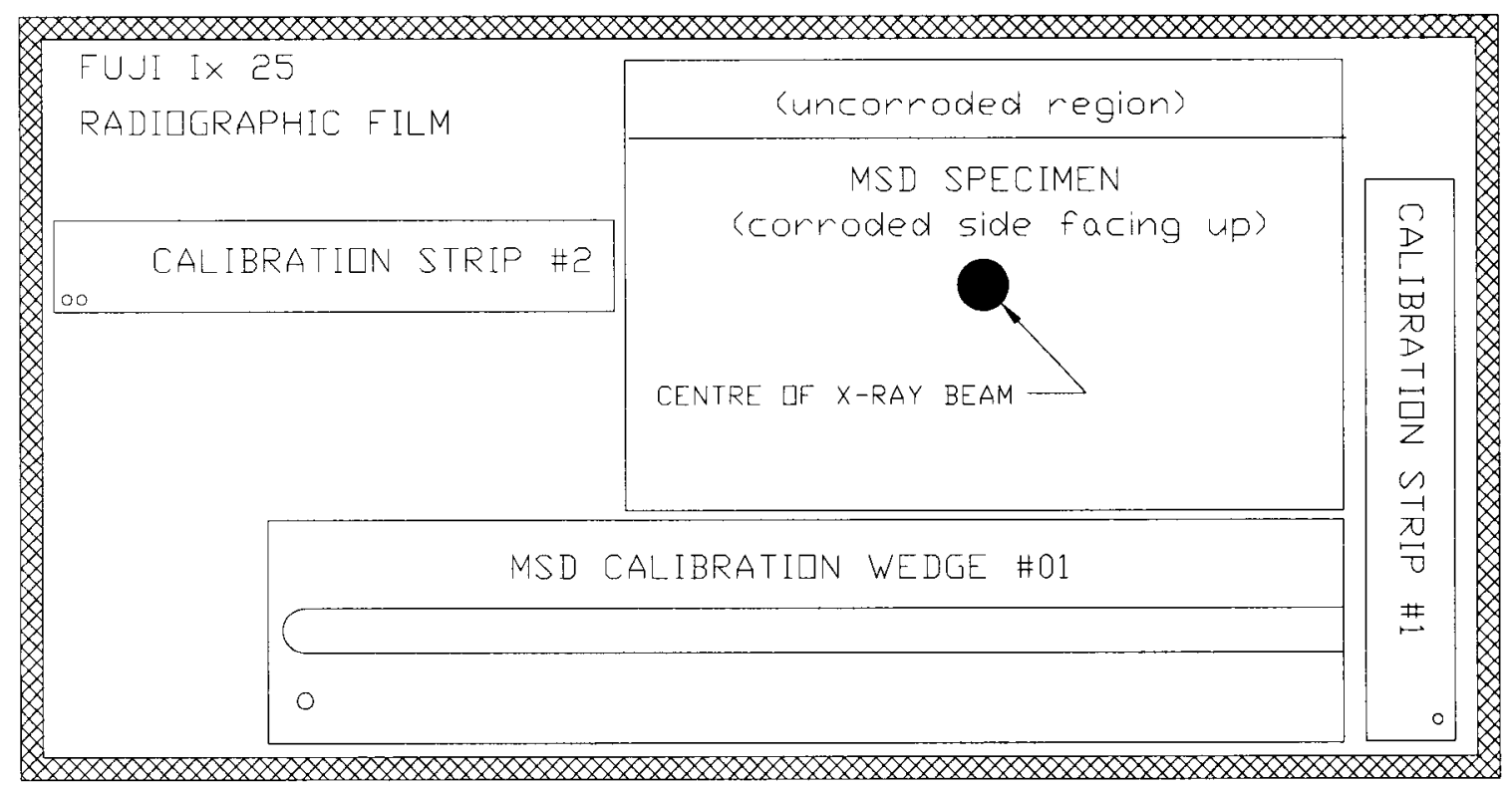

Figure 8-15: Configuration of aluminum 2024-T3 DXR calibration wedge and calibration strips

The x-ray film was processed using a Kodak Industrex M6-I film processor. A digital image was produced by scanning the processed x-ray film using an Epson Expression $836 \mathrm{XL}^{\mathrm{TM}}$ scanner at $800 \mathrm{dpi} \times \mathrm{x} 80 \mathrm{dpi}$ resolution.

The DXR image of the calibration wedge provides a direct correlation between the image greyscale value and the wedge thickness taken at the same location. A mathematical 
equation was developed to calibrate the DXR image, producing a thickness map of the corroded sheet according to the following procedure:

1. Scan the developed radiographic films using the Epson Expression 836XL ${ }^{\text {TM }}$ transparency scanner to create a 12-bit greyscale image (4096 shades of grey) with a spatial resolution of $800 \mathrm{dpi}$

2. Store the digitised $x$-ray data as a 16-bit ".tif" image file for later analysis

3. Using appropriate image analysis software ${ }^{10}$, determine the greyscale values in a small, 5-pixel by 5-pixel region in the centre of the calibration wedge, at each of the marked locations of known thickness (10 in total)

4. Generate a plot of greyscale value vs. actual thickness (as measured on the wedge)

5. Fit an exponential curve to this data (refer to Figure 8-16)

6. Record the equation of this curve fit. This equation is now the calibration equation for this particular DXR data set.

7. Calibrate the DXR image using an appropriate image analysis software package ${ }^{11}$. The calibration strips included in the $\mathrm{x}$-ray of the specimen are used to ensure proper calibration of the DXR image. Any discrepancies observed in the calibration strips (i.e. variations in x-ray intensity, or any thickness offset) after the initial thickness calibration is performed can be accounted for in a revised calibration of the image.

\footnotetext{
${ }^{10}$ In this thesis Image-Pro Plus ${ }^{\circledR}$ was used

"Software programmed using the Interactive Data Language (IDL $\left.{ }^{\circledR}\right)$ was used to calibrate the DXR images, and to perform subsequent topography analysis.
} 


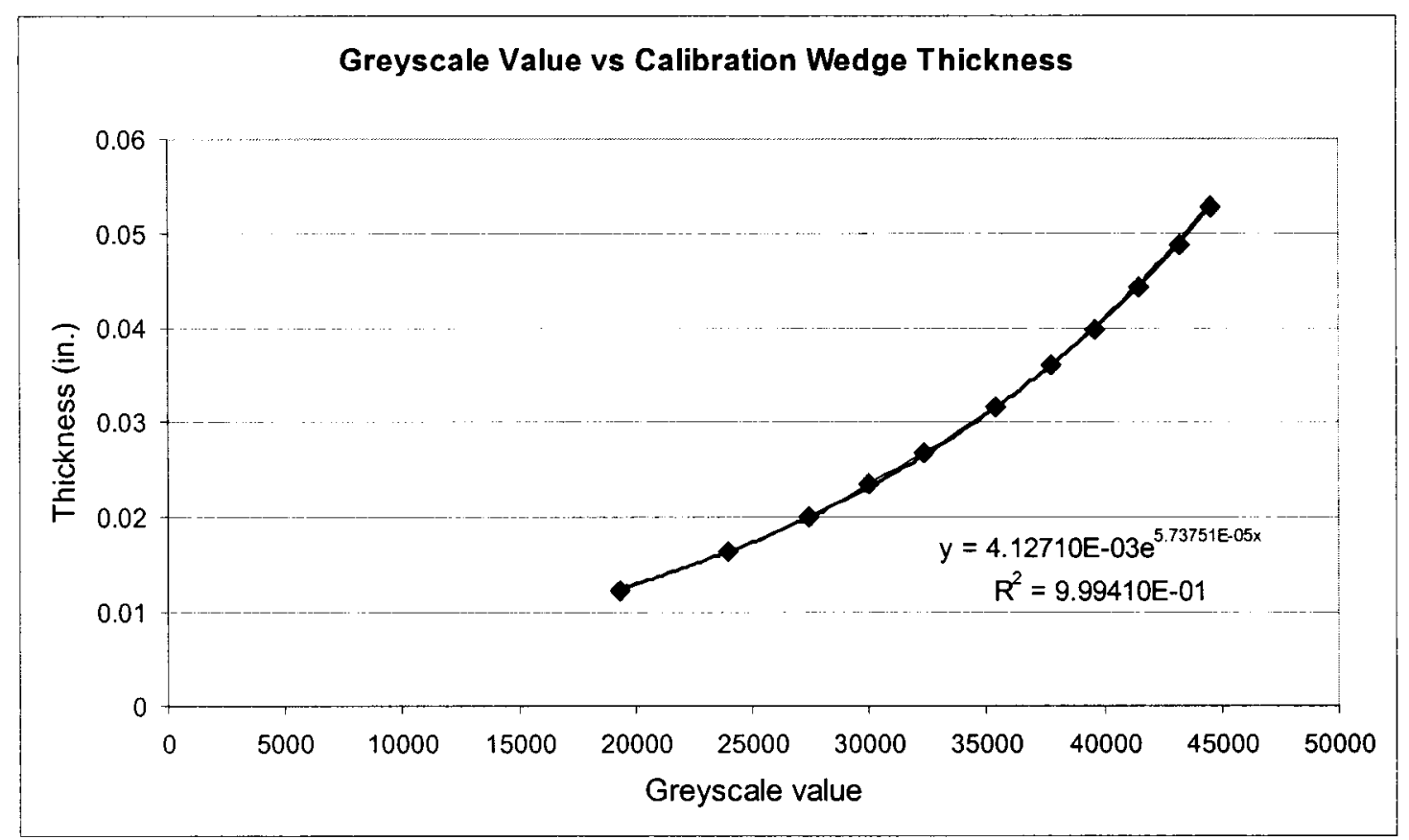

Figure 8-16: Graph of greyscale value vs. calibration wedge thickness showing the resulting exponential calibration equation.

Using the thickness calibrated DXR image and knowing the original sheet thickness (0.040 in.), the average thickness loss for each pitch (defined in Figure 8-17) and the overall average sheet thickness loss were determined. The former values were used in calculating the PTL ratio, which is discussed further in Section 8.3.4. By superimposing the average thickness loss for the outer and the inner sheets the total average thickness loss was developed for the intact joint.

The average percent thickness loss per pitch may be determined from the following relationship:

Average Thickness Loss $(\%)=\frac{\text { Original Thickness }- \text { Average Corroded Thickness }}{\text { Original Thickness }} \times 100 \%$ 


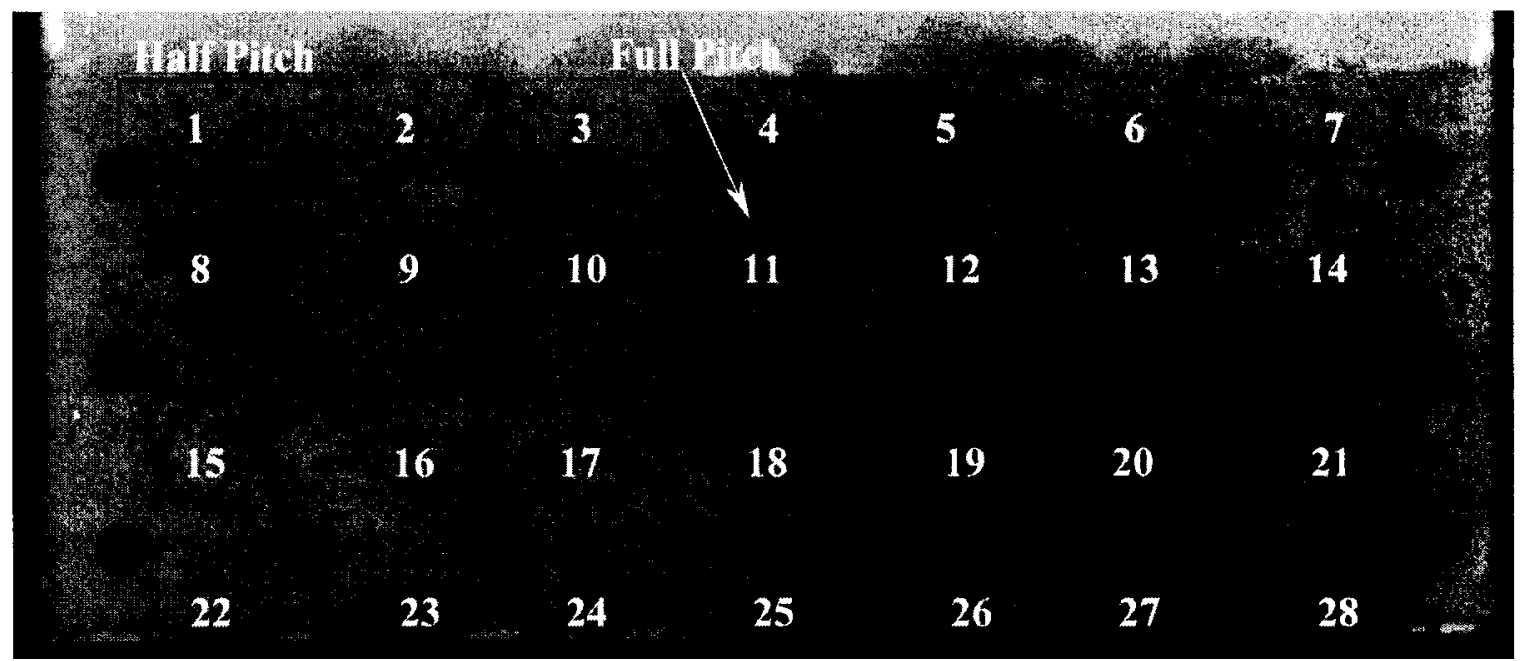

Figure 8-17: Definition and numbering of pitches for DXR, PTL and other analysis.

\subsubsection{Pillowing-to-Thickness-Loss (PTL) Ratio}

One method developed by Krizan (1999) to assess corrosion damage was the PTL ratio (Equation 8-2). It is a transfer function that approximates the average thickness loss of a rivet pitch using the peak corrosion pillowing measurements.

$$
\text { PTL Ratio }=\frac{\text { Peak Pillowing in Pitch }\left(\times 10^{-3} \text { in. }\right)}{\text { Avg. Thickness Loss in Pitch }\left(\times 10^{-3} \text { in. }\right)}
$$

Based on the analysis by Krizan (1999), the PTL ratio for the first five MSD-DOE specimens was $6.0 \pm 0.2$. This value was determined after all moisture had been removed from the specimens. Since the PTL ratio was used to estimate the thickness loss for each MSD panel during corrosion the original PTL ratio was modified to include added pillowing due to the presence of moisture within the joint. The resulting ratio, henceforth referred to as the wet-PTL ratio, was $6.4 \pm 0.4$. The slightly larger value indicates that the moisture within the lap joint increases the magnitude of corrosion pillowing. 


\subsubsection{Scanning Electron Microscopy}

A Hitachi S-570 scanning electron microscope (SEM) was used to analyse the fracture surfaces and the faying surfaces of torn down MSD specimens. For non-corroded specimens, features such as crack nucleation sites and fretting damage were investigated. For pre-corroded specimens crack nucleation sites were observed, and the defects (corrosion pits) at the crack origin were investigated. High magnification images of the faying surface corrosion damage were also obtained to classify corrosion damage.

\subsubsection{White Light Interferometry (Wyko ${ }^{\circledR}$ system)}

The $\mathrm{Wyko}^{\circledR}$ white light interferometry system at the NRC Innovation Centre - Vancouver was used to measure the surface topography of selected regions of corroded lap joints. The system has a vertical resolution of $1.2 \times 10^{-7} \mathrm{in} .(0.003 \mu \mathrm{m})$, and a spatial resolution ranging from $\sim 3.9 \times 10^{-6}-0.007$ in. $(0.1-180 \mu \mathrm{m})$, depending on magnification (Veeco, 2000). The results of this analysis provided accurate measurement of corrosion pit geometry, and were used to verify the geometry determined in the corroded surface topography analysis. 


\subsection{TEST PROGRAM AND RESULTS}

Fatigue testing of four pre-corroded and three non-corroded specimens was completed for this thesis. These specimens were part of a statistically designed corrosion-fatigue test program consisting of 23 specimens. This section summarises the results of these tests. The complete set of test data can be found in the individual specimen reports by Cook et al. (2001).

Prior testing of the first 5 pre-corroded and 5 non-corroded specimens was completed by Krizan (1999). The initial plan for this thesis was to corrode the remaining 9 precorrosion specimens and test the second set of 10 specimens ( 3 non-corroded, and 7 precorroded) based on the revised MSD-CF test plan. However, during the corrosion process difficulties were encountered with the Singleton salt fog chamber (SFC). The production of acidified salt fog in the chamber was reduced significantly during the first ninety days of exposure. Several specimens experienced failures in the one-inch wide region of the side-straps, where the spliced sheets of the specimen are bonded together (refer to Figure 8-7). These delays prompted a reduction in the number of specimens tested to 4 precorroded and 2 non-corroded. The remaining tests would be performed by the IAR.

The specimens were pre-corroded to an average thickness loss of 4-6\%. Krizan (1999) achieved a range of 5-6\% average thickness loss for the first five pre-corroded specimens. The lower bound for the four pre-corroded specimens reported on for this thesis is below that of Krizan (1999). This was because several specimens had the corrosion process halted prematurely due to side-strap disbonding. Section 9.1 briefly describes the repair of the bonded straps to allow fatigue testing of these specimens. A more in-depth discussion of the inspections and analysis performed is provided by Cook (2000). 


\subsection{Bonded Side-Strap Repair}

The bond failure was first identified on specimen MSD511-043 tested by Krizan (1999). The fatigue test was stopped prematurely as the left side-strap fractured after 189074 cycles. Preliminary investigation into the cause of the failure, indicates that a fatigue crack initiated at the epoxy bead located where the joint sheet butts with the bonded strap (denoted as "GAP" in Figure 8-7). At this location, when the joint is completely disbonded, which was the case for MSD511-043, the eccentricity of the load transfer induces large bending stresses in the single 0.040 -inch thick member adjacent to the epoxy bead. This increases the inner surface stresses significantly in this region.

Joint disbonding also increases the compliance of the joint. This may increase the load transfer experienced by rivets adjacent to the strap, causing premature and unwanted fatigue cracking in these locations. Some evidence of this was provided when a large crack appeared between rivets 1 and 2 on specimen MSD511-043 less than 2000 cycles before final failure of the strap.

The need for some form of repair to the bonded joint beneath the side-straps became apparent when disbonds in this region were visually detected in specimens MSD511-054, and -050 . The repair design is shown in Appendix A (Figure A-1). Five hi-lok ${ }^{\mathrm{TM}}$ fasteners were used per side-strap to provide load transfer.

\subsection{Pre-Corrosion Results}

It is believed that the prolonged exposure period had a pronounced effect on the time required to reach the desired level of corrosion. A summary of the exposure times for all pre-corroded DOE specimens (including those prepared by Krizan (1999)) is presented in Table 9-1.

It is believed that the longer the specimens remain in the corrosion chamber the more likely they are to experience corrosion in the straps, and subsequent disbonding of the joint. Krizan (1999) recorded one confirmed case, and one other instance was reported by 
Wakeman (1996). Side-strap corrosion and disbonding were detected in five of the nine pre-corroded specimens for the current research. Referring to Table 9-1, the nine precorroded specimens required, on average, $60 \%$ longer exposure times to achieve the same level of corrosion as compared to the five specimens corroded by Krizan (1999). It is likely that the difficulties experienced with the salt fog chamber led to longer exposure times, and more corrosive attack of the bonded joint.

Table 9-1: Length of pre-corrosion process (highlighted specimens have been tested and reported on for this thesis).

\begin{tabular}{|c|c|c|c|}
\hline $\begin{array}{c}\text { Specimen } \\
\text { Number }\end{array}$ & $\begin{array}{c}\text { Time in SFC } \\
\text { (Days) }\end{array}$ & $\begin{array}{c}\text { Total length of pre- } \\
\text { corrosion process } \\
\text { (days) }\end{array}$ & $\begin{array}{c}\text { Portion of pre- } \\
\text { corrosion spent in } \\
\text { SFC } \\
\text { (Days) }\end{array}$ \\
\hline Krizan (1999) & & & $63.1 \%$ \\
\hline MSD511-034 & 148.34 & 234.98 & $63.1 \%$ \\
MSD511-043 & 148.34 & 234.98 & $84.3 \%$ \\
MSD511-045 & 198.14 & 234.98 & $71.1 \%$ \\
MSD511-047 & 146.47 & 205.98 & $78.3 \%$ \\
MSD511-058 & 175.32 & 223.94 & $56.37 \%$ \\
Cook (2001) & & & $97.55 \%$ \\
\hline MSD511-035 & 276.80 & 491.09 & $97.22 \%$ \\
MSD511-037 & 291.50 & 298.83 & $96.79 \%$ \\
MSD511-044 & 290.54 & 298.83 & $95.91 \%$ \\
MSD511-049 & 255.33 & 263.80 & $97.20 \%$ \\
\hline MSD511-050 & 286.62 & 298.83 & $99.87 \%$ \\
MSD511-054 & 246.66 & 253.77 & $97.25 \%$ \\
MSD511-056 & 180.51 & 180.75 & $96.48 \%$ \\
\hline MSD511-057 & 253.83 & 261.00 & \\
MSD511-059 & 271.00 & 280.88 & \\
\hline
\end{tabular}

Micrometer measurements were taken regularly during the corrosion process to document the pillowing development (Figure 9-1) and provide thickness loss estimates via the PTL ratio. 


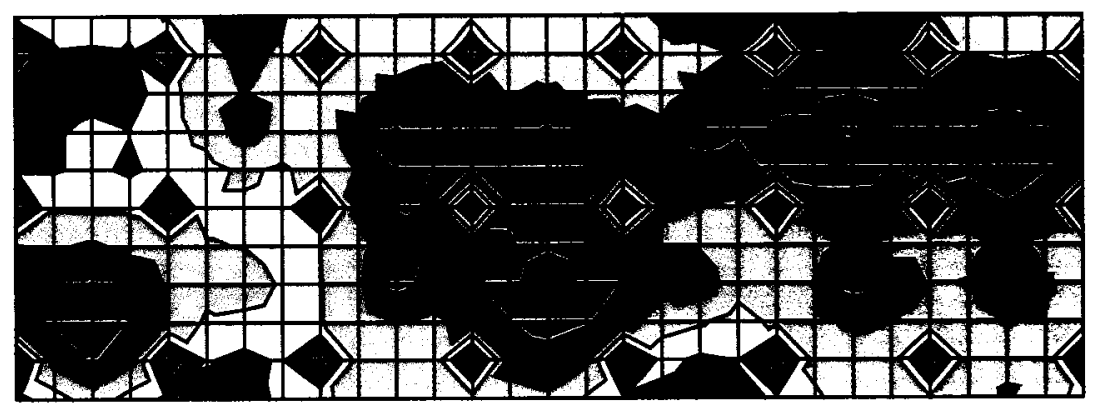

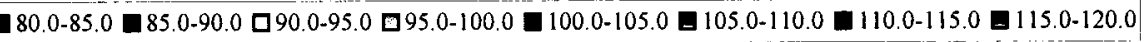

Splice Thickness (inch/1000)

Figure 9-1: Micrometer measurements of corrosion pillowing for specimen \#037 after pre-corrosion with the paint removed. Oriented as on an aircraft, countersunk sheet facing out, outer lip of joint facing down.

\subsubsection{Corrosion Characterisation}

The general appearance of the corrosion damage is similar to that experienced in naturally corroded aircraft joints. The development and composition of the corrosion product resembled that of a corroded lap joint from a retired Boeing 727 (Eastaugh et al., 1998). The observations made after testing and disassembling the corroded specimens were as follows:

1. The majority of corrosion product accumulated near the centre of the rivet pitches, which corresponds to the locations of highest pillowing

2. The location of corrosive attack appeared random in nature

3. Corrosion damage on the outer sheet was generally mirrored on the inner sheet

4. Less severe corrosion damage was observed around the rivet holes

5. Specimens 054, and 049 had large regions with no apparent corrosive attack (Figure 9-2) 


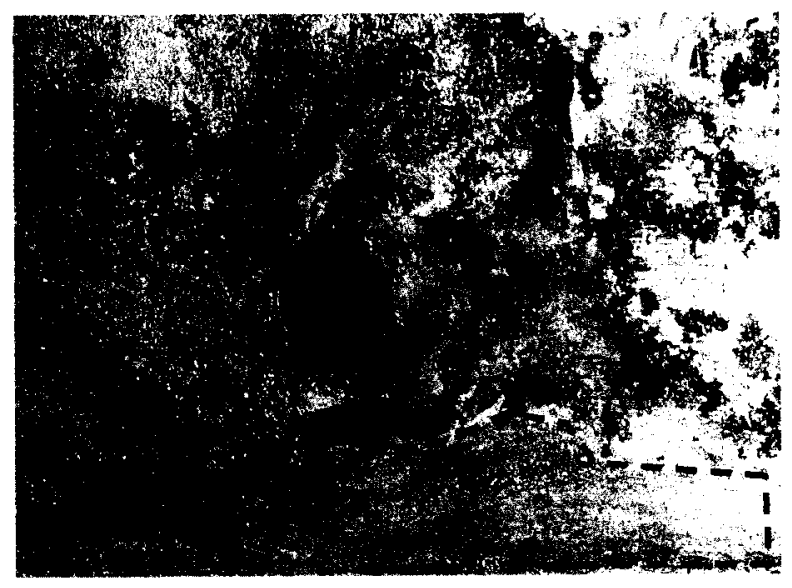

Figure 9-2: Region of light corrosion (Specimen 054 outer sheet, corrosion product removed). Dashed regions show intact clad layer with little pitting corrosion.

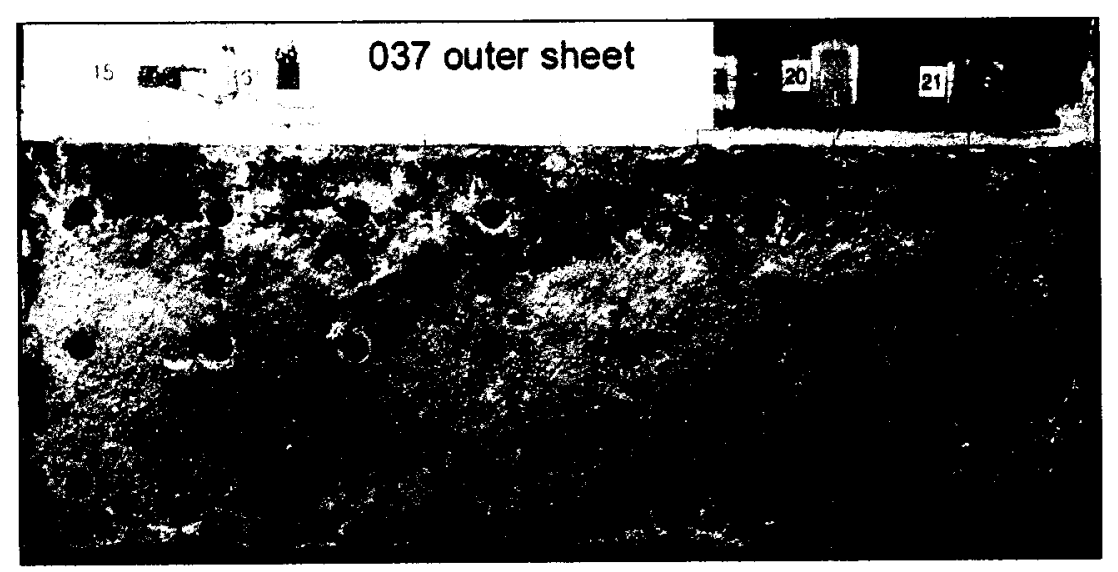

(a)

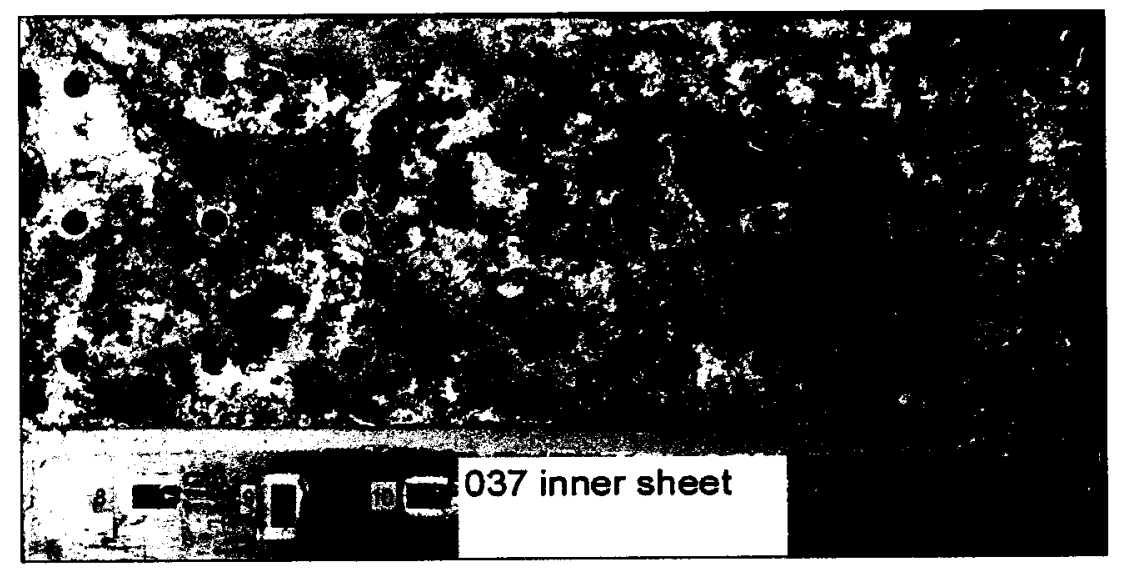

(b)

Figure 9-3: Photograph of specimen 037 faying surfaces after corrosion, with corrosion product intact, (a) outer sheet (b) inner sheet. 


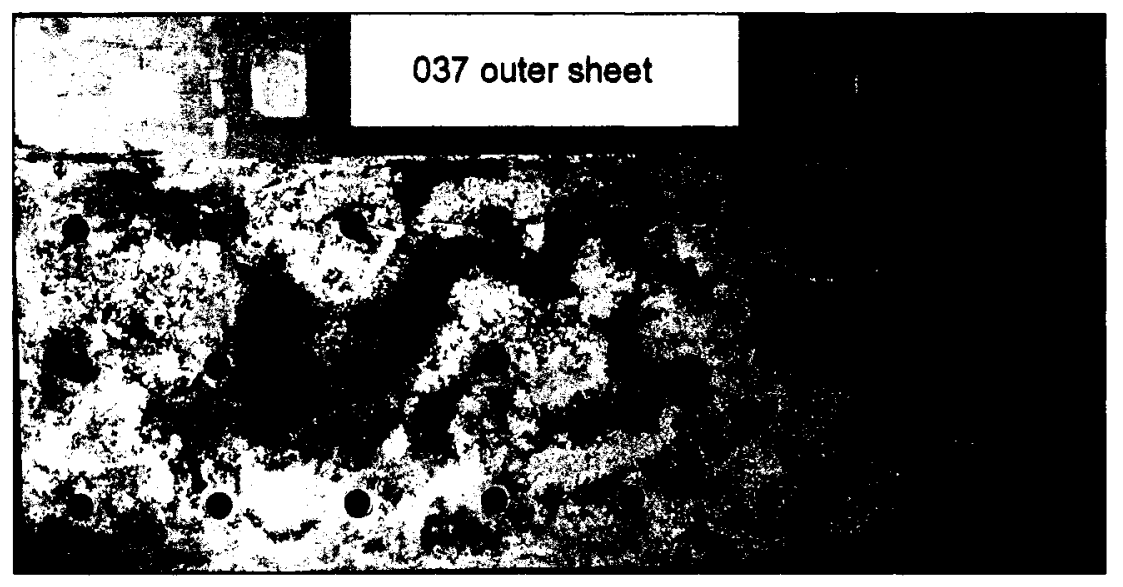

(a)

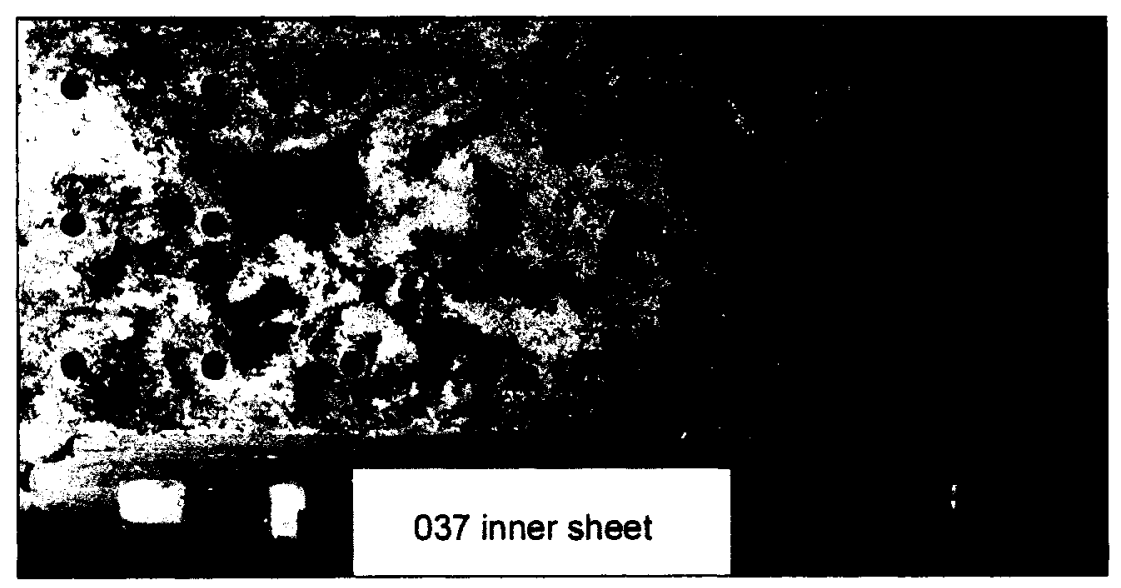

(b)

Figure 9-4: Photograph of specimen 037 faying surfaces after corrosion, with corrosion product removed, (a) outer sheet (b) inner sheet.

Microscopic investigation of the corroded surfaces shows the various stages of corrosive attack in joints. The corrosion first attacks the cladding in the form of generalised pitting attack, which dissolves the cladding layer, producing a scalloped pattern on the surface (Figure 9-5 (a)). Once the clad layer is breached, localised pitting occurs in the core metal (Figure 9-5 (c)). As pit colonies form and pits coalesce, the surface becomes smoother. Bellinger et al. (2000) have observed this on naturally corroded aircraft joints. It is believed that corrosion pits coalesce as a result of intergranular corrosion, resulting in a smoother surface and a thinner section. Further evidence of this phenomenon is presented as part of the topography analysis section of this thesis (Section 10.6). 

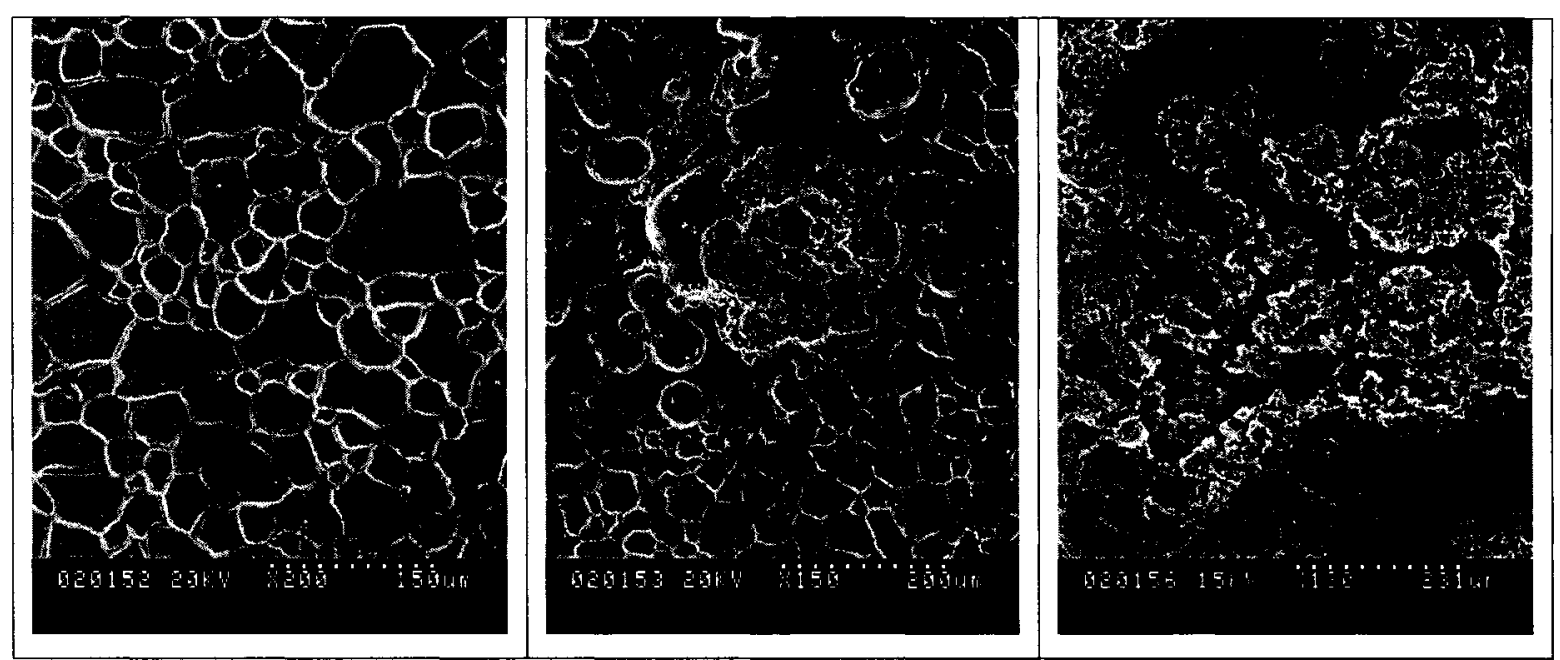

Figure 9-5: Stages of corrosion observed in MSD specimens (a) general attack of cladding (scalloped appearance) (b) transition from general to pitting corrosion of core metal (c) corrosion pitting in core metal.

\subsubsection{Thickness Loss}

The average thickness loss for each MSD specimen was determined using calibrated DXR data (Table 9-2). The DXR images for each specimen can be found in Appendix B, showing the corrosion damage in each sheet as well as for the both sheets combined.

Table 9-2: Summary of mean thickness loss of pre-corroded specimens, including MSD-DOE specimens tested by Krizan (1999). Note: Highlighted specimens were tested for this thesis.

\begin{tabular}{|c|c|c|c|}
\hline Specimen Number & Outer Sheet & Inner Sheet & Combined Shcets \\
\hline MSD511-034 & $7.7 \%$ & $4.7 \%$ & $6.2 \%$ \\
\hline MSD511-043 & $6.4 \%$ & $5.1 \%$ & $5.7 \%$ \\
\hline MSD511-045 & $5.8 \%$ & $6.3 \%$ & $6.0 \%$ \\
\hline MSD511-047 & $6.3 \%$ & $4.0 \%$ & $5.1 \%$ \\
\hline MSD511-058 & $7.0 \%$ & $5.1 \%$ & $6.0 \%$ \\
\hline MSD511-037 & $5.2 \%$ & $6.6 \%$ & $5.9 \%$ \\
\hline MSD511-049 & $5.0 \%$ & $4.5 \%$ & $4.7 \%$ \\
\hline MSD511-050 & $5.1 \%$ & $5.9 \%$ & $5.5 \%$ \\
\hline MSD511-054 & $3.6 \%$ & $4.8 \%$ & $4.2 \%$ \\
\hline
\end{tabular}


The mean thickness loss of both sheets, for the highlighted specimens, ranged from $4.2 \%$ to $5.9 \%$. It is interesting to note that for 3 of the 4 specimens tested for this thesis the thickness loss on the inner sheet was greater than the outer sheet. This is contrary to the findings of Krizan (1999). However, when all pre-corroded specimens are taken into account five of the nine have higher average corrosion levels on the outer sheet.

\subsection{Corrosion Metrics}

\subsubsection{Pillowing-to-Thickness Loss (PTL) Ratio}

The PTL ratio developed by Krizan (1999) has been modified. The original PTL ratio was updated, including the additional 4 corroded specimens tested in this thesis. The average PTL ratios for each pitch are presented graphically in Figure 9-6. It is possible to observe the higher variability in the outer pitches compared to the centre pitches. The outer two columns and the outer rows of pillowing measurements were not used to determine the PTL ratio of $5.9 \pm 0.5$.

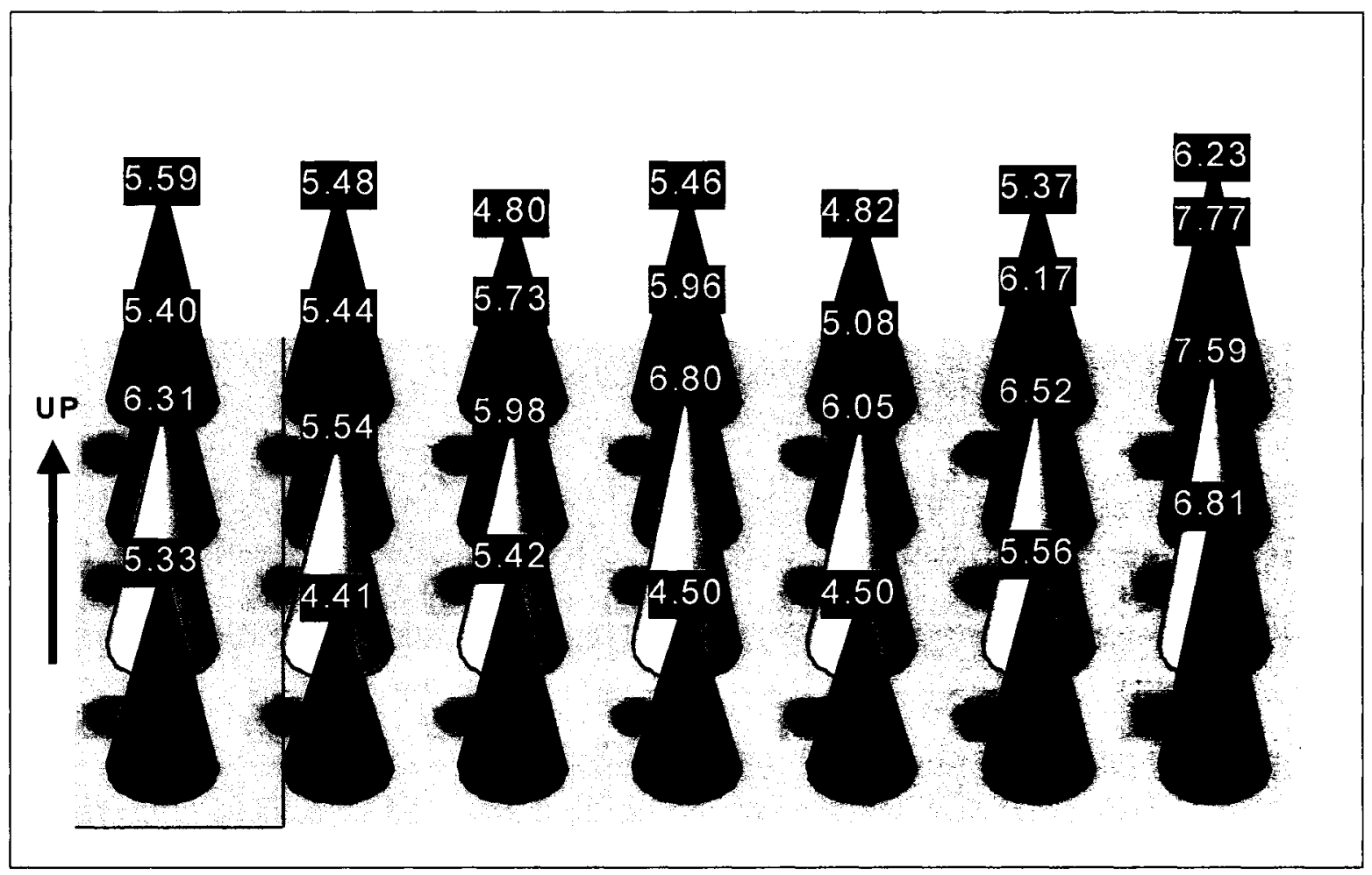

Figure 9-6: Mean PTL ratios for each pitch for 9 pre-corroded MSD specimens. 
As well, the influence of moisture on corrosion pillowing was used to modify the original PTL ratio, producing the wet-PTL ratio. The caliper measurements at the end of the precorrosion treatment, prior to specimen drying, were used in conjunction with the DXR thickness loss measurements. Again the outer columns and rows were not included in the analysis. Using the results from all MSD-DOE specimens to date, the wet-PTL ratio is $6.4 \pm 0.4$.

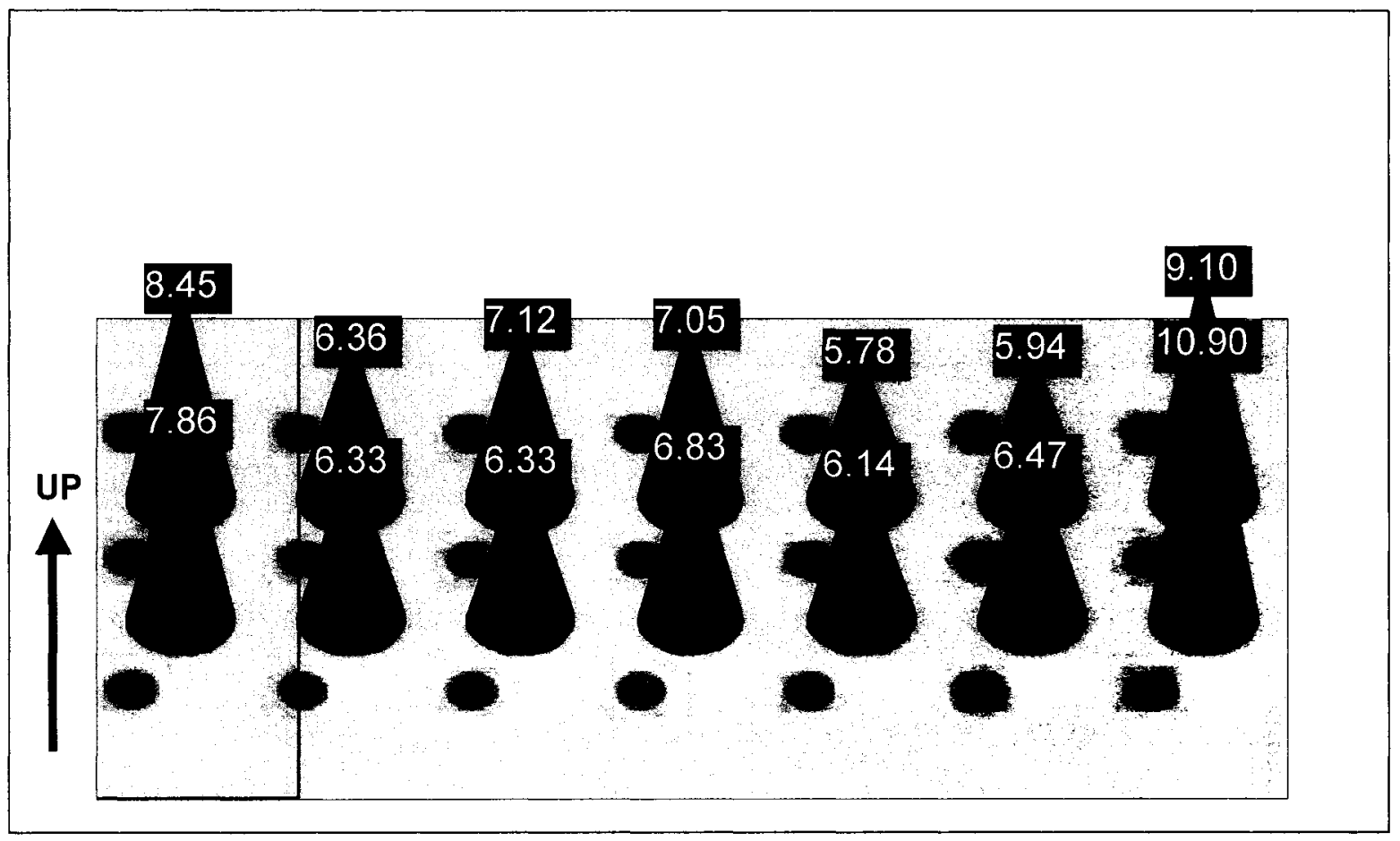

Figure 9-7: Mean wet-PTL ratio for 9 pre-corroded MSD specimens.

Note: the outer columns were not used in the analysis due to the variability of these results with respect to the mean wet-PTL ratio.

This is a useful tool for estimating the average thickness loss in a joint under laboratory conditions. However, in its present form it would be impractical for an operational situation due to the need to access both sides of the joint simultaneously. Until such time that an efficient method is developed to quantify the corrosion pillowing from the outer sheet alone, the PTL ratio could not be widely used to estimate corrosion damage on aircraft. Currently, D-sight of corroded joints provides only qualitative data. Laser scans of large areas of aircraft are difficult with the available equipment. Both of these methods 
show promise for measuring corrosion pillowing of the outer sheet, once the technical difficulties related to each are resolved.

\subsubsection{Conventional and Pulsed Eddy Current}

Two types of eddy current inspection were used to assess the severity of corrosion in the MSD specimens, multiple frequency eddy current, and pulsed eddy current. Both systems employed an automated raster scanning technique in order to cover the entire joint. Scanning was performed from the outer sheet only, as the rivet bucktails inhibited inspection of the inner sheet.

The multiple frequency eddy current scans the specimen with four different frequencies at the same time enabling different depths of penetration. The higher the frequency used the lower the depth of penetration (Table 8-2).

For most cases, the $17 \mathrm{kHz}$ frequency was analysed as it gave indications of corrosion damage only in the outer sheet of the joint. Good correlation, at least qualitatively, was obtained when comparing eddy current images (using $17 \mathrm{kHz}$ ) to DXR images for the outer sheet of specimen 037 (Figure 9-8).

The pulsed eddy current results obtained to date have been purely qualitative. Information on where corrosion exists in the joint was acquired, but not the severity of the damage (Figure 9-8). Signal processing techniques under development by Tektrend, the Department of National Defence and the NRC may enable quantitative thickness measurements in the future.

For both PEC and traditional eddy current the ability to detect corrosion over a region approximately the size of the probe diameter compares quite well to the DXR image in Figure 9-8. These methods would be useful for determining average thickness loss over small regions. However, due to eddy current probe sizes, it is unlikely that these techniques will be able to obtain the high resolutions required for damage tolerance analysis in the near future. 


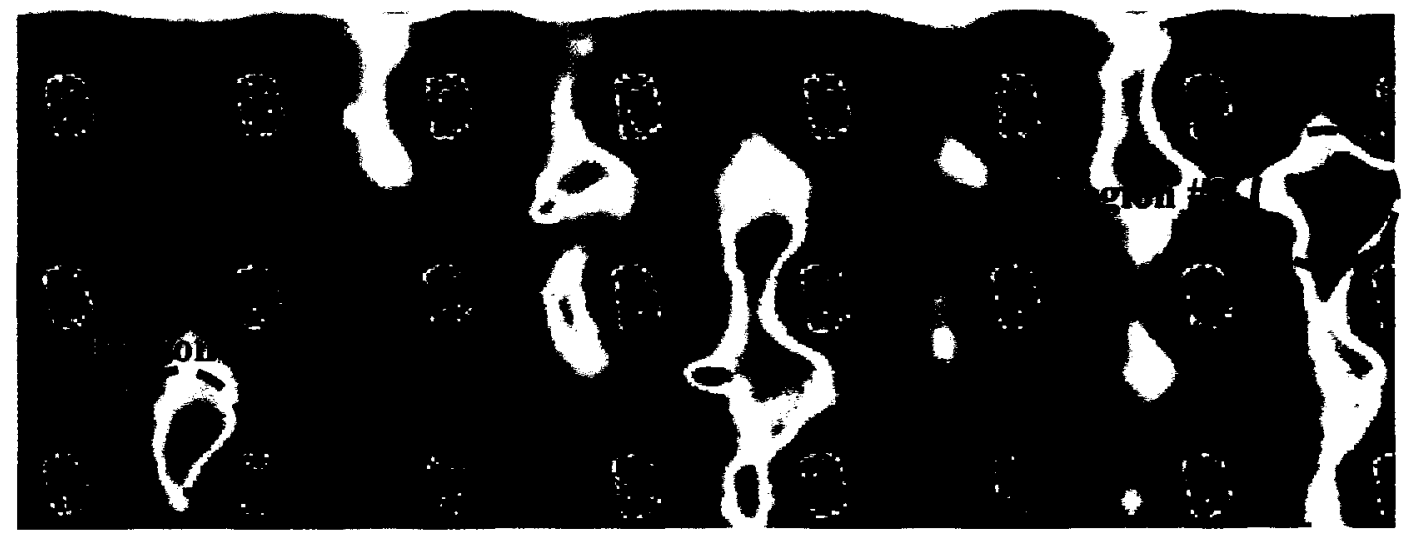

(a)

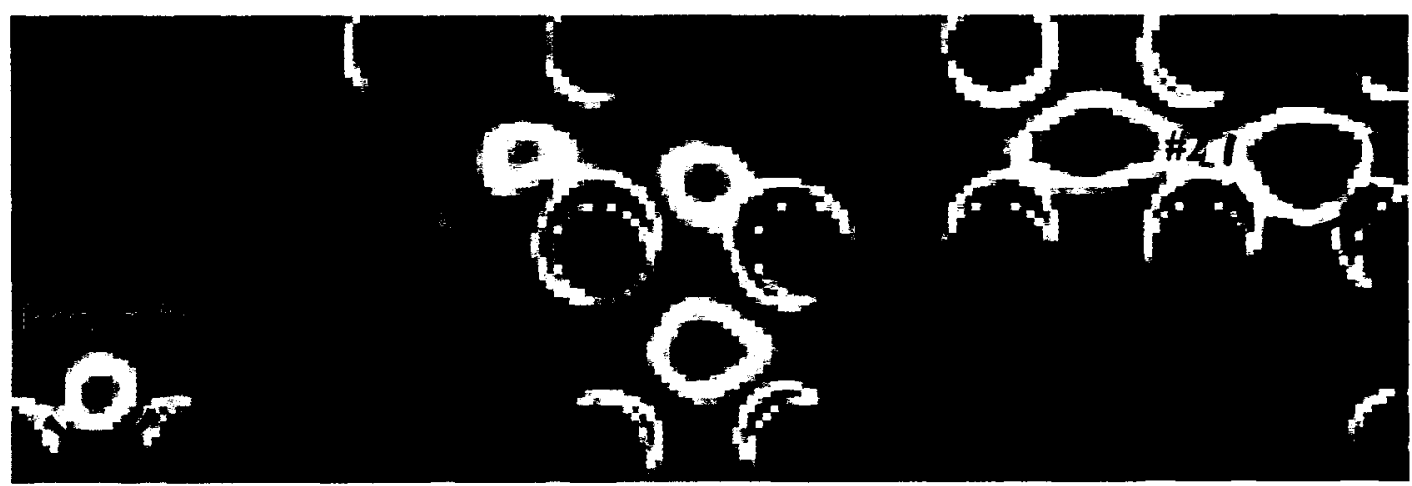

(b)

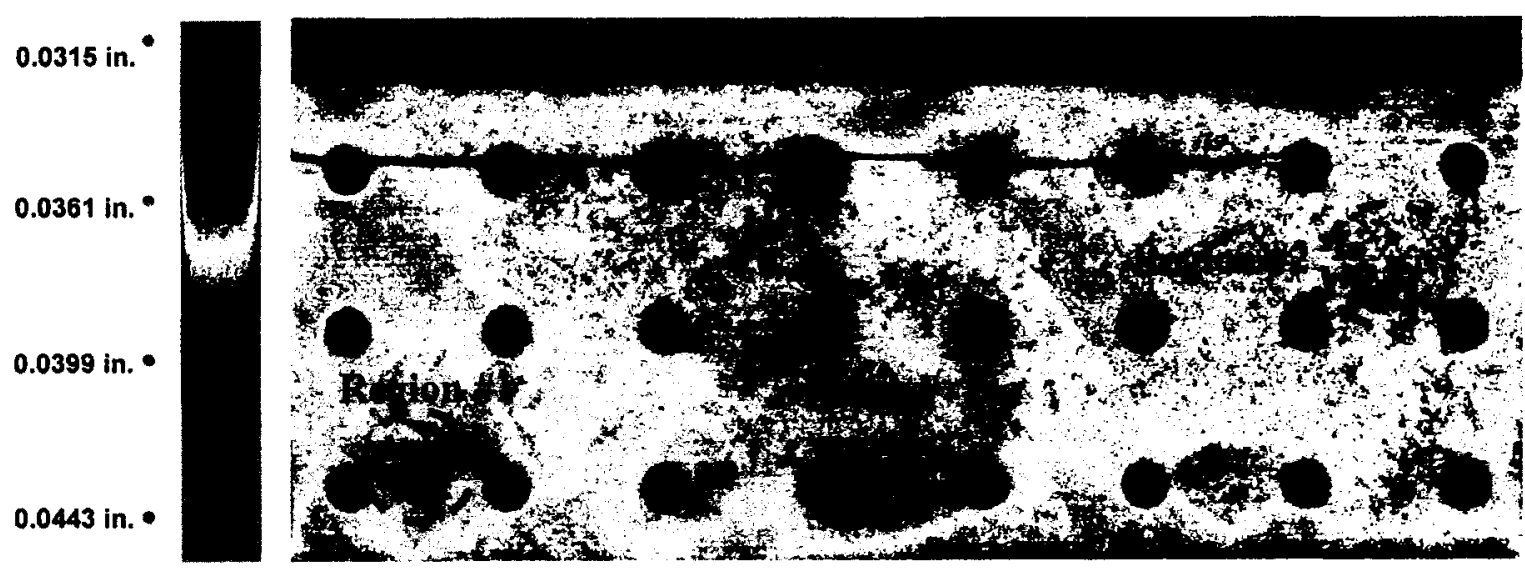

(c)

Figure 9-8: Comparison of eddy current $C$-scans to calibrated DXR image for outer sheet of specimens 037. (a) Eddy current scan, $17 \mathrm{kHz}$, (b) Pulsed eddy current scan, (c) coloured and calibrated DXR image. Dashed lines are an examples of the correlation of regions with severe corrosion. 


\subsection{Fatigue Test Results}

This section presents the fatigue test results for all 17 MSD-DOE specimens tested to date, with particular emphasis on the 7 specimens tested for this thesis (Table 9-3).

Table 9-3: Specimens tested for this thesis.

\begin{tabular}{|c|c|c|}
\hline Specimen Number & Treatment & Description \\
\hline MSD511-041 & Non-corroded & \\
\hline MSD511-042 & Non-corroded & \\
\hline MSD511-048 & Non-corroded & \\
\hline MSD511-037 & Pre-corroded & \\
\hline MSD511-049 & Pre-corroded & Side-strap repair implemented \\
\hline MSD511-050 & Pre-corroded & Side-strap repair implemented \\
\hline MSD511-054 & Pre-corroded & Side-strap repair implemented \\
\hline
\end{tabular}

\subsubsection{Non-Corroded Fatigue Test Results}

The non-corroded tests conducted for this thesis produced similar results to those reported by Krizan (1999). For brevity, the discussion of failure modes for the two noncorroded specimens $^{12}$ are grouped together.

1. Cracks always initiated in the outer sheet of the joint.

2. Multiple micro-cracks often formed and coalesced to form one lead crack from a rivet. This was observed as fracture surfaces with multiple planes.

3. Uniform MSD developed, in which an average of 7 cracks were present in the MSD specimen prior to first link-up (Figure 9-9).

4. Crack growth rates for cracks growing between rivets 3 and 6 ranged from $2 \times 10^{-7}$ (in./cycle) for early visible crack growth to $4 \times 10^{-3}$ (in./cycle) just prior to crack link-up (Figure 9-10).

5. Link-up of crack tips occurred in two ways: the cracks overlapped or the crack tips of two approaching cracks joined (Figure 9-11).

6. In several instances an approaching crack tip grew into the adjacent rivet without visual crack initiation from that rivet (Figure 9-11 (c)).

\footnotetext{
${ }^{12}$ Post-test analysis of specimen 048 was not available in time to be included in this thesis
} 
7. Cracks formed at the central rivets of the upper rivet row, above the centre line of the rivet. An example is shown in Figure 9-13. Visualising the rivet as a clock face, cracks tended to initiate at 10-11 o'clock and 1-2 o'clock for the central rivets. The reasons are that the bending stress is likely higher above the rivet hole and this corresponds to the location of heaviest fretting damage, as a result of rivet tilting. The first visible cracks for specimens 041 , and 042 appeared at rivet 5 , at cycle 320000 and 270000 cycles respectively.

8. Examination of the faying surfaces after tear down revealed that the cracks emanated from regions of heavy fretting (Figure 9-14). Fractographic investigation using SEM confirmed that cracks typically nucleated at surface defects created by fretting. For example, several cracks in specimen 041 are shown to originate from the fretted region adjacent to rivet 5 (Figure 9-15).

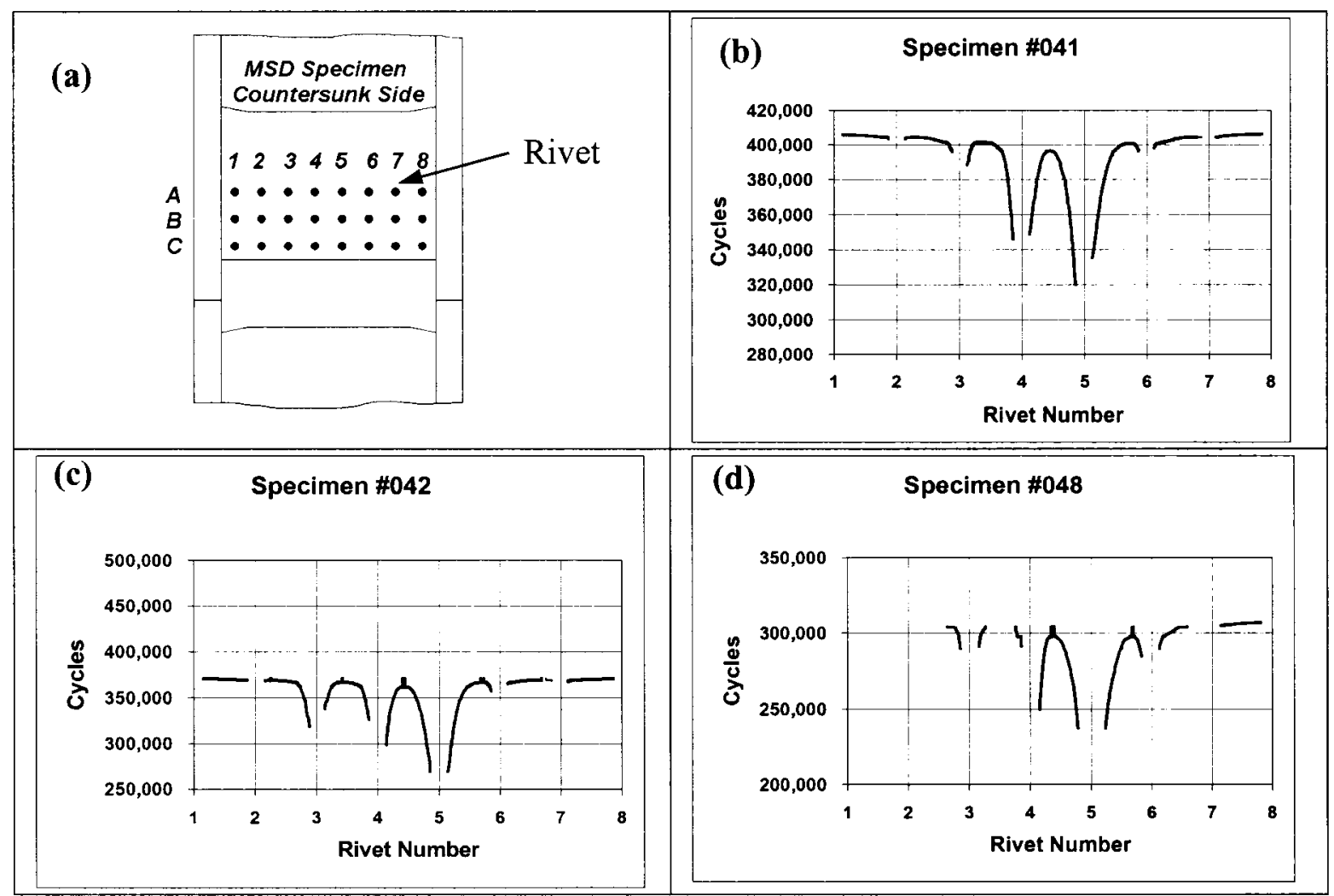

Figure 9-9: Crack growth curves for non-corroded MSD specimens, (a) legend, (b) specimen 041, (c) specimen 042, (d) specimen 048.

Note: These graphs plot longitudinal crack tip position relative to the origin (Section 8.2.2) vs. cycles. The horizontal axis represents the location of the rivets in the critical (upper) row of the joint. 


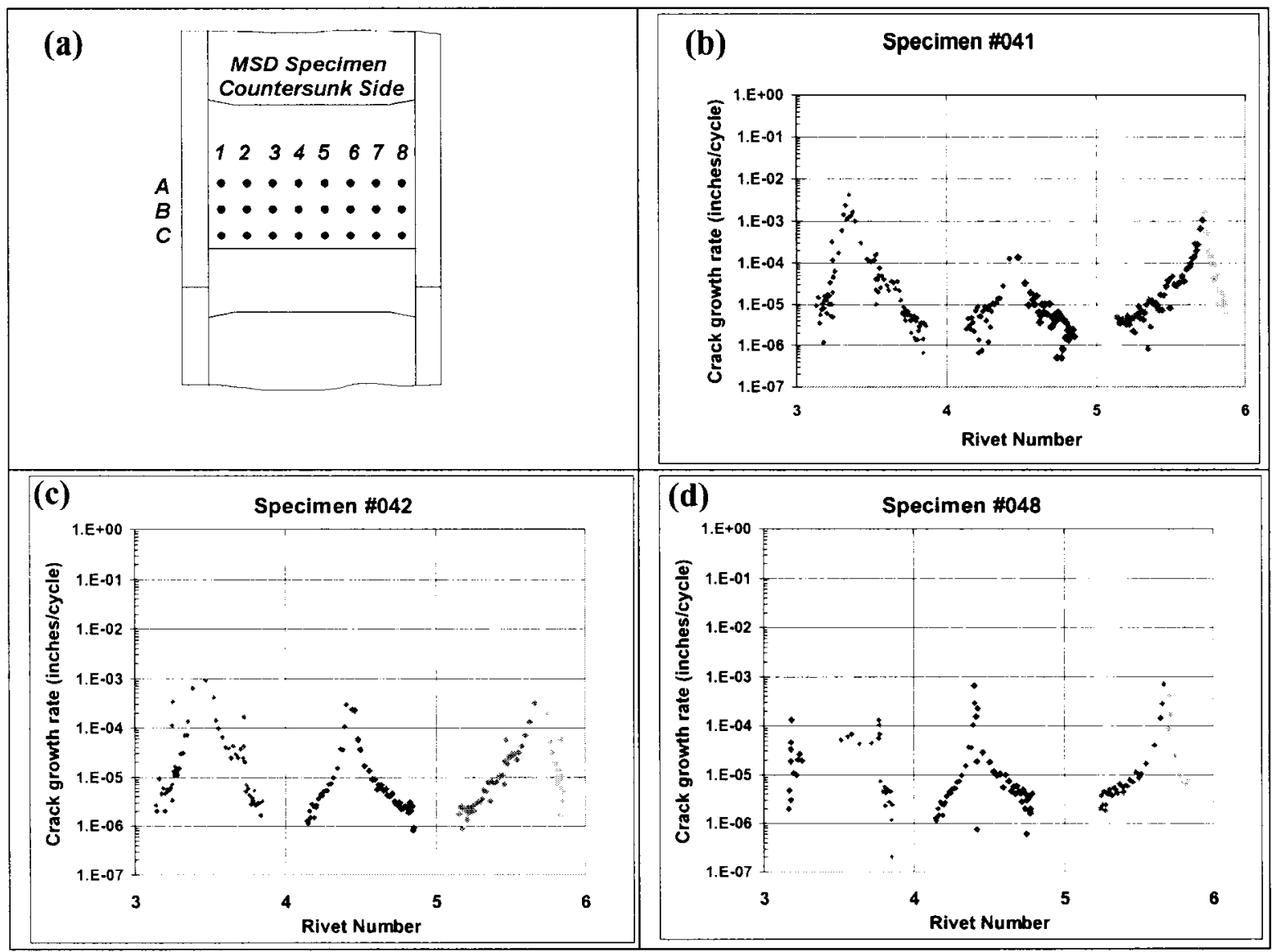

Figure 9-10: Crack growth rates for non-corroded MSD specimens, (a) legend, (b) specimen 041, (c) specimen 042, (d) specimen 048.

Note: These graphs plot crack growth for the central rivets at each inspection during testing. The horizontal axis represents the location of the rivets in the critical (upper) row of the joint. 


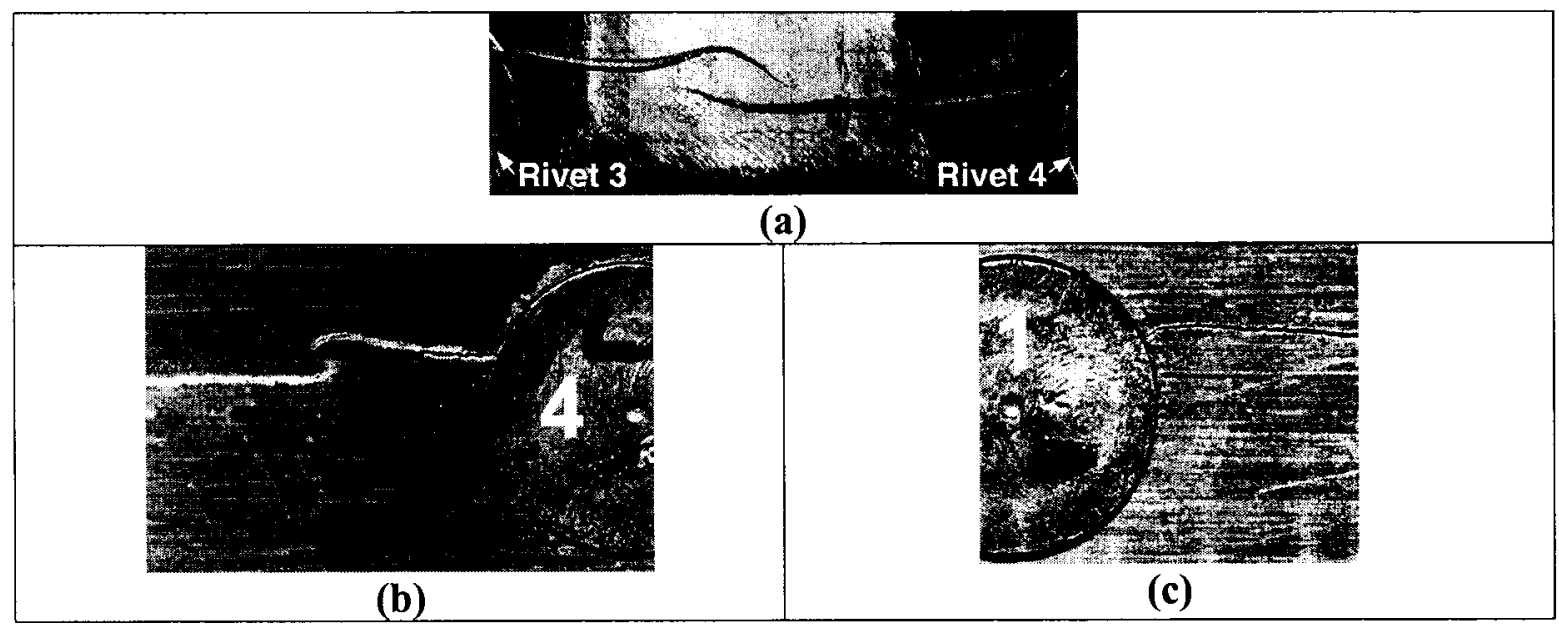

Figure 9-11: Examples of crack link-up. (a) overlapping cracks, (b) joining crack tips, (c) crack growth into rivet hole with no visible crack initiation.

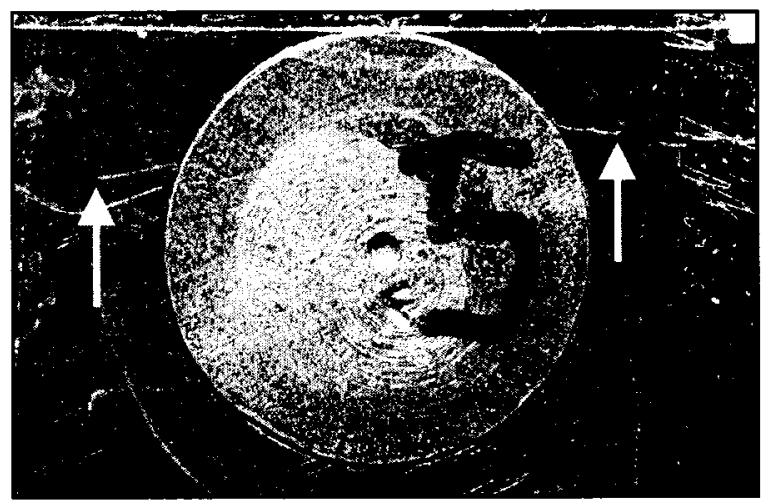

(a)

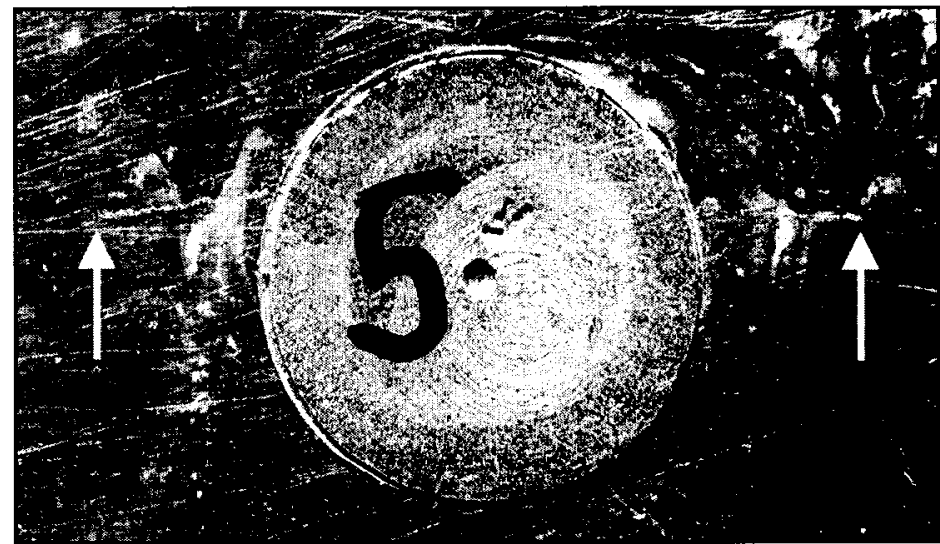

(b)

Figure 9-12: First Visibly detected cracks photographed shortly after detection: (a) specimen 041 both sides of rivet 5 , (b) specimen 042, both sides of rivet 5 (arrows show location of crack tips). 


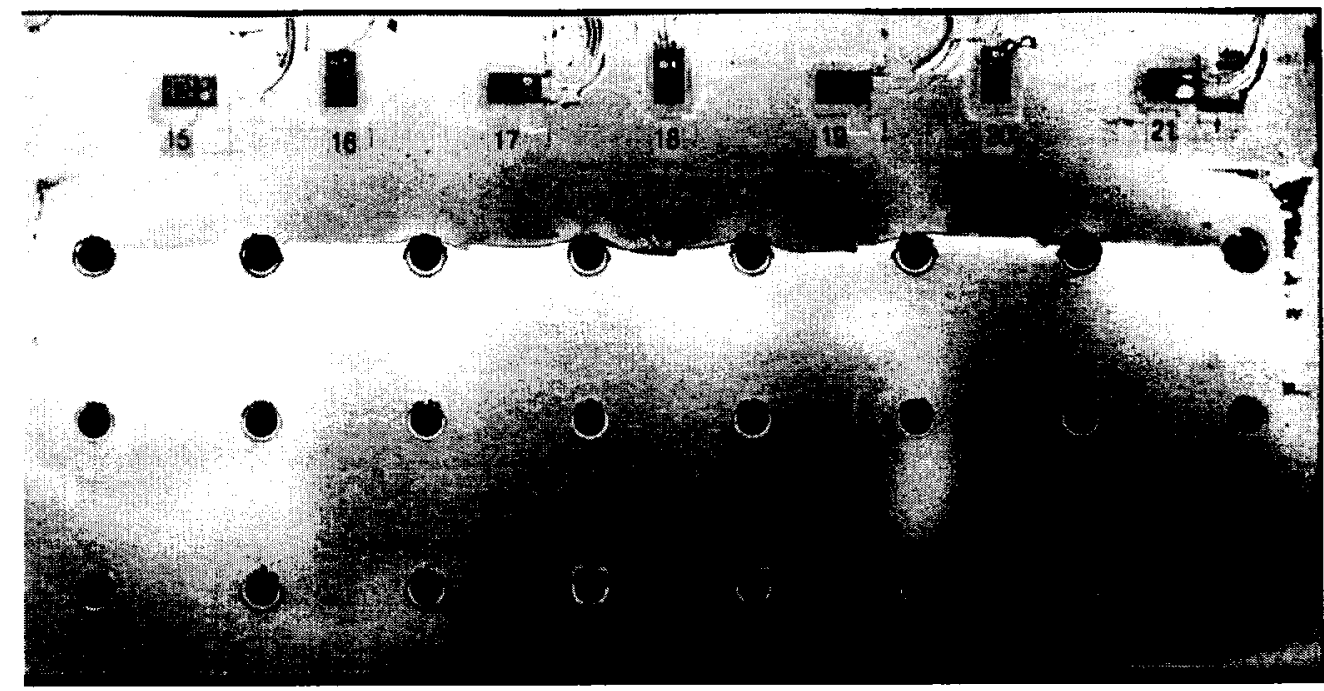

Figure 9-13: Example of final cracking pattern for non-corroded specimen (faying surface of countersunk sheet for specimen 041).

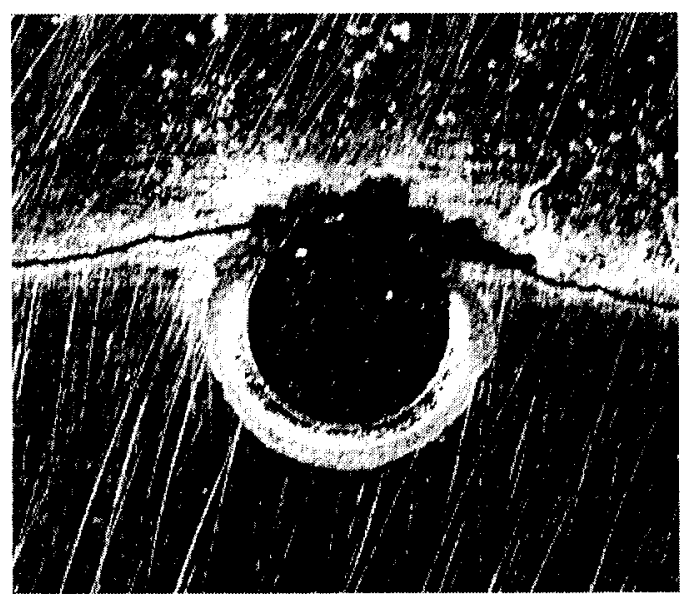

(a)

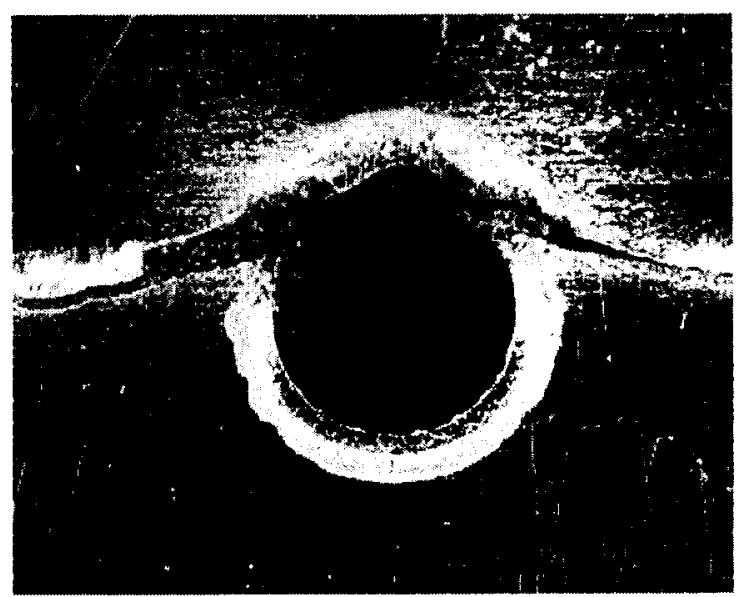

(b)

Figure 9-14: Faying surface photographs showing cracks emanating from fretting regions surrounding the rivet (a) specimen 041 rivet 5, (b) specimen 042 rivet 5. 


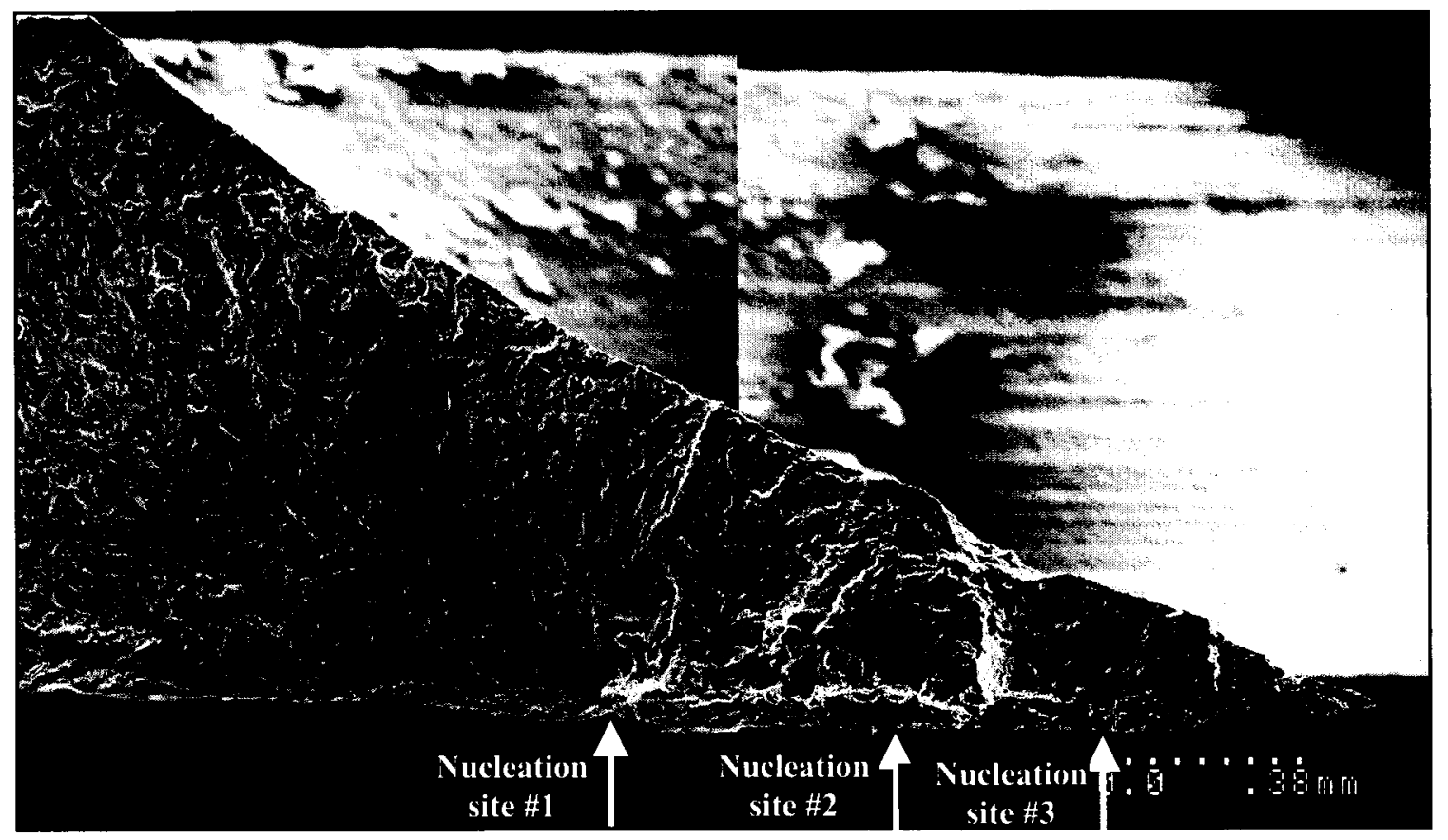

(a)

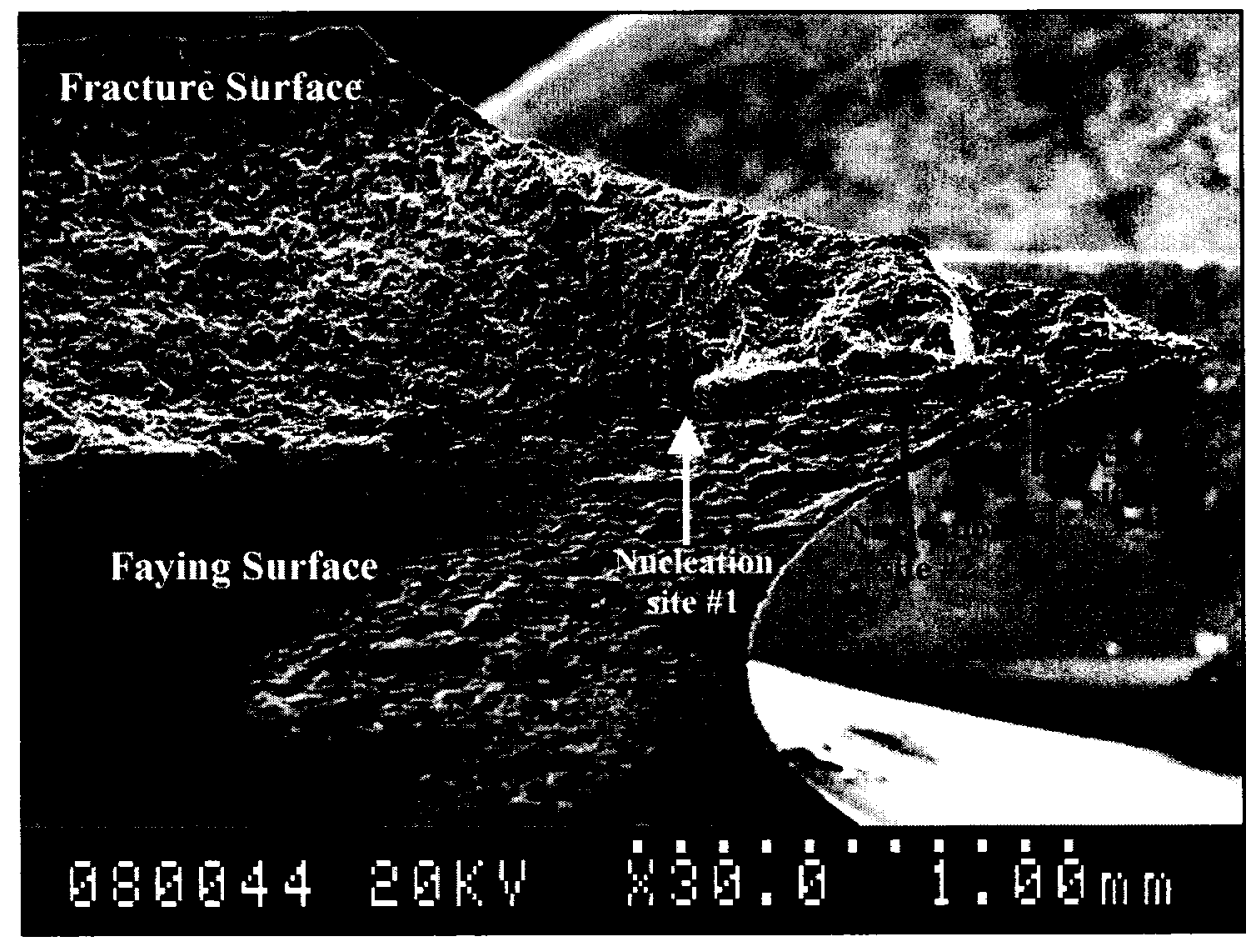

(b)

Figure 9-15: Multiple crack nucleation sites for specimen 041 at the fretted region adjacent to rivet 5 . (a) crack nucleation sites on the fracture surface. (b) tilted fracture surface revealing the fretted region near the rivet hole. 


\subsubsection{Pre-Corrosion Fatigue Test Results}

The crack growth curves for the pre-corroded tests conducted for this thesis are presented in Figure 9-16. The findings of these tests were as follows:

1. Cracks always nucleated in the outer sheet of the joint. Failure modes such as crack nucleation in the inner sheet below the lower row of fasteners or failure of rivets, reported by Krizan (1999) were not observed.

2. Cracks formed in the upper rivet row, above the centre line of the rivets. A typical crack pattern for pre-corroded specimens is shown in Figure 9-4 (a).

3. Specimen 050 had the longest fatigue life to visual crack detection of any specimen (corroded or non-corroded) at 600000 cycles.

4. Crack growth rates for cracks growing between rivets 3 and 6 typically ranged from $2 \times 10^{-7}$ (in./cycle) during early visible crack growth to $1 \times 10^{-3}$ (in./cycle) just prior to crack link-up. There was more variability of the crack growth rates as compared to the non-corroded specimens.

5. Crack link-up occurred in the same fashion as for non-corroded specimens (Figure 9-11).

6. In several instances an approaching crack tip grew into the adjacent rivet without visual crack initiation from that rivet (Figure 9-11).

7. Typically less uniform MSD developed as compared to non-corroded specimens. On average only 5 cracks existed in the specimen prior to first link-up (Figure 9-16).

8. Crack growth rates were comparable to non-corroded specimens, for non-repaired specimens (Figure 9-17).

9. Crack nucleation typically occurred at corrosion pits located at or near rivet holes. In only one instance, specimen 037 , did the crack nucleate outside the rivet countersink at a large site of pitting damage (Figure 9-19). The first cracks in specimen 050 , and 054 did not nucleate at a corrosion pit, but at the knife-edge instead. 


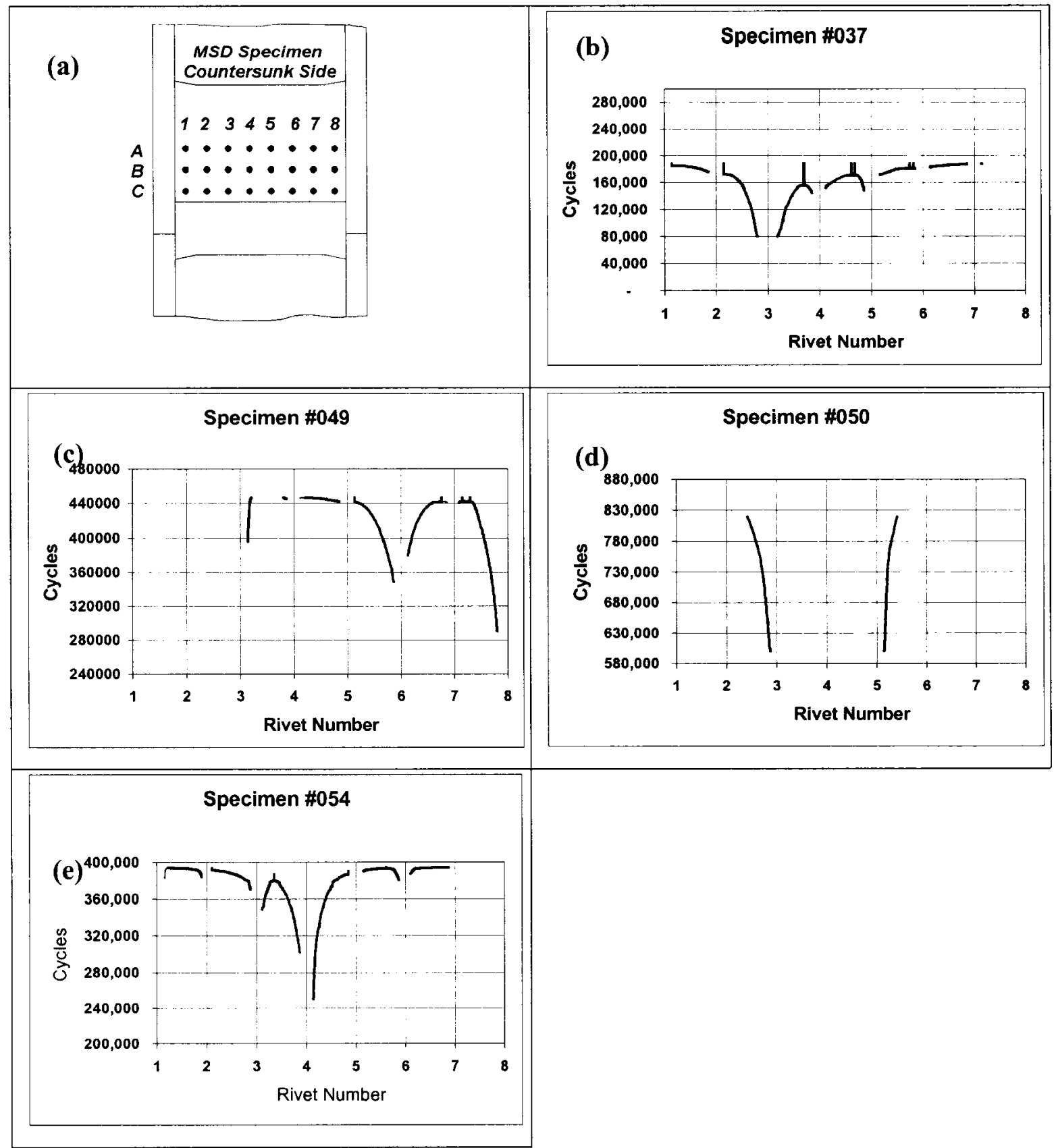

Figure 9-16: Crack growth curves for pre-corroded MSD specimens, (a) legend, (b) specimen 037, (c) specimen 049, (d) specimen 050 and (e) specimen 054.

Note: These graphs plot longitudinal crack tip position relative to the origin (Section 8.2.2) vs. cycles. The horizontal axis represents the location of the rivets in the critical (upper) row of the joint. 


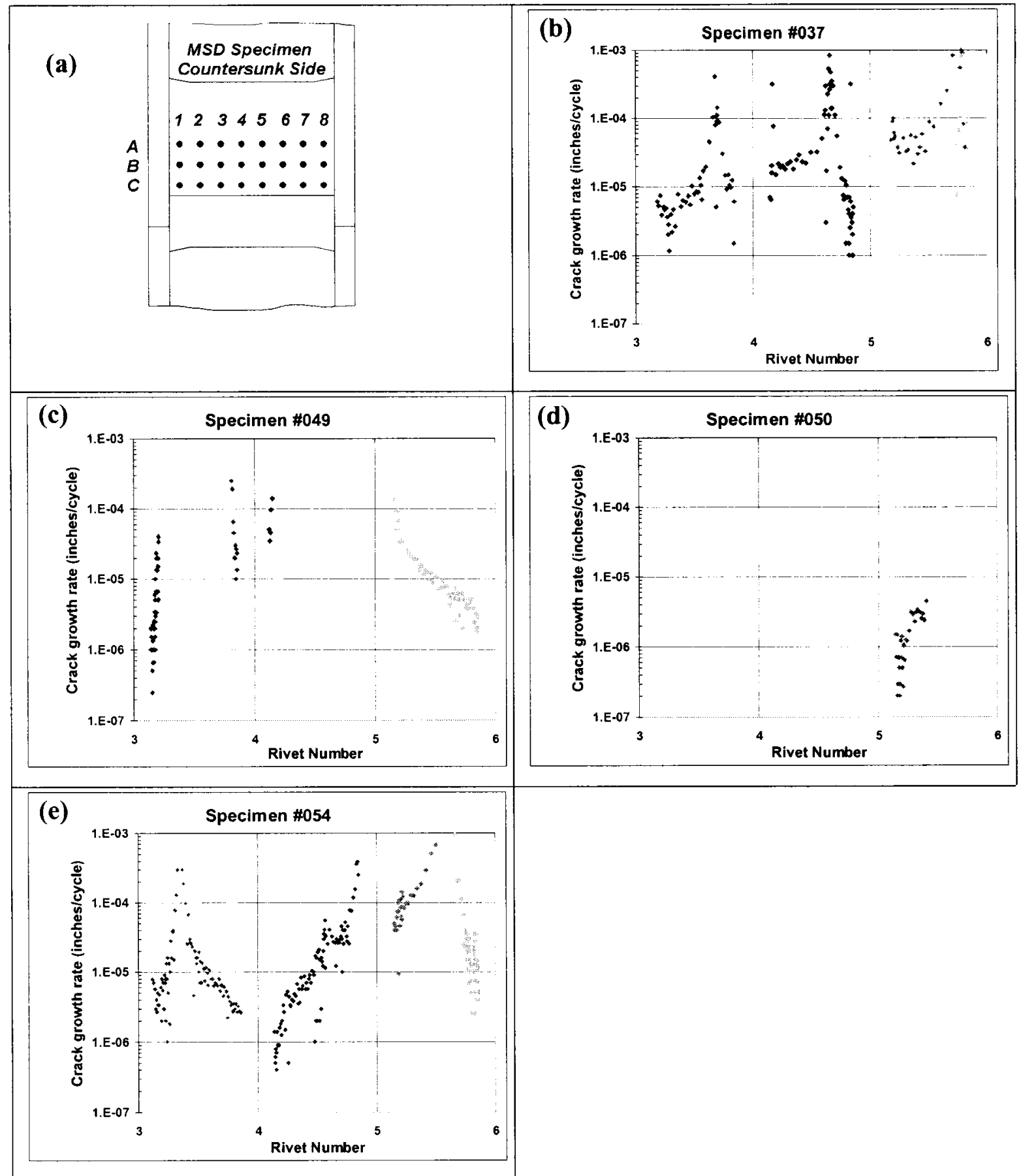

Figure 9-17: Crack growth curves for pre-corroded MSD specimens, (a) legend, (b) specimen 037, (c) specimen 049, (d) specimen 050 and (e) specimen 054.

These graphs plot crack growth at each inspection during testing. The horizontal axis represents the location of the rivets in the critical (upper) row of the joint. 
Since there were variations in modes of failure, each specimen is discussed separately.

\section{Specimen 037:}

The first visible cracks were detected on both side of rivet 3 at 80000 cycles. Two cracks were visible on the left side of rivet 3 . One crack extended from the rivet hole, while the other nucleated away from the rivet (Figure 9-18). These two cracks joined at cycle 153001 and proceeded to grow as the dominant crack in the specimen. Cracks were detected at rivet 4 (cycle 144501 and 152001 left and right side of rivet 4 respectively) and the left side of rivet 5 (cycle 148 501) prior to the first crack link-up.

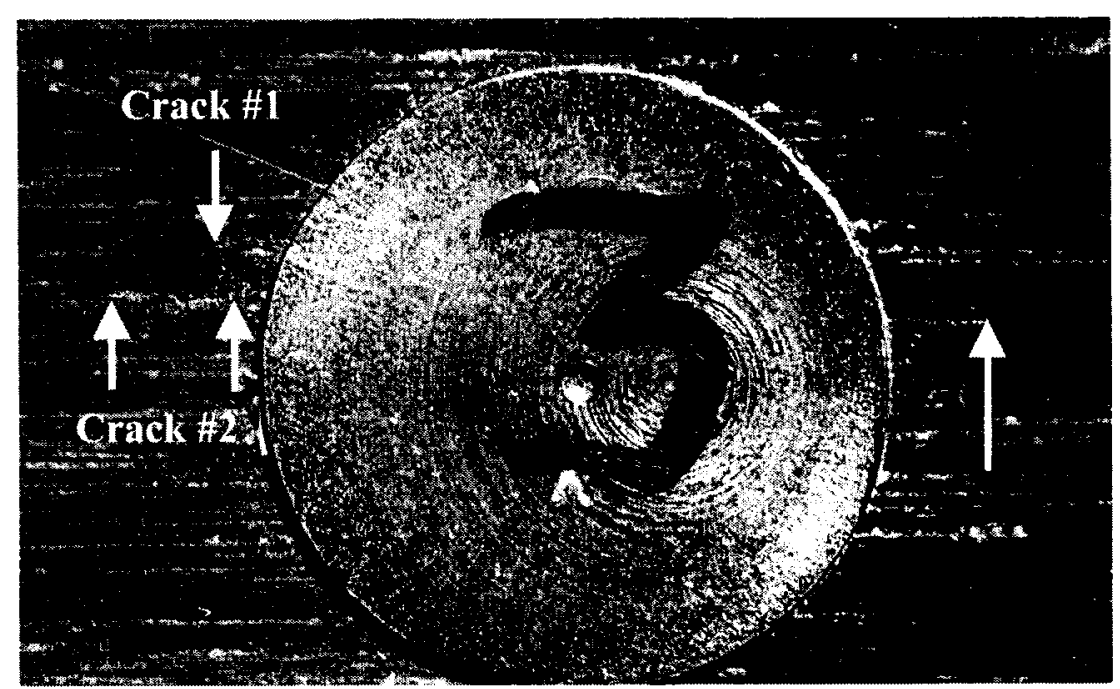

Figure 9-18: Crack detection for specimen 037 (photograph taken of rivet 3 at 81000 cycles).

\section{Note: Arrows indicate locations of crack tips.}

Post-test analysis revealed that the first crack nucleated at a large corrosion site just beyond the rivet countersink on the left side of rivet 3. Photographic evidence is presented in Figure 9-19 showing the pitting damage near the rivet hole on the faying surface. SEM analysis confirmed the nucleation location at corrosion pitting damage. Figure 9-20 shows the nucleation site for crack \#1 (Figure 9-18). The nucleation site for crack \#2 is not visible due to the overlapping of these two cracks. The tilted fracture 
surface indicates that this crack may have nucleated from a surface defect (pit) indicated by the arrow in Figure 9-20.

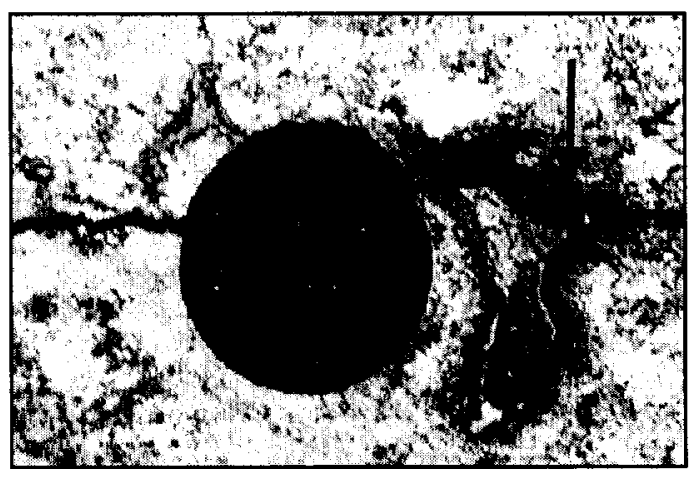

Figure 9-19: Photograph of specimen 037 faying surface showing large elongated corrosion damage region at rivet 3 .

Note: Arrow indicates approximate crack nucleation location.

The dissolution of particle clusters observed in Figure 9-20 was likely the result of overexposure to nitric acid during the chemical cleaning process. Tensile residual stresses on the fracture surface promote attack of these regions by the nitric acid. It is unlikely that this same phenomenon occurred on the faying surface, since no residual stresses are present. 

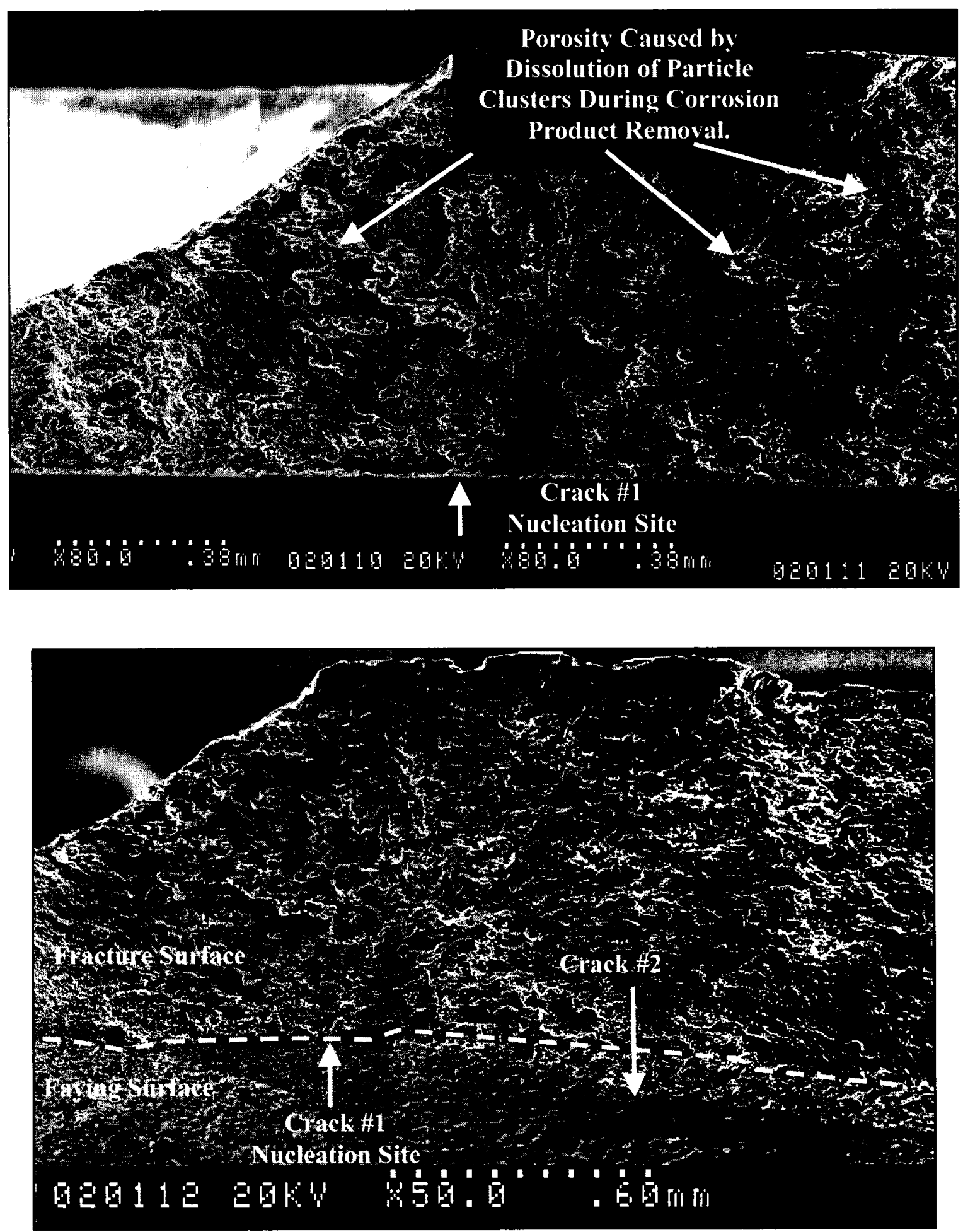

Figure 9-20: Micrograph of crack nucleation site for specimen 037 at a corrosion pit adjacent to rivet 3. (a) Crack nucleation site on the fracture surface marked by the arrow, (b) shows the tilted fracture surface revealing corrosion damage near the rivet hole. 


\section{Specimen 049:}

Cracks were detected on both sides of rivet 8 at cycle 290878 (Figure 9-21). This was a peculiar location for first visual detection to occur, as the stresses tend to be lower closer to the bonded side-straps. Based on Figure 9-16 there was a definite affinity for cracking on the right side of the specimen. This was most likely a result of the disbonded and repaired strap on that side. The effect of the repair will be discussed further in Section 9.4.4.

The lower stress near the straps was evident by the slow crack growth rate for the crack emanating from the right side of rivet 8. It took 155599 cycles for this crack to grow $0.5 \mathrm{in}$. from the rivet to the strap, whereas the cracks in the rest of the specimen had spanned from rivet 4 to rivet 8 . The test was ended at this time to preserve the integrity of the strap.

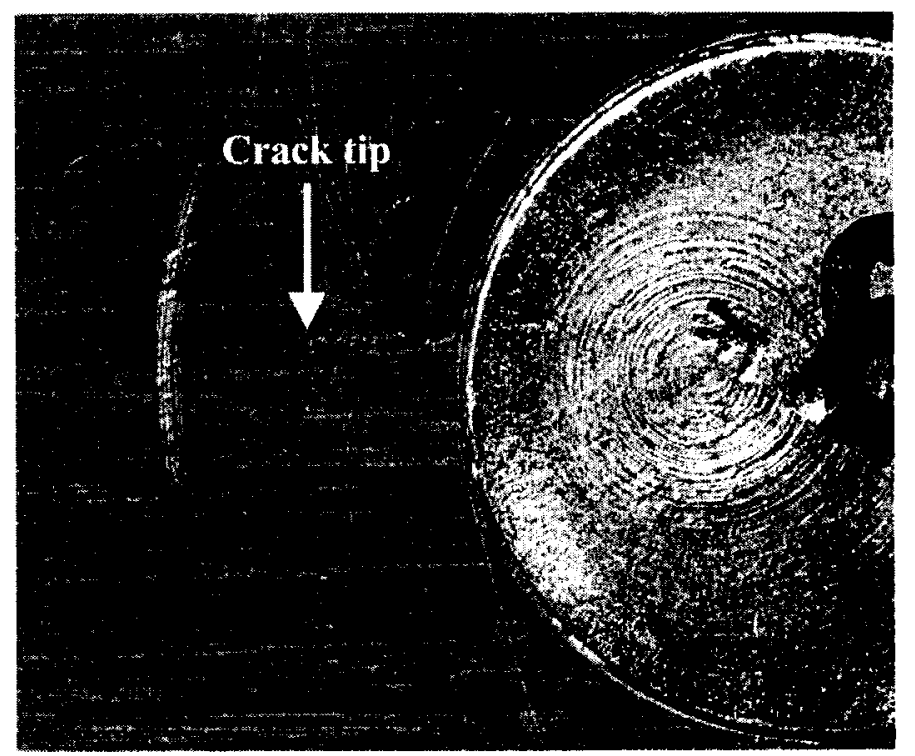

Figure 9-21: Crack detection for specimen 049, left side of rivet 8 (292 378 cycles).

Inspections of the faying surface revealed that several cracks nucleated at corrosion pits near the left side of rivet 8 . 


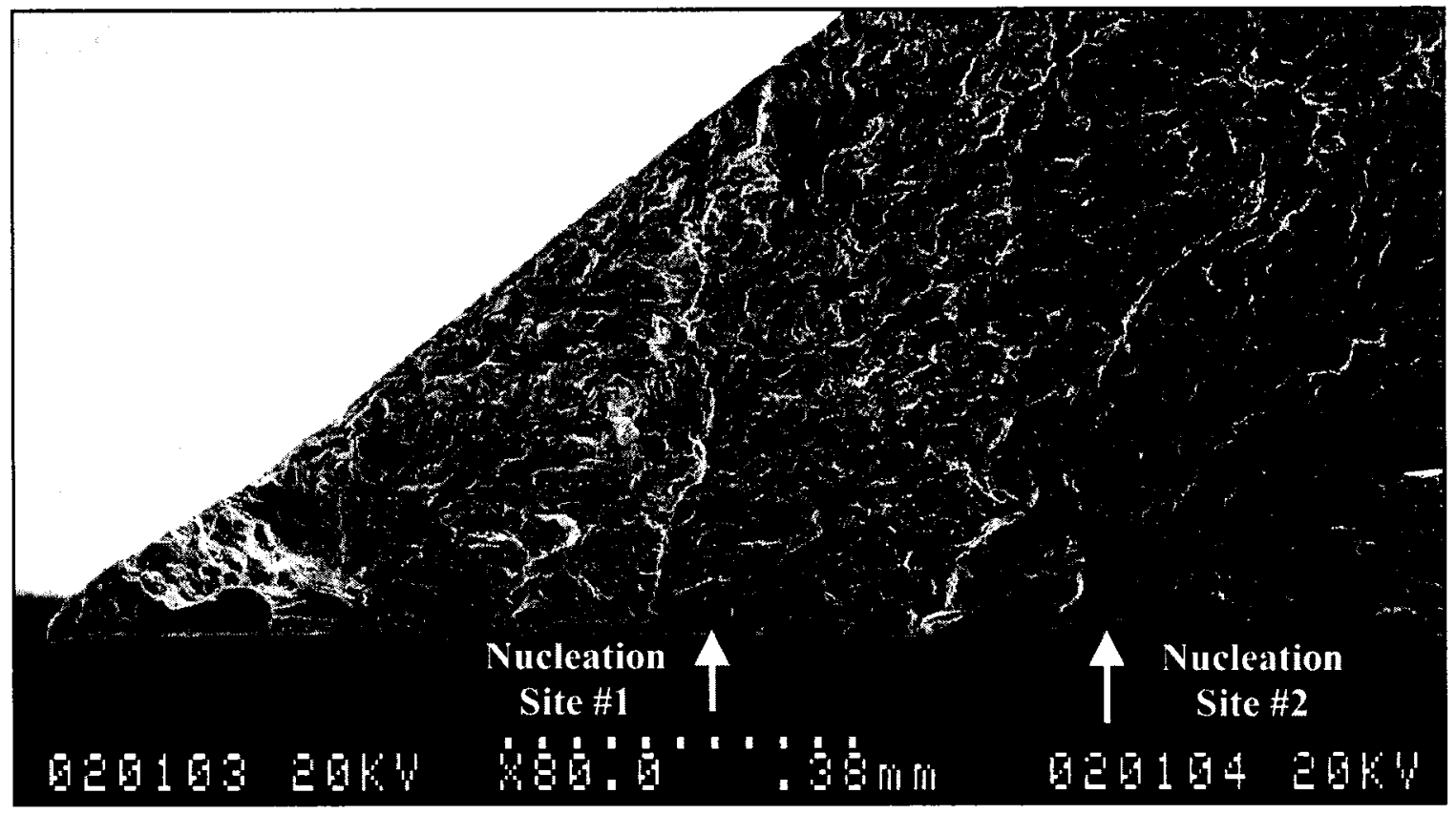

(a)

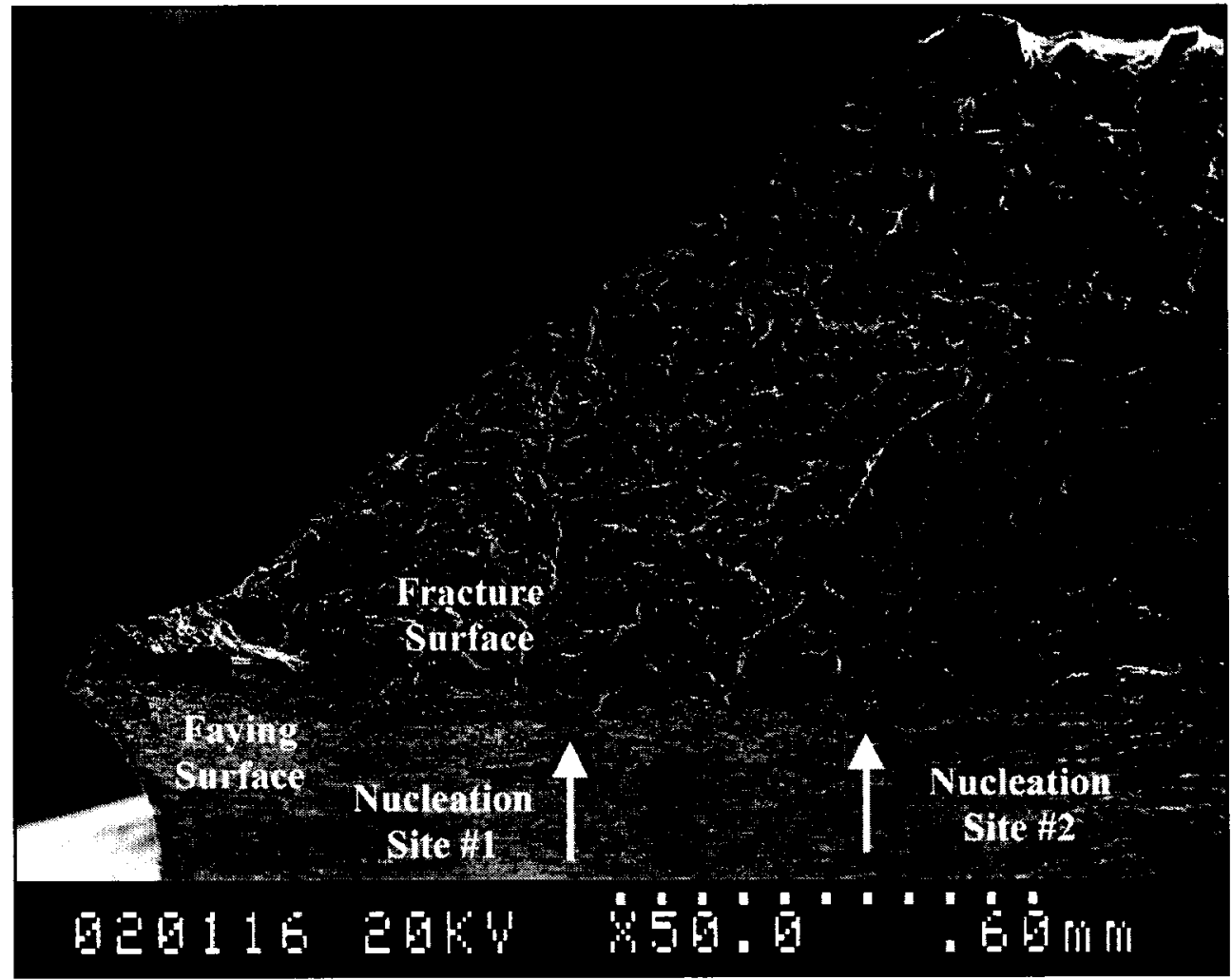

(b)

Figure 9-22: SEM micrograph of crack nucleation sites for specimen 049. (a) fracture surface (b) tilted fracture surface showing corrosion pitting at nucleation sites. 


\section{Specimen 050:}

Specimen 050 exhibited a very long life before visual crack detection. The first cracks were observed on the left side of rivet 3 and the right side of rivet 5 after 600000 cycles (Figure 9-23). The cracks grew slowly and as a result the test was ended after 218500 of visible crack growth ( 818500 total cycles). The crack lengths at the time the test was halted were 0.58 in. and $0.41 \mathrm{in}$. for cracks to the left of rivet 3 and to the right of rivet 5 respectively.

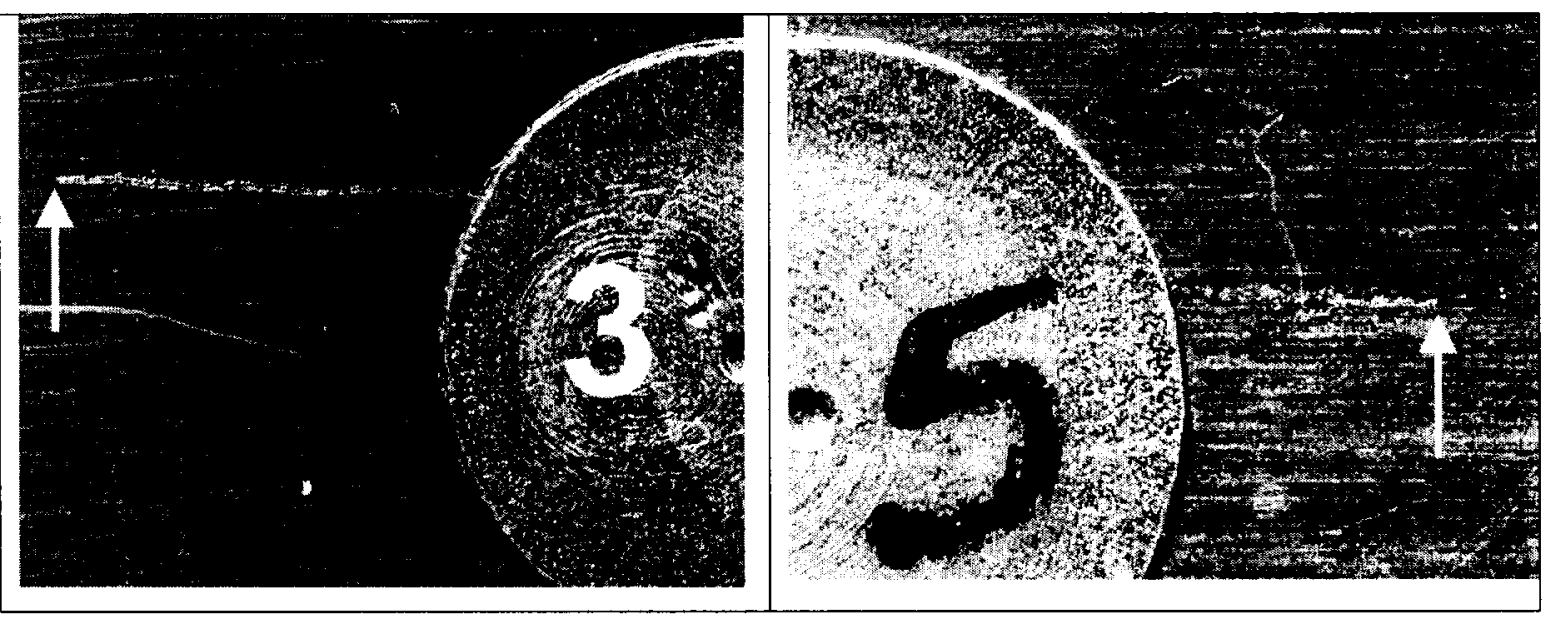

Figure 9-23: Photograph after visible crack detection for specimen 050 (cycle 748 500) (a) crack on the left side of rivet 3 (b) crack to the right of rivet 5.

Note: Arrows indicate crack tip locations.

Post-test analysis has shown that the cracks did not nucleate at corrosion pits, but rather at the edge of the countersink (Figure 9-24 and Figure 9-25). Corrosion close to rivet 3 was almost non-existent and there was only light corrosive attack of the cladding layer at rivet 5 . 


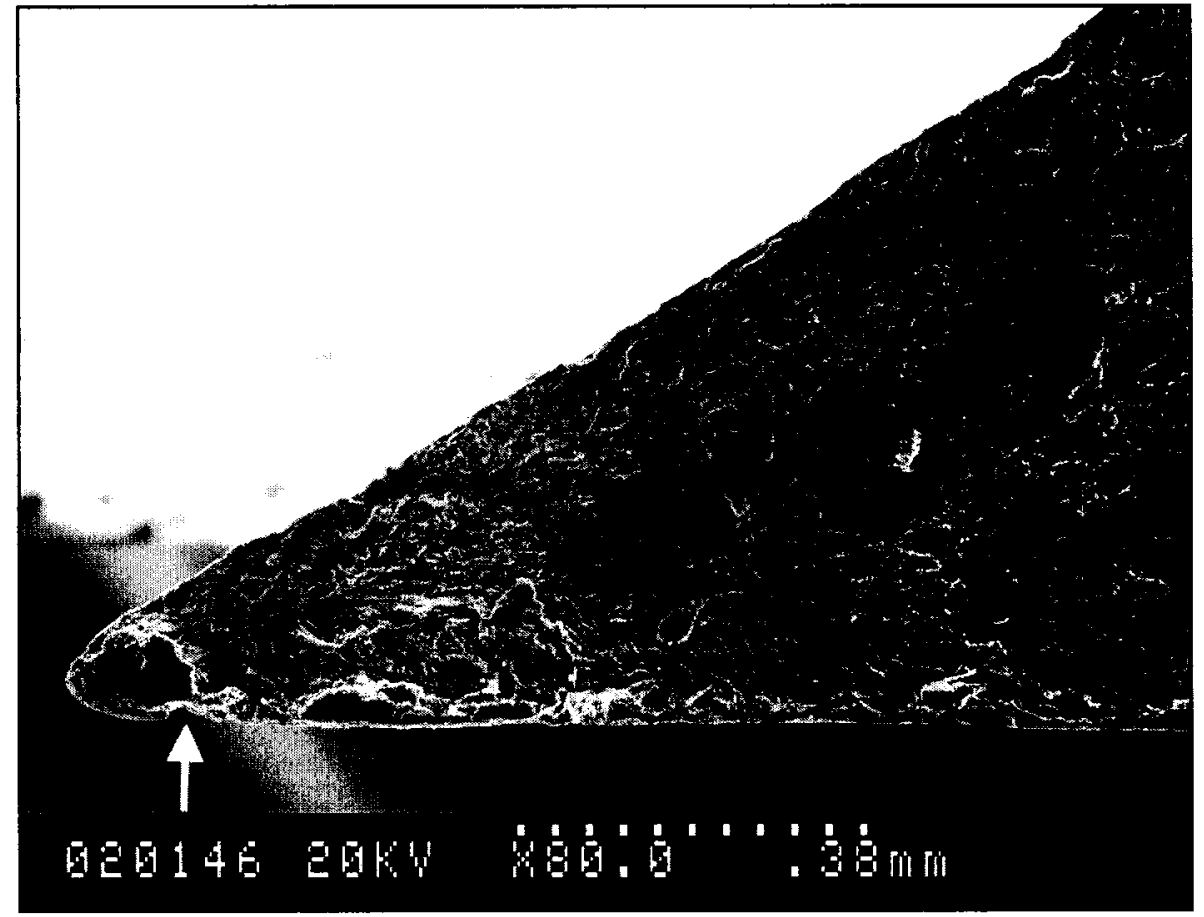

(a)

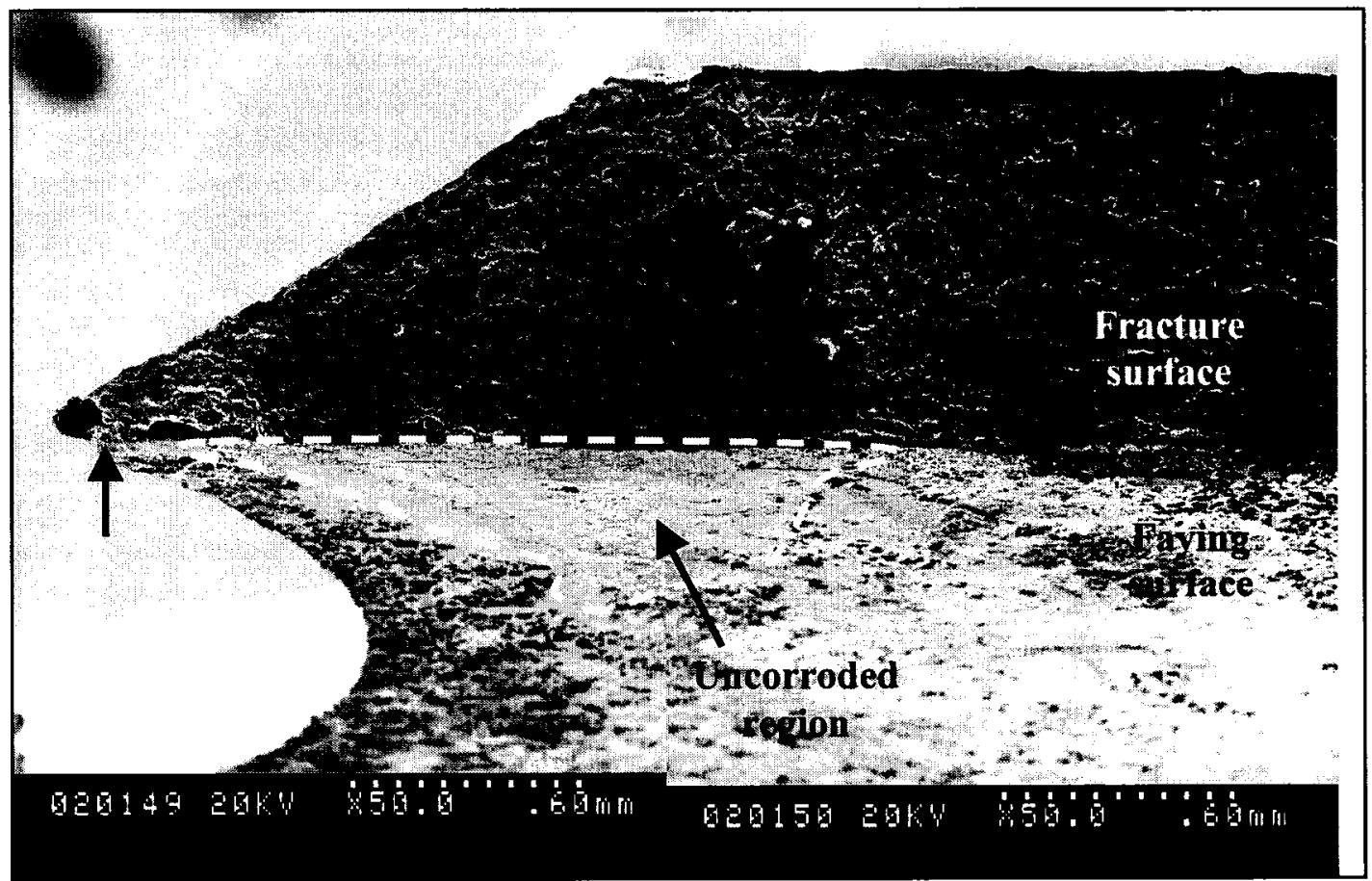

(b)

Figure 9-24: Crack nucleation site for rivet 3 of specimen 050 (a) fracture surface, (b) tilted fracture surface showing crack nucleation site and regions of little or no corrosion damage near rivet hole.

Note: Arrows indicate crack nucleation locations. 


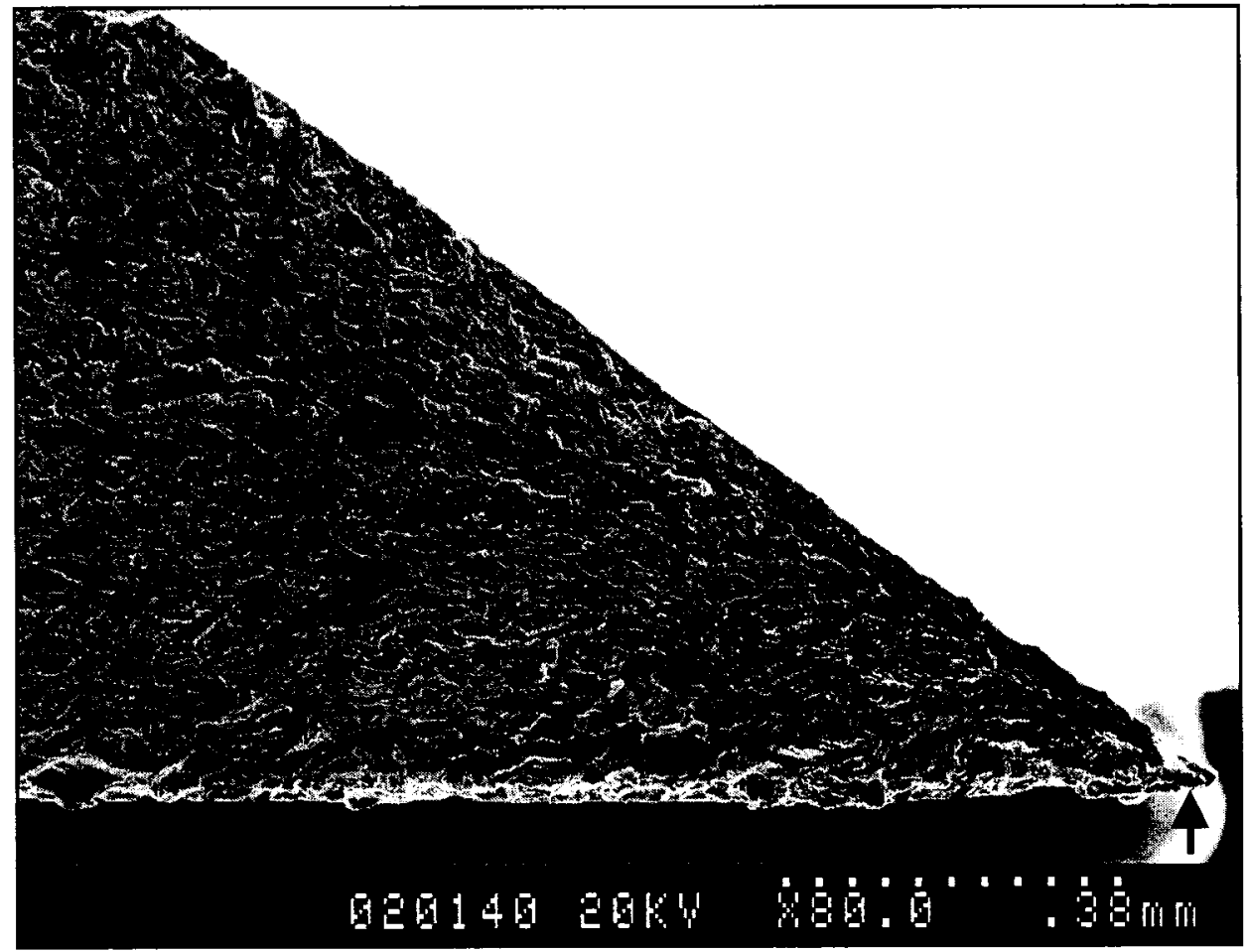

(a)

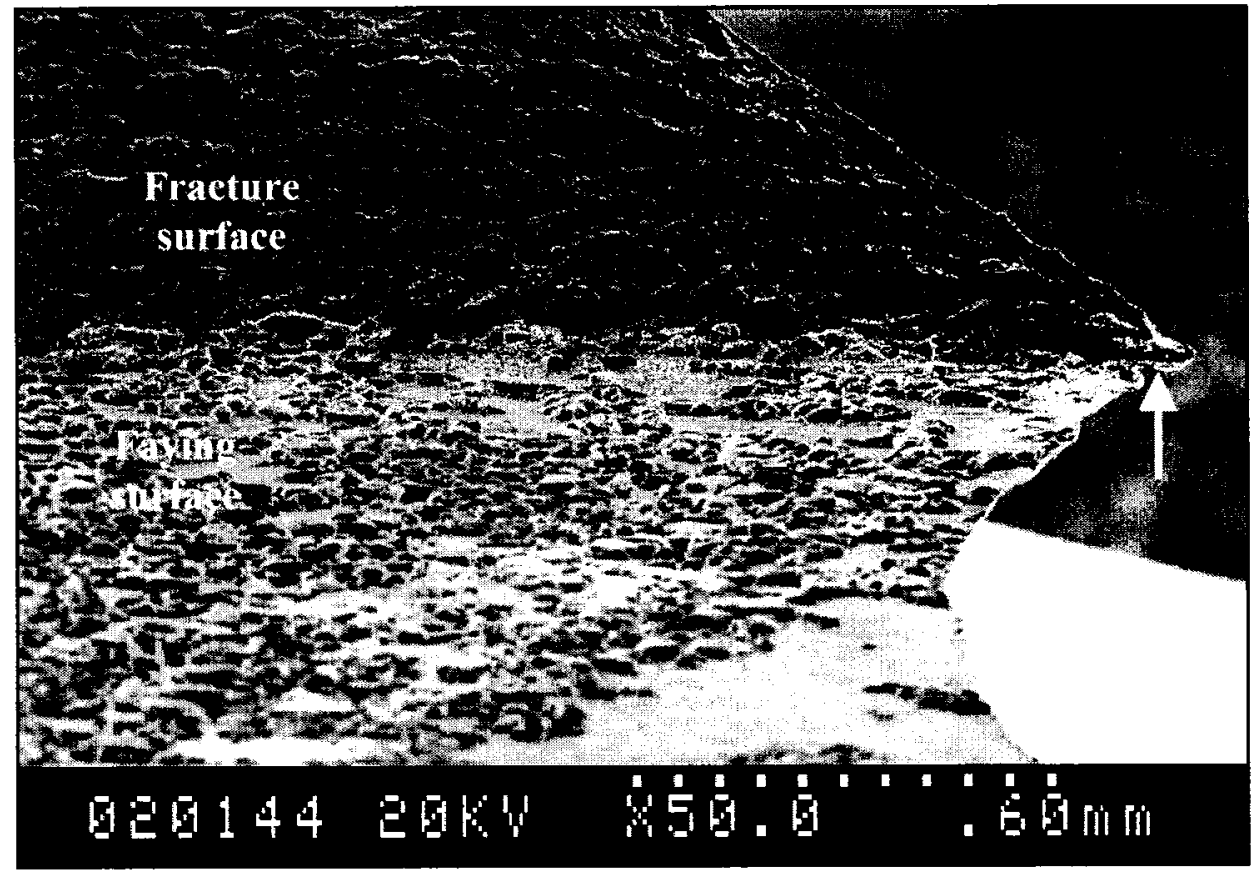

(b)

Figure 9-25: Crack nucleation site for rivet 5 of specimen 050 (a) fracture surface, (b) tilted fracture surface showing crack nucleation site and regions of light corrosion near rivet hole.

Note: Arrows indicates crack nucleation. 


\section{Specimen 054:}

The first visible cracks were detected at cycle 250000 on the right side of rivet 4 (Figure 9-26). Additional cracks developed prior to first link-up to the left of rivet 4 , to the right of rivet 3 and on the left side of rivet 3 at cycles 302500,348500 , and 371000 respectively. These cracks continued to grow until the test was stopped at cycle 394622 when a crack was detected to the left of rivet 1 . The test was halted at this point to preserve the integrity of the repaired side-strap.

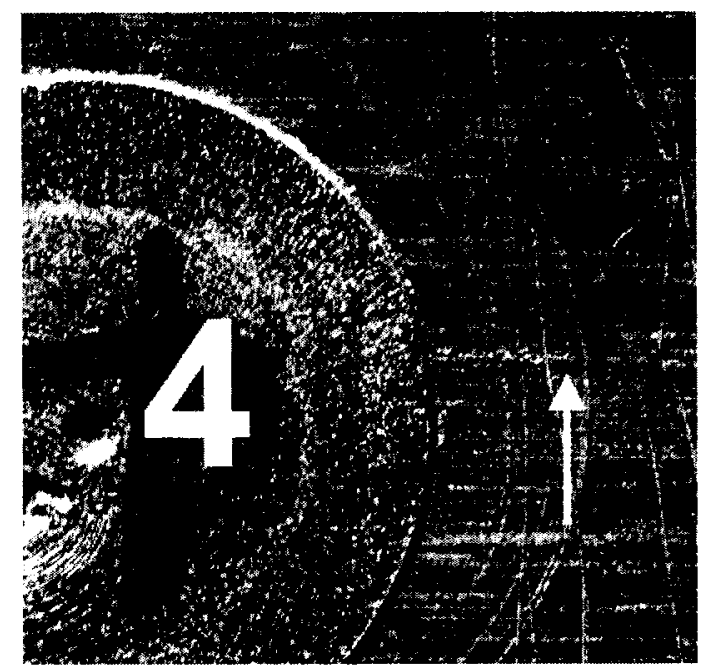

Figure 9-26: Photograph of visible crack at rivet 4 on specimen 054.

Note: Arrow indicates crack tip location.

Post-test analysis revealed that the first crack nucleated at the knife-edge of the countersunk rivet hole, and not at a corrosion pit. There was only light corrosive attack of the cladding layer near rivet 4 (Figure 9-27) which did not produce a significant corrosion pit near the crack nucleation site. 


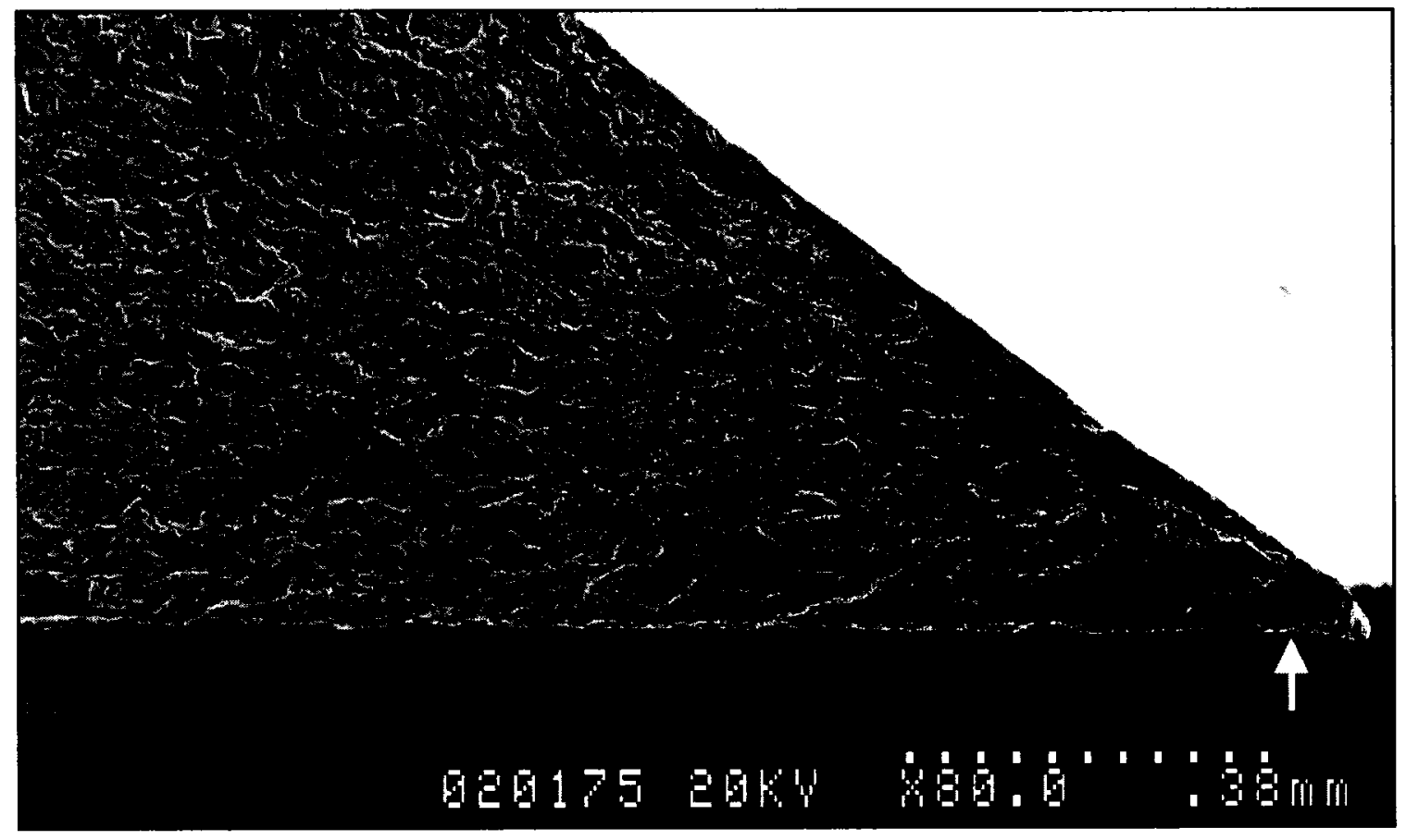

(a)

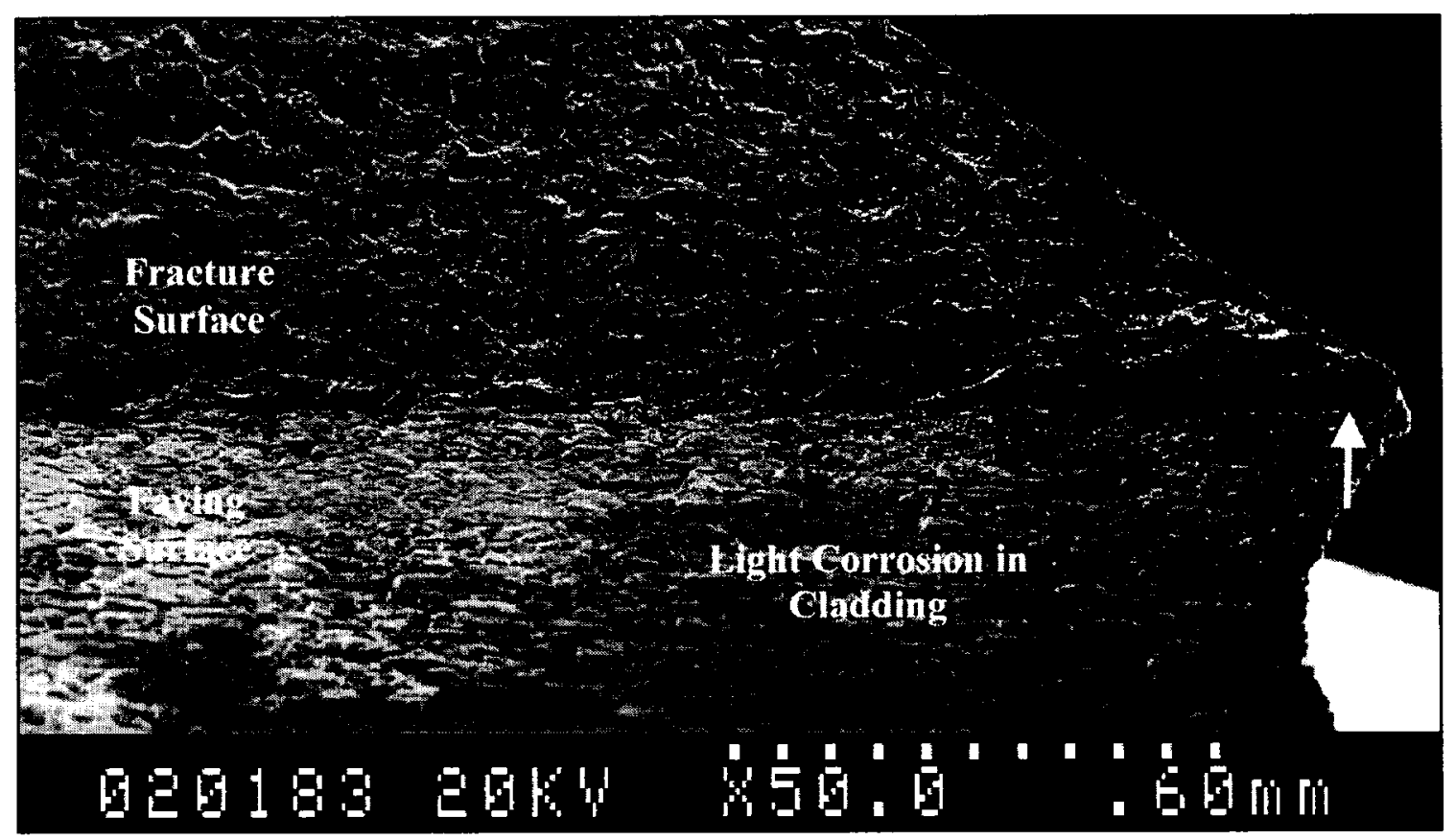

(b)

Figure 9-27: Crack nucleation site for the right side of rivet 4 of specimen 054 (a) fracture surface, (b) tilted fracture surface showing crack nucleation site and regions of light corrosion damage in the cladding.

Note: Arrows indicate crack nucleation locations. 


\subsubsection{Crack Growth}

Crack growth curves were developed to plot the cumulative lengths of all cracks growing at any instant in the MSD specimen. These aggregate crack curves are presented in Figure 9-28.

One of the key parameters used to compare fatigue characteristics for corroded and noncorroded specimens was visible crack detection life (VDL). The aggregate crack length curves, normalised using the CLD are presented in Figure 9-29.

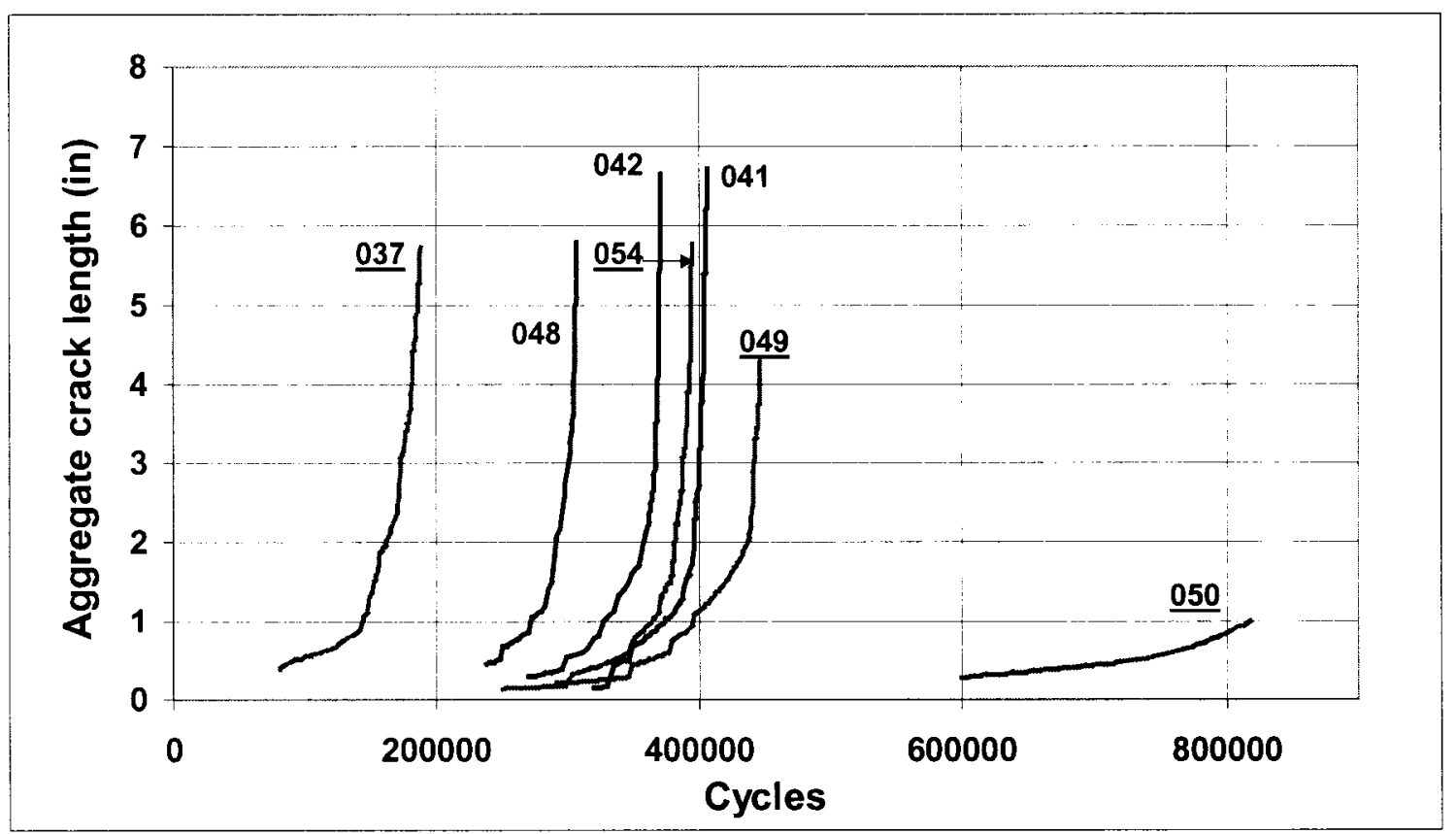

Figure 9-28: Aggregate crack growth curves.

Note: The underlined numbers identify pre-corroded specimens. 


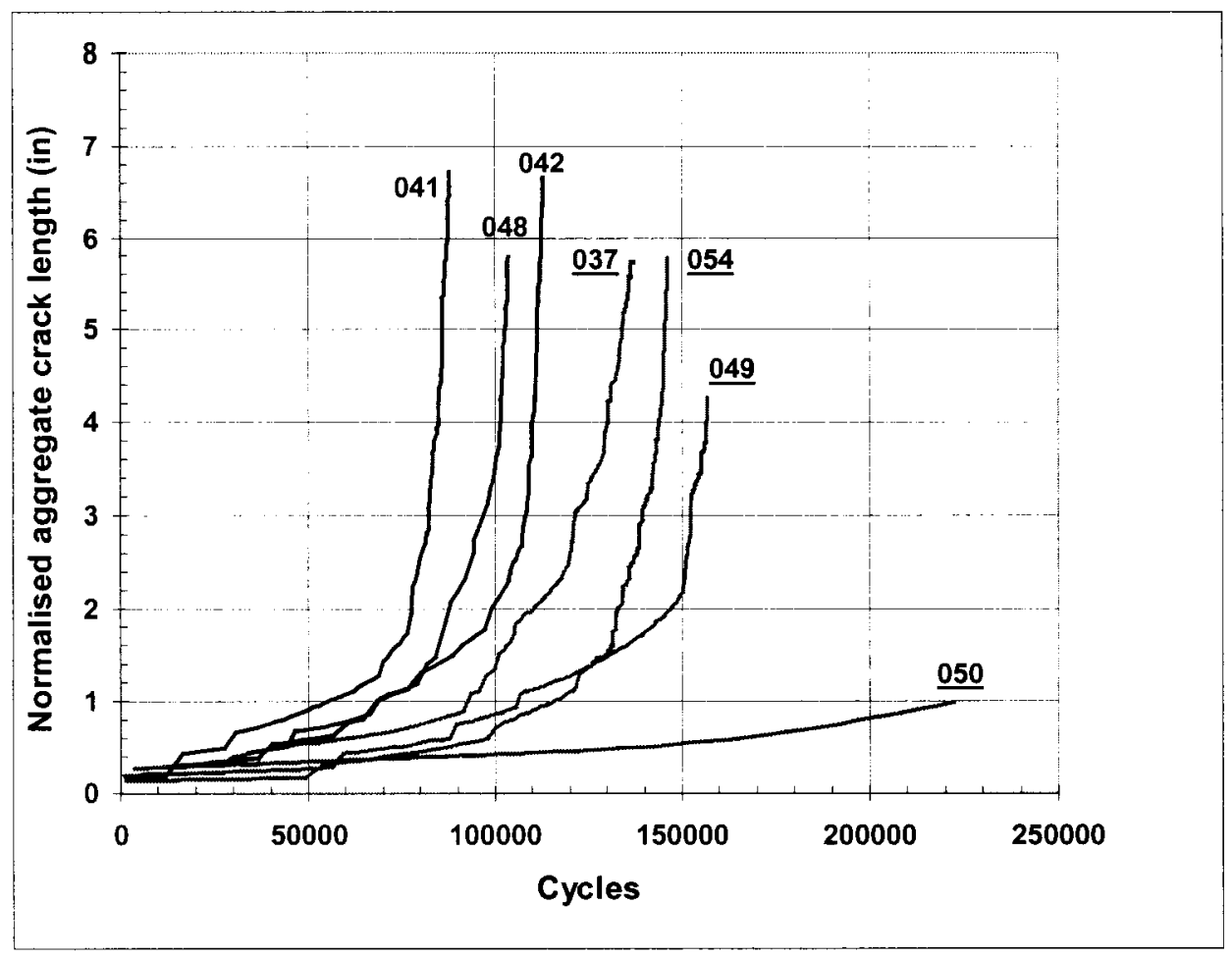

Figure 9-29: Normalised aggregate crack growth curves. The curves from Figure 9-28 have been normalised to the cycle at which the crack lengths equalled the CLD ( 0.150 in. measured longitudinally from the centre of the rivet).

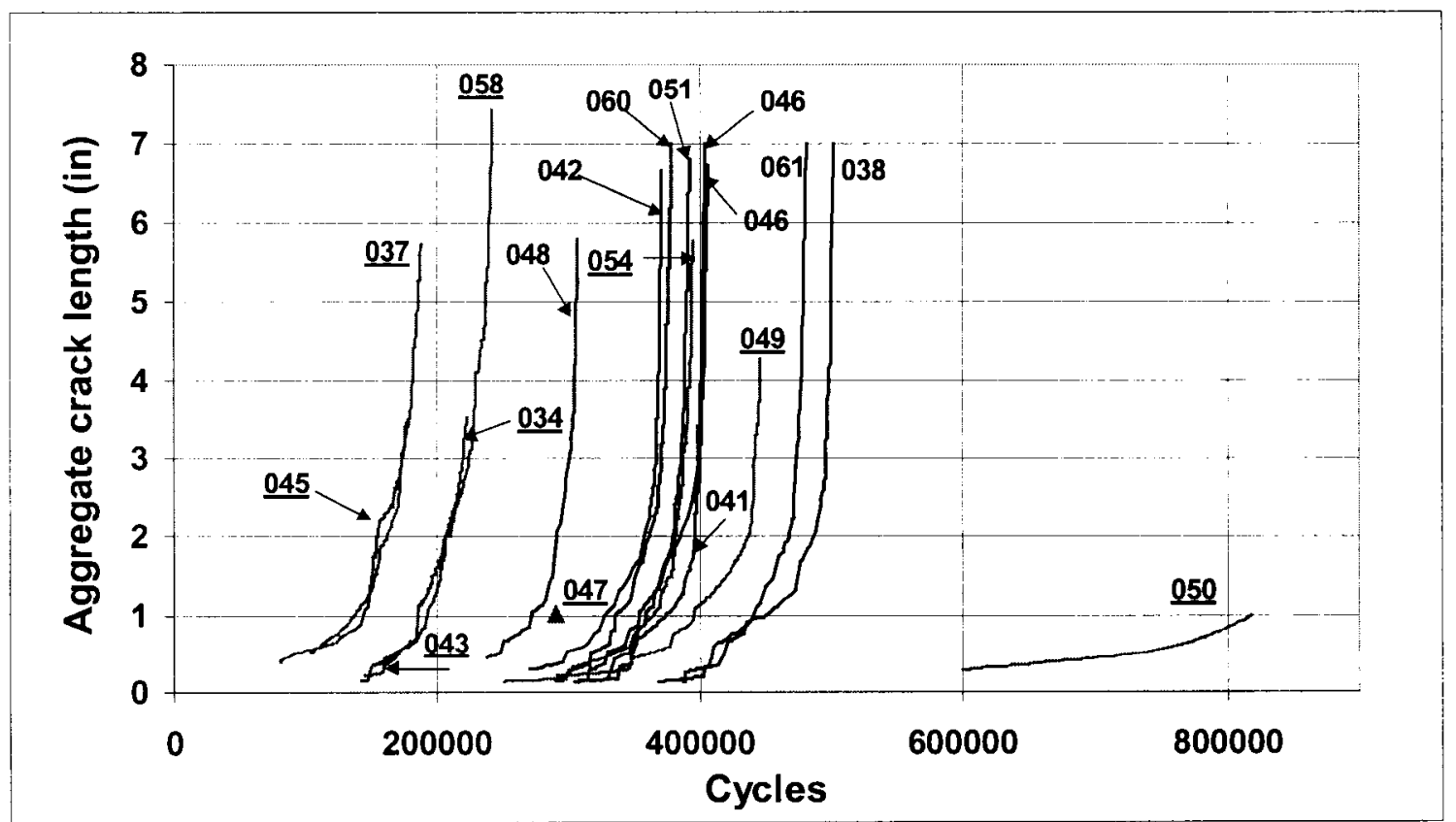

Figure 9-30: Aggregate crack growth curves for all MSD-DOE specimens tested to date. 
Based on Figures 9-28 to 9-30 the following observations were made:

1. Figures 9-28 and 9-30 clearly show the reduction in fatigue life of the nonrepaired, pre-corroded specimens.

2. The specimens with side-strap repairs typically had fatigue lives and crack growth rates similar to the non-corroded specimens. The exception was specimen 050 which had a significantly longer fatigue life and slower crack growth rates compared to all other specimens.

3. Figure 9-29 shows the longer period of visible crack growth for the corroded specimens. This may be the result of the less uniform MSD experienced on precorroded specimens. The growth of the dominant lead crack might overwhelm any increase in crack growth rate due to material thinning or other causes. This supports previous observations by Krizan (1999) and Eastaugh et al. (1995).

4. The scatter in fatigue life for non-corroded specimens is low.

\subsubsection{Influence of Repair on Corrosion-Fatigue Characteristics}

The strap repair affected the nominal stresses in the specimens, reducing the average faying surface stress of the outer sheet by $6 \%$ (Figure 9-31) and the bending stress by $55 \%$ compared to non-repaired, pre-corroded specimens. This change in stress is believed to be a result of the reduced stiffness of the repaired side-straps. An in-depth analysis has not been performed, and would be needed to determine the reason for the change in bending stress in the repaired MSD specimens. The lower bending stresses may explain the longer VDL for the repaired specimens when compared to non-repaired, pre-corroded specimens. 


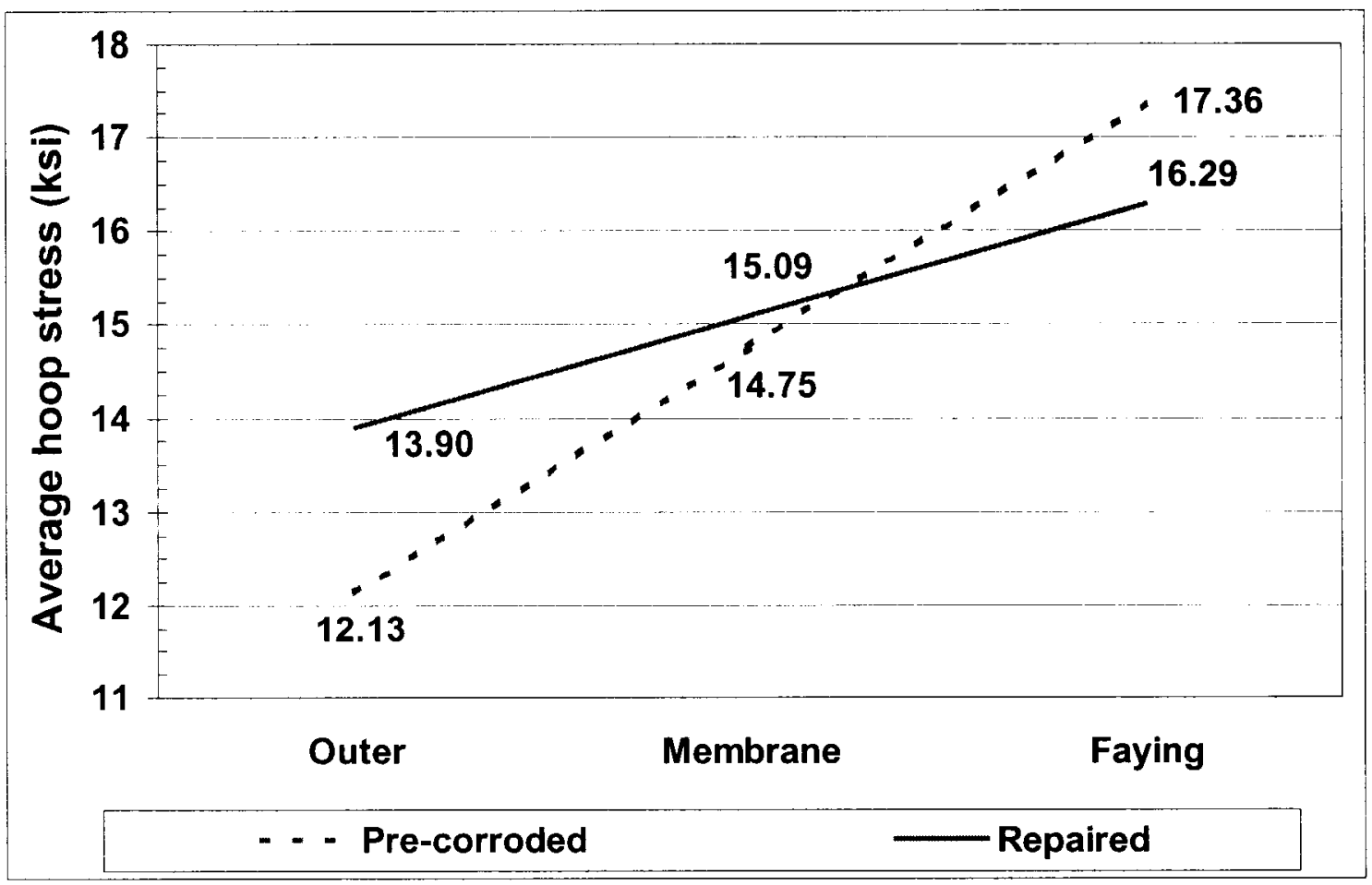

Figure 9-31: Comparison of average nominal stresses in the countersunk sheet for corroded MSD-DOE specimens with and without a side-strap repair.

\subsection{Summary of Fatigue Test Results}

A summary of the test results for all MSD-DOE specimens tested to date is shown in Table 9-4. The missing data signifies that the fatigue testing was not completed. In the case of specimens MSD511-034, and -047 the tests were halted when cracks were detected in the inner sheet, below the lower rivet row. The test for specimen 043 was stopped after a crack had propagated through the left strap of the specimen at 189074 cycles. Specimen 045 was stopped after a crack spanned from rivet 3 past rivet 6 so that the fracture surfaces could be preserved for fractographic analysis (Krizan, 1999). 
Table 9-4: Fatigue Testing Summary.

Note: The highlighted specimens were tested for this thesis, all others were tested by Krizan (1999).

\begin{tabular}{|c|c|c|c|c|c|c|c|c|c|}
\hline \multirow[b]{2}{*}{ ). } & \multicolumn{2}{|c|}{ VDL } & \multicolumn{2}{|c|}{$1^{\text {st }}$ link-up } & \multicolumn{2}{|c|}{ Full crack } & \multicolumn{2}{|c|}{ Crack growth life } & \multirow{2}{*}{$\begin{array}{l}\text { Total } \\
\text { life }\end{array}$} \\
\hline & Cycles & $\begin{array}{c}\% \text { of } \\
\text { total life }\end{array}$ & $\begin{array}{c}\text { Cycles } \\
\text { Since VDL. }\end{array}$ & $\begin{array}{c}\% \text { of } \\
\text { total life }\end{array}$ & eycles & $\begin{array}{c}\% \text { of } \\
\text { total life }\end{array}$ & $\begin{array}{c}\text { Cycles } \\
\text { Since VDI. }\end{array}$ & $\begin{array}{c}\% \text { of } \\
\text { total life }\end{array}$ & \\
\hline \multicolumn{10}{|c|}{ Non-corroded specimens } \\
\hline 038 & 387500 & $77.2 \%$ & 104211 & $20.8 \%$ & 10222 & $2.0 \%$ & 114433 & $22.8 \%$ & 501933 \\
\hline 046 & 314000 & $77.8 \%$ & 84908 & $21.0 \%$ & 4785 & $1.2 \%$ & 89693 & $22.2 \%$ & 403693 \\
\hline 051 & 304001 & $77.4 \%$ & 77531 & $19.7 \%$ & 11041 & $2.8 \%$ & 88572 & $22.6 \%$ & 392573 \\
\hline 060 & 290000 & $76.6 \%$ & 78650 & $20.8 \%$ & 10104 & $2.7 \%$ & 88754 & $23.4 \%$ & 378754 \\
\hline 061 & 368500 & $76.6 \%$ & 103200 & $21.4 \%$ & 9633 & $2.0 \%$ & 112833 & $23.4 \%$ & 481333 \\
\hline 041 & 320000 & $78.8 \%$ & 76433 & $18.8 \%$ & 9813 & $2.4 \%$ & 86246 & $21.2 \%$ & 406246 \\
\hline 042 & 270000 & $72.7 \%$ & 92438 & $24.9 \%$ & 8806 & $2.4 \%$ & 101244 & $27.3 \%$ & 371244 \\
\hline 048 & 235000 & $76.6 \%$ & 62600 & $20.4 \%$ & 9358 & $3.0 \%$ & 71958 & $23.4 \%$ & 306958 \\
\hline \multicolumn{10}{|c|}{ Pre-corroded specimens } \\
\hline 034 & 160000 & - & - & - & - & - & - & - & - \\
\hline 043 & 144000 & - & - & - & - & - & - & - & - \\
\hline 045 & 104107 & - & - & - & - & - & - & - & - \\
\hline 047 & 289629 & - & - & - & - & - & - & - & - \\
\hline 058 & 142000 & $58.7 \%$ & 75323 & $31.1 \%$ & 24586 & $10.2 \%$ & 99909 & $41.3 \%$ & 241909 \\
\hline 037 & 80000 & $42.5 \%$ & 156321 & $40.6 \%$ & 31763 & $16.9 \%$ & 108084 & $57.5 \%$ & 188084 \\
\hline 049 & 290878 & - & 150179 & - & - & - & - & - & - \\
\hline 050 & 600000 & - & - & - & - & - & - & - & - \\
\hline 054 & 250000 & $63.4 \%$ & 129865 & $32.9 \%$ & 14757 & $3.7 \%$ & 144622 & $36.6 \%$ & 394622 \\
\hline
\end{tabular}

For the group of specimens tested for this thesis, two had their tests ended prematurely. The test of specimen MSD511-049 was ended after the crack emanating from rivet 8 had grown into the side-strap. Testing of specimen 050 was halted after 818501 cycles due to the slow crack growth. A summary of the fatigue life segments is presented in Figure 9-32. 


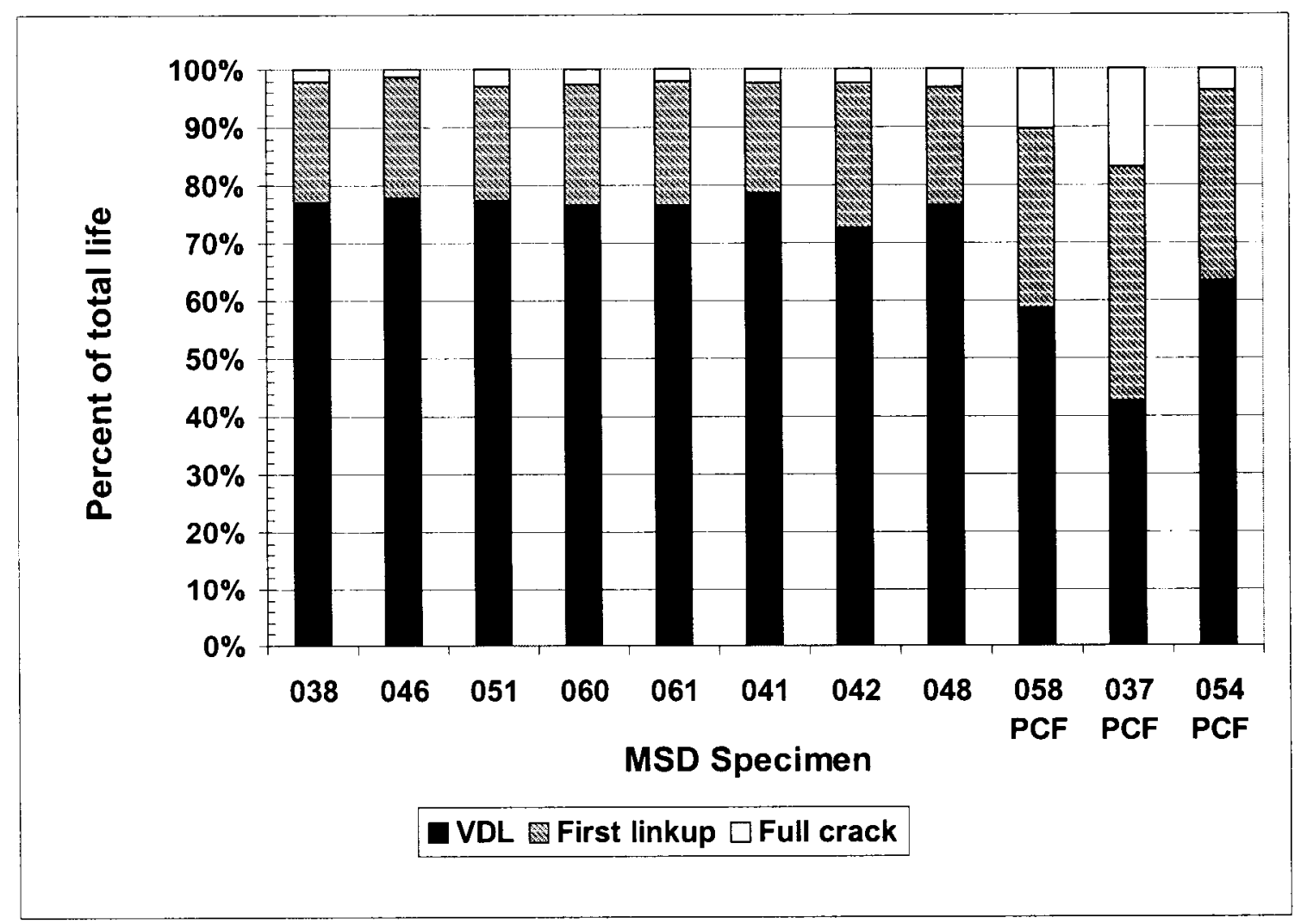

Figure 9-32: Visual crack detection life, and crack growth summary.

The findings based on the fatigue test results are as follows:

1. Fatigue crack nucleation usually occurs at corrosion pits for corroded specimens, and at locations of heavy fretting damage for non-corroded specimens.

2. The pre-corroded specimens tend to have shorter visual crack detection and overall fatigue lives (excluding specimens that have undergone side-strap repair).

3. Pre-corroded specimens which have been repaired tend to have longer VDL and overall fatigue lives than the non-repaired, pre-corroded specimens.

4. Repaired specimens have lower faying surface stresses and bending stresses than the non-repaired, pre-corroded specimens.

5. Specimen 050 exhibited a prolonged fatigue crack life. There are several probable causes, none of which have been substantiated. Lower than average bending stress, influence of the strap repair, and possible manufacturing discrepancies such as higher rivet squeeze force, which would result in higher clamping forces near the rivet, are a few of the possibilities. The lower levels of corrosion near the 
rivets in the upper rivet row may be a result of higher clamping forces, but this has not been verified.

6. Crack growth rates in pre-corroded specimens are similar to non-corroded specimens (except in the case of the repaired specimen 050).

\subsection{Corrosion-Fatigue Interaction}

\subsubsection{Changes in Visual Crack Detection Lives (VDL)}

The results from Table 9-4 show that for 5-6\% corrosion thickness loss the mean VDL is reduced by $52 \%$ compared to non-corroded specimens. The two-sided confidence interval for the mean VDL is presented in Figure 9-33 and shows a clear separation of the two populations.

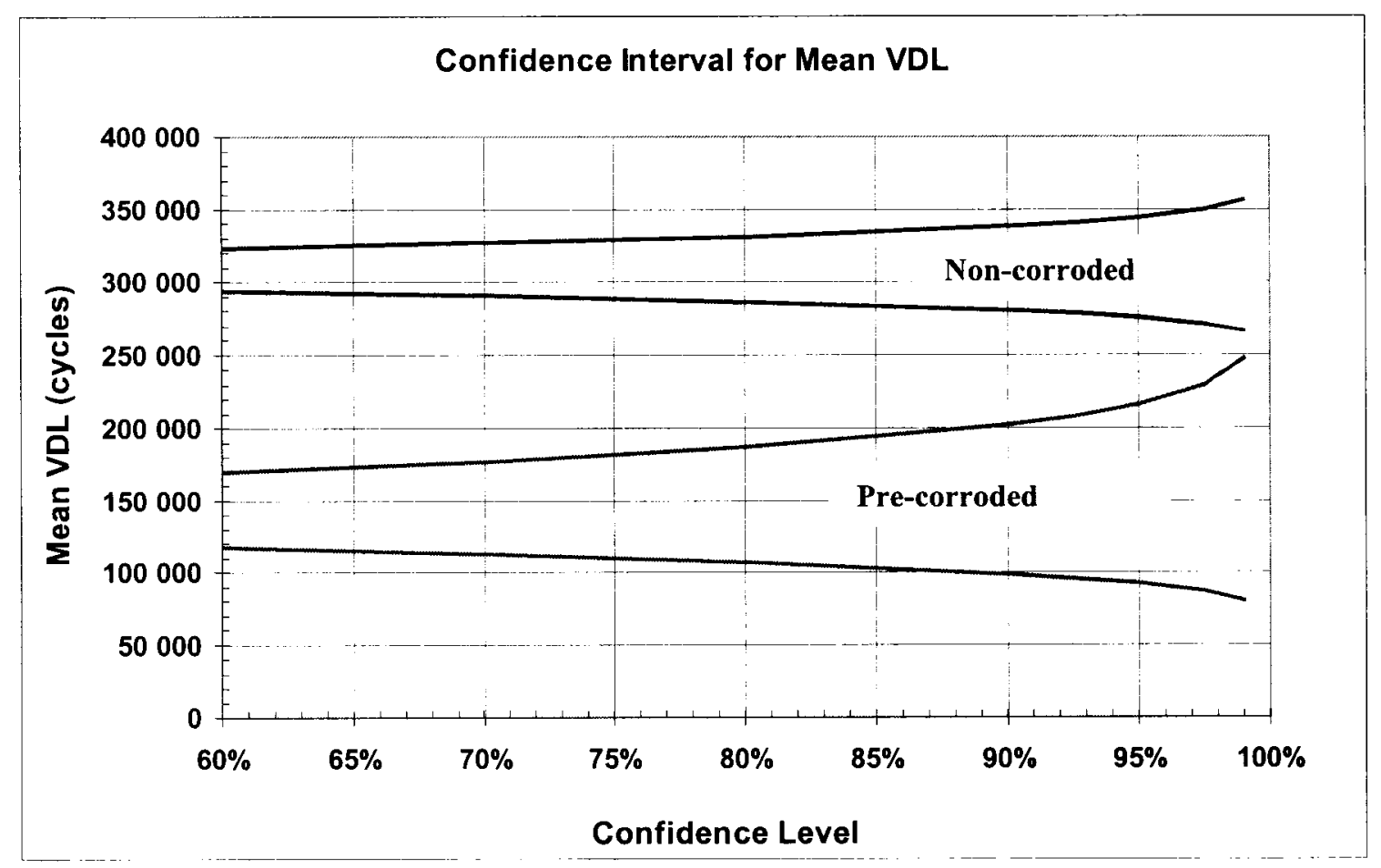

Figure 9-33: Two-sided confidence interval for Mean VDL using sample sizes of 8 non-corroded and 6 pre-corroded.

Note: Several specimens were not included in this analysis as they were determined to be outliers of the population based on their stress distribution. Among these were all three repaired MSD panels $(049,050,054)$. 


\subsubsection{Changes in Membrane and Bending Stresses}

During fatigue testing, the stresses at the nominal location ( 1 in. above the upper rivet row on the outer sheet) were monitored. The stress readings were taken on cycle 100 at full load (7219 lb.). This allows for comparison of corroded and non-corroded specimens before fatigue cracking influences the nominal stresses.

The nominal stresses for specimens 041,042 , and 048 (non-corroded) as well as for specimen 037 (pre-corroded) were added to the results previously collected by Krizan (1999). The results for the repaired specimens $(049,050$, and 054) were not included. They were considered outliers to the statistical population since they had stresses which deviated from the average pre-corroded stresses by more than three standard deviations (Beckwith, 1993). The results for the averaged stresses are presented in Figure 9-34 and Figure 9-35. A comparison of the nominal stresses between corroded and non-corroded specimens has been performed and is presented in Figure 9-36.

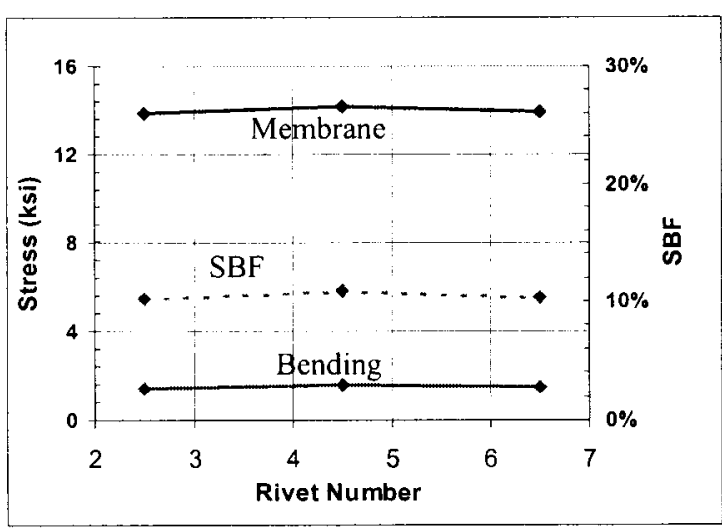

Figure 9-34: Average nominal location stresses for non-corroded specimens.

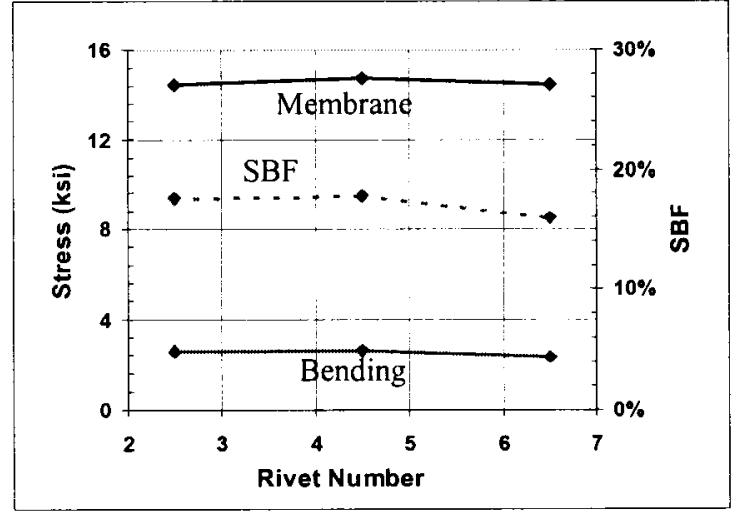

Figure 9-35: Average nominal location stresses for pre-corroded specimens. 


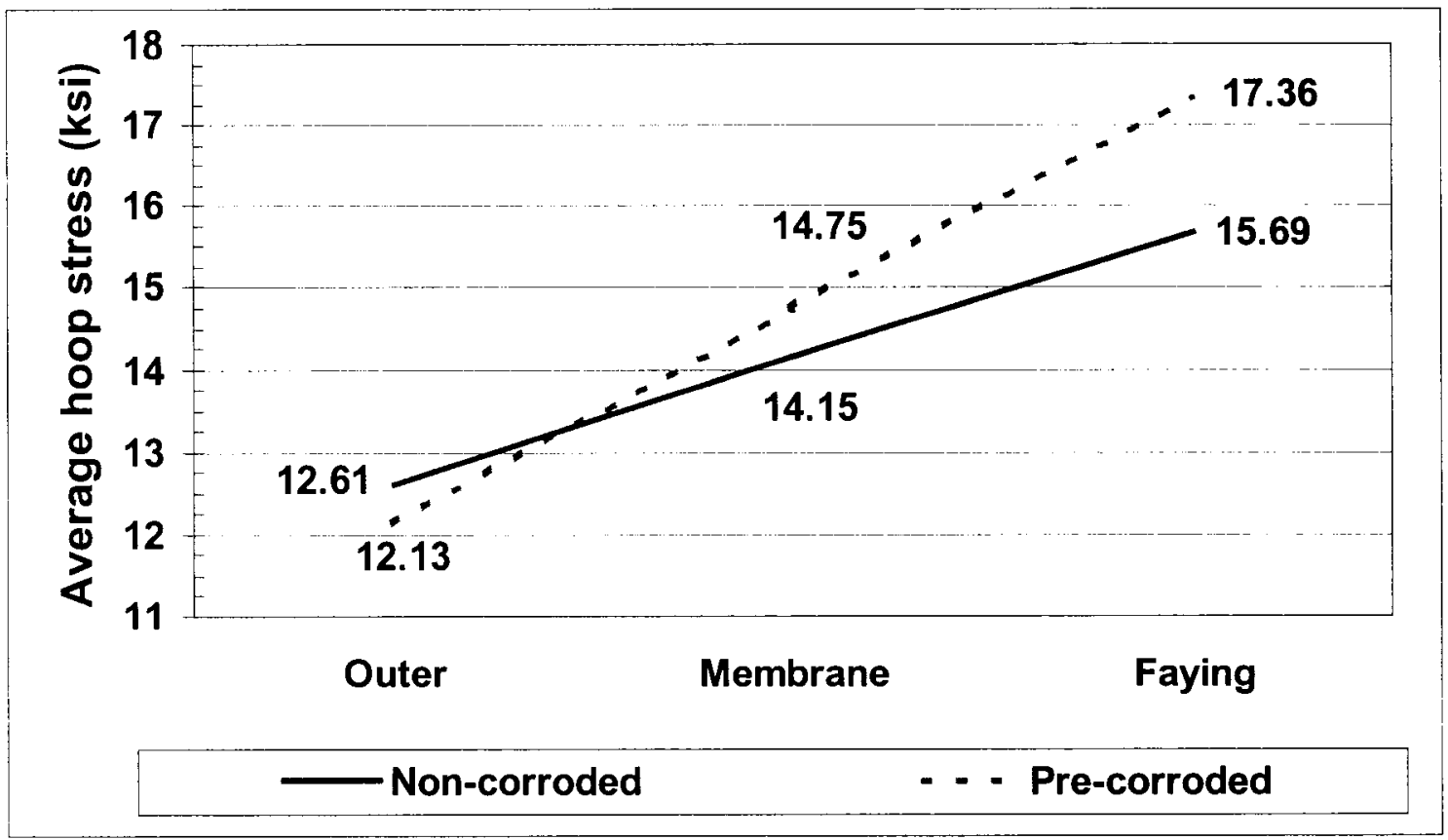

Figure 9-36: Comparison of average nominal stresses.

Note: Outer - refers to outer surface of outer sheet.

Faying - refers to the inner (faying) surface of the outer sheet.

Corrosion increases the faying surface and membrane stresses by $11 \%$ and $4 \%$ respectively. The increased faying surface and bending stresses at the nominal location indicate that a corresponding increase could be expected near the upper rivet row of the outer sheet. The faying surface stress has been plotted against VDL for both corroded and non-corroded specimens in Figure 9-37. The reduction in VDL with increasing faying surface stresses is evident. This provides one explanation for the reduction in visible crack detection lives for the pre-corroded specimens. 


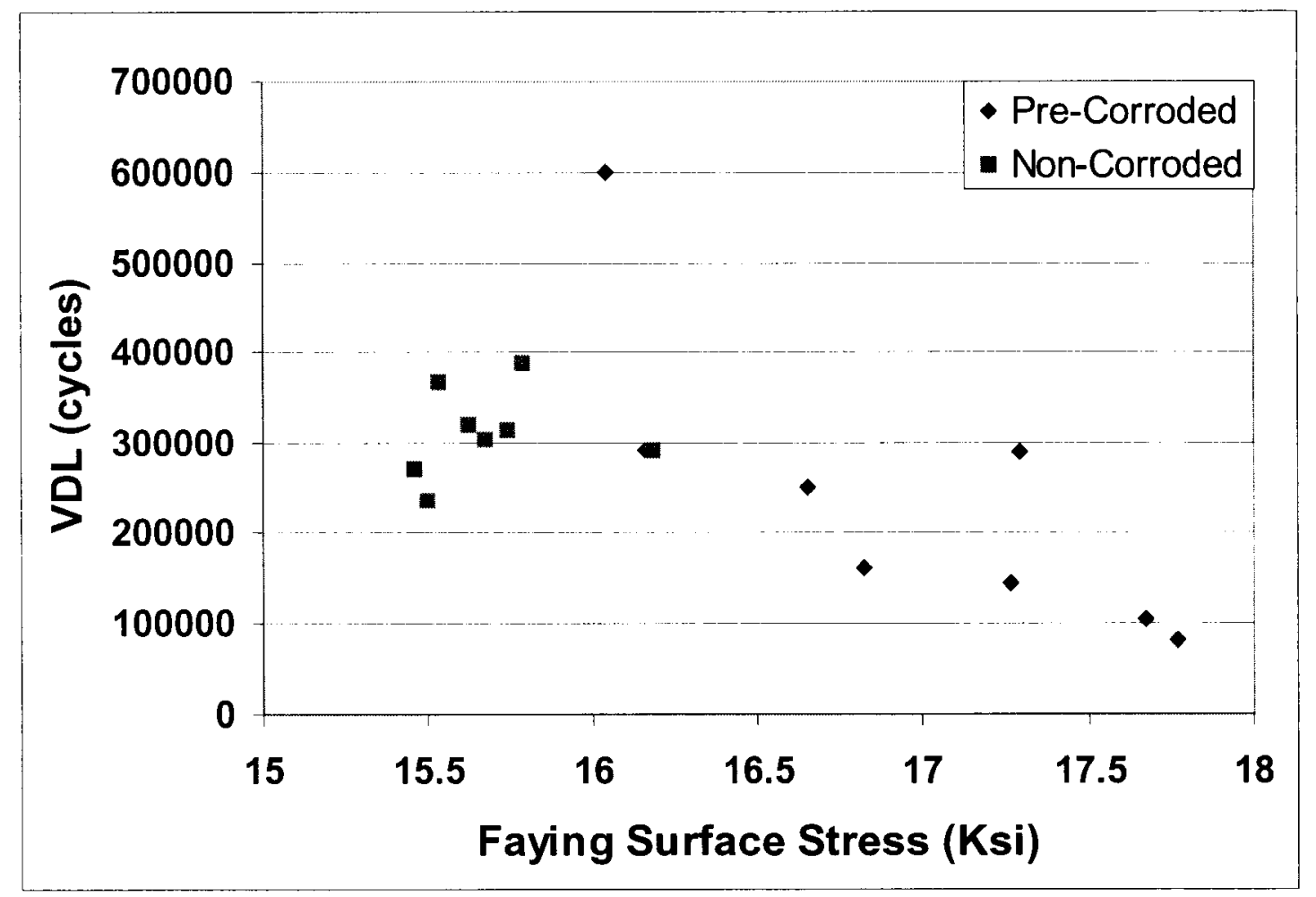

Figure 9-37: Graph showing the relationship between faying surface stress and visible crack detection life (cycle 100 at 7219 lb.).

Note: Specimen 058 was not included in this analysis since the failed rivets affected the stress-state.

\subsubsection{Change in Fretting Wear}

The fretting wear patterns for non-corroded specimens were presented in Section 3.2, and Figure 9-14. The corroded specimens did not exhibit fretting wear on the faying surface. It was concluded that for the corrosion levels under investigation (5-6\% thickness loss) fretting wear around rivet holes is reduced, or eliminated. Two possible reasons for this are:

1. Two sheets are forced apart by the internal pressure created by the accumulation of corrosion product.

2. The corrosion product near the rivets may act as a form of solid lubricant, reducing or eliminating friction wear between the two sheets. 


\subsection{CORRODED SURFACE TOPOGRAPHY ANALYSIS}

This section outlines the development of tools used to analyse corroded surface topography and the results of this analysis. The applicability of this research to a fracture mechanics based approach for modelling corrosion-fatigue of lap joints will also be presented. The overall approach for using surface topography in fracture mechanics analysis of corroded structures was outlined in Section 5.3. A detailed description of the approach taken to quantify the corrosion damage will be presented in later sections.

As discussed in Section 5.4 there is currently no methodology for using the corroded surface topography to predict the effect of corrosion on the durability and damage tolerance of aircraft structures. Currently, the method for dealing with corrosion on aircraft is to remove the corrosion by grinding, or replace the affected region if the damage is beyond tolerable levels. Better maintenance and repair practices could probably be developed through a fracture mechanics-based analysis of the structure, as discussed in Section 5.3.1.

In an operational environment, eddy current inspections can detect average thickness loss in the outer sheet of fuselage joints over regions approximately 0.16-0.25 in. diameter (equal to the typical probe diameter for 0.040 in. thick aluminum sheets, commonly used in fuselage skins). The resolution of these inspections is not sufficient to determine a suitable maintenance response based on corrosion-fatigue modelling ${ }^{13}$. Another means of obtaining the corrosion topography of a fuselage joint is a teardown of each damaged structure. However, this is not feasible. Therefore, it is proposed that probabilistic relations linking the corrosion topography to average thickness loss, detected by NDI, be used. To develop this method, it is first necessary to characterise the corrosion damage topography of disassembled fuselage joint specimens using high precision methods. In this section the development of such relationships from DXR data analysis is discussed.

\footnotetext{
${ }^{13}$ It has been suggested that a spatial and depth resolution of approximately $0.001 \mathrm{in} .(25 \mu \mathrm{m})$ is required in order to adequately model corrosion damage (Personal correspondence with Brooks, and Prost-Domasky of APES Inc.). This is not attainable by available NDI methods.
} 
The results developed in the current work are applicable to Alclad 2024-T3 sheet used in riveted fuselage lap joints. Other structures and materials may corrode in different fashions producing different corroded topography characteristics than those observed in this work.

\subsection{Probabilistic Approach for Assessing Corrosion Damage Topography}

The surface topography is obtained by analysing a digitised x-ray image of a corroded specimen. This image is then manipulated using programs written in the Interactive Data Language $^{\circledR}\left(\mathrm{IDL}^{\circledR}\right)$ software to develop various statistics, which serve as metrics for quantifying the corrosion damage. Initially, corrosion pit geometric parameters such as pit depth, width, length, and planform area were investigated. Typical combinations of these parameters were then related to estimated stress concentration factors for use in fracture mechanics analyses (refer to Section 11.0).

The following terminology has been used for the corrosion topography analysis. Figure 10-1 is a simplification of the corrosion pits typically observed in fuselage joints. The cold rolling process elongates grains and inclusions along the rolling direction. As a result, corrosion pits in rolled sheets are often elongated. 


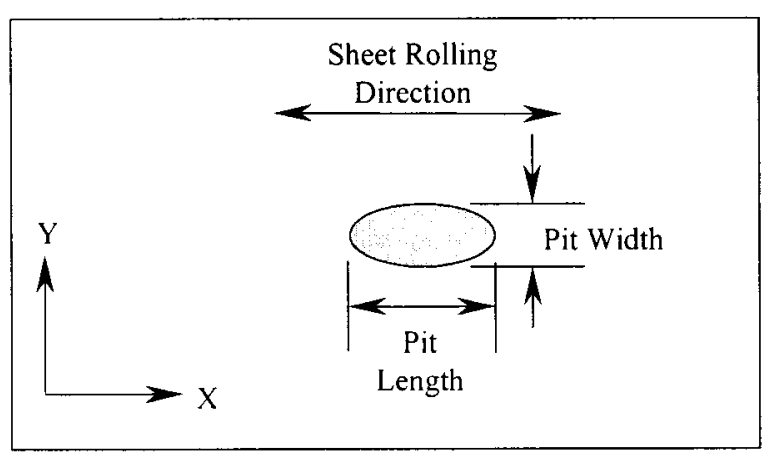

Top View

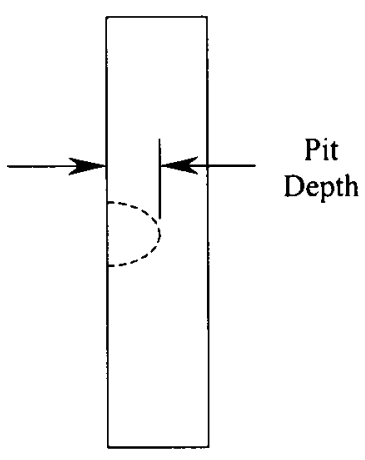

Right Side View

Figure 10-1: Corrosion Pit Geometry Terminology.

Pit Length: Dimension of the corrosion pit along the sheet rolling direction.

Pit Width: Dimension of the corrosion pit perpendicular to the sheet rolling direction

Pit Aspect Ratio: Ratio of pit length to pit width

Pit Area: $\quad$ The area of the pit "mouth" at the surface of the metal (shaded region in Figure 10-1)

The general approach used for quantifying the surface topography of corroded MSD511DOE coupons is shown in Figure 10-2. Some of the key activities are discussed in subsequent sections. 


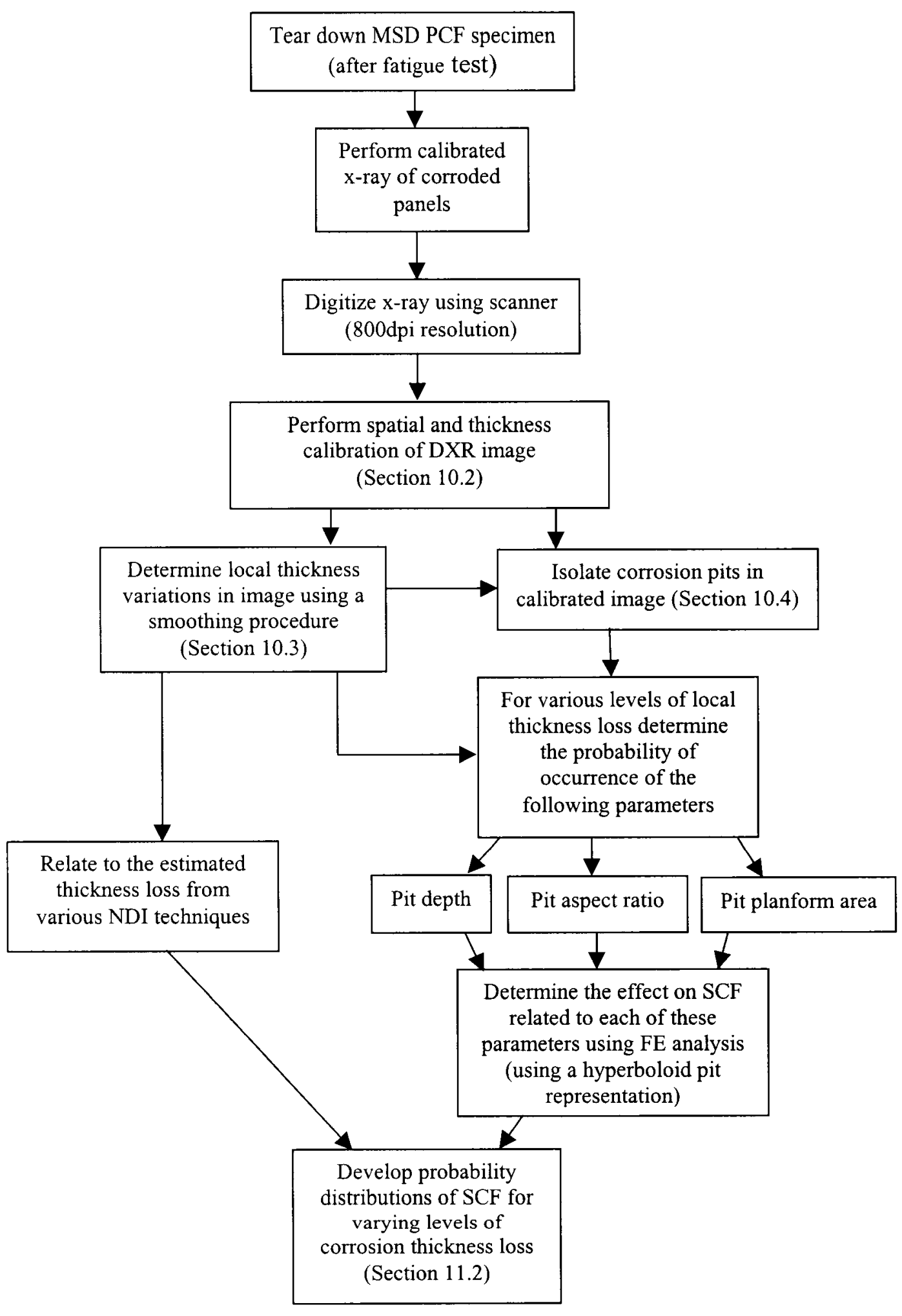

Figure 10-2: General approach to quantify corrosion damage for MSD511-DOE specimens. 


\subsection{Calibration of DXR Images}

This section describes the various algorithms applied to the digitised $\mathrm{x}$-ray image to achieve a thickness and spatial image calibration.

\subsubsection{Thickness Calibration}

Thickness calibration of the DXR images was performed according to the procedure described in Section 8.3.3. The $\mathrm{IDL}^{\circledR}$ program, developed to perform the thickness calibration of the original DXR image, obtains the calibration curve from the user. The calibration curve used is an exponential equation $\mathrm{Ae}^{\mathrm{Bx}}$, where $\mathrm{A}$ and $\mathrm{B}$ are constants, and $x$ represents the image greyscale value. Once input, the thickness calibration program applies this equation to the entire image array. The calibrated image can no longer be saved as an image file since the pixel values are not recognisable greyscale integer values. Therefore, the calibrated data is written to a binary data file, with important file information such as image dimensions, resolution, and the original specimen thickness (0.040 in. for the MSD specimens).

\subsubsection{Spatial Calibration}

Spatial calibration of the digitised $x$-ray image is accomplished using the pixel dimensions of the scanned image. For all scans, the maximum optical resolution of the scanner was used, which for the Epson Expression 836XL ${ }^{\mathrm{TM}}$ was 800dpi. This gives a pixel size of 0.00125 in. $x 0.00125$ in. $(31 \mu \mathrm{m} \times 31 \mu \mathrm{m})$.

In the event that a different resolution is used, the $\mathrm{IDL}^{\circledR}$ program receives the image resolution (in dpi) from the user. The image is calibrated by dividing both the $\mathrm{x}$ and $\mathrm{y}$ pixel co-ordinates by the inverse of the resolution (inch/pixel). The resulting data from the spatial calibration is an m-by-n matrix with the same dimensions as the original image. 


\subsection{Local thickness variation}

The next stage in the analysis of the corroded surface topography is to determine the local thickness variation. Since the corroded surface is very rough, the thickness values determined (reference Section 10.2.1) are not directly applicable for thickness mapping. A smoothing procedure must first be implemented to remove surface roughness effects.

The image smoothing procedure uses a "boxcar" average of all pixels within the prescribed kernel. If, for example, a 3-pixel by 3-pixel kernel is chosen, pixel $i$ (the central pixel), takes on the average of the 9 pixels within the kernel. A representation of this kernel is shown in Figure 10-3 below.

\begin{tabular}{|l|l|l|}
\hline 1 & 1 & 1 \\
\hline 1 & 1 & 1 \\
\hline 1 & 1 & 1 \\
\hline
\end{tabular}

Figure 10-3: Boxcar averaging kernel (highlighted cell is $i^{\text {th }}$ pixel).

A 0.250 in. by 0.250 in. (201-pixel by 201-pixel for 800 dpi DXR images) kernel was used to smooth the image. This kernel size was selected because profiles of the topography from regions of different corrosion severity indicated that it would usually provide a reasonable representation of the local average surface for fracture mechanics purposes. It was also selected because it approximates the diameter of typical eddy current probes, and the inspection resolution ${ }^{14}$ achieved. The resulting averaged thickness data is referred to in this thesis as a thickness map. An example of a smoothed corroded surface as well as the original surface is presented in Figure 10-4.

Using this degree of smoothing a direct comparison between the DXR thickness map, eddy current, pulsed eddy current and ultrasonic data may be made. This is useful since eddy current is the main technique used to assess corrosion damage in aircraft structures (Boeing, 1996).

\footnotetext{
${ }^{14}$ The signals for eddy current and ultrasonic inspections are essentially averaged over an area equal to the size of the probe diameter. Therefore the resolution of these techniques is equal to the probe diameters.
} 

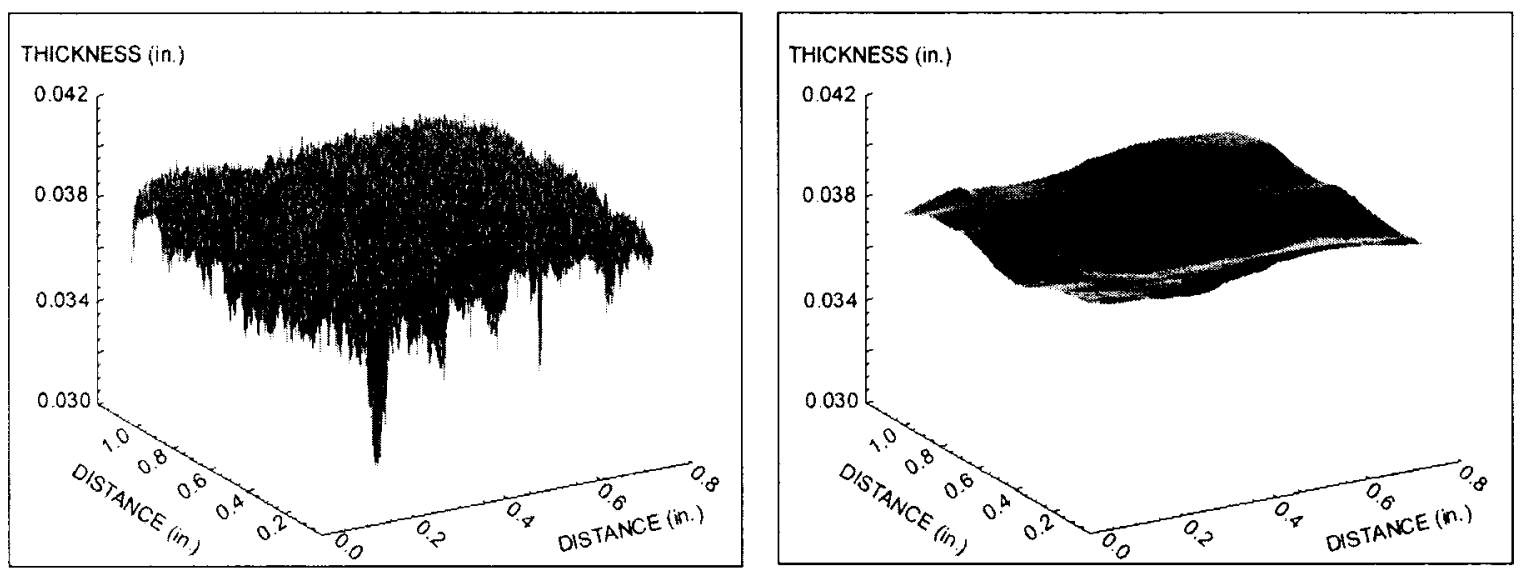

Figure 10-4: Original corroded surface with corresponding smoothed image (Specimen MSD511-045).

The calibrated and smoothed thickness map of the corroded surface and original corroded surface are used to isolate corrosion pits.

\subsection{Corrosion Pit Detection}

The accurate detection and measurement of corrosion pits is paramount for surface topography analysis. It is crucial to be able to distinguish corrosion pits from small variations in the corroded surface, hereinafter referred to as surface roughness. There are many different methods that could be applied to accomplish this goal. Wavelet transforms, and thresholding, were the two most popular shape recognition techniques, found in the literature.

\subsubsection{Corrosion Pit Detection Techniques}

Numerous methods to identify corrosion pits and analyse their geometry were investigated. The most recent, and perhaps the most promising technique for image analysis was the wavelet transform. The wavelet transform is quite similar to the Fourier transform, in that a time function is mapped into a two-dimensional function (or space). The wavelet, maps the original function to a scale-space domain ( $a$ and $b$ ) whereas the Fourier transform maps to a frequency-time domain ( $\omega$ and $\tau$ ) (Chan, 1995). As such the wavelet is ideally suited to analyse two-dimensional images. 
A very modest description of wavelet analysis will be given here. More detailed and elaborate explanations of multiresolution and image analysis using wavelets is presented by Kaiser (1994), Starck et al. (1998) and Meyer (1991). The premise behind multiresolution image analysis using wavelets is that the data often contains information stored in different layers of the image. By decomposing the original data into different resolution scales, faint phenomena, or patterns can be detected (Starck et al., 1998). The decomposition is achieved by splitting the image into a "blurred" version at a coarser scale (i.e. $\Delta b=2 \tau$ ) and the features from the previous scale (i.e. $\Delta b=\tau$ ), successively smoothing the image, extracting the prominent details at every stage (Kaiser, 1994). These features can be isolated and analysed depending on the requirements.

For this research the features being extracted would be regions of lower thickness, which constitute corrosion pits in the calibrated DXR image. These regions could be isolated, and measured to develop the needed statistics. The advantage of using wavelets over other analysis techniques is their computational efficiency. As compared to the Fast Fourier Transform (FFT) which requires $n \log (n)$ computations, where $\mathrm{n}$ is the number of input data points, the wavelet transform requires only $n$ calculations (Starck et al., 1998). This is advantageous when dealing with large image files, as is the case for the MSD specimens.

The wavelet transform provides an efficient technique for detection of image features. The complication arises in the implementation of wavelets to detect and measure corrosion pits in the DXR images. As there are many different wavelet transforms available, studies to determine the most suitable function for this application are required. Once a wavelet type has been chosen, variables are needed to define the image features that represent corrosion pits. Some work has been done in this area by Frantziskonis et al. (2000) but only for individual, well defined, corrosion pits. A robust method for identifying and measuring corrosion pits for a large specimen (corroded MSD specimen) is not available. Development of such a method using wavelet transforms is beyond the scope of this thesis. 
From the outset, a simple and straightforward approach for quantifying the corroded surface topography was desired. Detection of corrosion pits in DXR images was accomplished using thresholding. Thresholding defines a range of brightness values in the original image and selects the pixels within this range as belonging to the "foreground" while all other pixels are considered the "background" (Russ, 1992). Once this is accomplished, the data can be presented as a binary image, where the background appears as black, and the foreground is white.

Thresholding requires two images of the same region. The first image was the original calibrated DXR image, and the second was the calibrated thickness map image (defined in Section 10.3). The calibrated DXR thickness value at each pixel location is compared to the same array location in the thickness map. If the calibrated thickness value is less than the thickness map value minus the threshold, that location is considered to be located within a corrosion pit (refer to Equation 10-1).

\section{Corrosion pits $=$ where[calibrated thickness LT (calibrated thickness map - threshold)] \\ Corrosion pit map(corrosion pits) $=65535$

The first line in equation 10.1 determines the location of all corrosion pits in the original image, while the second line sets those regions to white (a greyscale value of 65535 for 16-bit images).

For the current analysis a threshold of 0.003 in. was used. This was based on discussions with Brooks and Prost-Domasky (Analytical Processes Engineered Solutions Inc.). It is believed, based on preliminary fracture mechanics analysis, that pits smaller than 0.003 in. deep do not significantly influence fatigue characteristics in lap joints. Further sensitivity studies need to be performed to refine this value. 


\subsubsection{Pit Segmentation and Labelling}

The next step is to group pixels that belong to the same pit, and be able to distinctly identify each pit in the image. The first part is accomplished using the SEGMENT function written in $\mathrm{IDL}^{\circledR}$, which sets each array element identified as belonging to a pit to white (pixel value of 65535) and all others to black (pixel value of 0 ). This creates a binary pit map image of the corroded surface that highlights all corrosion pits of interest. An example of this is presented in Figure 10-5. It is important to note that the background of the image is black, while the corrosion pits (white) make up the foreground.

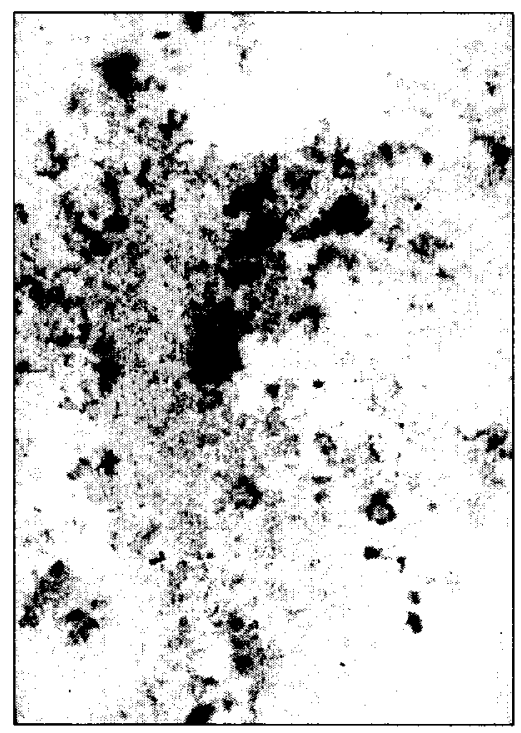

(a)

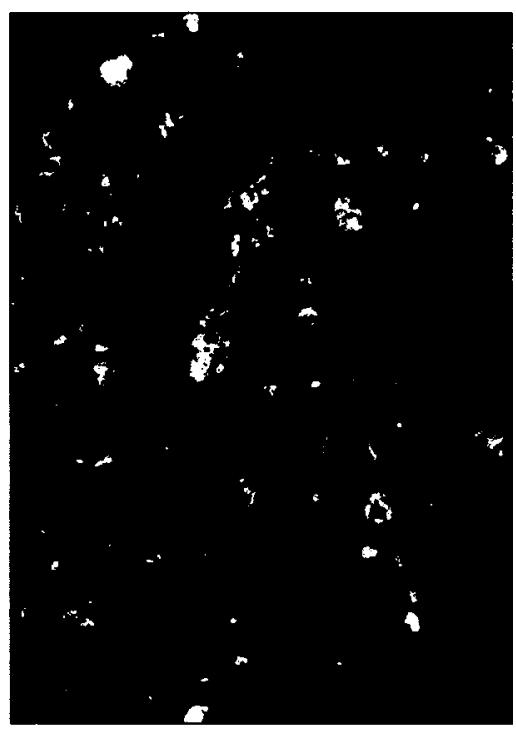

(b)

Figure 10-5: Corrosion pit map example (section taken from specimen MSD511045). (a) Original greyscale DXR image, (b) pit map of the corresponding region. 
Looking at Figure 10-5 (a) many small regions, on the order of 1 pixel in size, are present. These regions may represent pits measuring approximately $0.001 \mathrm{in}$. diameter, or Gaussian noise $^{15}$ in the image. Pits approximately $0.001 \mathrm{in}$. in diameter are similar size to many particles in aluminum 2024-T3, and are not considered to have a major influence on crack nucleation for corroded joints. Gaussian (random) image noise is undesirable as it introduces false thickness measurements into the analysis. To improve the efficiency and accuracy of the analysis these regions were removed. This is accomplished using a morphological opening which removes small features (e.g. noise) from the image, while retaining primary image features (Russ, 1992).

A morphological opening is an erosion operation followed by a dilation operation. The erosion operation removes the edges of all foreground regions (white regions in Figure 10-5 (b)) that touch the background pixels (black regions). If one foreground pixel was located by itself, surrounded by the background, this pixel would be removed. The result is that all extraneous pixels are permanently removed from the image. As a result, the foreground features (corrosion pits) will shrink since the edge pixels have been removed. If left this way, measurements of corrosion geometry would be inaccurate. To counteract this effect, a dilation operation is applied which restores the size of the foreground features. Dilation (the reverse of erosion) sets any background pixel touching a foreground pixel to ON (i.e. sets it equal to the foreground) (Russ, 1992). This results in the addition of a layer of pixels around periphery of all regions, restoring the primary image features (corrosion pits) to their original size.

Another process applied to the pit map image is a morphological closing. This operation is the reverse of the morphological opening. It is a dilation operation followed by an erosion, which fills in any gaps within the foreground clusters. This serves to remove any single background pixels present within the corrosion pit regions. The final result is a corrosion pit map as shown in Figure 10-6.

\footnotetext{
${ }^{15}$ Gaussian noise in digitised images is random intensity variations mainly due to inaccuracies in the digitisation process (transparency scanner for the case of DXR).
} 


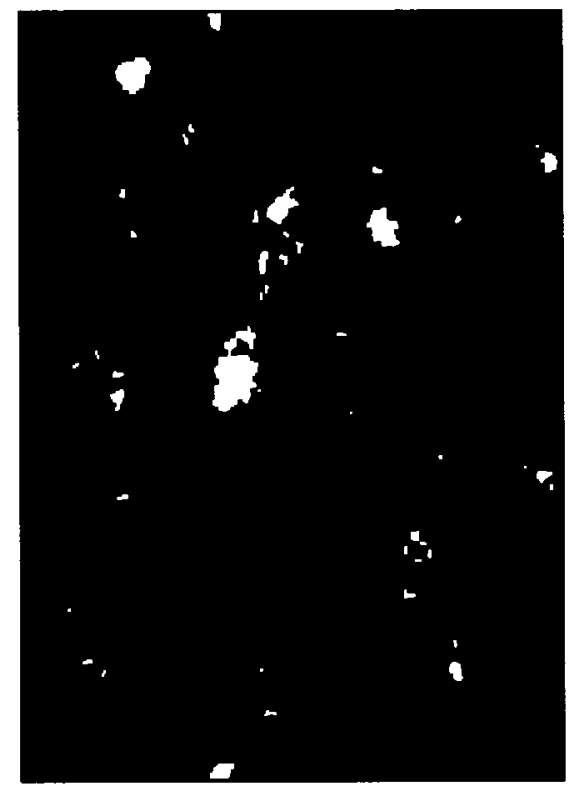

Figure 10-6: Corrosion pit map from Figure 10-5 after application of a morphological opening and closing operation.

In the pit map each pit must be identified for future analysis. To accomplish this, the $L A B E L_{-} R E G I O N$ function built into the $\left.\mathrm{IDL}^{(}\right)$program was used. This function consecutively labels all of the distinct regions of a bi-level image with a unique region index. A region is a set of non-zero pixels within a neighbourhood surrounding the pixel under examination. The result of the function is an integer array of the same dimensions with each pixel containing its region index. A region index of zero indicates that the original pixel was zero and belongs to no region (i.e. the background) (Research Systems Inc., 1997-1). Thus, all the pixels belonging to an individual pit may be isolated, and analysed. Figure 10-7 is an example of the pit map where each pit region has been labelled. Note the progression of pit shading from dark to light, representing the incremental labelling of corrosion pits.

Once the corroded surface image is segmented and labelled both the pit map and the labelled pit map are saved as Tiff (Tag Image File Format) image files, since they support 16-bit unsigned integer data. 


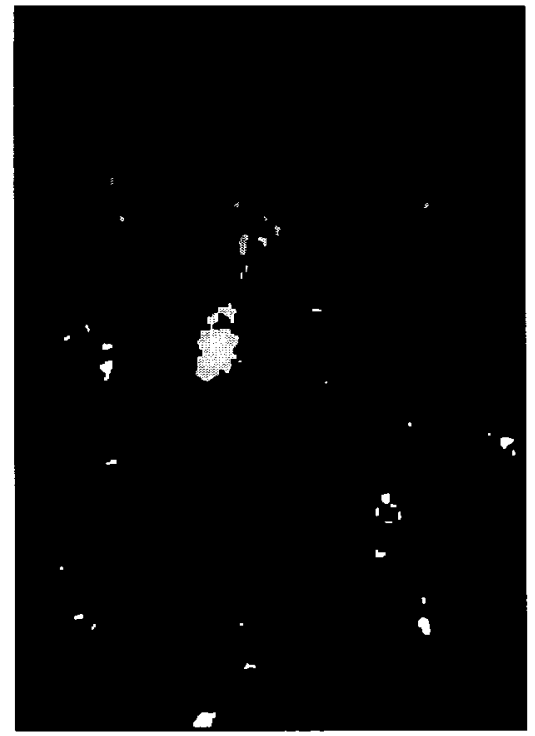

Figure 10-7: Labelled corrosion pit map (section taken from specimen MSD511-045) Note: The labelled pit map has been contrast-enhanced for presentation.

\subsection{Measurement of Corrosion Pit Geometric Parameters}

In order to classify corrosion pitting damage, the geometric parameters of each pit identified in the previous section must be measured. Initially, all geometric parameters were considered, e.g. pit depth, $x$ and $y$ pit dimensions, planform area etc. This data was used to classify the corrosion pits with respect to the geometric parameters. As every corrosion pit could not be analysed, commonly occurring geometry was investigated.

\subsubsection{Corrosion Pit Geometry Measurement Using Optical Microscopy}

Optical micrographs of cross-sectioned and polished corroded 2024-T3 specimens were evaluated to determine typical corrosion pit shapes. A selection of these micrographs is presented in Figure 10-8. Using these images it was determined which simplified geometry, such as a hemisphere, a hyperboloid or some other geometry, would best represent the corrosion pits.

The hemispherical geometry could only represent pits having a diameter-to-depth ratio of 2.0, which is not the case for many corrosion pits observed in fuselage joints. Using a hyperboloid shape would allow a deep slender pit to be represented for finite element 
modelling. Geometry such as an elliptic paraboloid would allow representation of pits, which vary in depth, width as well as length (refer to Figure 10-1) which would be more representative of actual corrosion pits than a hyperboloid.
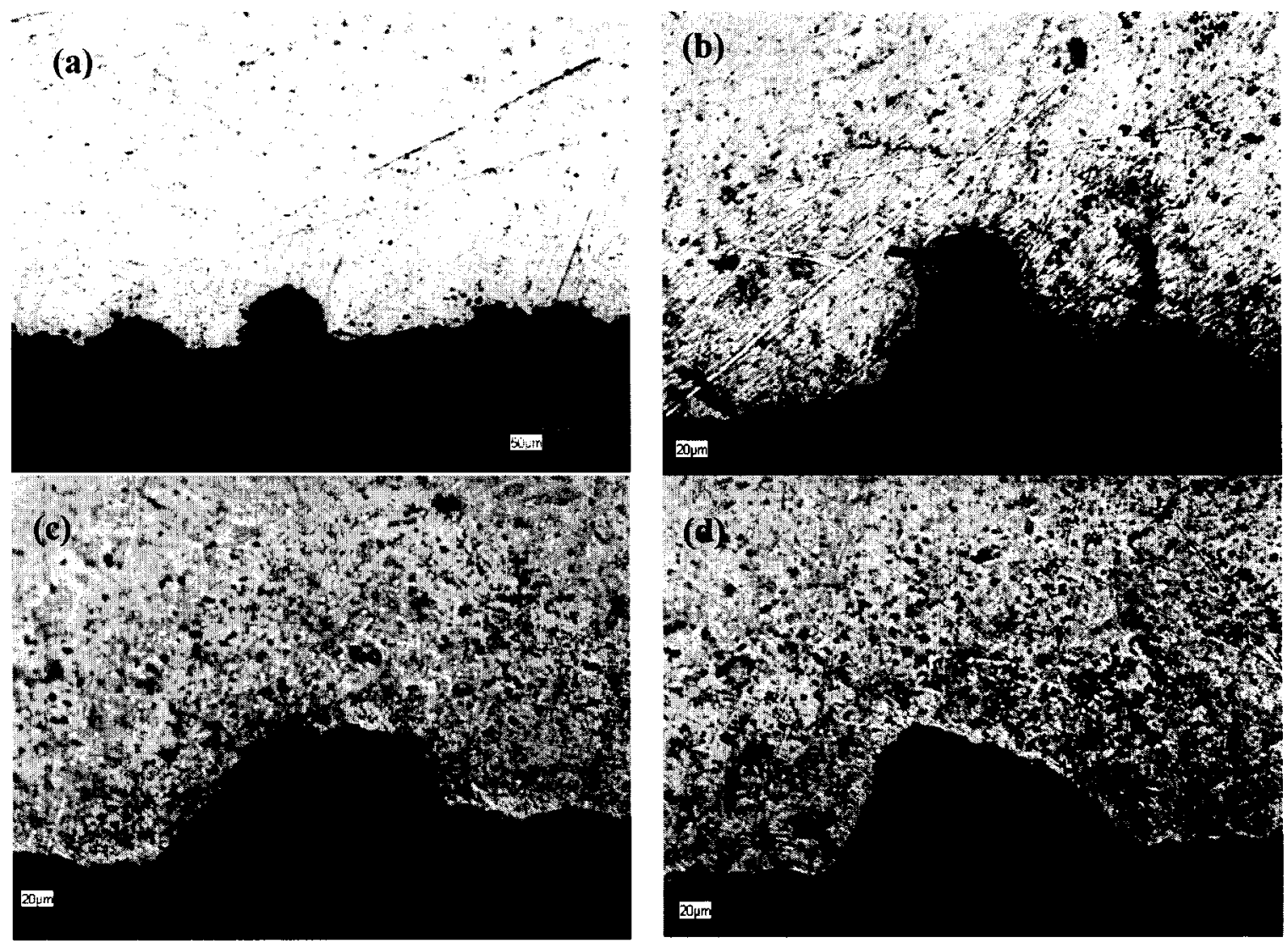

Figure 10-8: Samples of polished, corroded sections of 2024-T3 aluminum specimens (courtesy of Bellinger at NRCC).

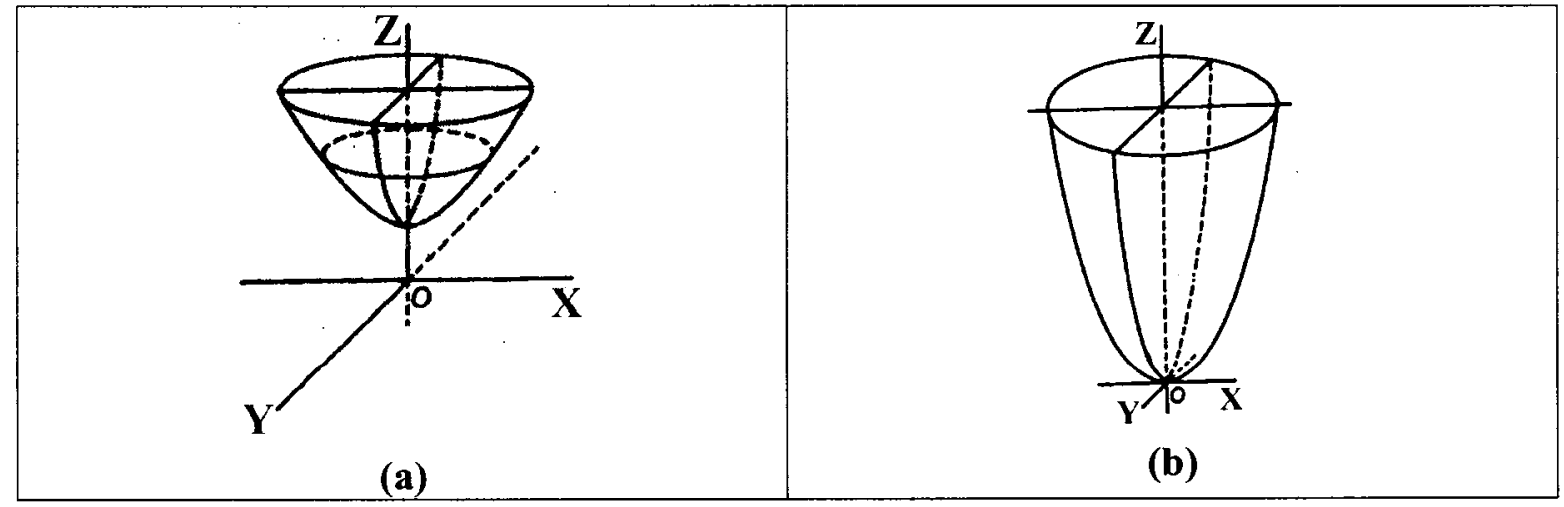

Figure 10-9: Possible simplified geometry used to model corrosion pits (a) Hyperboloid (b) Elliptic paraboloid. 
The hyperboloid was selected to represent corrosion pit geometry. Selection of the hyperboloid over an elliptic paraboloid was due to the available stress concentration factor results for hyperboloid cavities in thin plates (refer to Section 11.0).

The important parameters required to describe the pit geometry using the hyperboloid are the pit depth and the diameter. Since pits are often elongated, the diameter was assumed to equal the average of the measured width and length (refer to Figure 10-1).

\subsubsection{Measurement of corrosion pit geometry using IDL ${ }^{\circledR}$ analysis}

Measurement of corrosion pit geometry was accomplished using the labelled pit map image in conjunction with the calibrated thickness data. For each corrosion pit identified in Section 10.4.2, all of the pixels representing the pit were determined using the labelled pit map image. Each unique region in this image was given a pixel value corresponding to the region identification number (i.e. pits are consecutively labelled 1 through 20 , if 20 corrosion pits were identified). The location and value of the maximum pit depth could then be determined by investigating these same array locations in the original calibrated thickness data.

The length of the corrosion pits (as defined in Figure 10-1) was determined by subtracting the minimum $\mathrm{x}$ co-ordinate from the maximum $\mathrm{x}$ co-ordinate of the pit (Figure 10-10). The same approach was used for measuring the width.

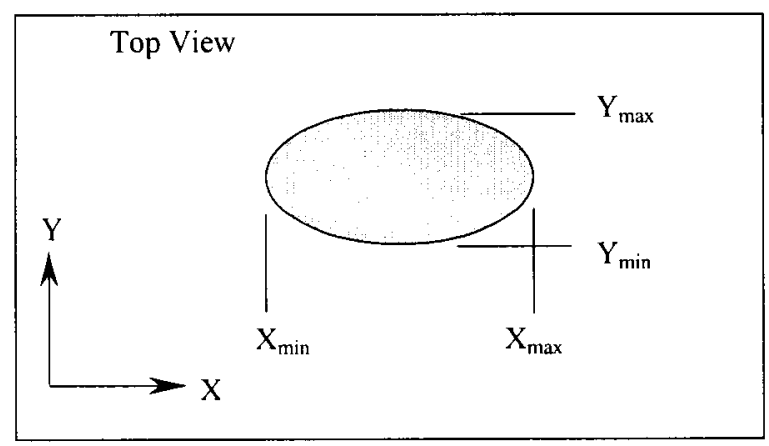

Figure 10-10: Maximum and Minimum pit co-ordinate diagram. 
The pit area is determined by summing the number of pixels comprising the corrosion pit region in the pit map image. Since the pixel dimensions are known (0.00125 in. by $0.00125 \mathrm{in}$.) the total area of the pit can be calculated. The pit diameter $\left(D_{\text {pit }}\right)$ is calculated as:

$$
D_{p i t}=\frac{\left(X_{\max }-X_{\min }\right)+\left(Y_{\max }-Y_{\min }\right)}{2}
$$

Other geometric parameters can be derived using the pit depth, length, width and area. Ratios of the length/width, area/depth, length/depth, and width/depth were all calculated and saved in an ASCII text file for future analysis.

\subsection{Corroded Surface Topography Analysis Results}

\subsubsection{Thickness Map Results}

Thickness map data was compared to eddy current inspection data to determine whether the chosen kernel size was representative of these inspections. Figure 10-11 presents line profile data for the countersunk sheet of specimen 037 midway between the middle and lower rivet rows. No thickness calibration for eddy current was available which makes it impossible to quantify the difference in thickness readings between the two sets of data. The general agreement of these curves indicates the smoothing kernel size used to create the thickness map is adequate. The thickness map provides a good representation of the eddy current c-scan data obtained for the outer sheet of the MSD specimens. 


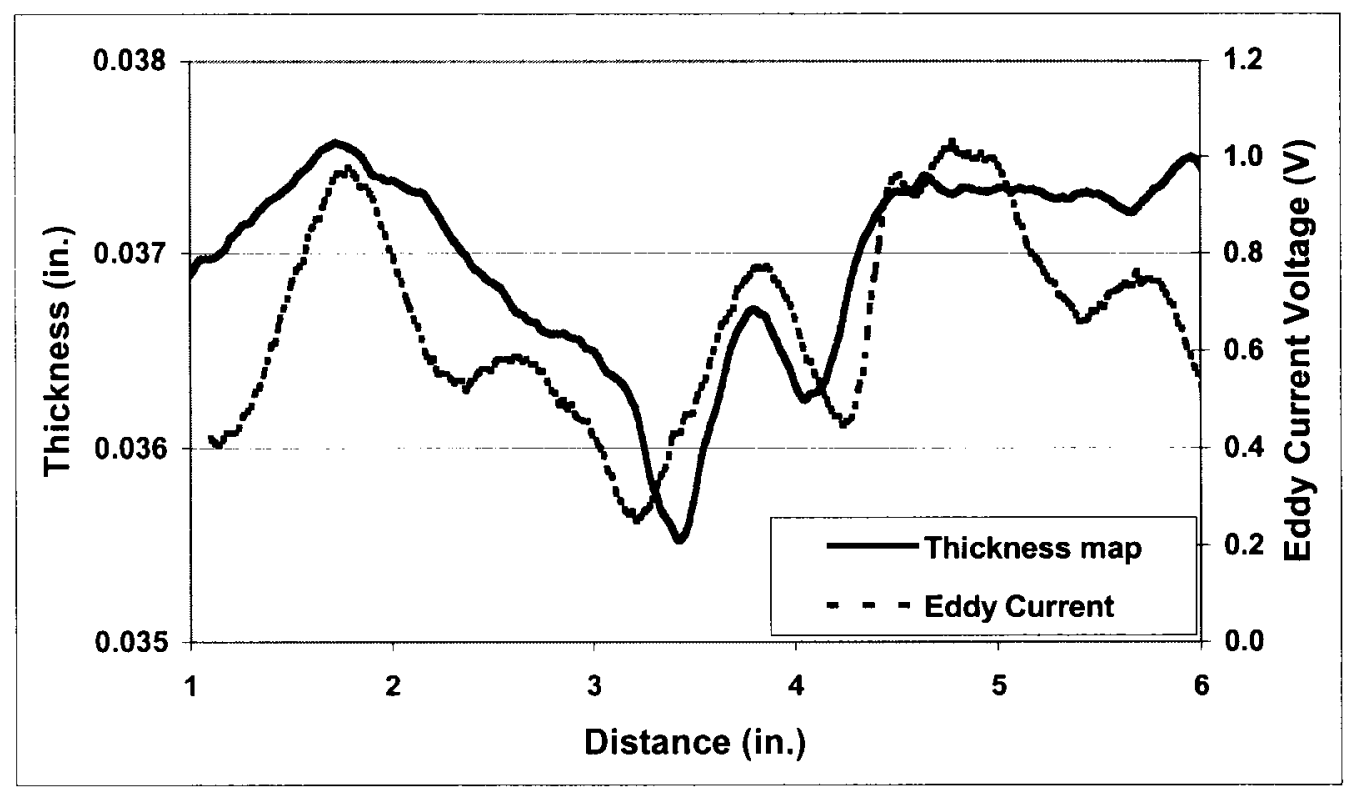

Figure 10-11: Comparison of line profiles for thickness map and eddy current data between the middle and lower rivet rows specimen 037 .

\subsubsection{Corrosion Pit Analysis Results}

Pit maps were developed for each of the eight corroded sheets analysed. The size and distribution of pits deeper than 0.003 in. are highlighted as the white regions in Figure 10-12. The pit map images for all specimens are presented in Appendix C.

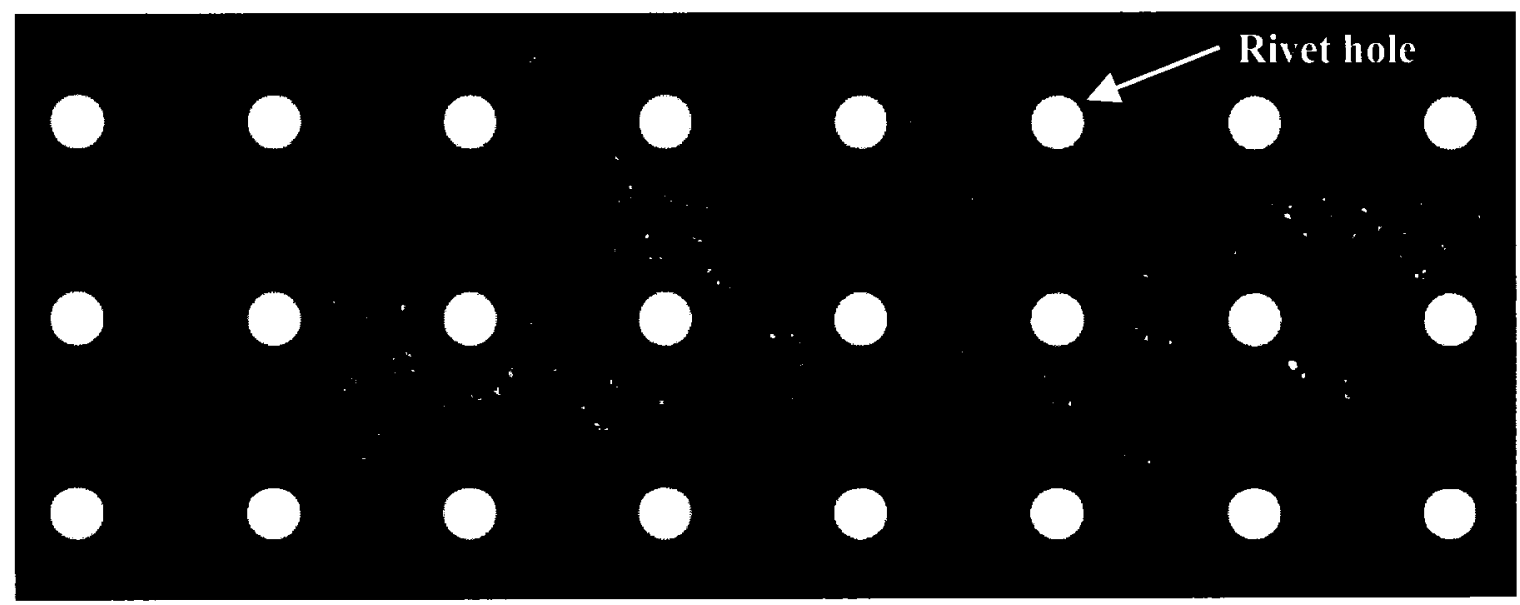

Figure 10-12: Pit map image for outer sheet of specimen 050. White regions, excluding rivet holes, represent corrosion pits. 
After all eight corroded sheets were analysed, the pit depth results were compiled to produce probability distributions of pit depth for various levels of local thickness loss (Figure 10-13). The population sizes, mean values and standard deviations for these three distributions are shown in Table 10-1. The pit depth probability distributions are believed to be representative of the population in corroded clad 2024-T3 aluminum sheet. However, more data is needed to build confidence in these results.

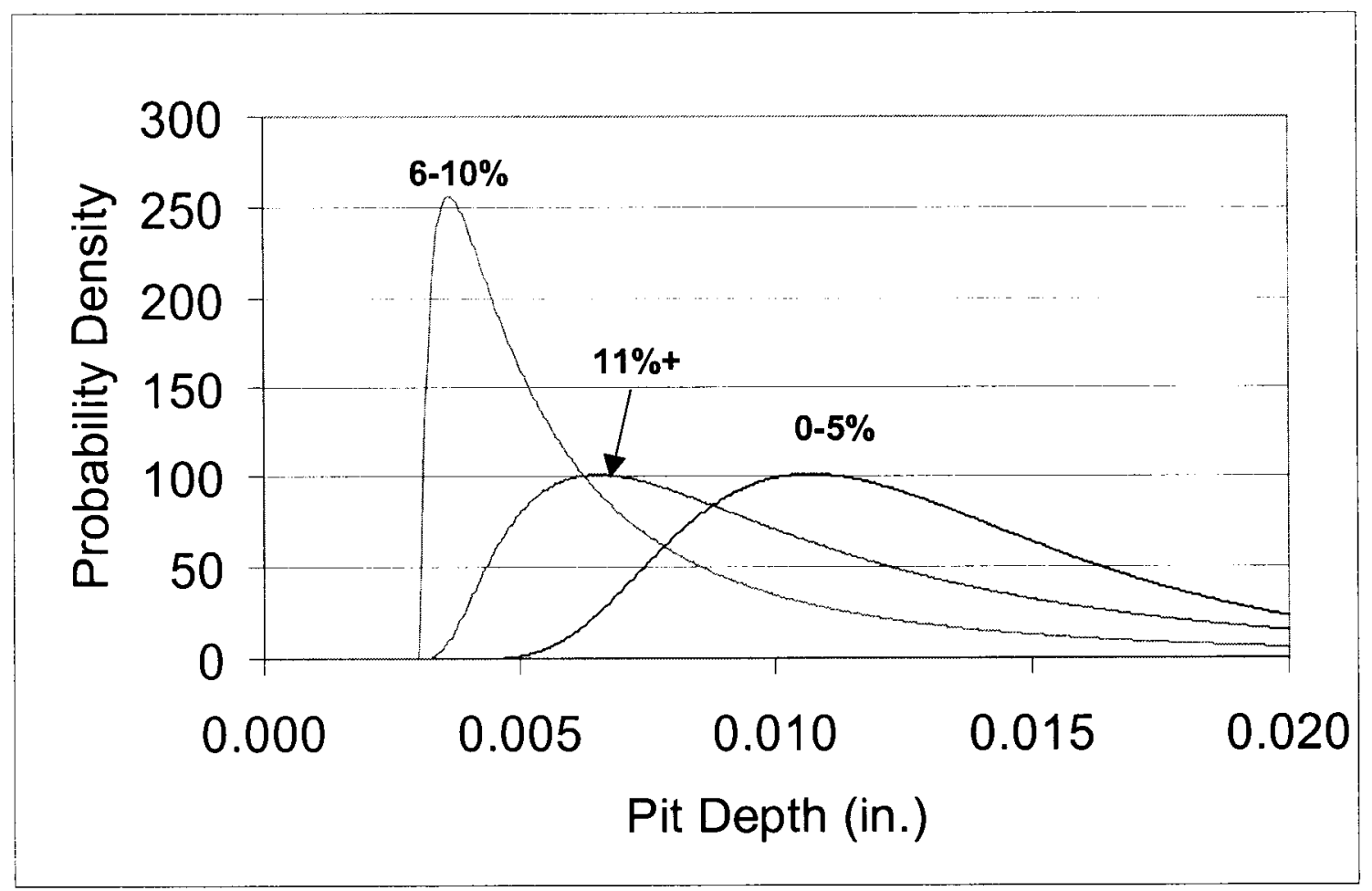

Figure 10-13: Lognormal probability density functions of pit depth for various levels of local corrosion thickness loss.

Note: Density functions have been normalised such that the area under curves is equal to 1.0 .

Table 10-1: Population information for pit depth probability density distributions.

\begin{tabular}{|c|c|c|c|}
\hline $\begin{array}{c}\text { Percent Thickness } \\
\text { Loss }\end{array}$ & Population Size & Mlean & Standard Deviation \\
\hline $0-5 \%$ & 760 & $0.011 \mathrm{in}$. & 0.022 in. \\
\hline $6-10 \%$ & 1885 & $0.004 \mathrm{in}$. & $0.006 \mathrm{in}$. \\
\hline $11 \%+$ & 136 & $0.007 \mathrm{in}$. & $0.009 \mathrm{in}$. \\
\hline & Total $=\mathbf{2 7 8 1}$ & & \\
\hline
\end{tabular}


Both the mean and variability (standard deviation) of pit depth initially decrease as the corrosion increases above 5\% thickness loss. They then increase as the average thickness loss increases above $10 \%$. It is believed that corrosion pits coalesce, forming deep and wide corrosion pits. Figure 10-13 seems to indicate that this pit coalescence occurs at corrosion levels of approximately $11 \%$ average thickness loss, and above. Preliminary evidence of this phenomenon has also been reported by Bellinger et al. (2000).

\subsubsection{Pit Geometry Validation}

White light interferometry (Wyko ${ }^{\circledR}$ NT2000 optical profiler) confocal microscopy and SEM were used to verify the pit geometry determined from the DXR image analysis. Low spatial resolution $(0.0005$ in. $(\sim 13 \mu \mathrm{m})$ pixel size $)$ surface profiles were obtained for 0.30 in. by 0.23 in. $(7.5 \times 5.9 \mathrm{~mm})$ regions surrounding several individual corrosion pits using the $\mathrm{Wyko}^{\circledR}$ system. The same pits were scanned using both the confocal microscope and the $\mathrm{Wyko}^{\circledR}$ optical profiler at high-resolution, $\sim 6 \times 10^{-5} \mathrm{in}$. and $10 \times 10^{-5}$ in. pixels sizes $(1.6 \mu \mathrm{m}$ and $2.5 \mu \mathrm{m})$ respectively.

The pit geometry determined using high resolution $\mathrm{Wyko}^{\circledR}$ scans was considered to be the "true" geometry of the corrosion pits based on the precision of the measurements $\left(4 \times 10^{-9}\right.$ in.). The pit shapes determined using image analysis were compared to the true geometry. A typical result is presented in Figure 10-14, and shows a close agreement between DXR image segmentation and the optical surface measurement techniques. Several other comparisons of DXR pit geometry with Wyko ${ }^{\circledR}$ and confocal microscopy are presented in Appendix C.

The lower resolution scans were used for direct comparison with the pit depths determined from DXR topography analysis since the high-resolution scans did not have a sufficient reference surface from which to measure pit depths. The average surface height of the $0.30 \mathrm{in}$. by $0.30 \mathrm{in}$. region surrounding the corrosion pit was used as a reference to measure the pit depth. This reference for pit depth is used for the line profiles showing the sectional view of the pits in Figure 10-15. 


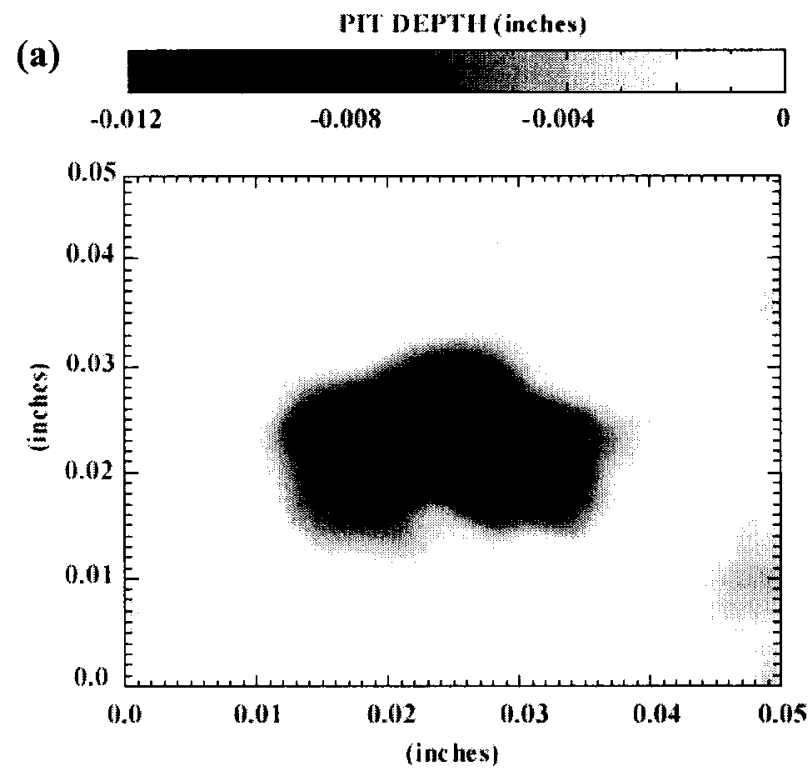

(b)
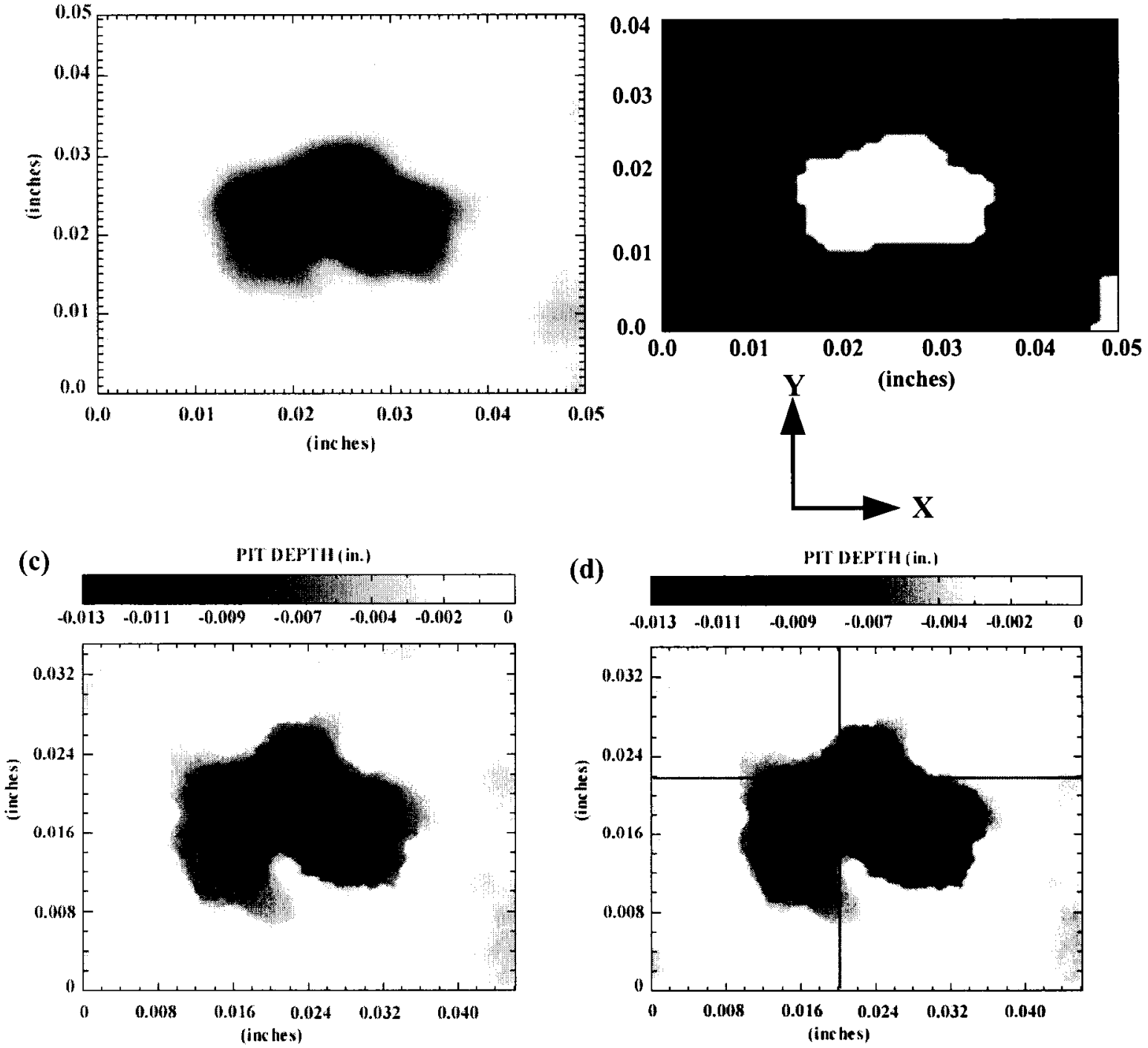

Figure 10-14: Comparison of corrosion pit geometry for specimen 050 csk pit 4 (a) DXR image (b) Segmented pit geometry from DXR image analysis (c) Confocal microscope (d) $\mathrm{Wyko}^{\circledR}$ optical profiler.

Note: vertical and horizontal lines on the $\mathrm{Wyko}^{\circledR}$ image indicate locations of line profiles used in Figure 10-15. 


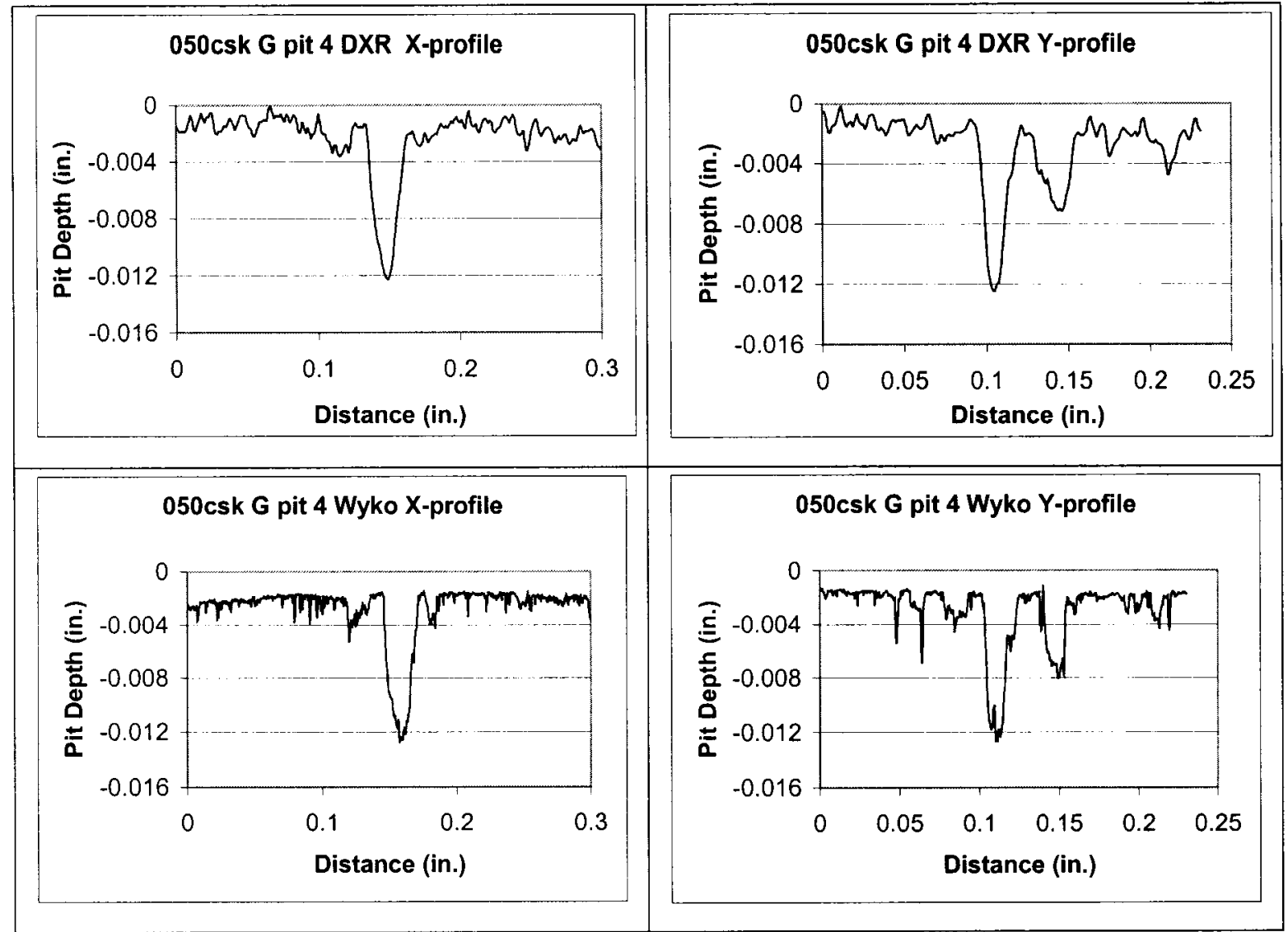

Figure 10-15: Sample line profile comparisons of DXR to Wyko ${ }^{\circledR}$ low-resolution scans.

Table 10-2 summarises the pit depth measurement comparison. The results show that pit depths determined by analysis of DXR data were within \pm 0.0004 in. $( \pm 11 \mu \mathrm{m})$ of the actual corrosion pit depths obtained from a similar analysis of $\mathrm{Wyko}^{\circledR}$ data.

DXR pit measurements have also been compared to fractographic measurements made after ASTM E466 specimen testing of naturally corroded aircraft material (Bellinger et $a l ., 2000$ ), and testing of MSD specimens. The pit depths determined using DXR analysis were generally consistent with those found at crack nucleation sites in both specimen types.

These results show that corrosion topography for large areas can be measured efficiently and accurately, using the DXR image analysis techniques developed in this thesis. The resolution of this topography data should be sufficient for fracture mechanics modelling 
of corrosion-fatigue (refer to Section 10.0). The importance of this measurement accuracy for fracture mechanics-based analysis will be discussed in Section 12.0.

Table 10-2: Comparison of pit measurements using DXR topographical analysis to low-resolution Wyko ${ }^{\circledR}$ scans.

\begin{tabular}{|c|c|c|c|c|c|c|}
\hline \multirow{3}{*}{ Specimen } & \multicolumn{6}{|c|}{ Pit Depth Measurement (in.) } \\
\hline & \multicolumn{2}{|c|}{ DXR Analysis } & \multicolumn{2}{|c|}{ WYKO } & \multicolumn{2}{|c|}{ Absolute Difference } \\
\hline & X-Profile & Y-Profile & X-Profile & Y-Profile & $X$-Profile & Y-Profile \\
\hline 037csk E pit 3 & 0.0055 & 0.0055 & 0.0065 & 0.0078 & 0.0009 & 0.0023 \\
\hline 049csk L pit 2 & 0.0061 & 0.0061 & 0.0052 & 0.0067 & 0.0009 & 0.0006 \\
\hline 049drv L pit 2 & 0.0054 & 0.0054 & 0.0051 & 0.0046 & 0.0003 & 0.0008 \\
\hline 050 csk G pit 1 & 0.0078 & 0.0078 & 0.0067 & 0.0080 & 0.0012 & 0.0002 \\
\hline 050csk G pit 4 & 0.0105 & 0.0105 & 0.0099 & 0.0097 & 0.0005 & 0.0008 \\
\hline
\end{tabular}

\subsection{Digitised X-Ray Error Assessment}

Since the digitised $\mathrm{x}$-ray technique is being used to measure such small variations in thickness it is crucial that the errors involved are minimised. Krizan (1999) found several DXR images which had variations in the digitised image intensity, as well as an offset between the calibration wedge and the specimen. Mechanical measurement of the calibration wedge, noise in the DXR image along the calibration wedge, and thickness calibration methods used were the governing factors in the DXR error (Krizan, 1999).

A great deal of effort has been put forth to reduce unwanted errors experienced in the past. A preliminary error assessment was performed by the IAR on the equipment and techniques used previously for DXR analysis. Numerous changes to both the equipment and the analysis techniques have been made, and a proper error assessment of the revised DXR process was performed.

Each step in this process introduces error. The error in each step was estimated, and the total error for the final thickness values calculated. This section discusses the results of the detailed error assessment performed using the DXR image for specimen MSD511037. 


\subsubsection{Measurement Error}

Measuring the thickness of both the calibration wedge and the calibration strips introduces errors due to the accuracy of the micrometer measurements. The micrometer used had two spherical measuring surfaces. Thus, the measurements represented the maximum thickness in the small contact region. The precision of the micrometer used was $0.00005 \mathrm{in}$. The resulting measurement error was determined to be $\pm 0.0001 \mathrm{in}$. based on a series of measurements of a known thickness.

\subsubsection{Surface Roughness Error}

The surface roughness of the calibration wedge and the calibration strips could possibly lead to thickness variations in the DXR image. To address this concern surface roughness measurements were taken of both the pristine calibration strips and the wedge. In both cases, the surface roughness was approximately $4 \times 10^{-5}$ in. $(1 \mu \mathrm{m})$, equivalent to the $32 \mu$-in surface finish specified for the wedge. This error is quite small, and would not significantly impact the overall process error.

\subsubsection{Radiographic Film Grain Variations}

The radiographic film used for high-resolution DXR imaging was Fuji 25 Ix Industrial film ( 7 in. by 17 in.). This film provides high contrast and very small grain size, averaging $1.0 \times 10^{-5}$ in. $(0.25 \mu \mathrm{m})$. Grains are polydispersed, meaning they vary slightly in size but are dispersed equally throughout the film. With the current scanner, the maximum spatial resolution achievable is $0.00125 \mathrm{in} .(31.75 \mu \mathrm{m})$, at $800 \mathrm{dpi}$, significantly larger than the film grain size. As such it has been assumed that the variation in grain size and distribution in the $\mathrm{x}$-ray film was a negligible source of error.

\subsubsection{X-Ray Beam Variation}

Any variation in the $\mathrm{x}$-ray beam intensity would typically result in a gradual variation of film density, which corresponds to DXR thickness. Any such variation would appear as a gradual increase or decrease in thickness of the specimen away from the centre of the 
$\mathrm{x}$-ray beam. This change would be detected by comparing the measured thickness values of the $0.040 \mathrm{in}$. calibration strips to the calibrated DXR thickness at the same location.

Analysis of the calibration strips for specimen MSD511-037 indicates that no such deviation exists (Figure 10-16). The effect of the x-ray beam variation is not considered to introduce significant error into the thickness calibration, and is thus neglected in the error calculations.

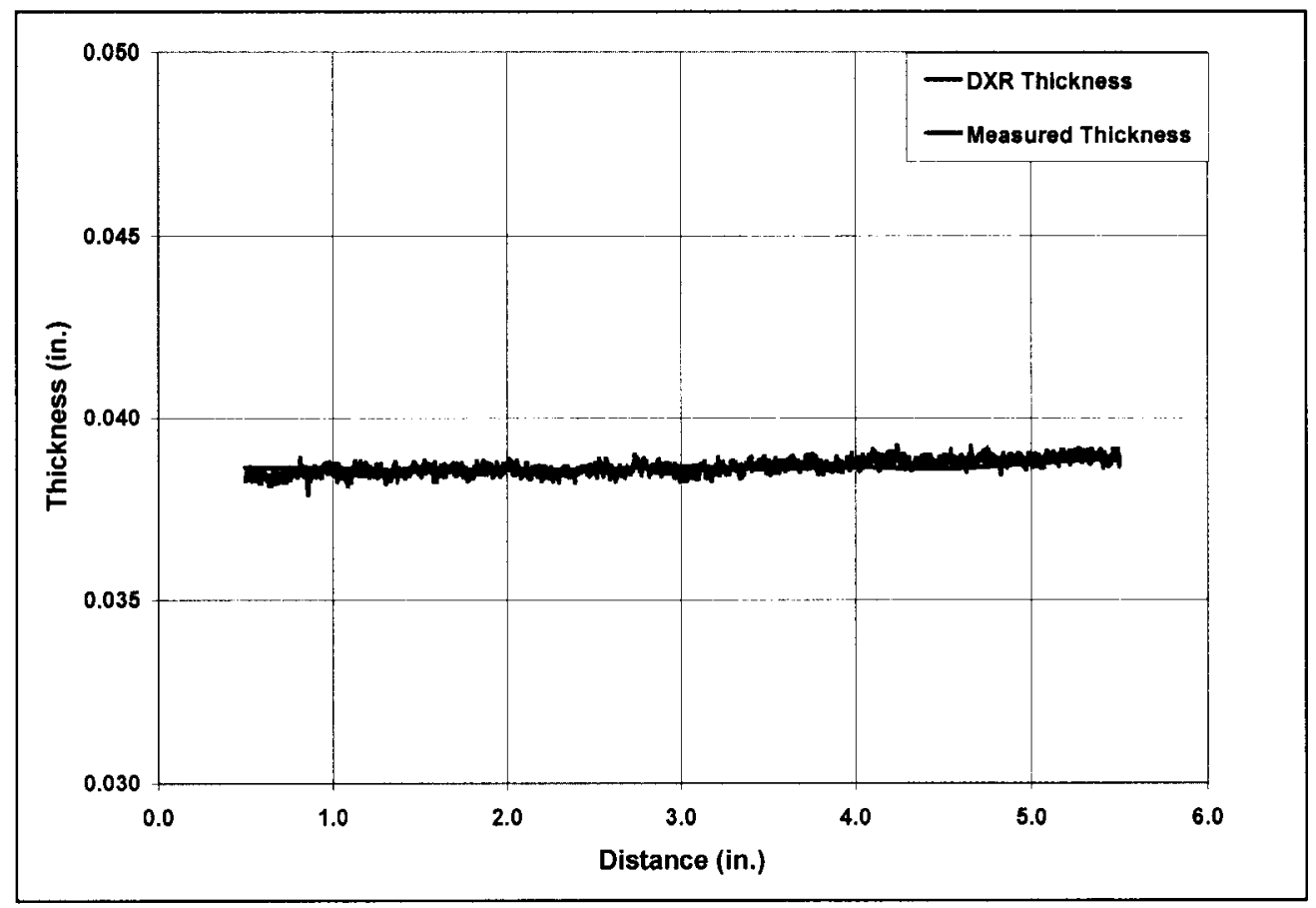

Figure 10-16: Line profile of calibration strip \#2 taken from DXR image for MSD511-037 csk.

\subsubsection{Intensity Variations in the Processed X-Ray Film}

Several past $\mathrm{x}$-ray films contained both abrupt and gradual intensity variations caused by the film processor. It is believed that the development solution was not applied in a uniform fashion, creating unwanted density variations in the developed films. To rectify this problem a new processor, with better process control, was used for all DXR work presented in this thesis. 
Figure 10-16 was used to check for processing variations. Similar to the $\mathrm{x}$-ray beam intensity variations, there do not appear to be any gradual or drastic variations in film density in the calibration specimens. Therefore, this source of error was also disregarded for the purpose of estimating errors in the current DXR system.

\subsubsection{Calibration Error}

The calibration procedure uses an exponential curve fit of thickness of the wedge vs. image greyscale value to derive the calibration equation. This approach inherently introduces error to the calibrated thickness values. The $\mathrm{R}^{2}$ value for specimen 037 data was 0.999 meaning it is an excellent curve fit, and the errors should be quite small.

In order to estimate the errors introduced by this calibration method, micrometer thickness measurements of the calibration strips were compared to the average calibrated thickness values in a 5-pixel by 5-pixel region at the same location. The difference between these readings was taken as the calibration error.

A 5-pixel by 5-pixel averaged value was used to remove the local variations in the image from x-ray film noise, material composition variations, and digitisation noise. This size was selected to provide the smallest region that would provide a sufficient population to average, without being influenced by sheet thickness variations.

The calibration error was found to be 0.0002 in. using the standard error formula ((Sum of squared residuals $/ n$ ) $)^{1 / 2}$, where $n$ is the number of measurement points.

\subsubsection{Collective Errors}

Several errors are difficult to assess separately, thus they are considered as one error source. Errors introduced by x-ray film variations (Section 10.7.3) or material composition variations are considered negligible, but they do enter into the final error. A more significant error source is the digitisation error. Considerable effort has been made to estimate and reduce the errors introduced in the digitisation process. 
The variation of pixel greyscale values was first estimated using a calibrated step tablet, shown in Figure 10-17. This technique provided an indication of the scanner noise at various optical densities. However, it was soon realised that the step tablet had variations of $2 \%$ of the optical density of the step under investigation, or 0.02 optical density units, which ever was greater. This method is useful for comparing the accuracy of multiple scanners, but was considered less appropriate for estimating the errors introduced in scanning radiographic films.

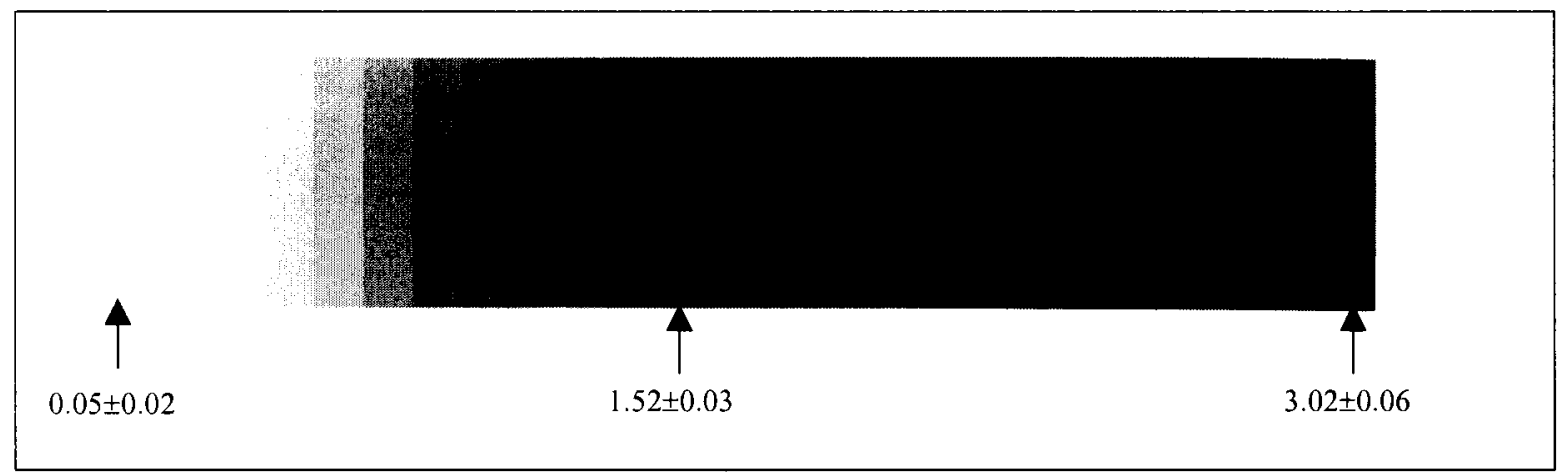

Figure 10-17: Kodak step tablet of varying optical densities.

The variation of calibrated thickness values within the 5-pixel by 5-pixel $(0.0063 \mathrm{in}$. by 0.0063 in.) region of known thickness on the calibration strips (Section 10.7.6) was used to approximate the errors introduced by the scanner, as well as the film and the material composition. Sheet thickness variations in this region were considered to be negligible, as the changes in thickness are generally a gradual effect caused by the rolling process.

The resulting variation in the pixel values was determined to be \pm 0.0004 in. for the 0.040 in. thick calibration strips. 


\subsubsection{Total DXR Error}

The final error is calculated as the root-squared sum of the individual errors, as the sources of error are considered to be independent of one another. As such, the errors are unlikely to have their maximum values occur simultaneously. A summary of the pertinent errors is presented below.

$\begin{array}{ll}\text { Measurement Error: } & \pm 0.0001 \mathrm{in.} \\ \text { Surface roughness: } & \pm 0.00004 \mathrm{in} . \\ \text { Calibration Error: } & \pm 0.0002 \mathrm{in} . \\ \text { Film, material and scanner noise: } & \pm 0.0004 \mathrm{in} .\end{array}$

The total thickness error at each pixel location in the calibrated DXR image was determined as follows:

$$
\begin{aligned}
& E=\left[(\text { Measurement Error })^{2}+(\text { Surface Roughness })^{2}+(\text { Calibration Error })^{2}+\right. \\
& \left.(\text { Collective Errors })^{2}\right]^{1 / 2} \\
& E=\left[(0.0001)^{2}+(0.00004)^{2}+(0.0002)^{2}+(0.0004)^{2}\right]^{1 / 2} \\
& E=.0005 \text { in. }
\end{aligned}
$$

The average error of \pm 0.0004 in., found comparing the DXR topography measurements to the real topography (Section 10.6.3) validates the total error estimate. This error represents an uncertainty of $15 \%$ for a 0.003 in. pit. For deeper corrosion pits, which tend to be crack nucleation sites, this error is proportionally less. Therefore, the effect of this error on fracture mechanics modelling results may not be significant, but has not yet been investigated.

Based on this error assessment the largest portion of the total error is believed to be from the digitisation process. In an effort to reduce these errors improved digitisation equipment and procedures are being investigated. 


\subsection{CORROSION PIT SCF ESTIMATION}

\subsection{Finite Element Modelling}

In an effort to develop a relationship between pit geometry and stress concentration factor at the root (bottom) of the pit, a range of pit depths and diameters were modelled using NASTRAN ${ }^{\circledR}$. The set of pit geometry was selected to encompass corrosion pits observed in the MSD specimens and sectioned corroded specimens (Section 10.5.1). The effects of reduced sheet thickness, corrosion pillowing, or out-of-plane bending on SCF are not included.

A two-dimensional model was initially considered, but was quickly discarded as it would not capture the three-dimensional characteristics of a corrosion pit. Using 2-D modelling would overestimate the pit stress concentration since the pit would be modelled as an edge-notch in a thin sheet. The stress concentration would increase to infinity as the pit depth is increased to the full depth of the sheet, which is obviously not the case for a corrosion pit in a semi-infinite plate.

Hence, a quarter-symmetry, three-dimensional finite element model was developed. Pits were modelled as hyperboloid cavities (Figure 10-9) in a 0.040 in. thick sheet of 2024-T3 aluminum. The ratio of sheet width to pit radius was kept large (ranging from 10 to 25) to avoid edge effects which would result in less accurate SCF estimates. The model geometry is shown in Figure 11-1. Four-noded tetrahedron elements were used due to the curved nature of the pit surface.

Biaxial applied loads, with a 2:1 load ratio for hoop stress versus axial stress, were used to simulate the loading conditions in longitudinal fuselage joints. The magnitude of the applied loads was chosen to produce an average remote stress of approximately $1.0 \mathrm{ksi}$. The stress concentration is determined as $\sigma_{\max } / \sigma_{\text {remote, }}$ where $\sigma_{\max }$ occurs at the bottom of the pit. 

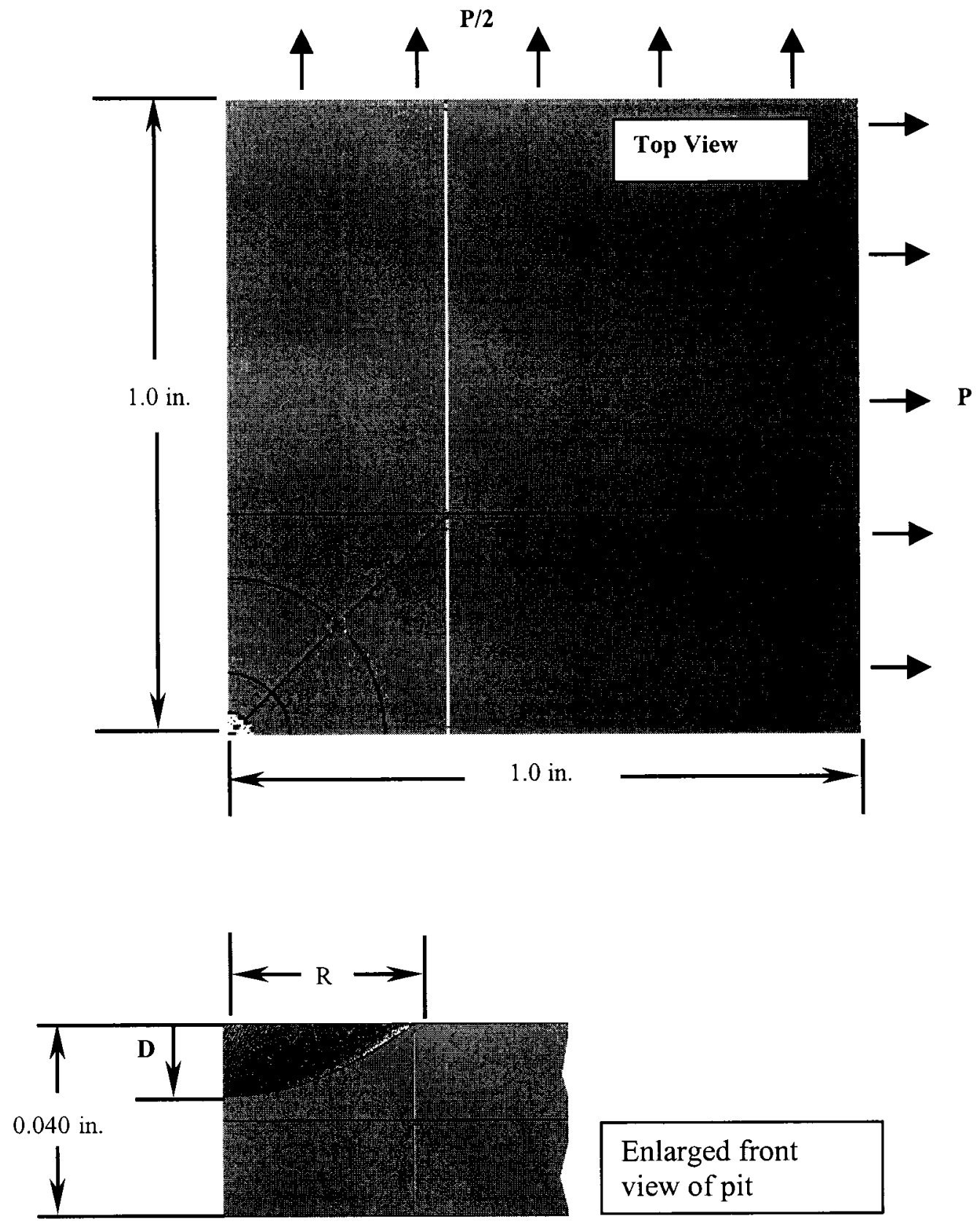

Enlarged front view of pit

Figure 11-1: Corrosion pit finite element model geometry.

Note: D-pit depth, $R$-pit radius.

To determine if clusters of corrosion pits influence SCF, another model was created. Three additional corrosion pits of the same size and shape were placed in close proximity to a pit that was previously modelled. To determine the location of these pits in relation 
to the central pit, corrosion scenarios in the MSD specimens were observed. The model geometry used is presented in Figure 11-2. Using the same loading and boundary conditions, the SCF for the central pit was compared to the previous results for a single pit.
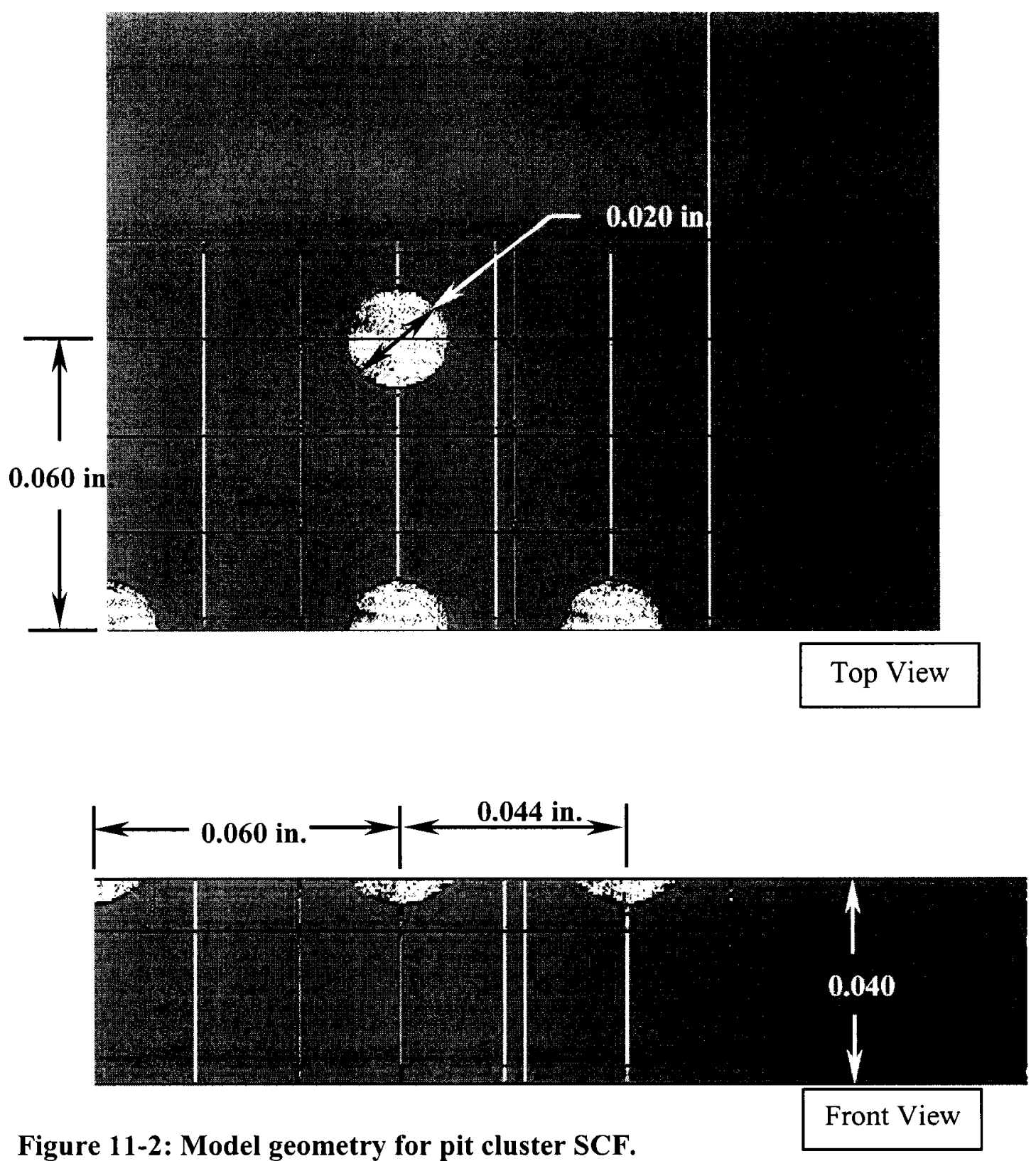

Figure 11-2: Model geometry for pit cluster SCF. 


\subsubsection{Finite Element Model Validation}

In order to build confidence in the SCF results, the finite element model must first be validated against established results for similar model conditions. Reed and Wilcox (1970) present results for stress concentrations of hyperboloid cavities in a thin plate under equal biaxial loading. Both $60^{\circ}$ and $45^{\circ}$ hyperboloid geometry were assessed. Stress concentrations were obtained through finite element analysis and experimental results.

To verify the corrosion pit SCF, modelling of two cavity shapes (shown in Figure 11-3) investigated by Reed and Wilcox (1970) was performed. The identical modelling techniques used in Section 11.1 were applied to these cases, adjusted for the different specimen shapes. Tabulated analysis results are presented in Table 11-1.

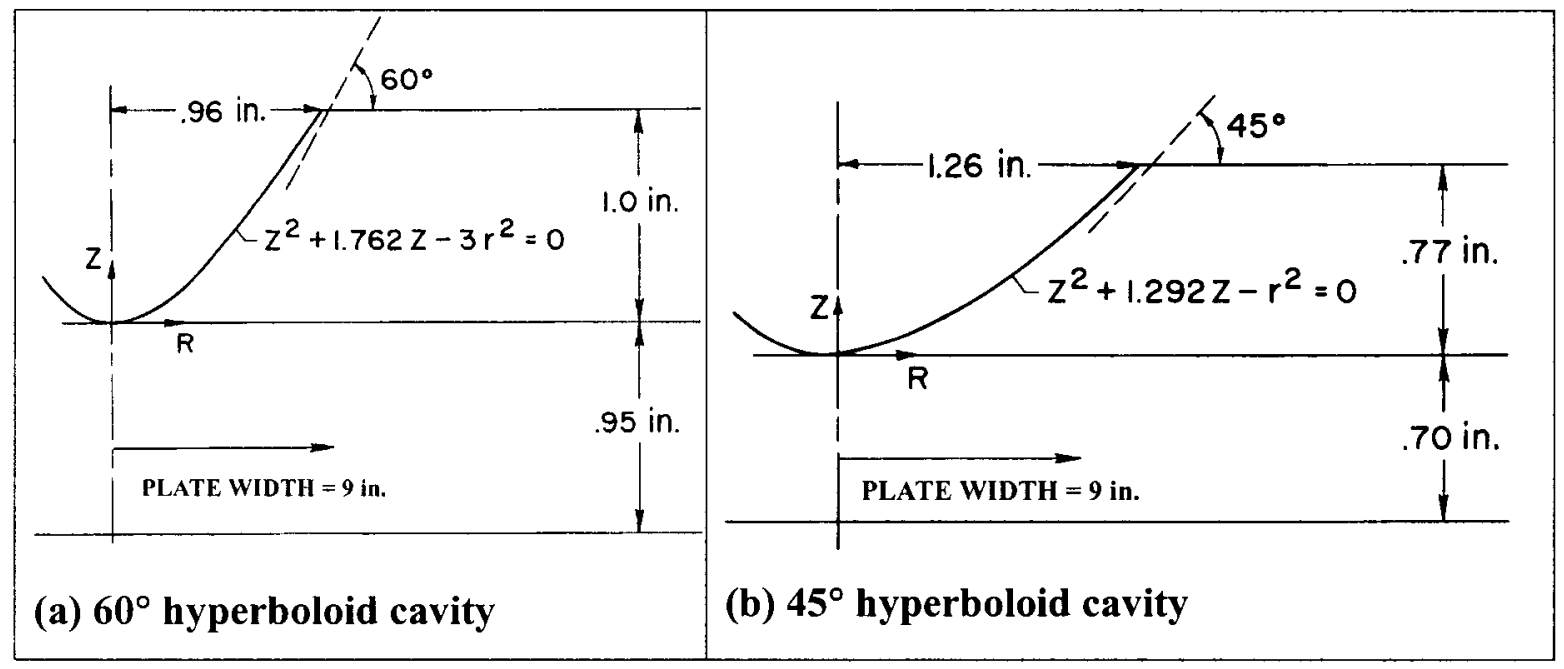

Figure 11-3: Hyperboloid cavity geometry investigated by Reed and Wilcox. 
Table 11-1: Comparison of SCF results to those produced by Reed and Wilcox (1970) through experimentation and analysis.

\begin{tabular}{|c|c|c|c|}
\hline Cavity (icometry & $\begin{array}{c}\text { Experimental SCF } \\
\text { Results } \\
\text { (Recd and Wilcos) }\end{array}$ & $\begin{array}{c}\text { Analytical SCF Results } \\
\text { (Reed and Wilcos) }\end{array}$ & $\begin{array}{c}\text { Finite Element Model } \\
\text { SC F Results }\end{array}$ \\
\hline $\begin{array}{c}60^{\circ} \text { hyperboloid } \\
(\mathrm{h} / \mathrm{d}=0.51)\end{array}$ & 3.65 & 3.5 & 3.4 \\
\hline $\begin{array}{c}45^{\circ} \text { hyperboloid } \\
(\mathrm{h} / \mathrm{d}=0.52)\end{array}$ & 3.65 & 3.8 & 3.6 \\
\hline
\end{tabular}

These results verify that the modelling techniques, for hyperboloid cavities in thin plates used in this thesis are suitable.

\subsubsection{Pit SCF Results}

An example of the stress distribution at the base of a pit predicted using FEM is shown in Figure 11-4. A summary of the geometry cases analysed for this thesis and the SCF determined are presented in Table 11-2. Figure 11-5 plots SCF as a function of pit depth for varying pit diameters.
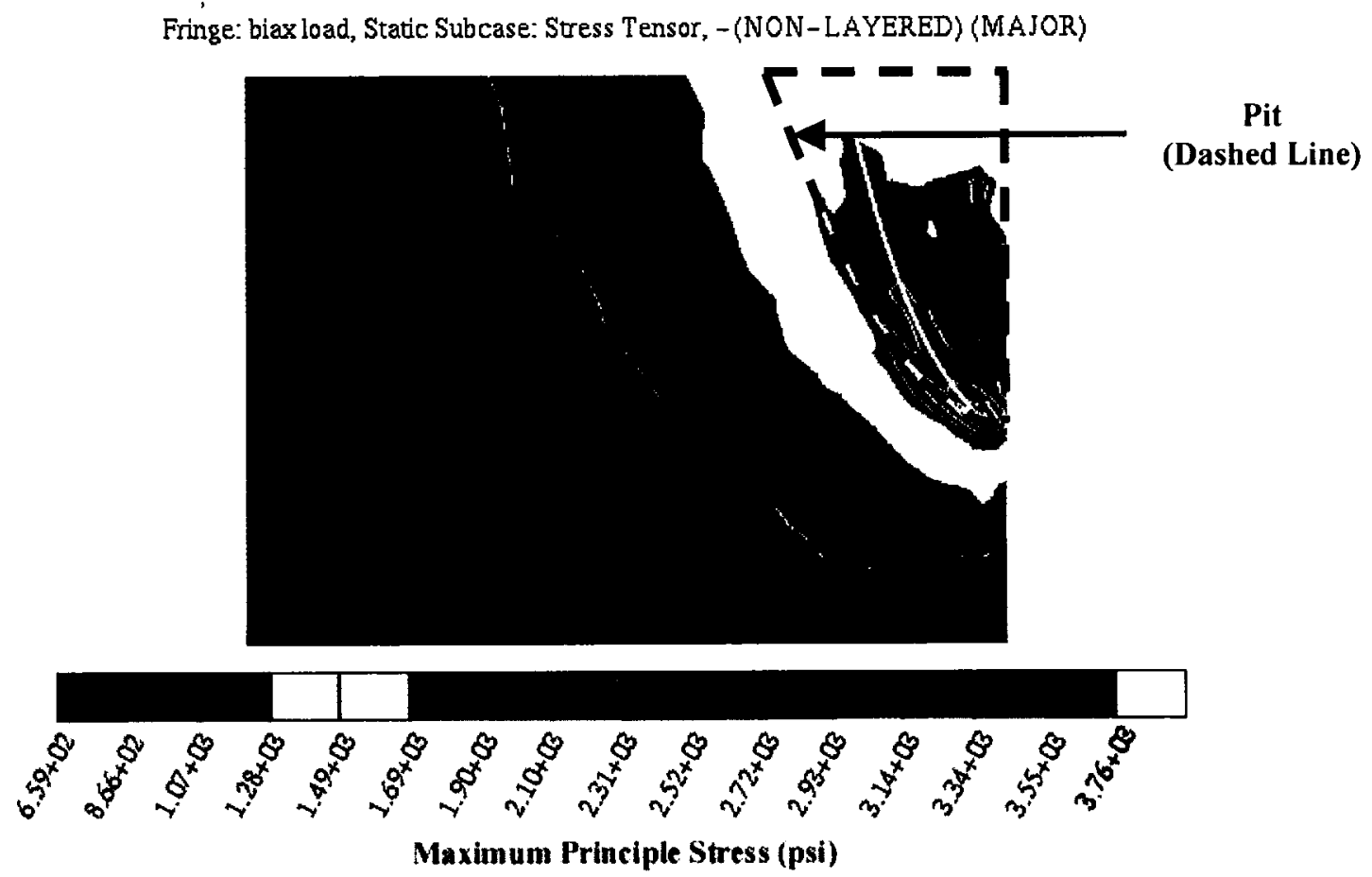

Figure 11-4: Estimated maximum principal stress distribution at the bottom of a corrosion pit (MSD_pit_model_15). 
Table 11-2: Summary of pit SCF models

\begin{tabular}{|l|c|c|c|c|c|} 
Model & $\begin{array}{c}\text { Pit depth } \\
\text { (in.) }\end{array}$ & $\begin{array}{c}\text { Pit Diameter } \\
\text { (in.) }\end{array}$ & $\begin{array}{c}\text { Maximum Stress } \\
\text { (psi) }\end{array}$ & $\begin{array}{c}\text { Remote Stress } \\
\text { (psi) }\end{array}$ & SCF \\
\hline MSD_pit_model_1 & 0.008 & 0.050 & 1250 & 1000 & 1.25 \\
\hline MSD_pit_model_2 & 0.008 & 0.020 & 1581 & 1000 & 1.58 \\
\hline MSD_pit_model_3 & 0.008 & 0.080 & 1230 & 1000 & 1.23 \\
\hline MSD_pit_model_4 & 0.008 & 0.100 & 1170 & 1000 & 1.17 \\
\hline MSD_pit_model_5 & 0.005 & 0.020 & 1300 & 1000 & 1.30 \\
\hline MSD_pit_model_6 & 0.005 & 0.040 & 1190 & 1000 & 1.19 \\
\hline MSD_pit_model_7 & 0.005 & 0.060 & 1110 & 1000 & 1.11 \\
\hline MSD_pit_model_8 & 0.005 & 0.080 & 1100 & 1000 & 1.10 \\
\hline MSD_pit_model_9 & 0.005 & 0.100 & 1020 & 1000 & 1.02 \\
\hline MSD_pit_model_10 & 0.010 & 0.020 & 1750 & 1000 & 1.75 \\
\hline MSD_pit_model_11 & 0.010 & 0.040 & 1470 & 1000 & 1.47 \\
\hline MSD_pit_model_12 & 0.010 & 0.060 & 1420 & 1000 & 1.42 \\
\hline MSD_pit_model_13 & 0.010 & 0.080 & 1360 & 1000 & 1.36 \\
\hline MSD_pit_model_14 & 0.010 & 0.100 & 1360 & 1000 & 1.36 \\
\hline MSD_pit_model_15 & 0.015 & 0.020 & 2220 & 1000 & 2.22 \\
\hline MSD_pit_model_16 & 0.015 & 0.040 & 1980 & 1000 & 1.98 \\
\hline MSD_pit_model_17 & 0.015 & 0.060 & 1750 & 1000 & 1.75 \\
\hline MSD_pit_model_18 & 0.015 & 0.080 & 1700 & 1000 & 1.70 \\
\hline MSD_pit_model_19 & 0.015 & 0.100 & 1590 & 1000 & 1.59 \\
\hline Pit cluster model & 0.005 & 0.020 & 1620 & 1250 & 1.30 \\
\hline
\end{tabular}




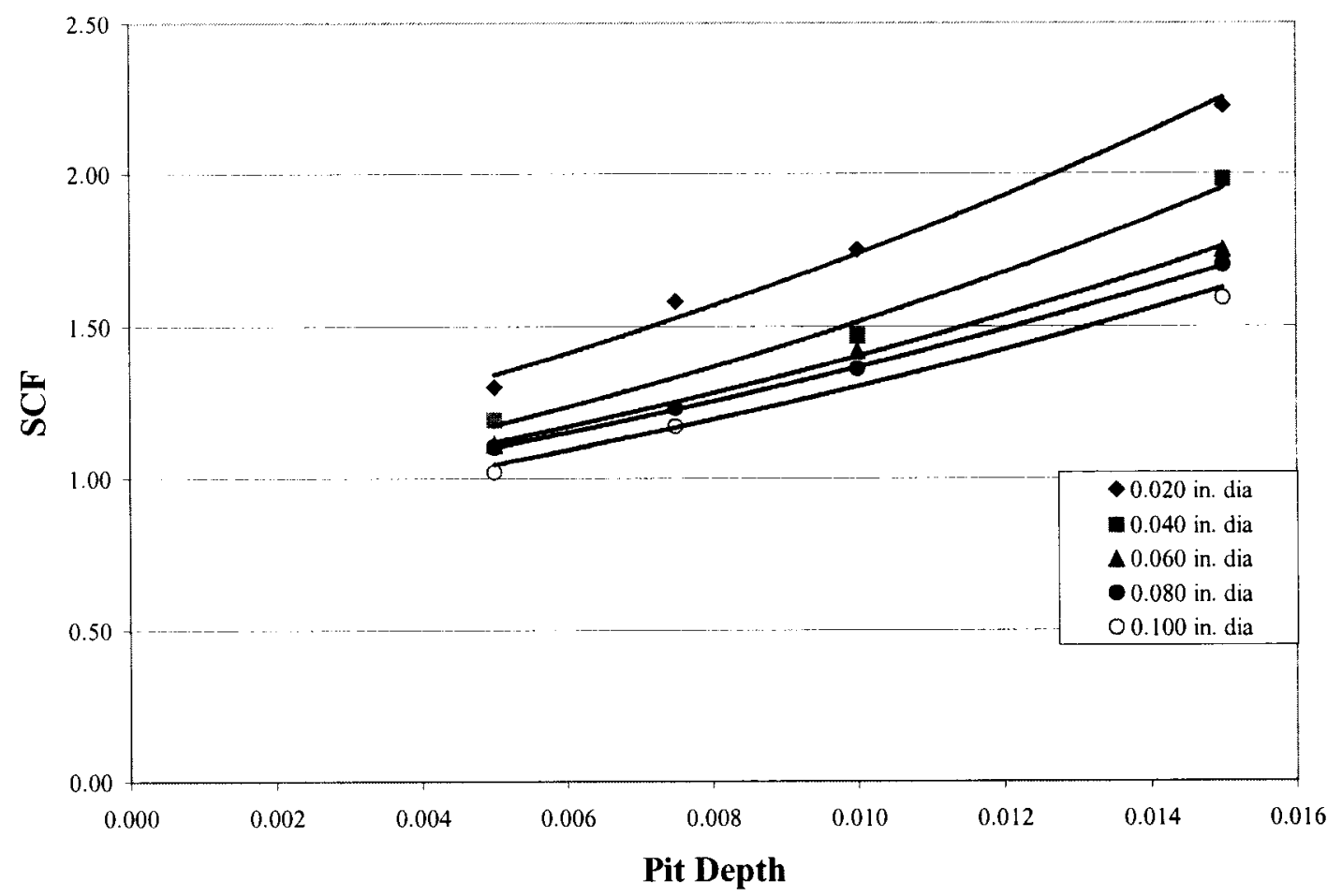

Figure 11-5: Graph of SCF vs. Pit depth for different pit diameters

Pit depth appears to be the dominant factor in determining the SCF for corrosion pits. The SCF is more sensitive to increases in pit depth than increases in pit diameter as shown in Figure 11-5.

Comparing the results of the pit cluster model to MSD_pit_model_5, which has the same pit depth and diameter, shows that there was no change in the SCF with the additional pits present. The spacing of the adjacent pits may be too large, negating the presence of these pits. Using St. Venant's principle, the adjacent pits should be within 2-diameters of the central pit in order to show the interaction of pit SCF. In the current model, the pits adjacent to the central pit are 3-diameters away. However, the SCF is reduced in the presence of closely spaced notches of the same size (Pilkey, 1997). This is most likely the case for closely spaced corrosion pits in a thin sheet. This situation should be investigated further to confirm the SCF of pit clusters. 


\subsection{Stress Concentration Factor Probability Distributions}

Using the relationships established in the previous section, the stress concentration factors were assigned to each corrosion pit using both the average pit diameter and maximum pit depth. The pit stress concentration factors were compiled to produce probability distributions of SCF for various levels of local thickness loss and are presented in Figure 11-6. The population sizes, mean values and standard deviations for these three distributions are shown in Table 11-3.

Table 11-3: Population information for SCF probability density distributions

\begin{tabular}{|c|c|c|c|}
\hline $\begin{array}{c}\text { Percent Thickness } \\
\text { Loss }\end{array}$ & Population Size & Mean & \\
\hline $0-5 \%$ & 760 & 1.38 & 0.15 \\
\hline $6-10 \%$ & 1885 & 1.31 & 0.16 \\
\hline $11 \%+$ & 136 & 1.16 & 0.08 \\
\hline & Total $=\mathbf{2 7 8 1}$ & & \\
\hline
\end{tabular}




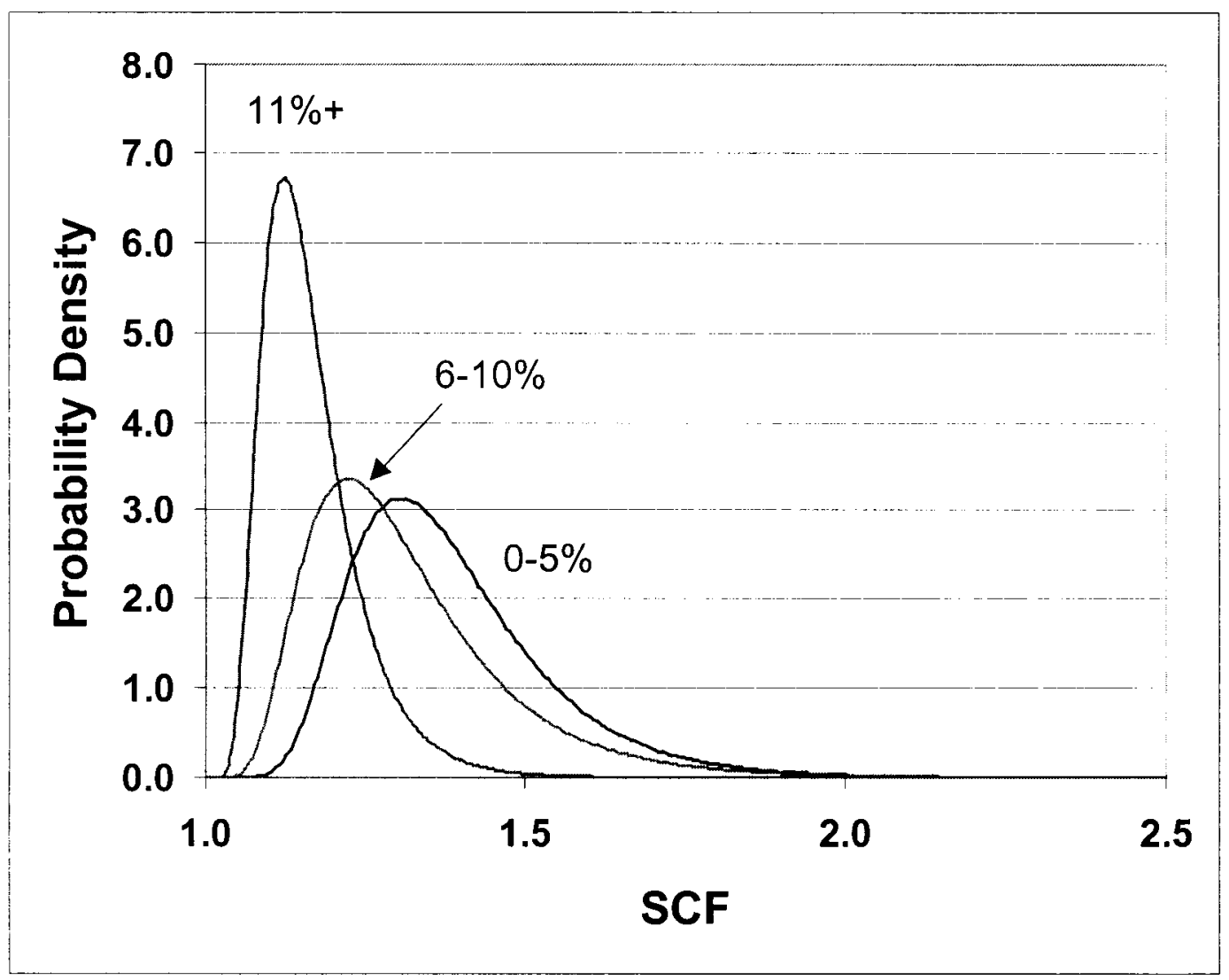

Figure 11-6: Lognormal probability density functions of pit SCF for various levels of local corrosion thickness loss.

Note: Density functions have been normalised such that the area under curves is equal to 1.0

The SCF distributions for these pits do not show quite the same trend as for the pit depth distributions (Figure 10-13). While they show a reduction in the mean and variability of SCF with increased average thickness loss, there is no eventual reversion to a higher mean and variability. Initially deep pits form in the material at numerous locations. These pits are thought to coalesce producing wider, lower aspect ratio pits, which tend to have lower SCF. 


\subsection{DISCUSSION}

In this research work, seven MSD specimens were tested. This brings the total number of specimens tested, in the collaborative research project between Carleton University and the National Research Council of Canada, to 9 pre-corroded and 8 corroded. These specimens were part of the test program developed by Krizan (1999) for testing the corrosion-fatigue characteristics of longitudinal fuselage joints using a specially designed MSD test specimen.

These test results showed a pronounced influence of pre-existing corrosion damage on fatigue properties of riveted fuselage joints. A reduction of visible crack detection life (VDL) of $52 \%$ was observed, when corrosion levels of $5-6 \%$ thickness loss were introduced. Figure 9-37 indicates that the increase of faying surface stress for precorroded specimens reduces the VDL compared to non-corroded specimens. In addition, corrosion pillowing increases the faying surface stress near the rivet holes. Combination of these stresses, tends to promote earlier fatigue crack nucleation, compared to noncorroded MSD specimens.

During the pre-corrosion process 5 of the 9 specimens experienced disbonding in the region of the side-straps. It is believed that the prolonged exposure times, required to achieve the desired corrosion levels, resulted in corrosive attack of the straps. The precorrosion time averaged $60 \%$ longer than for specimens corroded by Krizan (1999), resulting in a $36 \%$ increase in side-strap disbonds.

A repair was designed and implemented on these specimens so that fatigue testing could be performed. The results of these tests indicate that the out-of-plane bending was significantly reduced, compared to other corroded specimens. This resulted in longer VDL for the repaired specimens. Due to the changes in stress-state in these specimens, the fatigue test results were not included in any statistical analysis. However, the specimens were used to analyse the corroded surface topography. 
Post-test analysis of corroded MSD specimens has shown that fatigue cracks tend to nucleate at corrosion pits. To investigate this phenomenon, the corrosion topography of the MSD specimens was quantified using a special digitised $x$-ray technique (DXR), and programs written using IDL ${ }^{\circledR}$.

The accuracy of the DXR measurements is \pm 0.0005 in. Considering the worst case (applying the \pm 0.0005 in. error in pit measurement to a 0.015 in. deep, 0.020 in. diameter pit, refer to Figure 11-5), the uncertainty in SCF is approximately \pm 0.05 (or $2.2 \%$ ). This should be suitable for fracture mechanics modelling, although more fracture mechanics analysis is required to confirm this statement.

Probabilistic distributions of corrosion pit depths and stress concentration factors were developed for the four corroded MSD specimens. The stress concentration factors do not include the stress increase due to material thinning. The results of this analysis, presented in Figures 11-13, and 12-6, indicate that corrosion pitting is a cyclic process. Initially pits form in the aluminum, and increase in depth up to approximately $5 \%$ average thickness loss in the surrounding metal. For more severe corrosion (above $10 \%$ thickness loss) the pits are believed to coalesce, forming wider pits which have lower stress concentration factors (Figure 11-6). Preliminary work by Bellinger et al. (2000) supports these findings.

In the present form, these results could not be applied to fracture mechanics modelling of corrosion-fatigue in fuselage joints. Material thinning, and corrosion pillowing effects on SCF must be considered using the method of superposition. The stress intensity factors must then be calculated using the estimated stress concentration factors and specimen stress distribution.

Another piece of information required for fracture mechanics modelling, is the corrosion pitting distribution within the joint. It is important to determine whether corrosion pitting develops uniformly throughout the joint. There is evidence that for some MSD specimens, pitting around rivets may be less severe than in other areas of the joint. Examples of this are specimens 050 , and 054 . Very little corrosion was present around 
the rivets (Figures 10-23, 10-24 and 10-26), while Figures B-9 and B-10 show more severe corrosion away from rivet.

Once these issues are investigated, a probabilistic representation of corrosion pitting could be used as input to a fracture mechanics-based model for corrosion-fatigue of fuselage joints. The development of such a method would aid aircraft manufacturers and operators in developing more cost effective maintenance practices for ageing aircraft. 


\subsection{CONCLUSIONS}

The main objective of this thesis was to investigate the role of corrosion pitting on the corrosion-fatigue properties of single-shear fuselage joints. Also, techniques for quantifying pitting corrosion damage, including the probability distributions for corrosion pit depths and SCF were developed.

\subsection{Corrosion-Fatigue Testing Using MSD Specimens.}

Testing of 4 pre-corroded and 3 non-corroded specimens was performed. The results of these tests provided insight into corrosion development and corrosion-fatigue interactions for riveted lap joints. Conclusions drawn from these tests were as follows:

\section{A. Corrosion Development}

1. Corrosion levels representative of naturally corroded aircraft, ranging from $5-6 \%$ thickness loss were achieved consistently unless the specimens suffered nuisance corrosion damage to the side-straps.

2. The average exposure time required to corrode the MSD specimens for this thesis was $60 \%$ longer than reported by Krizan (1999). This was due to reduced acidified salt fog production in the Singleton salt fog chamber (SFC) during the first ninety days of exposure. As a result, there was a $36 \%$ increase in the number of disbonds in the region of the side-straps than experienced by Krizan (1999).

3. To avoid extended corrosion exposure times, and corrosion damage in the sidestrap region the salt fog collection rate in the corrosion chamber should be no less than $0.012 \mathrm{cu}$-in. $(0.20 \mathrm{ml})$ per hour.

4. The pillowing-to-thickness-loss (PTL) ratio was effective in estimating the average level of corrosion in the entire joint.

5. The original PTL ratio developed by Krizan (1999) was improved upon using the results of the additional 4 corroded specimens. The revised PTL ratio was $5.9 \pm 0.5$. 
6. The wet-PTL ratio was developed to relate corrosion pillowing to the average thickness loss in the MSD specimen during corrosion, while the interior of the joint contains moisture. The resulting wet-PTL ratio was determined to be $6.4 \pm 0.5$.

7. Several NDI techniques employed showed relatively good qualitative correlation to the final DXR results. Inspection results show a general correlation between all of these techniques. Calibration techniques for eddy current and pulsed eddy current are in development. This will enable a quantitative comparison between the aforementioned inspection techniques.

B. Crack Nucleation and Growth Data

1. Increasing faying surface stresses decreases the VDL.

2. Considering the normalised aggregate crack curves, corroded specimens have longer periods of visible crack growth. Less uniform MSD may offset the material thinning, and other corrosion effects, which would tend to increase crack growth rates.

3. The scatter for fatigue lives of non-corroded specimens was low. This was likely a result of quality control implemented during manufacturing, and the rigorous fatigue testing procedures adhered to.

C. Corrosion-Fatigue Interaction

1. Average corrosion thickness loss of 5-6\% for the MSD specimens, considered moderate for aircraft, resulted in approximately a 52\% decrease in VDL when compared to non-corroded specimens.

2. Heavy fretting damage surrounding rivet holes in the upper row was the main crack nucleation location for non-corroded specimens.

3. Scanning electron microscopy indicates a tendency of fatigue cracks to nucleate at corrosion pits near the countersunk rivet holes.

4. From conclusions 2 and 3 above, it is obvious that crack nucleation in MSD specimens occur primarily at geometric surface asperities, which act as stress raisers. 
5. An increase in membrane, faying surface and bending stresses of $4 \%, 11 \%$ and $70 \%$ respectively was observed between the corroded and non-corroded specimens.

6. The repaired specimens exhibited higher membrane stresses $(2 \%)$, but lower faying surface and bending stresses $(-6 \%$ and $-55 \%$ respectively) than the corroded, non-repaired MSD specimens. This was likely a result of the reduction of shear stiffness in the straps due to the repair. Thus, the load transfer in the straps may be reduced, increasing load transfer and the membrane stresses in the riveted joint.

7. Repaired specimens had longer VDL than corroded specimens with no repair. The reduction in VDL is likely the result of lower faying surface stresses compared to non-repaired, corroded specimens.

8. VDL is strongly dependent on the faying surface stresses. Generally the higher the faying surface stresses the lower the time to visual crack detection.

9. Fretting damage was reduced significantly for corroded MSD specimens when compared to non-corroded MSD specimens. This may be a result of reduced contact forces on the faying surface due to corrosion pillowing.

\subsection{Forensic Analysis of Corroded MSD Specimens}

A post-test analysis of corroded MSD specimens was performed. Using SEM, Wyko ${ }^{\circledR}$ optical profilometry, confocal microscopy and digitised x-radiography (DXR) the corroded surface topography was analysed.

1. An efficient method of extracting quantitative corrosion topography data for the joint sheets has been developed using digitised $\mathrm{x}$-ray and image processing procedures using $\mathrm{IDL}^{\circledR}$.

2. If utilised properly the accuracy of the DXR thickness measurements at an individual pixel is \pm 0.0005 in. The accuracy is strongly dependent on the film processing and digitising equipment. Other factors which affect the accuracy, albeit to a lesser extent, are film grain size, material composition, cleanliness of 
film (dust, dirt particles can introduce artifacts into the images), and mechanical measurements of the calibration system.

3. The accuracy could potentially be improved using a higher resolution scanner and an image smoothing procedure. For example, using a 2500 dpi scanner to digitise the $\mathrm{x}$-ray films, and then applying 3 pixel by 3 pixel smoothing, the image "noise" would be reduced. The effective resolution would be $833 \mathrm{dpi}(2500 \mathrm{dpi} / 3)$. The problem with this approach is that the image files would be approximately ten times the size (memory requirements) of the 800 dpi scans currently performed.

4. Scanning electron microscopy allowed acquisition of 2-D pit geometry from the faying surface, as well as from the fracture surface.

5. The $\mathrm{Wyko}^{\circledR}$ optical profiler provided high-resolution geometry data for individual corrosion pits as well as larger regions of specimen faying surfaces.

6. Confocal microscopy has been performed on numerous corrosion pits to determine their shapes and dimensions. High-resolution images of the corroded surface were obtained using this method.

\subsection{Corrosion Topography Quantification}

The corroded surface topography of MSD specimens was analysed using the forensic analysis results. The following conclusions have been made:

1. Image analysis software has been written in the Interactive Data Language (IDL ${ }^{\circledR}$ ) to analyse corrosion topography using the DXR images. This software provides an efficient method for measuring corrosion pits in thin aluminum sheets.

2. Corrosion pit geometry determined using topographical analysis of calibrated DXR images has been verified using Wyko $\left.^{(}\right)$optical surface mapping and confocal microscopy. These preliminary results indicate that pit measurements using DXR data were within \pm 0.0004 in. $( \pm 11 \mu \mathrm{m})$ of the "actual" size of the pits, measured using the $\mathrm{Wyko}^{\circledR}$ system. The $\mathrm{Wyko}^{\circledR}$ system was considered to measure the "actual" pit size based on the measurement precision of $4 \times 10^{-9}$ in. $(0.1 \mathrm{~nm})$. 
3. Based on the measurement accuracy, image thresholding is an adequate technique for detecting corrosion pits.

4. Finite element modelling was used to estimate the stress concentration factors for corrosion pits. A hyperboloid representation of pits ranging from $0.005-0.015$ in. deep, and $0.020-0.100$ in. diameter was used. Corrosion pits with high aspect ratio (ratio of depth to diameter) had higher SCF compared to wider and shallower pits.

5. The suitability of the finite element models was validated using analytical and experimental results of Reed and Wilcox (1970) for hyperboloid depressions in thin plates.

6. Probability distributions relating corrosion pit depth and stress concentration factors, for various levels of corrosion thickness loss, have been developed. Based on these probability distributions it is believed that corrosion pit growth is cyclic in nature. Initially, deep and narrow pits form. Adjacent pits coalesce creating a region of general material thinning, rather than distinct corrosion pits. It is believed that this trend repeats.

7. In order to use the SCF probability distributions for fracture mechanics-based modelling of corrosion-fatigue, the effects of material thinning and corrosion pillowing must be incorporated. Also the distribution of pitting throughout the lap joint must be determined.

8. Corrosion pit depths measured using DXR topography analysis correlate well with the pit sizes identified at the nucleation sites of the corroded ASTM 466 specimens. 


\subsection{FUTURE WORK}

\subsection{Fatigue Test Program}

To improve on existing corrosion-fatigue testing at NRC the following recommendations could be implemented:

1. The specimen design and corrosion protection system should be improved to avoid side-strap disbonding during the pre-corrosion process.

A corrosion inhibitor could be applied to the bonded splice region to prevent disbonding.

2. Alternating corrosion and fatigue tests should be performed to determine if sequential corrosion-fatigue has a significant impact on pitting development, and the fatigue properties of the MSD specimen. A test of this type of test would be comprised of initial cyclic loading followed by a period of exposure and further fatigue cycling. The number of blocks of fatigue cycling and corrosion would need to be determined, and would depend on time and cost constraints.

3. Specimens should be corroded to different average thickness loss to investigate the effect on fatigue properties of the MSD specimens. This would also aid in the development of corrosion pitting probability distributions for varying severity of corrosion damage.

4. Further refinement of the pillowing-to-thickness-loss (PTL) ratio is required using results of the 5 remaining pre-corroded specimens.

5. A PTL ratio should be developed based on corrosion pillowing measurements of the outer sheet of the MSD specimen. The measurements could be obtained using laser scans or similar inspection technique. 


\subsection{DXR Process}

There are several steps that could be taken to refine and improve the DXR process.

1. An x-ray beam intensity survey should be performed to determine if any localised intensity variations exist that could affect the specimen thickness measurement accuracy.

2. Using a higher resolution scanner (preferably 2500 dpi optical resolution or better) the local pixel variations can be removed by smoothing the images with a 3-pixel x 3-pixel region. This would produce an image with better than $800 \mathrm{dpi}$ resolution while simultaneously removing the random scanner noise.

3. 16-bit scans of the x-rays could be used in the analysis, rather than the current 12bit images, increasing the precision of the thickness measurements. If the magnitude of pixel intensity variation remains the same for a 16-bit scanner, the absolute value of the error would be reduced since each level of grey represents a smaller change in sheet thickness. Currently for the 12-bit images, each increment of the greyscale value (i.e. from a grey value 1000 to 1001) represents approximately $4.8 \times 10^{-5}$ in. thickness change. By using a 16-bit scanner this would be decreased to $3.0 \times 10^{-6}$ in. per grey value.

\subsection{Corrosion Topography Analysis}

1. Further finite element modelling of corrosion pits and various combinations of corrosion pitting damage should be performed to refine the stress concentration factors developed in this thesis.

2. The specimen stress field, material thinning and pillowing stresses must be considered when determining the SCF of corrosion damage topography in a lap joint. The stress increases due to corrosion pits, material thinning, and corrosion pillowing could be superimposed on the stress field of a non-corroded joint. This would identify stress "hot-spots" in the specimen for correlation with the crack nucleation sites observed in testing. Such a correlation would be useful for corrosion-fatigue modelling. 
3. Studies on the correlation between the calculated stress concentration factors, the resulting SCF probability distributions, and fatigue test results from coupon tests are required. These results would then build confidence in the probabilistic representation of corrosion topography for fracture mechanics purposes.

4. This work has shown that in some cases little or no corrosion was present on the faying surface beneath the rivets. Therefore, the distribution of corrosion pit sizes in the various regions throughout the MSD specimen must be determined. This would provide information pertaining to corrosion pit sizes near rivets and other fatigue sensitive regions. This same analysis should also be performed on naturally corroded fuselage joints to determine if the corrosion pit distributions compare with those of artificially corroded specimens. This data is needed for realistic fracture mechanics modelling of fuselage joints.

5. In order to implement fracture mechanics modelling of corrosion-fatigue in aircraft joints, a correlation between NDI inspection results and the underlying corrosion topography is required. This would allow aircraft operators to relate NDI inspection results to a probabilistic representation of the corrosion damage. Knowing this, and the acceptable damage limits of the structure (based on prior fracture mechanics modelling) an appropriate maintenance response can be implemented. 


\section{REFERENCES}

Advanced Structural Repair for Engineers. Boeing Aircraft Corporation Training Course, 1996.

"Aircraft Accident Report - Aloha Airlines Flight 243, Boeing 737-200, N73711, Near Maui, Hawaii, April 28, 1989." National Transportation Safety Board (NTSB/AAR-89/03, PB89-910404) June, 1989.

Andrews, Scott and Sehitoglu, Huseyin "A computer model for fatigue crack growth from rough surfaces" "International Journal of Fatigue, 2000, V.22, n. 7, pp. 619-630.

ASTM Standard B368-85: Standard Test Method Copper-Accelerated Acetic Acid-Salt (Fog) Testing (CASS Test). Vol. 02.05, American Society for Testing and Materials, Philadelphia, 1993.

ASTM Standard E647-93: Standard Test Method for Measurement of Fatigue Crack Growth Rates. Vol. 03.01, American Society for Testing and Materials, Philadelphia, 1999.

ASTM Standard E739-91: Standard Practice for Statistical Analysis of Linear or Linearized Stress-Life (S-N) and Strain Life $(\varepsilon-N)$ Fatigue Data. Volume 03.01, American Society for Testing and Materials: Philadelphia, 1998.

ASTM standard F 1438-93 Standard test method for determination of surface roughness by scanning tunnelling microscopy for gas distribution system components. Volume 10.05, American Society for Testing and Materials: Philadelphia, 1999

Atluri, S. N., Sampath, S. G., Tong, P. (Eds.). Structural Integrity of Aging Airplanes. Berlin: Springer-Verlag, 1991.

Beckwith, T.G., Marangoni, R.D., Lienhard V. Mechanical Measurements: Fifth Edition. New York: Addison-Wesley Publishing Company, 1993.

Bellinger, N. C., Krishnakumar, S. Komorowski, J. P. "Modelling of Pillowing Due to Corrosion in Fuselage Lap Joints." Canadian Aeronautics and Space Journal, 1994, v.40, n.3, pp.125-130.

Bellinger, N.C., Benak, T.J., Chapman, C.E., and Komorowski, J.P. "Application of the Equivalent Corrosion Damage Methodology to Corroded Fuselage Lap Joints" LTR-ST2240, National Research Council of Canada, Institute for Aerospace Research Technical Report, November 1999.

Bellinger, N.C., Cook, J.C., Forsyth, D.S., and Komorowski, J.P. "The Role of Surface Topography in Corroded Fuselage Lap Joints" USAF Aircraft Structural Integrity Program Conference, 2000. 
Bellinger, N.C. and Komorowski, J.P. "Environmentally Assisted Cracks in 2024-T3 Fuselage Lap Joints." Published in the proceeding of the Third Joint FAA/DoD/NASA Conference on Aging Aircraft, Albuquerque, New Mexico, September 20-23, 1999.

Bellinger, Nick C., Komorowski, Jerzy .P. "Corrosion Pillowing Stresses in Fuselage Lap Joints." AIAA Journal, February 1997, v. 35, n. 2, PP 317-320.

Boeing Company Service Engineering Customer Support. "727 Fuselage Lap Joint Lower Row Cracking.", Boeing Message Number M-7200-99-00549, February, 1999.

Brooks, Craig L. "Determining the Initial Quality State for Materials." USAF Aircraft Structural Integrity Program Conference, 1998.

Brooks, Craig L. "Modelling Corrosion Morphology and Effects of Initial Quality State." Technical Interchange Meeting: Corrosion/Fatigue Effects on Aging Aircraft, May 4-5, 1998.

Brooks, Craig L., Peeler, Deb, Honeycutt, Kyle T., and Prost-Domasky, Scott. "Predictive Modeling for Corrosion Management: Modeling Fundamentals." $3^{\text {rd }}$ FAA/DoD/NASA Conference on Aging Aircraft: Albuquerque, Sept. 1999.

Brooks, Craig L., Prost-Domasky, Scott, and Honeycutt, Kyle. "Corrosion is a Structural and Economic Problem: Transforming Metrics to a Life Prediction Method." NATO-RTO Air Vehicle Technology Panel Workshop on Fatigue in the Presence of Corrosion: Corfu, October 7-8, 1998.

Brown, J.M. and Newton, C.J. "Quantified three-dimensional imaging of pitted aluminum surfaces using laser scanning confocal microscopy." British Corrosion Journal: Vol. 29, No. 4, 1994, pp. 261-269

Bruhn, E.F. Analysis and Design of Flight Vehicle Structures Jacobs Publishing Inc: Indianapolis, 1973.

Building IDL Applications. Research Systems Inc: Boulder, Colorado, 1997-2.

Chan, Y. T. Wavelet Basics. Klewer Acedemic Publishers: Boston,1995.

Chandrasekaran, Dr. V., Taylor, A.M.H., Yoon, Young-In, Hoeppner, D.W. "Quantification and Correlation of Pit Parameters to "Small" Fatigue Cracks." 20th International Committee On Aeronautical Fatigue Symposium, 1999.

Cook J.C., Godin, D., Merati, A.A., Straznicky, P.V., and Eastaugh, G.F. "Preliminary Test Report on MSD Specimen Serial No. MSD511-037." (to be published) National Research Council Canada, Institute for Aerospace Research, Ottawa, 2001

Cook J.C., Godin, D., Merati, A.A., Straznicky, P.V., and Eastaugh, G.F. "Preliminary Test Report on MSD Specimen Serial No MSD511-041." (to be published) National Research Council Canada, Institute for Aerospace Research, Ottawa, 2001 
Cook J.C., Godin, D., Merati, A.A., Straznicky, P.V., and Eastaugh, G.F. "Preliminary Test Report on MSD Specimen Serial No MSD511-042." (to be published) National Research Council Canada, Institute for Aerospace Research, Ottawa, 2001

Cook J.C., Godin, D., Merati, A.A., Straznicky, P.V., and Eastaugh, G.F. "Preliminary Test Report on MSD Specimen Serial No MSD511-049." (to be published) National Research Council Canada, Institute for Aerospace Research, Ottawa, 2001

Cook J.C., Godin, D., Merati, A.A., Straznicky, P.V., and Eastaugh, G.F. "Preliminary Test Report on MSD Specimen Serial No MSD511-050." (to be published) National Research Council Canada, Institute for Aerospace Research, Ottawa, 2001

Cook J.C., Godin, D., Merati, A.A., Straznicky, P.V., and Eastaugh, G.F. "Preliminary Test Report on MSD Specimen Serial No MSD511-054." (to be published) National Research Council Canada, Institute for Aerospace Research, Ottawa, 2001

Cook, J.C. "Repair Design for Joint Disbond in MSD Specimen Straps" Design report for $N R C$ contract 31184-9-7243/001/ST, 2000.

DeBartolo, E. A. and Hillberry, B. M. "Effects of constituent particle clusters on fatigue behaviour of 2024-T3 aluminum alloy." International Journal of Fatigue, 1998, V.20, $n$. 10, pp. 727-735.

Eastaugh, G. F., Merati, A.A., Simpson, D.L. "An Experimental Study of Corrosion/Fatigue Interaction in the Development of Multiple Site Damage in Longitudinal Fuselage Skin Joints." NATO-RTO Air Vehicle Technology Panel Workshop on Fatigue in the Presence of Corrosion, Corfu, 7-8 October 1998.

Eastaugh, G. F. Multiple Site Fatigue Damage in Fuselage Skin Joints. M. Eng. Thesis, Carleton University: Ottawa, 1993.

Eastaugh, G.F., Simpson, D.L., Straznicky, P.V., Wakeman, R.B. "A Special Uniaxial Coupon Test Specimen for the Simulation of Multiple Site Fatigue Crack Growth and Link-up in Fuselage Splices." AGARD-CP-568, December 1995.

Eastin, Robert G. "Aging Aircraft: Widespread Fatigue Damage \& Proposed DT Operating Rules." Federal Aviation Administration, Engine \& Propeller Directorate DER Recurrent Seminar. 3 May 2000.

Fanning, David W. IDL Programming Techniques. Fanning Software Consulting: Fort Collins, Colorado, 1998.

Federal Aviation Administration, Department of Transportation "Repair Assessment for Pressurized Fuselages: Final Rule." Federal Aviation Administration, May 25, 2000.

FM 73 Film Adhesive Cytec Fiberite Inc., 2000

Fontana, Mars G. Corrosion Engineering. New York: McGraw-Hill, Inc., 1986. 
Forsyth, D.S., Chapman, C.E., Giguere, S., Lepine, B.A., Marincak, A. "Nondestructive Inspections of Calibration Specimens and KC 135 Aircraft Specimens." LTR-ST-2267, National Research Council of Canada, Institute for Aerospace Research Technical Report, February 2000.

Frantziskonis, George N., Simon, Laura B., Woo, Jung, Matikas, Theodore E. "Multiscale characterization of pitting corrosion and application to an aluminum alloy." European Journal of Mechanics A: Solids, V. 19, n.2, 2000, pp. 309-318.

Godard, H. P., Jepson, W. B., Brothwell, M. R., and Lane, R. K. The Corrosion of Light Metals. New York: John Wiley \& Sons, Inc., 1967.

Hoeppner, D. W., Chandrasekaran, V., Taylor, A. M. H. "Review of Pitting Corrosion Fatigue Models." 20th International Committee On Aeronautical Fatigue Symposium, 1999.

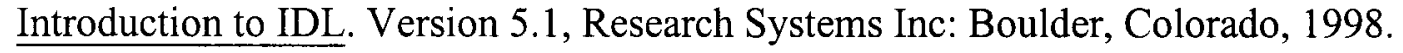

Kaiser, Gerald A Friendly Guide to Wavelets. Birkhäuser: Boston,1994.

Kingsley-Jones, Max. "Ageing Airliner Census 2000." Flight International, Vol. 157, No. 4733, Sutton, Surrey, U.K.: Reed Business Information Ltd., 2000, pp. 53-65.

Kinzie, Richard and Peeler, Deborah. "Corrosion Modelling of KC-135 Lap Joints." 20th International Committee On Aeronautical Fatigue Symposium, 1999.

Koch, Gerhardus H., Yu, Le, Katsube, Noriko, Paul, Clare A. "Mathematical Model to Predict Fatigue Crack Initiation in Corroded Lap Joints." $3^{\text {rd }}$ FAA/DoD/NASA Conference on Aging Aircraft: Albuquerque, Sept. 1999.

Komorowski, J.P., Gould, R.W., Marincak, A., Krishnakumar, S. "Application of D Sight for Corrosion Detection in Fuselage Lap and Butt Joints." LTR-ST-1960, National Research Council of Canada, Institute for Aerospace Research Technical Report, January, 1994.

Krizan, David V. Assessing the Effects of Corrosion Damage on Longitudinal Fuselage Joints. M. Eng. Thesis, Carleton University: Ottawa, 1999.

Laz, P. J., and Hillberry, B. M. "Fatigue Life Prediction from Inclusion Initiated Cracks." International Journal of Fatigue, 1998, V.20, n. 4, pp. 263-270.

Lepine, B. A., Wallace, B. P., Forsyth, D. S., Wyglinsky, A. "Pulsed Eddy Current Method Developments for Hidden Corrosion Detection in Aircraft Structures." CSNDT Journal, 20 No. 6, November 1999, pp. $6-15$.

Liao, C.M., Olive, J.M., Gao, M., Wei, R.P. "In-Situ Monitoring of Pitting Corrosion in Aluminum Alloy 2024." Corrosion-The Journal of Science and Engineering Vol.54, N.6 1998, pp. 451-459. 
Little, R.E. Manual on Statistical Planning and Analysis for Fatigue Experiments. American Society for Testing and Materials: Philadelphia, 1975

Lynch, S.P. "Mechanisms of Fatigue and Environmentally Assisted Fatigue." Fatigue Mechanisms, ASTM Special Technical Publication 675. Baltimore: ASTM, 1979, pp. 174202.

Merati, A.A. "Chemical Procedure for the Removal of Corrosion Products from Aluminum Alloy 2024-T3 Clad Sheet." LTR-ST-2212, National Research Council of Canada, Institute for Aerospace Research Technical Report, April 2000.

Meyer, Y. (Ed.) Wavelets and Applications: Proceedings of the International Conference. Springer-Verlag: Berlin, 1991.

Müller, Richard Paul Gerhard An Experimental and Analytical Investigation on the Fatigue Behaviour of Fuselage Riveted Lap Joints. Delft, The Netherlands: Delft University of Technology, 1995.

Newman, J. C., Jr, Phillips, E. P., Swain, M. H., and Everett, R. A. "Fatigue mechanics: An assessment of a unified approach to life prediction." Advances in Fatigue Lifetime Predictive Techniques, ASTM STP 1122. Eds. Mitchell, M. R. and Landgraf, R. W., Philadelphia: American Society for Testing of Materials, 1992, pp. 5-27.

Niu, Michael C.Y. Airframe Structural Design Conmilit Press Ltd.: Los Angeles, 1995.

Pelloux, R., Warren, A., and O'Grady, J. "Fractographic Analysis of Initiation and Growth of Fatigue Cracks at Rivet Holes." Structural Integrity of Aging Airplanes, Eds. Atluri, S. N., Sampath, S. G., Tong, P., Berlin: Springer-Verlag, 1991, pp. 293-308.

Pilkey, Walter D. Peterson's Stress Concentration Factors, Second Edition. New York: John Wiley \& Sons, Inc. 1997.

"Recommendations for Regulatory Action to Prevent Widespread Fatigue Damage in the Commercial Airplane Fleet." Airworthiness Assurance Working Group, Final Report, Rev. A, June 29, 1999.

Reed, R.E., and Wilcox, P.R. "Stress Concentration Due to a Hyperboloid Cavity in a Thin Plate." NASA-TN-D-5955, 1970.

Reithmaier, Larry Ed. Standard Aircraft Handbook 5th ed. TAB/Aero Books: Pennsylvania, 1991.

Rokhlin, S.I., Kim, J.-Y., Nagy, H., Zoofan, B. "Effect of Pitting Corrosion on Fatigue Crack Initiation and Fatigue Life." Engineering Fracture Mechanics, Vol. 62,n. 4-5, 1999 , p.p. $425-444$.

Russ, John C. The Image Processing Handbook. CRC Press Inc: Boca Raton,1992. 
Scheuring, Jason N., Grandt, Alten F. "Quantification of Corrosion Damage Utilizing a Fracture Mechanics Based Methodology." $3^{\text {rd }}$ FAA/DoD/NASA Conference on Aging Aircraft: Albuquerque, Sept. 1999.

Schijve, J. "Fatigue Predictions and Scatter." Fatigue and Fracture of Engineering Materials and Structures, Vol. 17, No. 4, 1994, pp. 381-396.

Schütz, D. and Lowak, H. The Effect of Secondary Bending on the Fatigue Strength of Joints. Laboratorium für Betriebsfestigkeit, Report FB-113, RAE Library Translation 1858, 197.

Scott, Jason P. Corrosion and Multiple Site Damage in Riveted Fuselage Lap Joints. M. Eng. Thesis, Carleton University: Ottawa, 1997.

Shivakumar, K.N. and Newman, J.C., Jr. "Stress Concentrations for Straight-Shank and Countersunk Holes in Plates Subjected to Tension, Bending, and Pin Loading." NASA Technical Paper 3192, 1992.

Smallman, R.E. Modern Physical Metallurgy, Fourth Edition. London: Butterworths \& Co., 1985, pp. 463-520.

Staley, J.T., and Rolf, R.L. "Trends in alloys for aircraft." In Bickert, C., Proceedings of the International Symposium on Light Metals Processing and Applications, 1993, pp. 629-642.

Starck, J.-L., Murtaugh, F. and Bijaoui, A. Image Processing and Data Analysis: The Multiscale Approach. Cambridge University Press: Cambridge, 1998.

Swift, T. "Repair to Damage Tolerant Aircraft." Structural Integrity of Aging Airplanes, Eds. Atluri, S. N., Sampath, S. G., Tong, P., Berlin: Springer-Verlag, 1991, pp. 433-483.

Using IDL. Research Systems Inc: Boulder, Colorado, 1997-1.

Wakeman, R. Brett Interaction of Multiple Site Damage and Corrosion in Fuselage Lap Joints. M. Eng. Thesis, Carleton University: Ottawa, 1996.

Walker,E.K. "Forecasting Fleetwide Fatigue Cracking in Aircraft Structure." Workshop prepared for the Directorate of Technical Airworthiness, National Defence Headquarters: Ottawa, May 1997.

Wei, Robert P., and Harlow, D. Gary "Corrosion and Corrosion Fatigue of Airframe Materials." Technical Report, DOT/FAA/AR-95/76, U.S. Department of Transportation, Federal Aviation Administration, 1996.

What's New in IDL 5.3. Research Systems Inc: Boulder, Colorado, 1999. 
Wilhelm, M., Nageswararao, M., Meyer, R. "Factors Influencing Stage I Crack Propagation in Age-Hardened Alloys." Fatigue Mechanisms, ASTM Special Technical Publication 675. Baltimore: ASTM, 1979, pp. 214-229.

"Wyko NT Series Ultrafast Optical Profilers." Product brochure from Veeco Instruments Inc., 2000. 


\section{APPENDIX A: SIDE-STRAP REPAIR DRAWING}

The repair design for pre-corroded specimens with disbonded side-straps is presented in this section. 


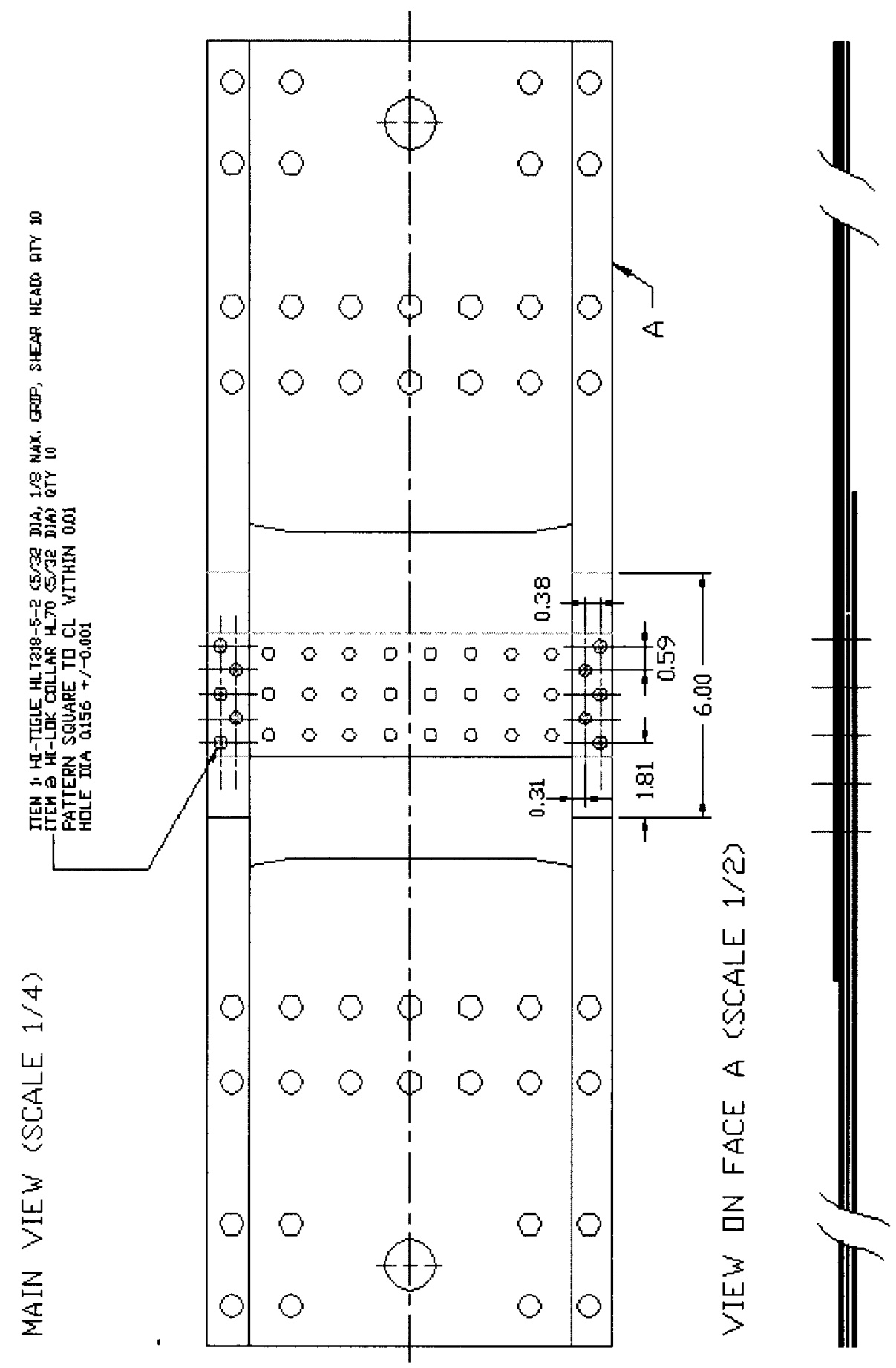

Figure A- 1: Bonded joint repair drawing. 


\section{APPENDIX B: INSPECTION RESULTS FOR PRE- CORRODED SPECIMENS}

The non-destructive and the post teardown results are presented in this section. Corrosion pillowing measurements, D-sight, eddy current, pulsed eddy current, as well as DXR images are included. 
MSD511-037: Inspection results at the end of pre-corrosion.

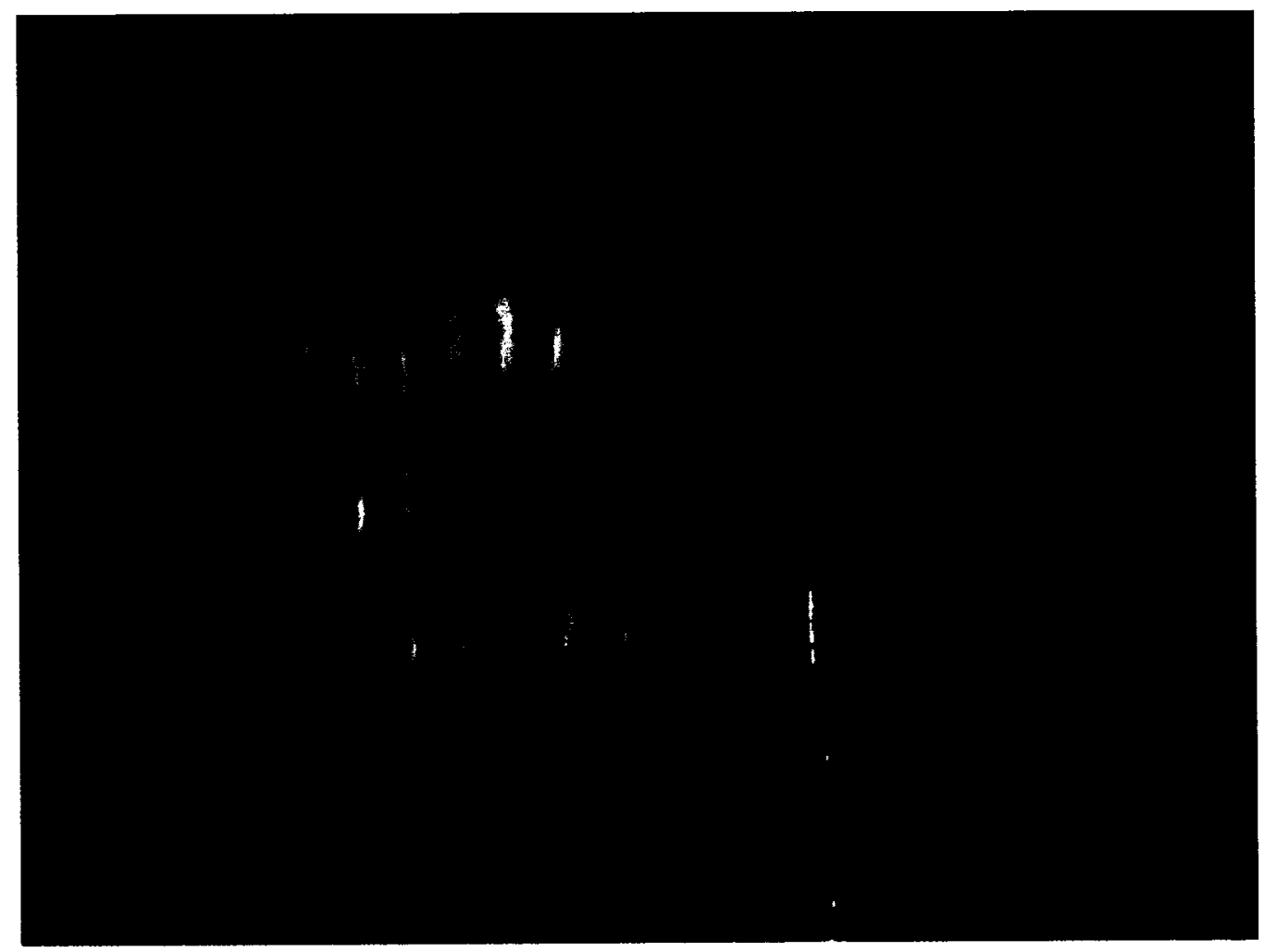

(a)

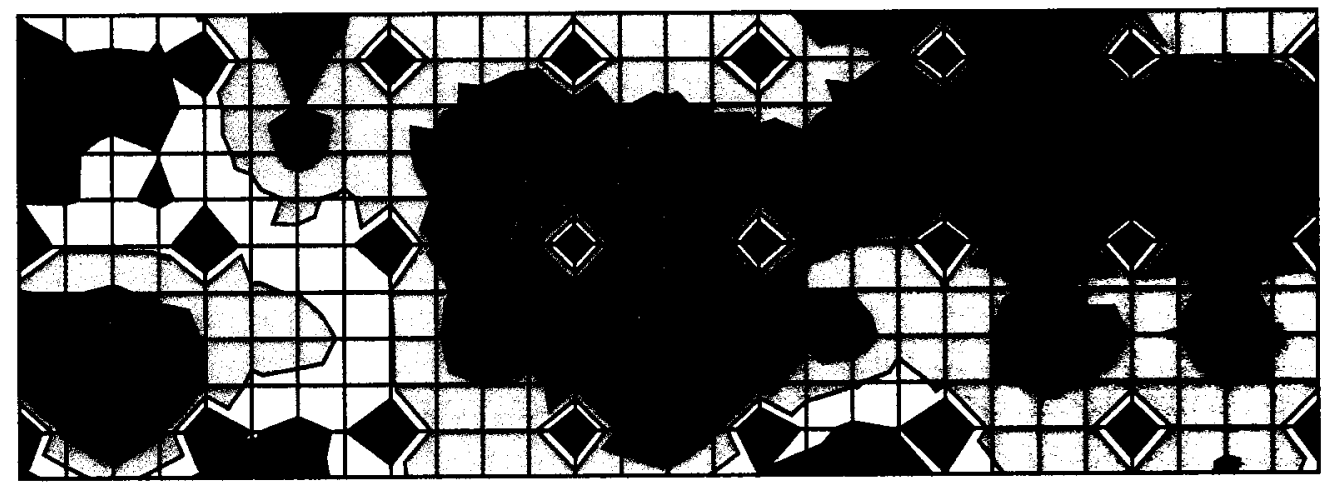

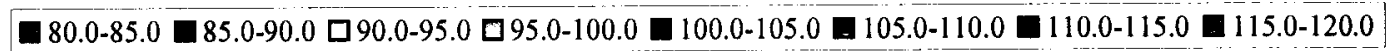

(b)

Figure B- 1: Specimen 037 (a) D-sight, (b) Micrometer pillowing measurements. 


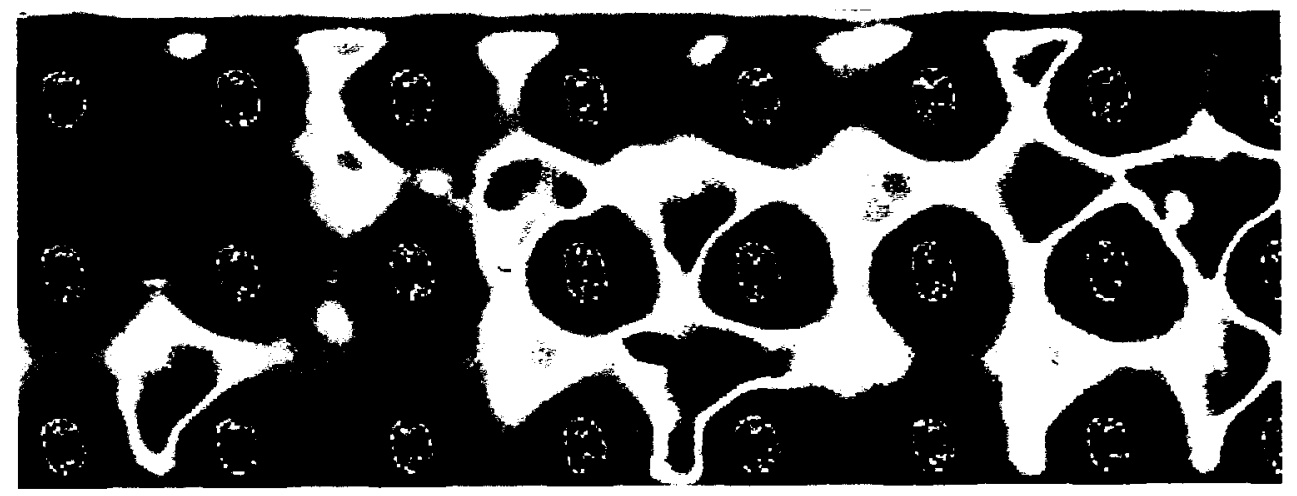

(a)

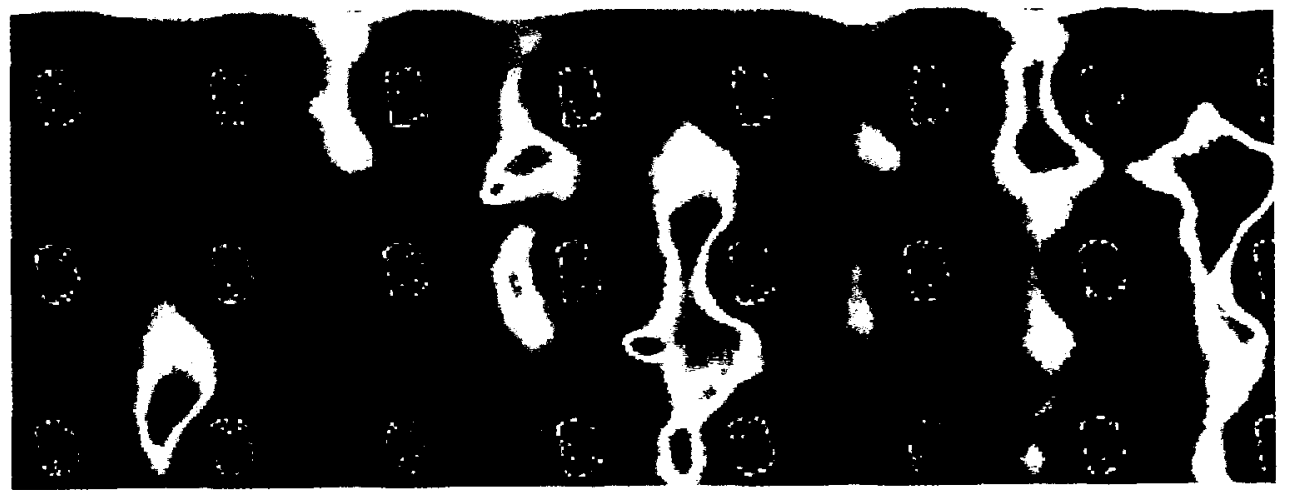

(b)

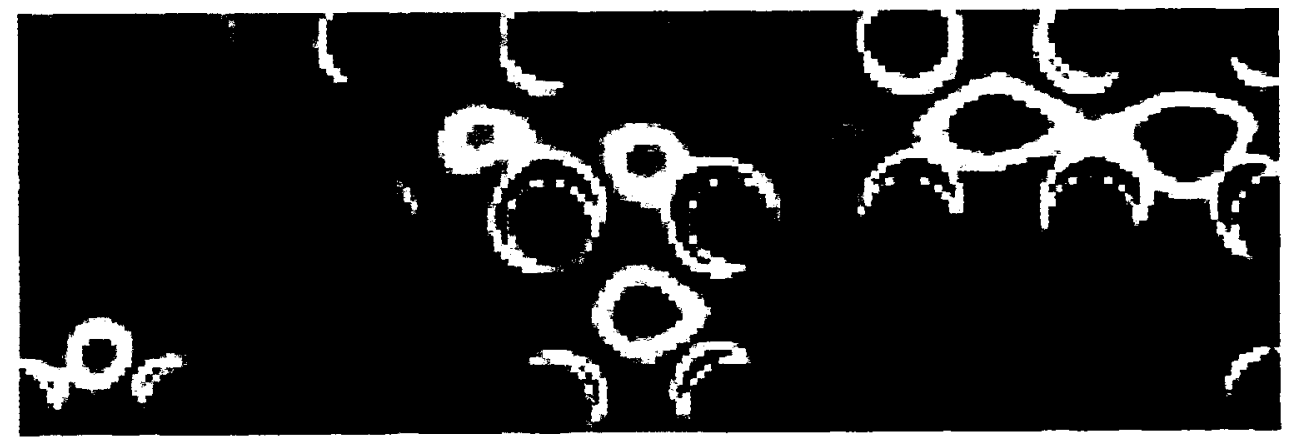

(c)

Figure B- 2: Specimen 037 (a) Eddy current c-scan at $5.5 \mathrm{kHz}$, thickness loss in both sheets. (b) Eddy current c-scan at $17 \mathrm{kHz}$, thickness loss in outer sheet only. (c) Pulsed Eddy current c-scan, thickness loss in both sheets. 


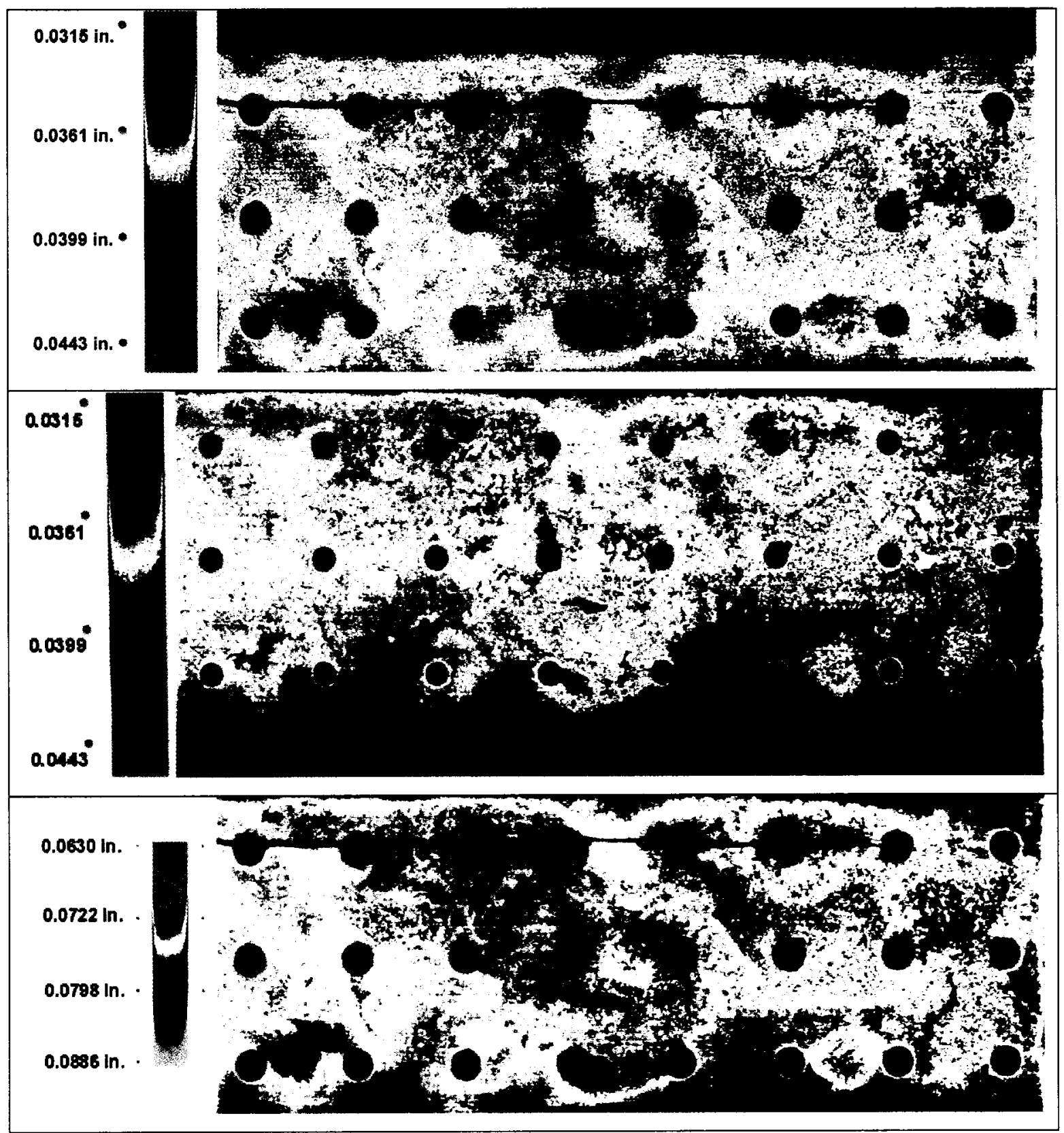

Figure B- 3: Specimen 037 calibrated DXR images (a) outer sheet, (b) inner sheet, (c) combined sheets. 
MSD511-049: Inspection results at the end of pre-corrosion.

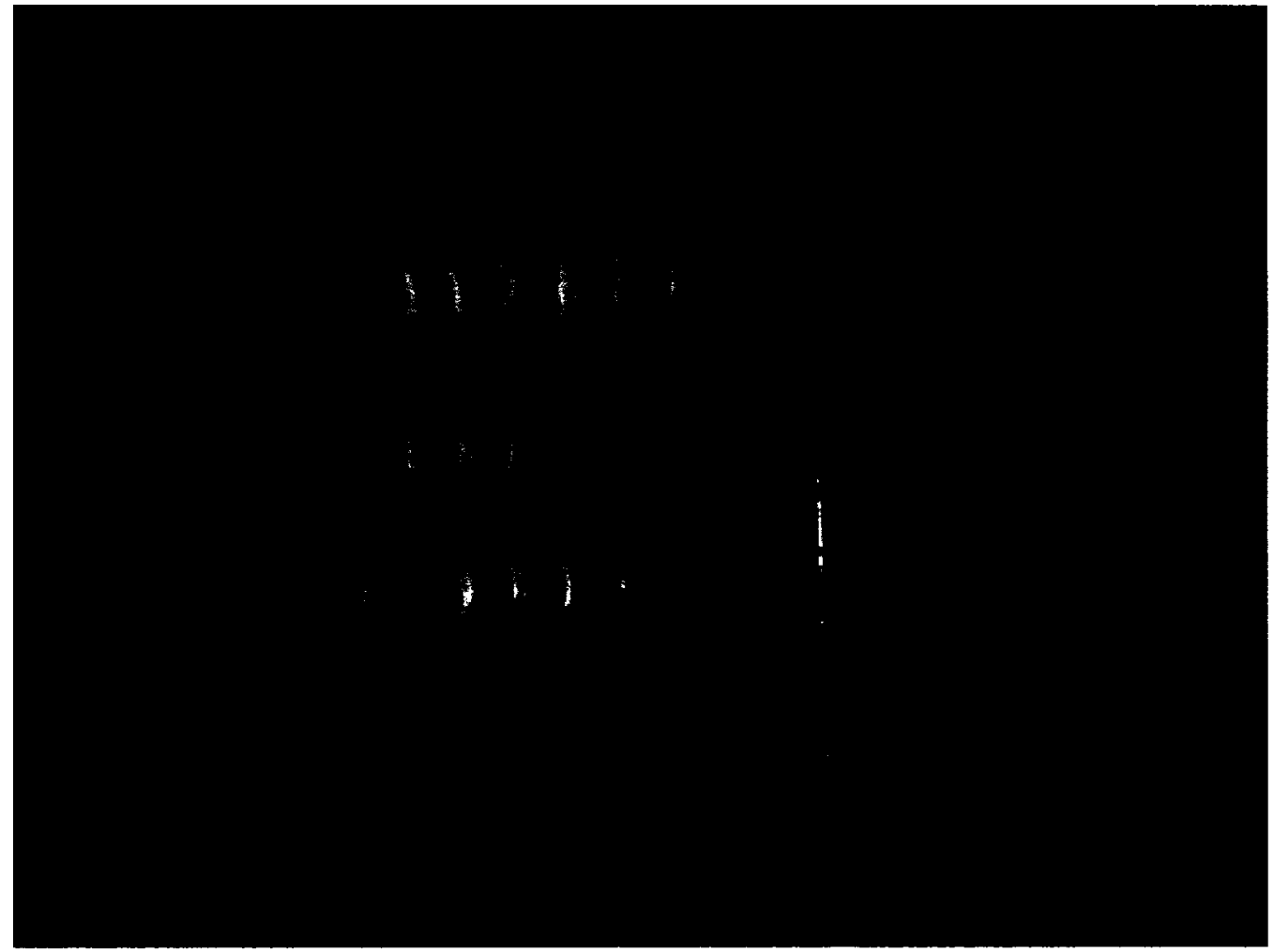

(a)

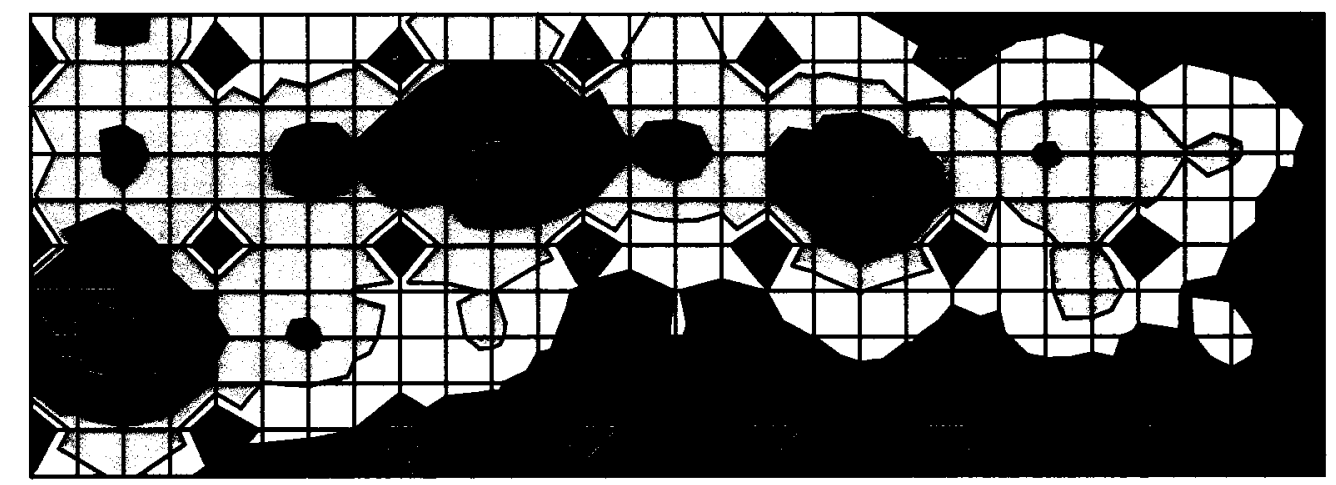

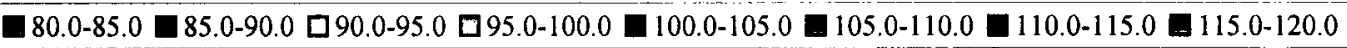

(b)

Figure B- 4: Specimen 049 (a) D-sight , (b) Micrometer pillowing measurements. 


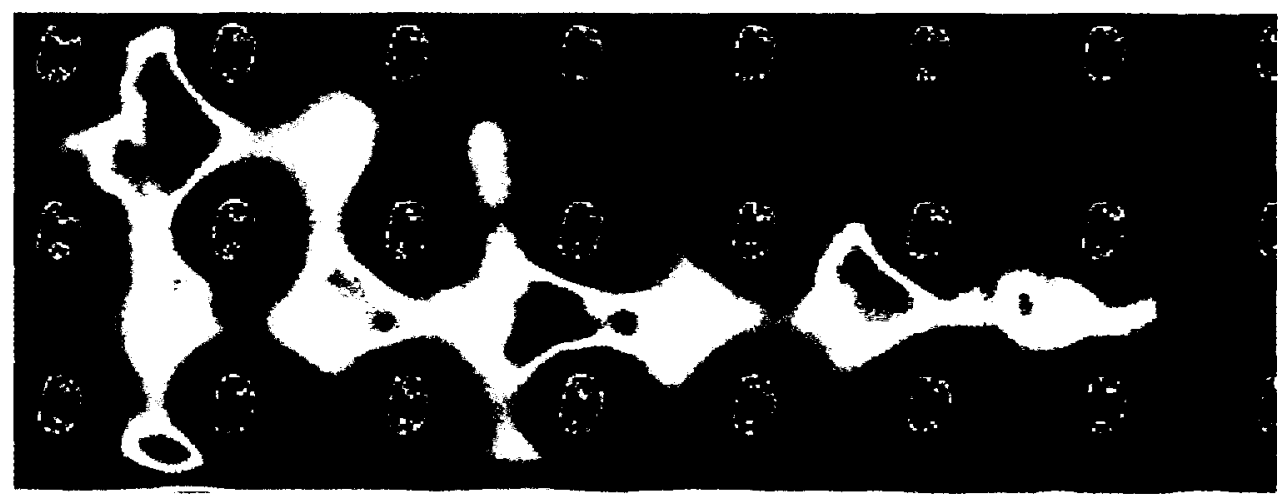

(a)

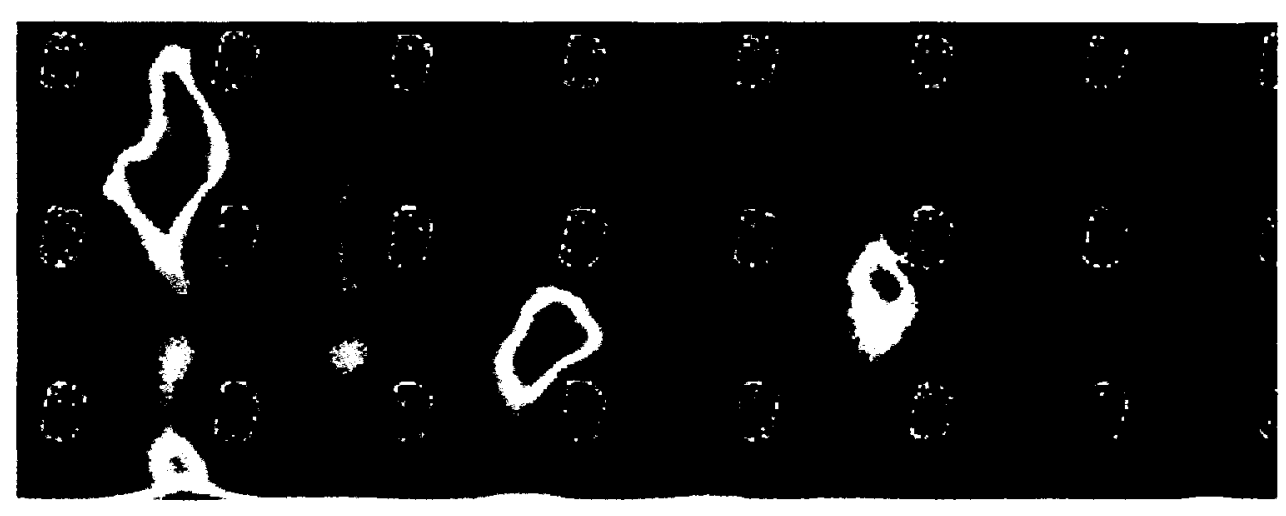

(b)

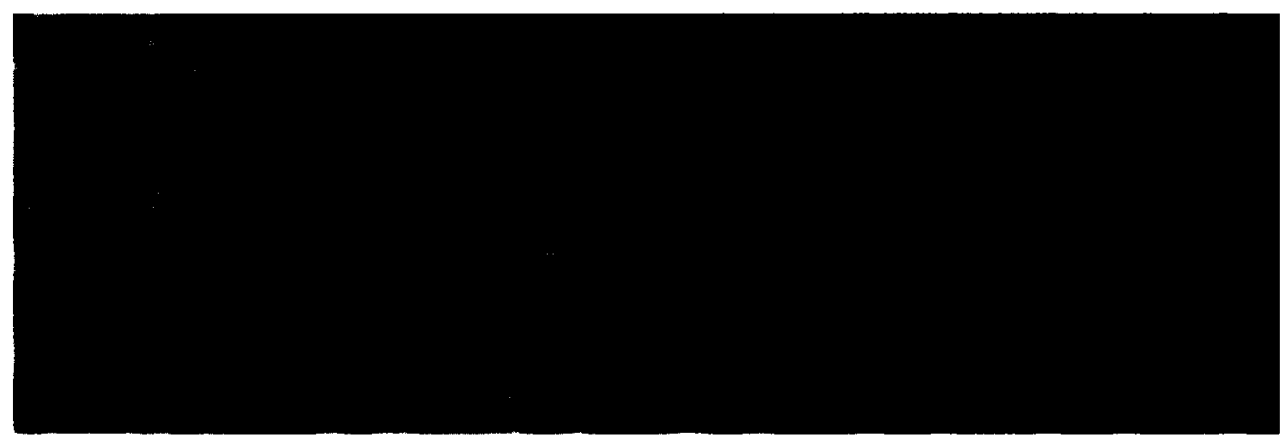

(c)

Figure B- 5: Specimen 049 (a) Eddy current c-scan at $5.5 \mathrm{kHz}$, thickness loss in both sheets. (b) Eddy current c-scan at $17 \mathrm{kHz}$, thickness loss in outer sheet only. (c) Pulsed Eddy current c-scan, thickness loss in both sheets. 


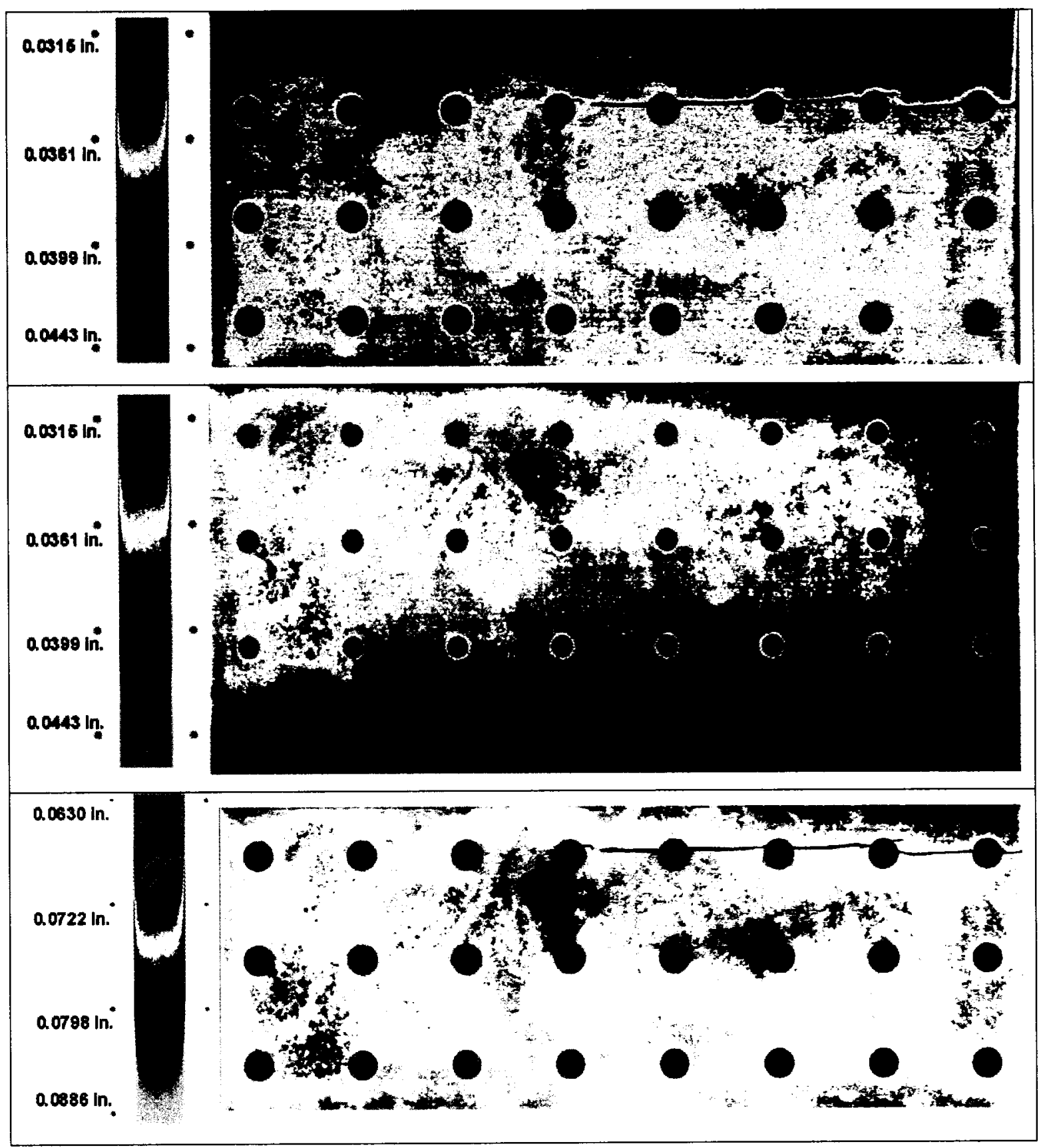

Figure B- 6: Specimen 049 calibrated DXR images (a) outer sheet, (b) inner sheet, (c) combined sheets. 
MSD511-050: Inspection results at the end of pre-corrosion.

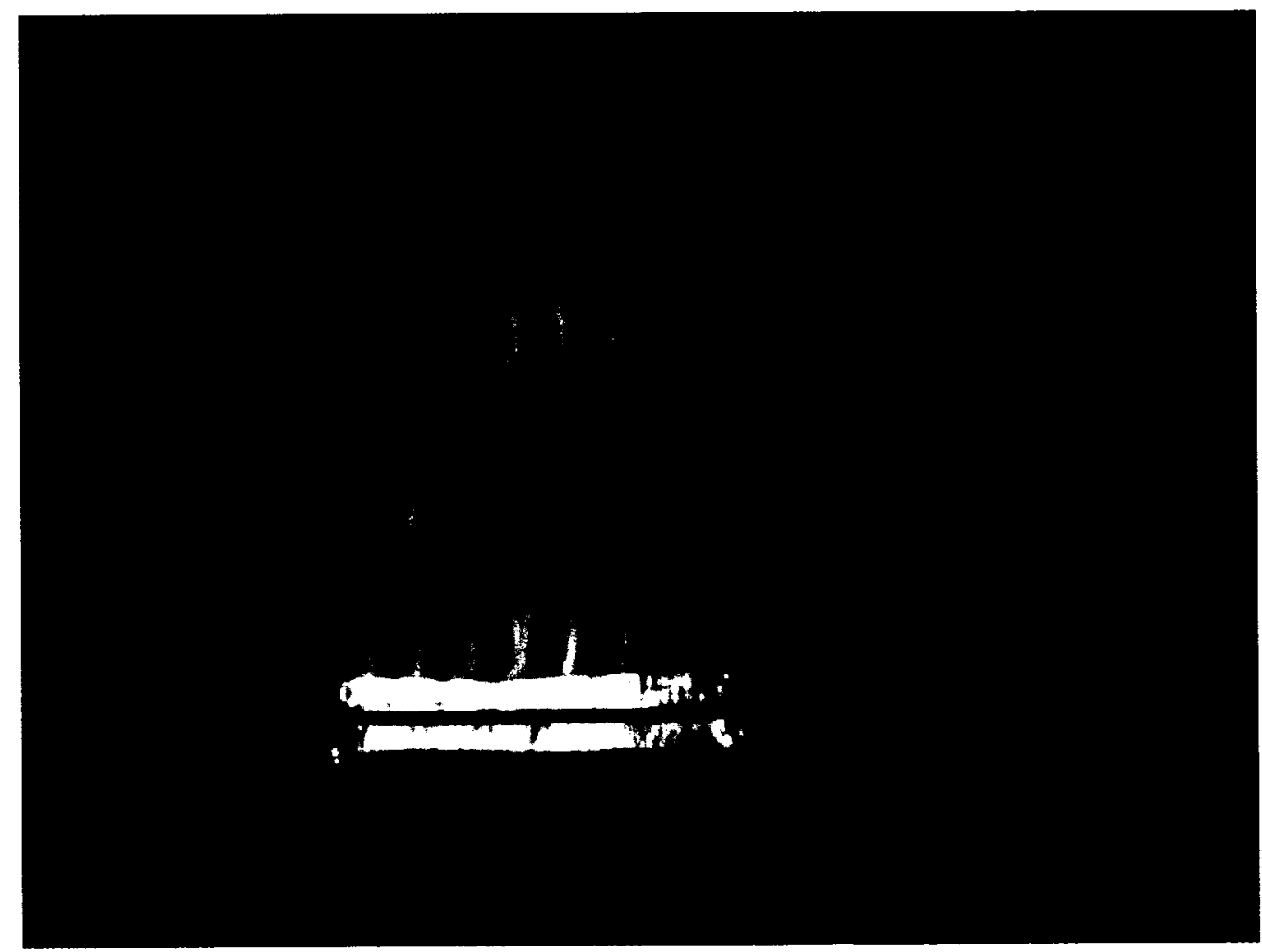

(a)

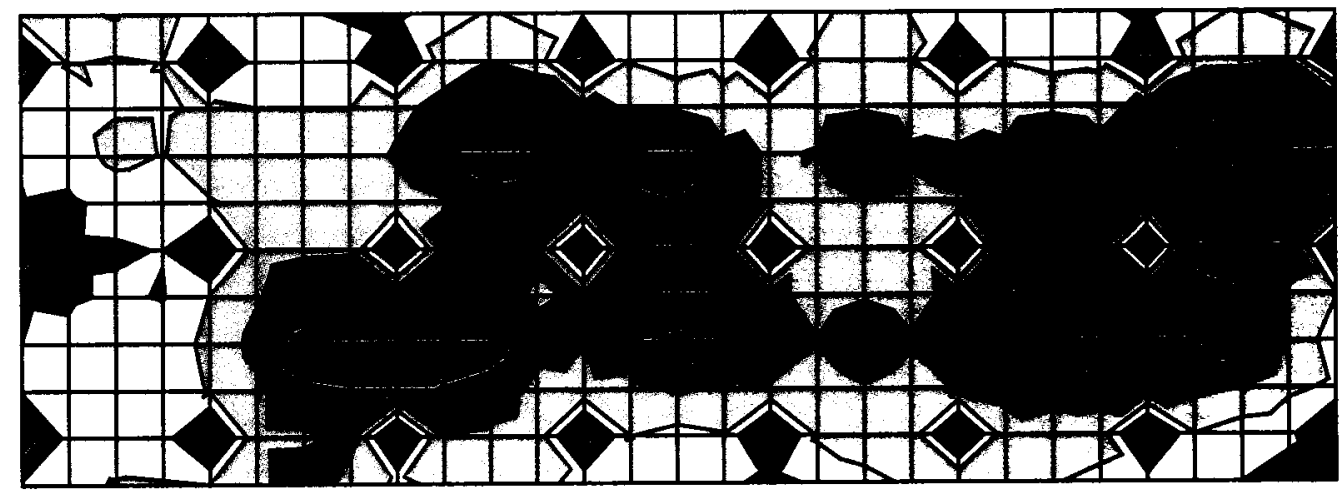

80.0-85.0 $\square 5.0-90.0 \square 90.0-95.0 \square 95.0-100.0 \square 100.0-105.0 \square 105.0-110.0 \square 110.0-115.0 \square 115.0-120.0$

(b)

Figure B- 7: Specimen 050 (a) D-sight, (b) Micrometer pillowing measurements. 


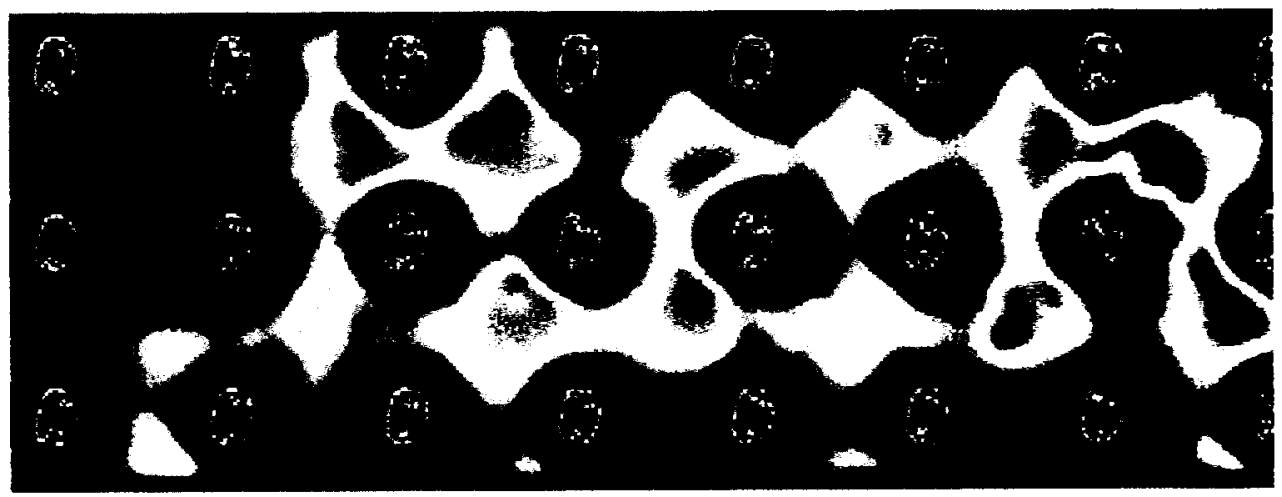

(a)

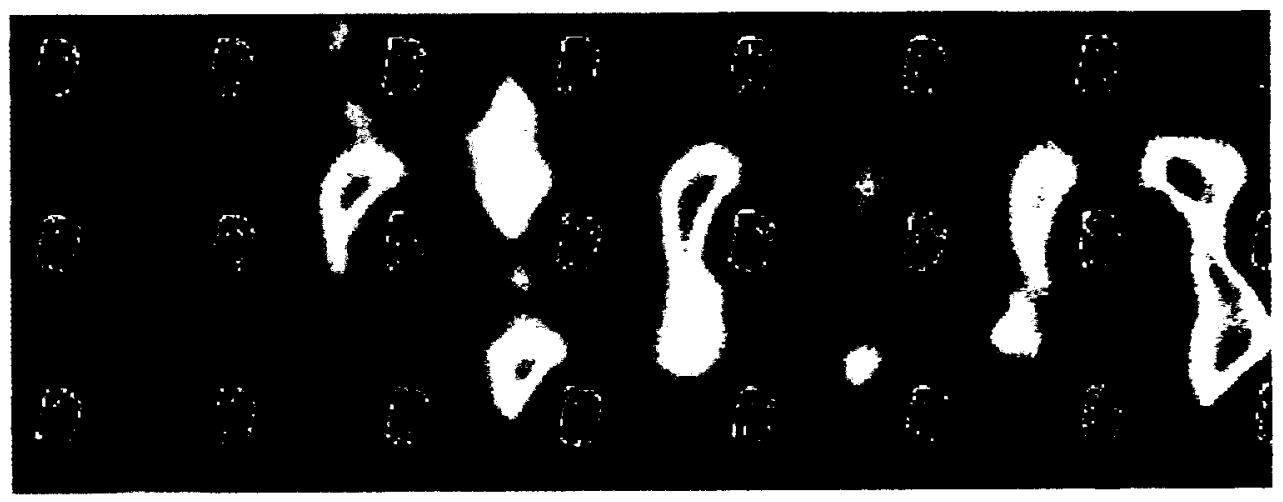

(b)

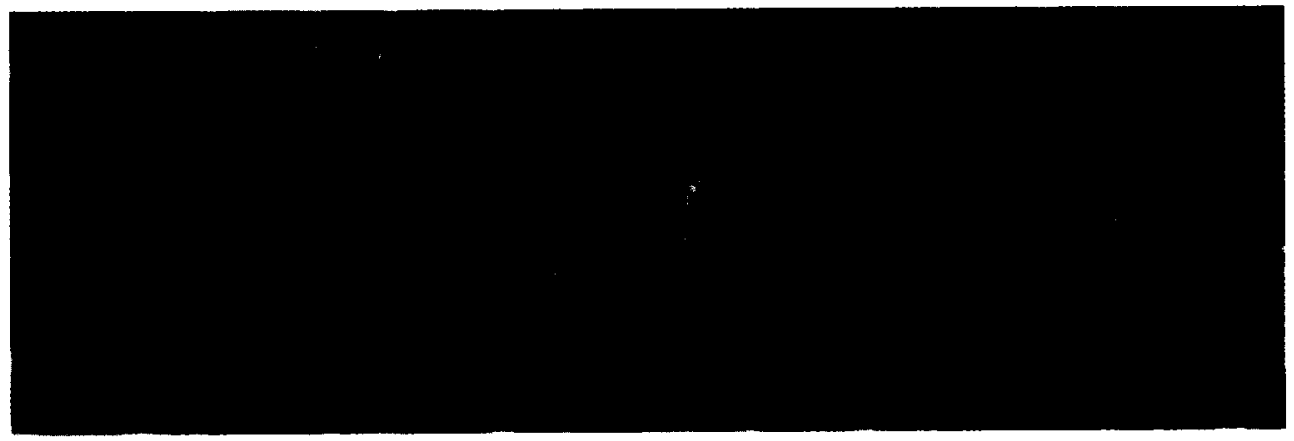

(c)

Figure B- 8: Specimen 050 (a) Eddy current c-scan at $5.5 \mathrm{kHz}$, thickness loss in both sheets. (b) Eddy current c-scan at $17 \mathrm{kHz}$, thickness loss in outer sheet only. (c) Pulsed Eddy current c-scan, thickness loss in both sheets. 


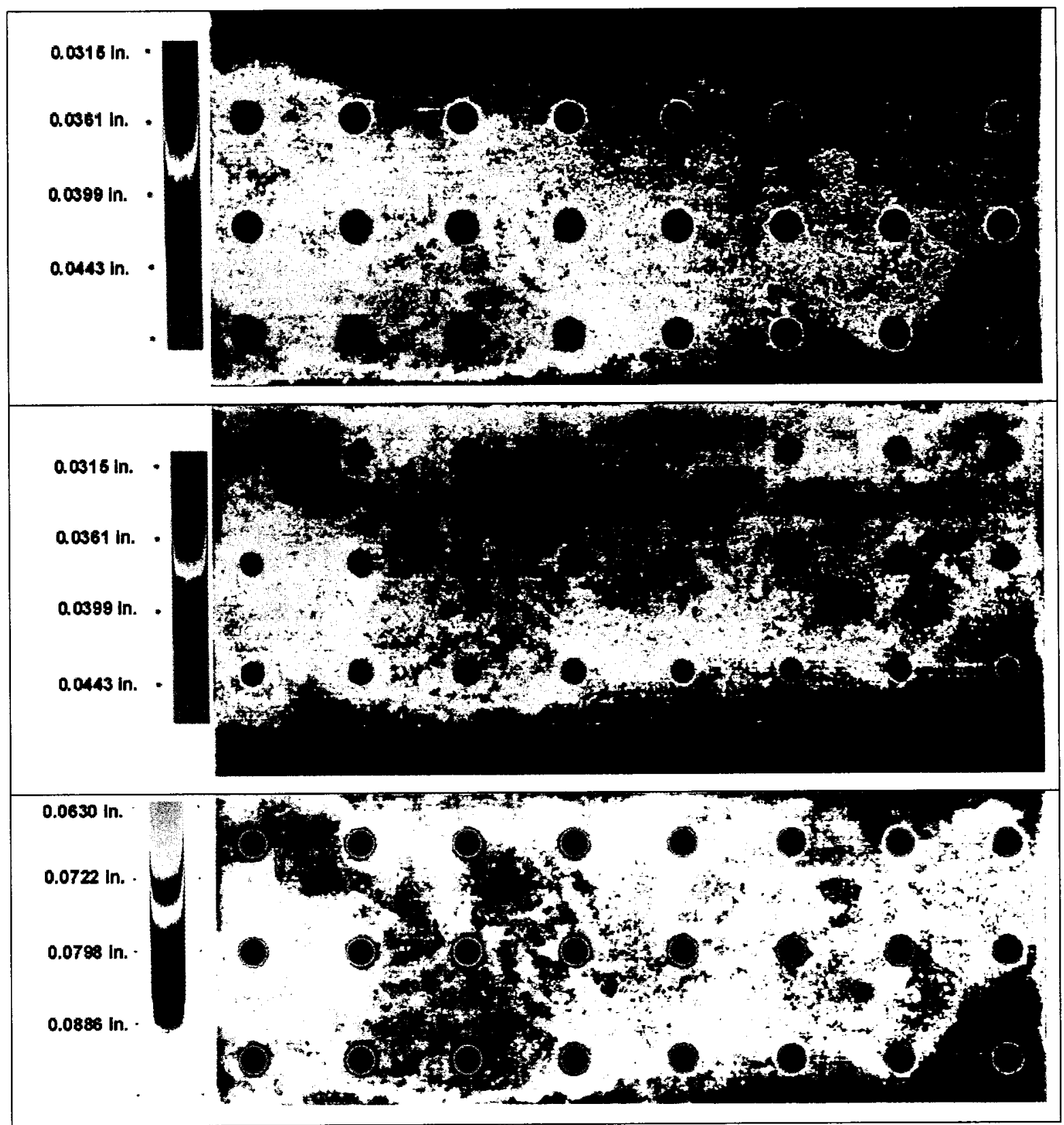

Figure B- 9: Specimen 050 calibrated DXR images (a) outer sheet, (b) inner sheet, (c) combined sheets. 
MSD511-054: Inspection results at the end of pre-corrosion.

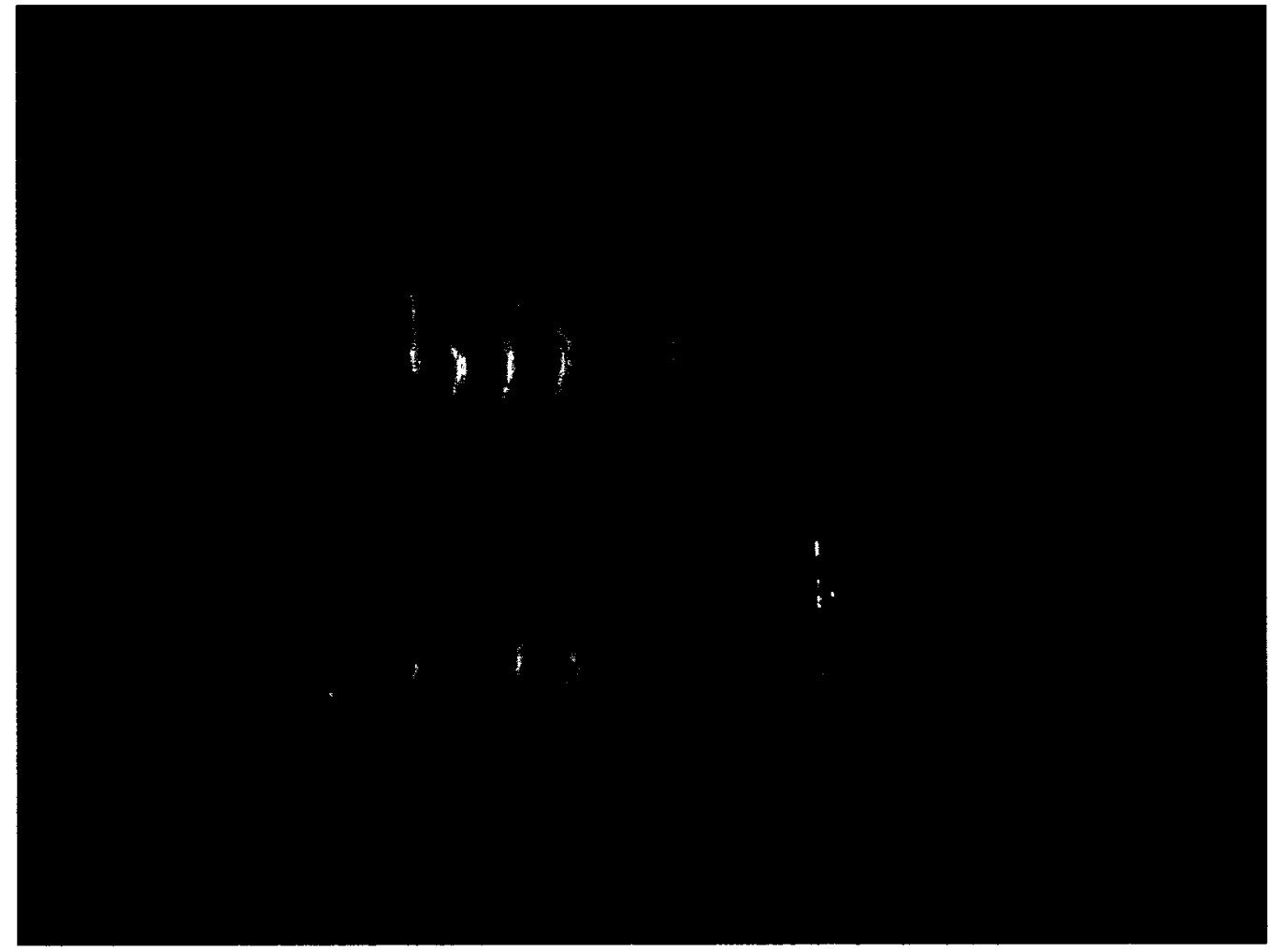

(a)

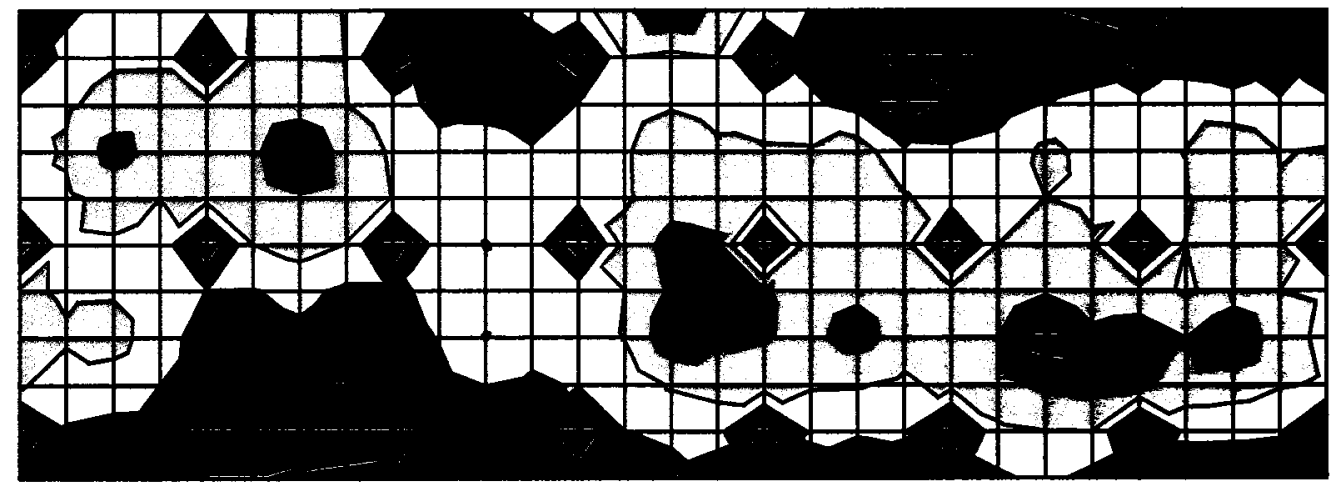

$\square$ 80.0-85.0 $\square 85.0-90.0 \square 90.0-95.0 \square 95.0-100.0 \square 100.0-105.0 \square 105.0-110.0 \square 110.0-115.0 \square 115.0-120.0$

(b)

Figure B- 10: Specimen 054 (a) D-sight , (b) Micrometer pillowing measurements. 


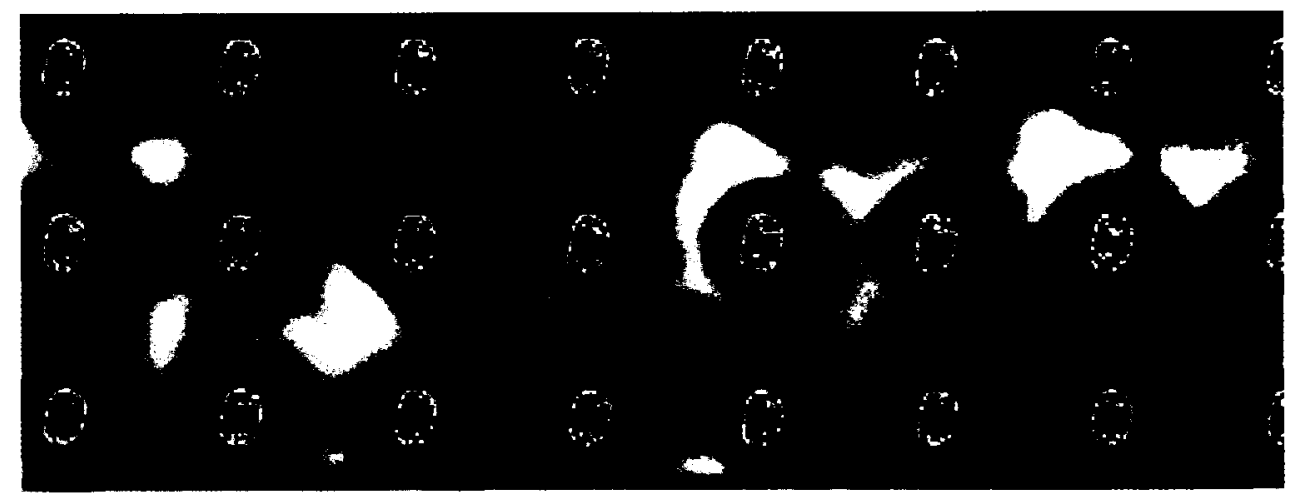

(a)

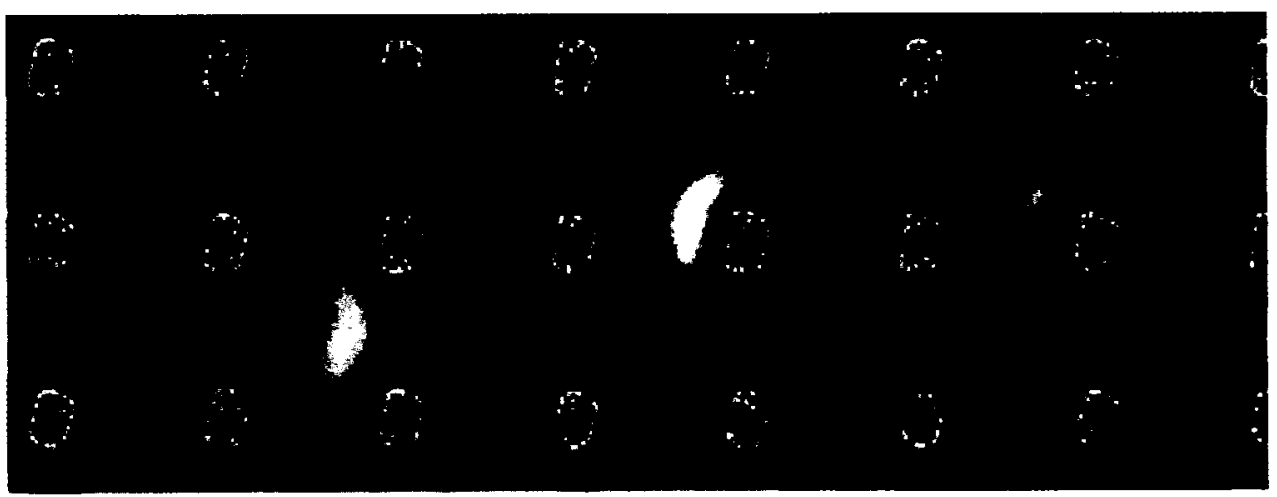

(b)

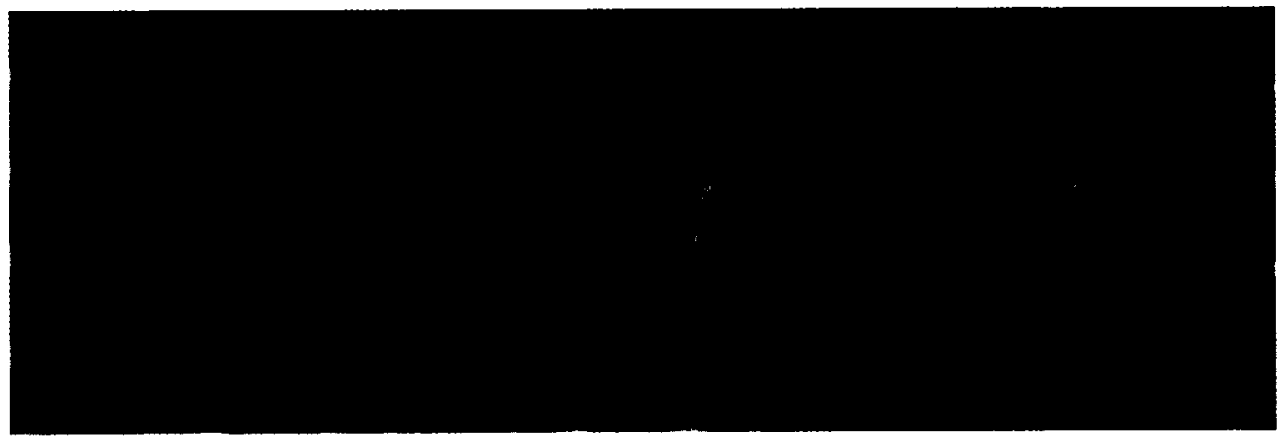

(c)

Figure B- 11: Specimen 054 (a) Eddy current c-scan at $5.5 \mathrm{kHz}$, thickness loss in both sheets. (b) Eddy current c-scan at $17 \mathrm{kHz}$, thickness loss in outer sheet only. (c) Pulsed Eddy current c-scan, thickness loss in both sheets. 


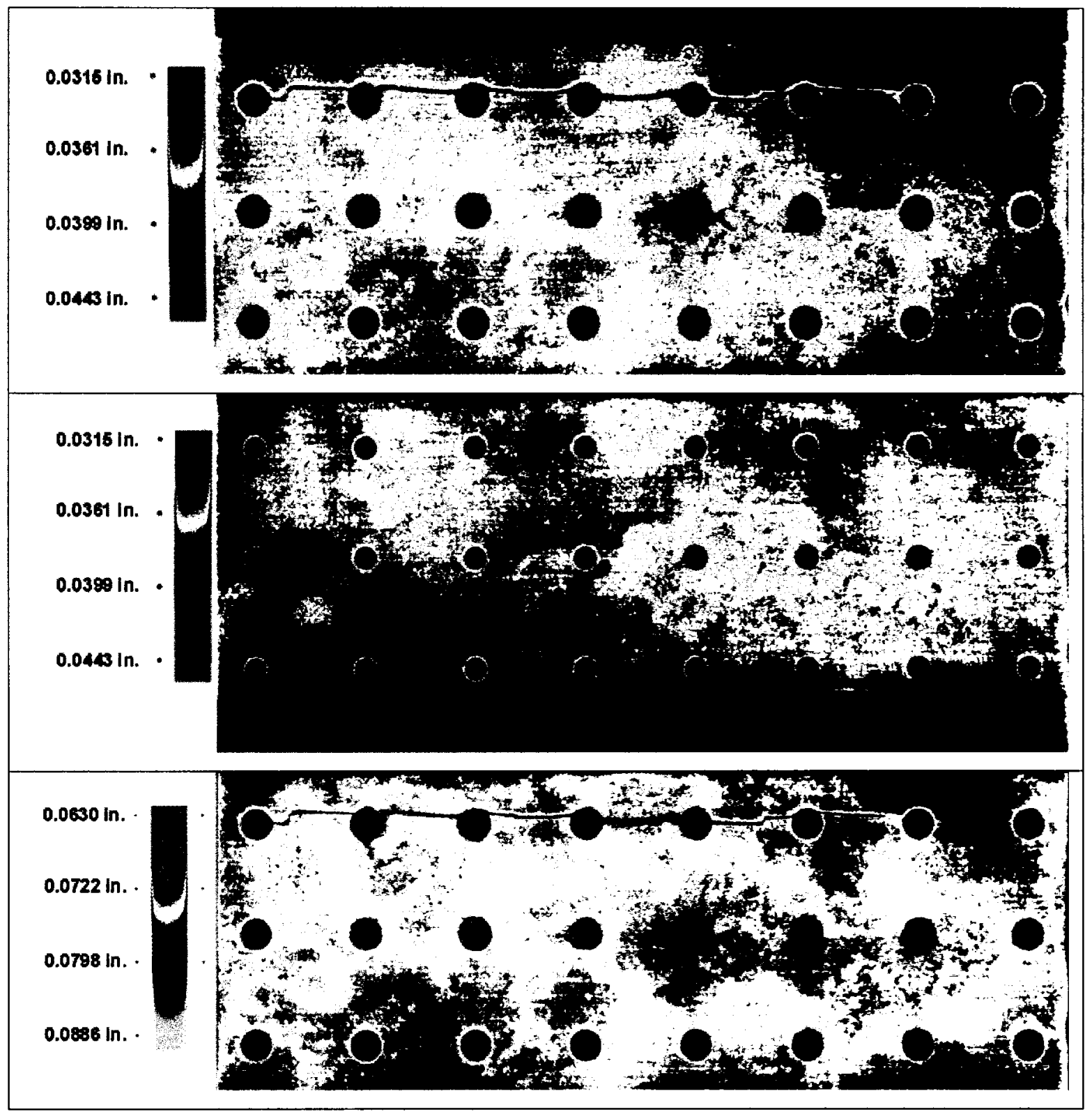

Figure B- 12: Specimen 054 calibrated DXR images (a) outer sheet, (b) inner sheet, (c) combined sheets. 


\section{APPENDIX C: CORROSION TOPOGRAPHY DATA}

Results from corrosion topography analysis are contained in this appendix. Corrosion pit maps, images for single pit data from $\mathrm{Wyko}^{\circledR}$ scans, confocal microscopy, DXR and image segmentation are included. 


\section{C-1: Pit Map Images}

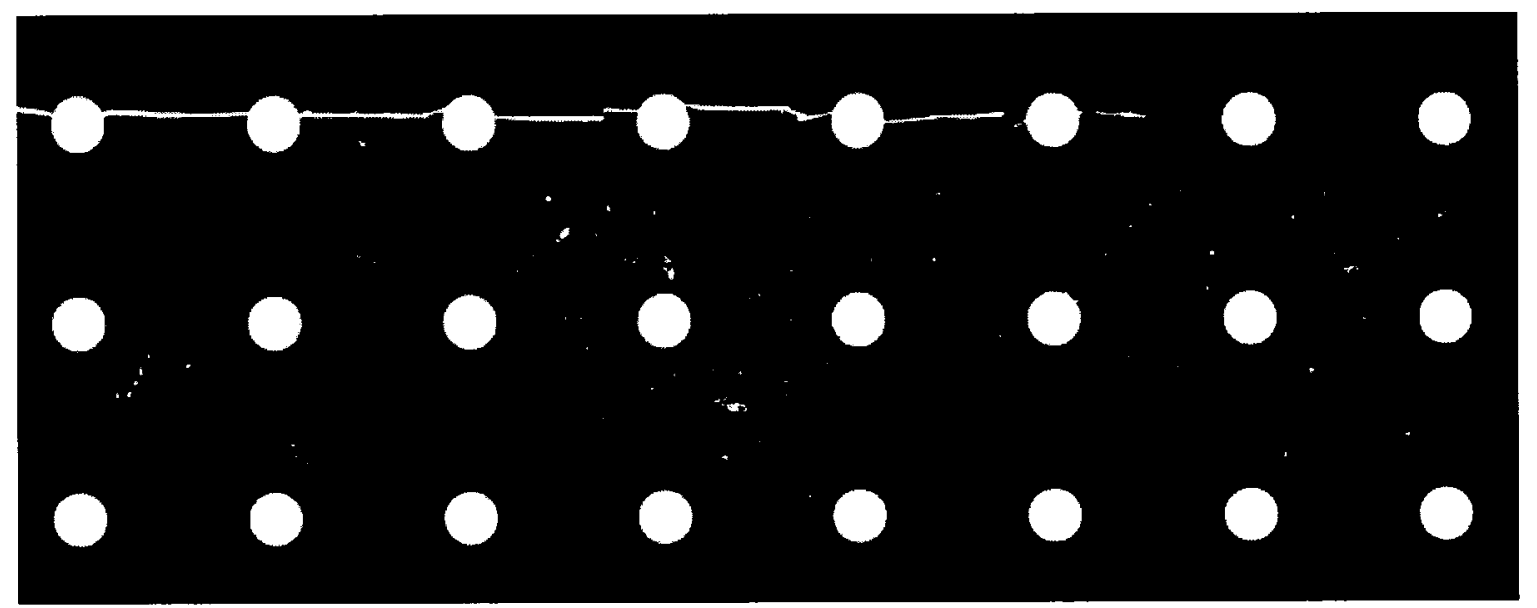

Figure C-1: Pit map image for specimen 037, outer sheet

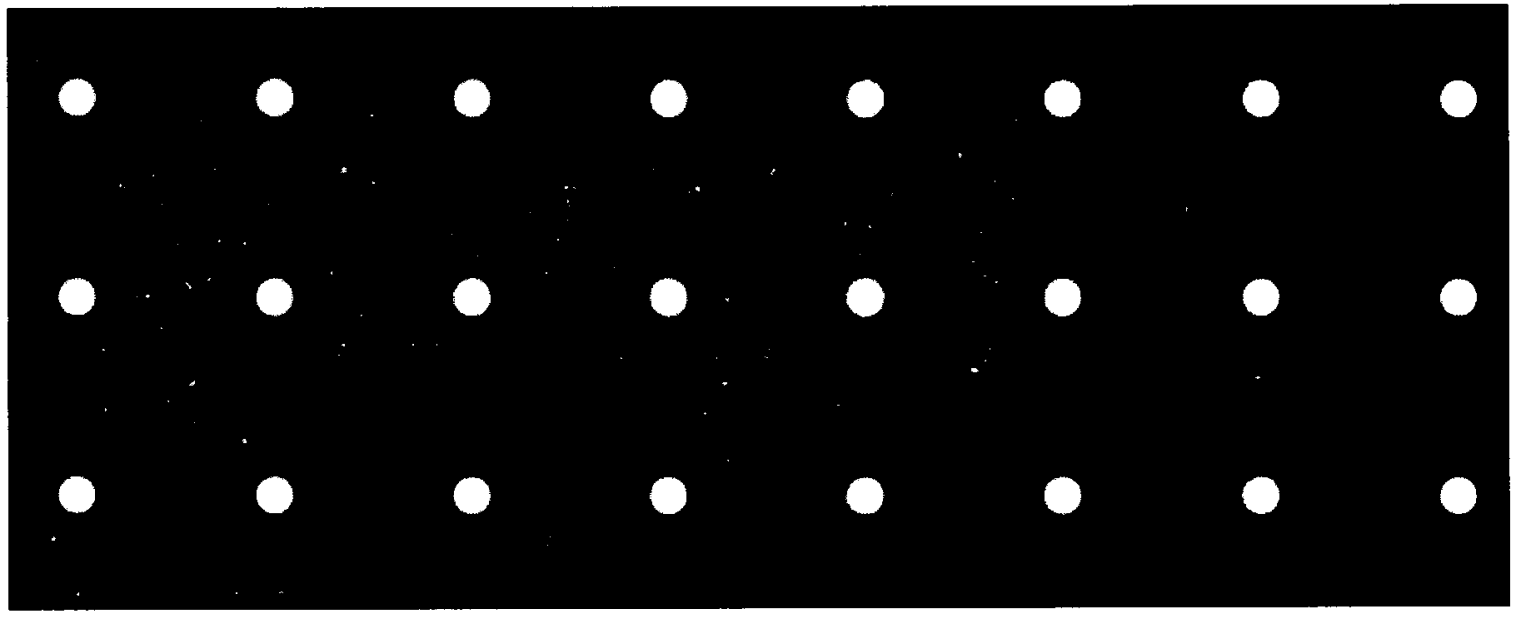

Figure C- 2: Pit map image for specimen 037, inner sheet 


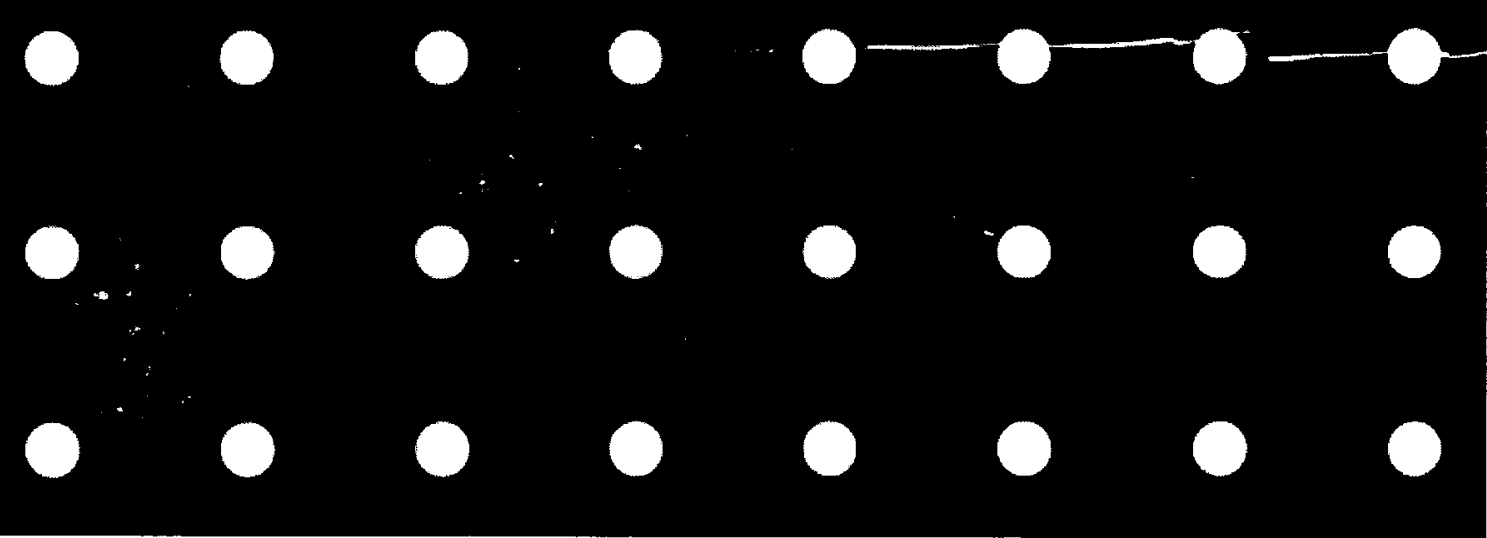

Figure C- 3: Pit map image for specimen 049, outer sheet

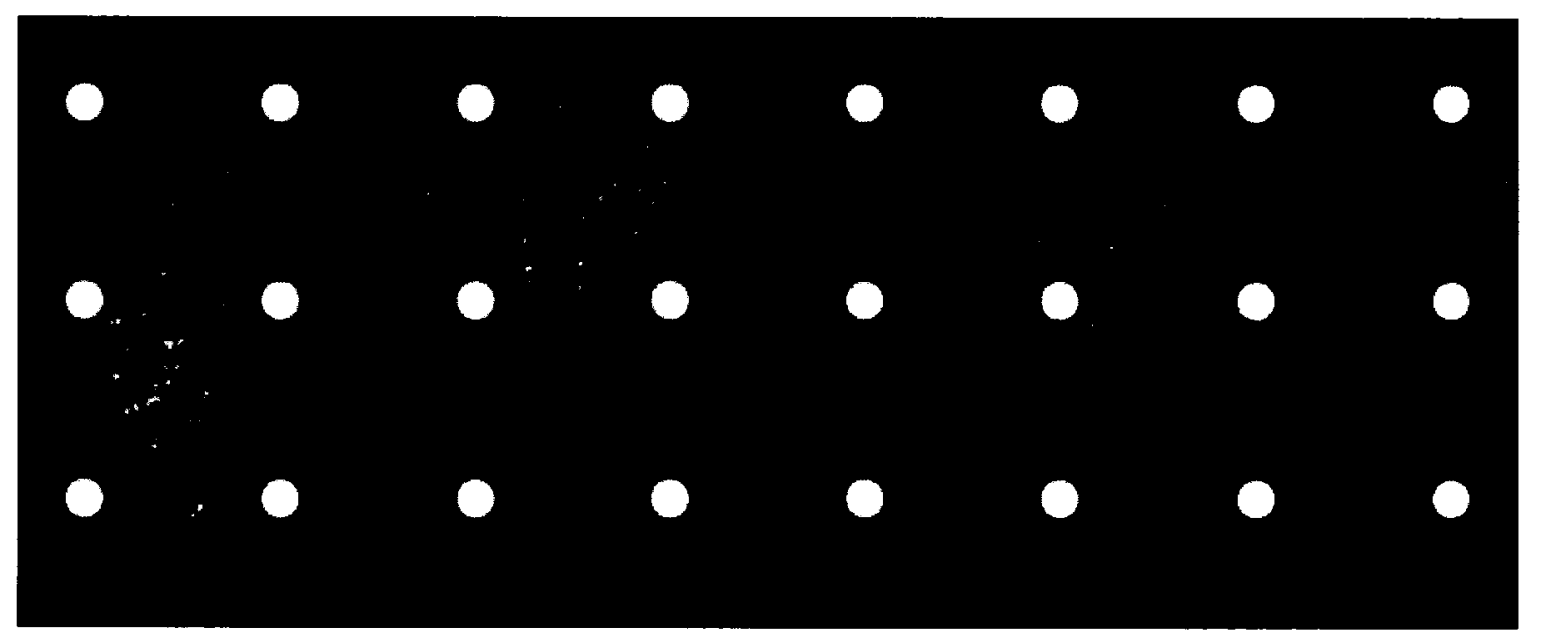

Figure C- 4: Pit map image for specimen 049, inner sheet 


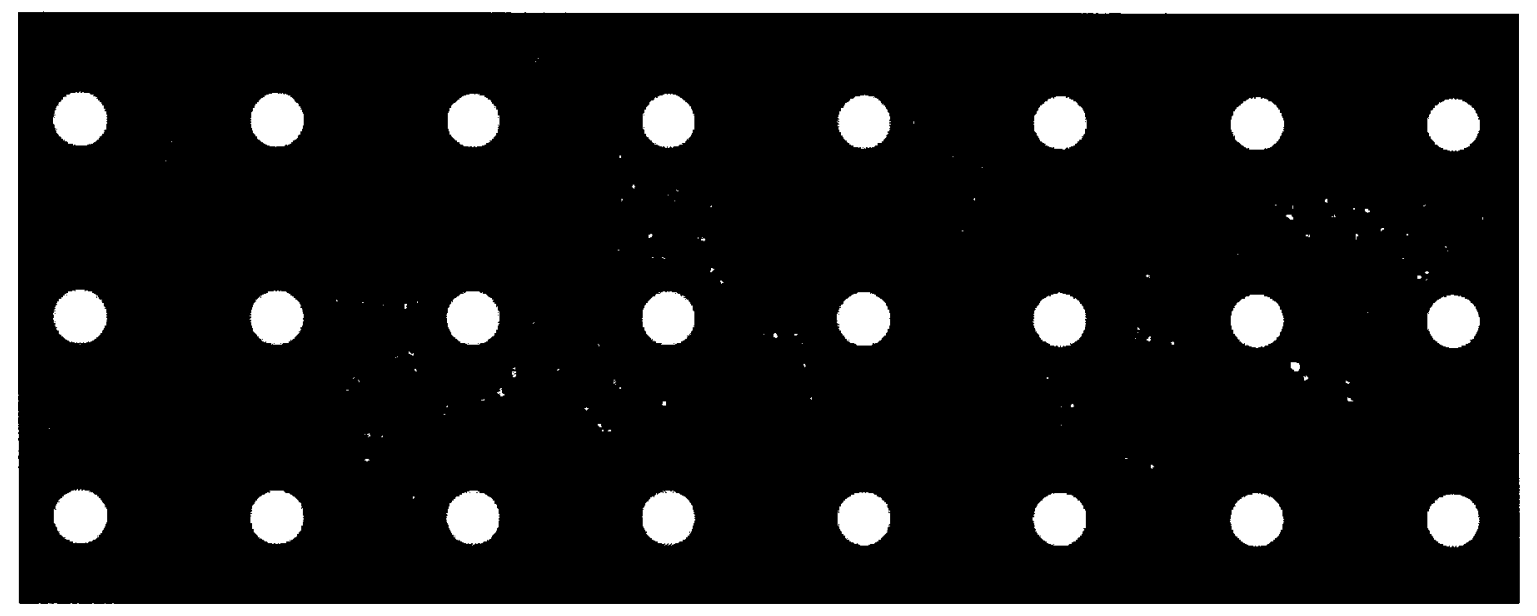

Figure C- 5: Pit map image for specimen 050, outer sheet

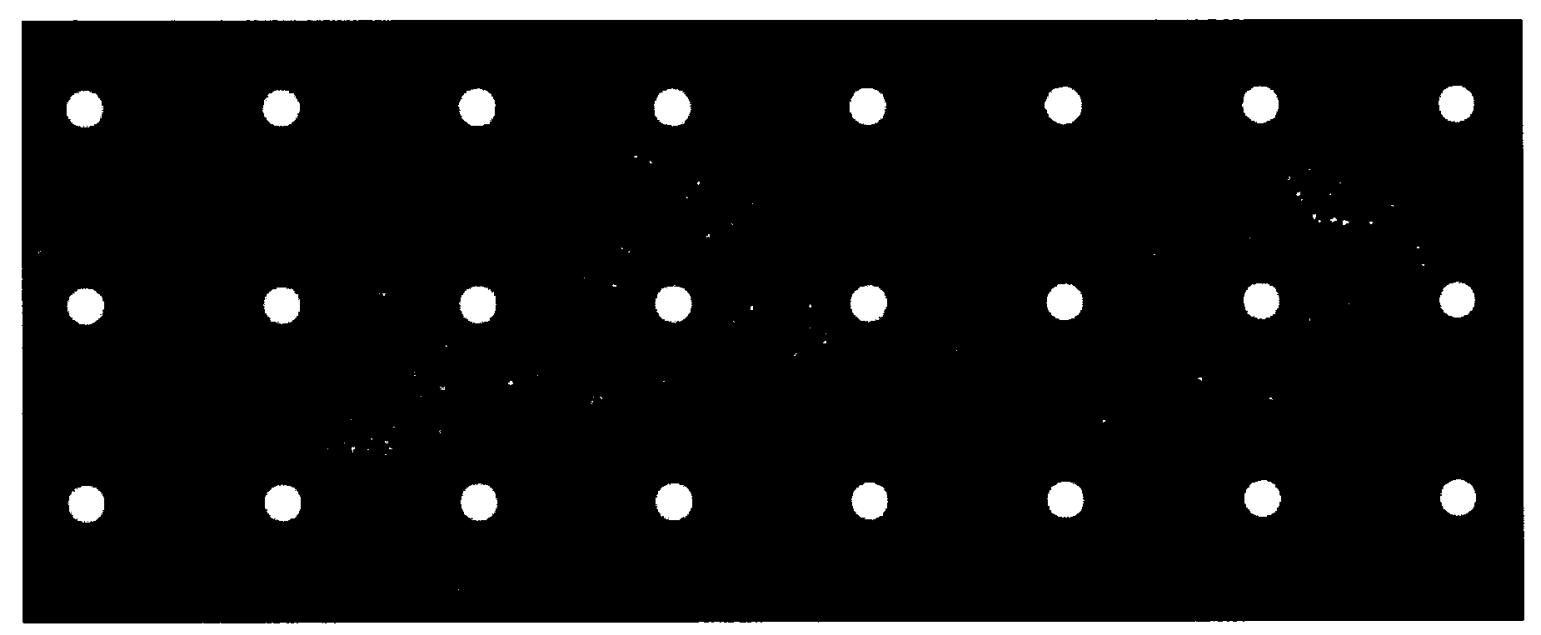

Figure C- 6: Pit map image for specimen 050, inner sheet 


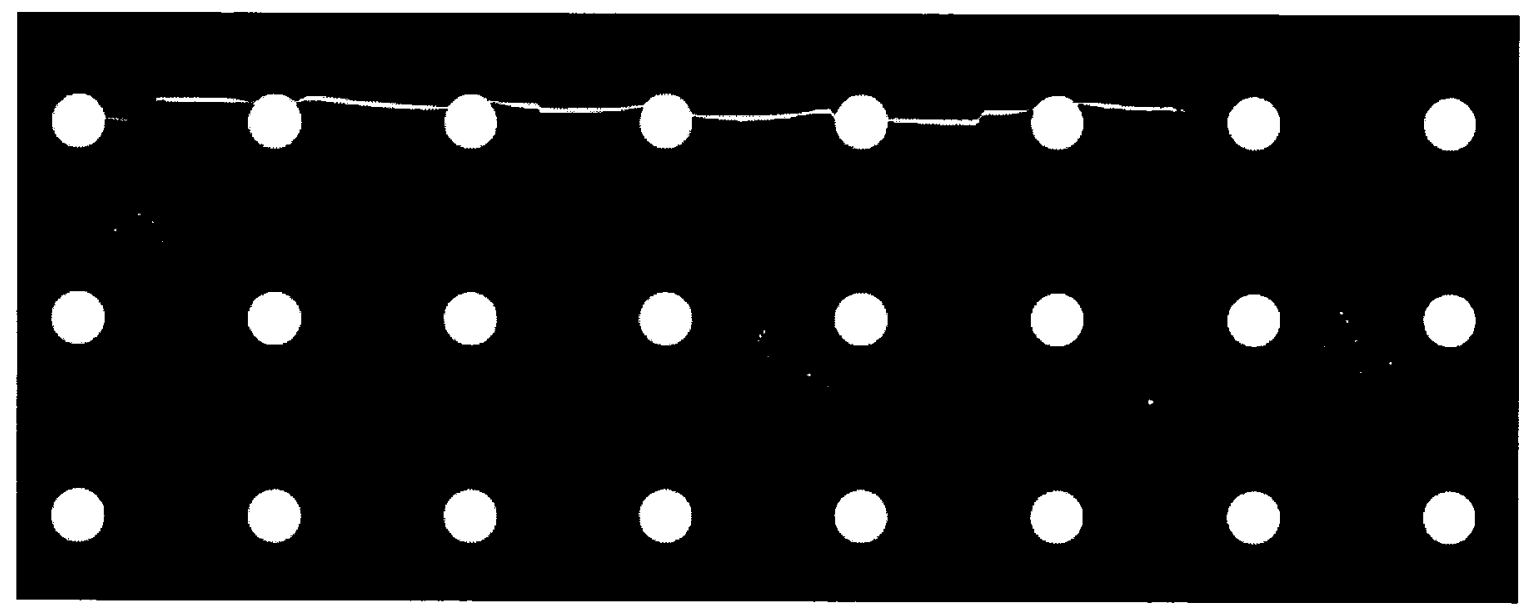

Figure C- 7: Pit map image for specimen 054, outer sheet

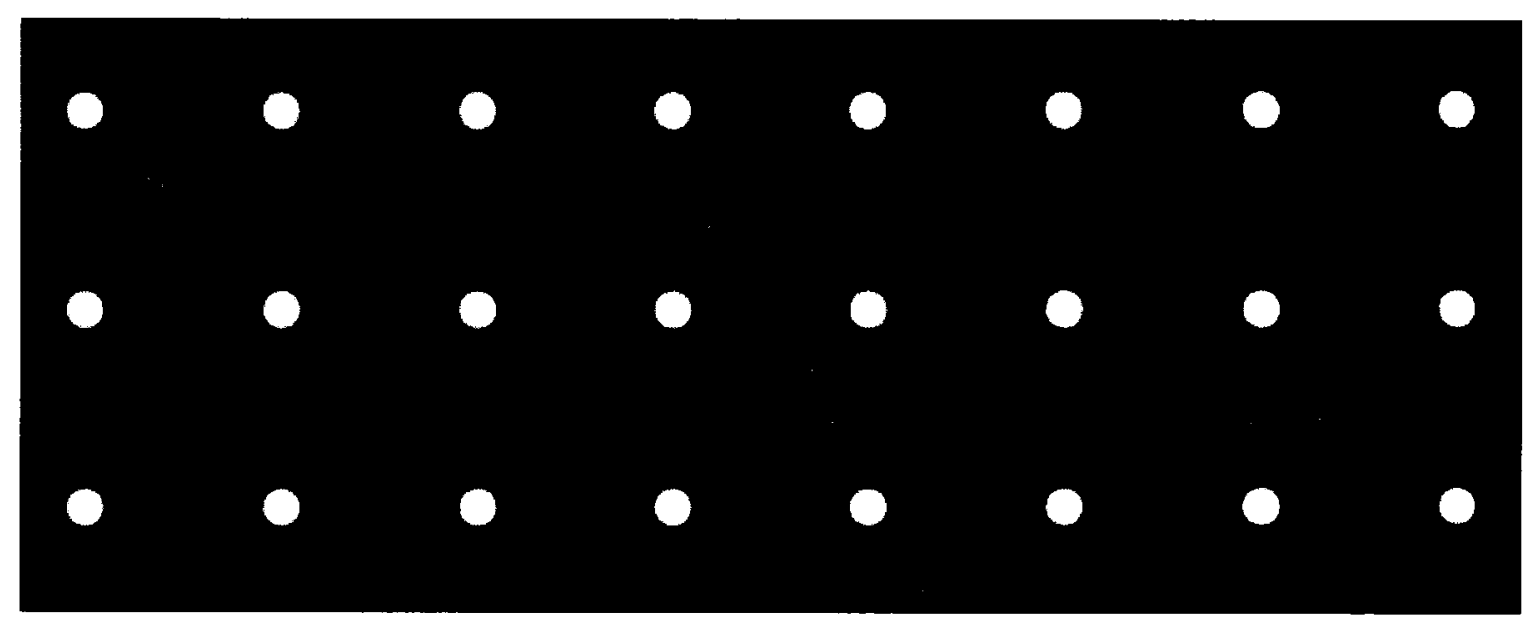

Figure C- 8: Pit map image for specimen 054, inner sheet 


\section{C.2: Pit Geometry Verification Data}

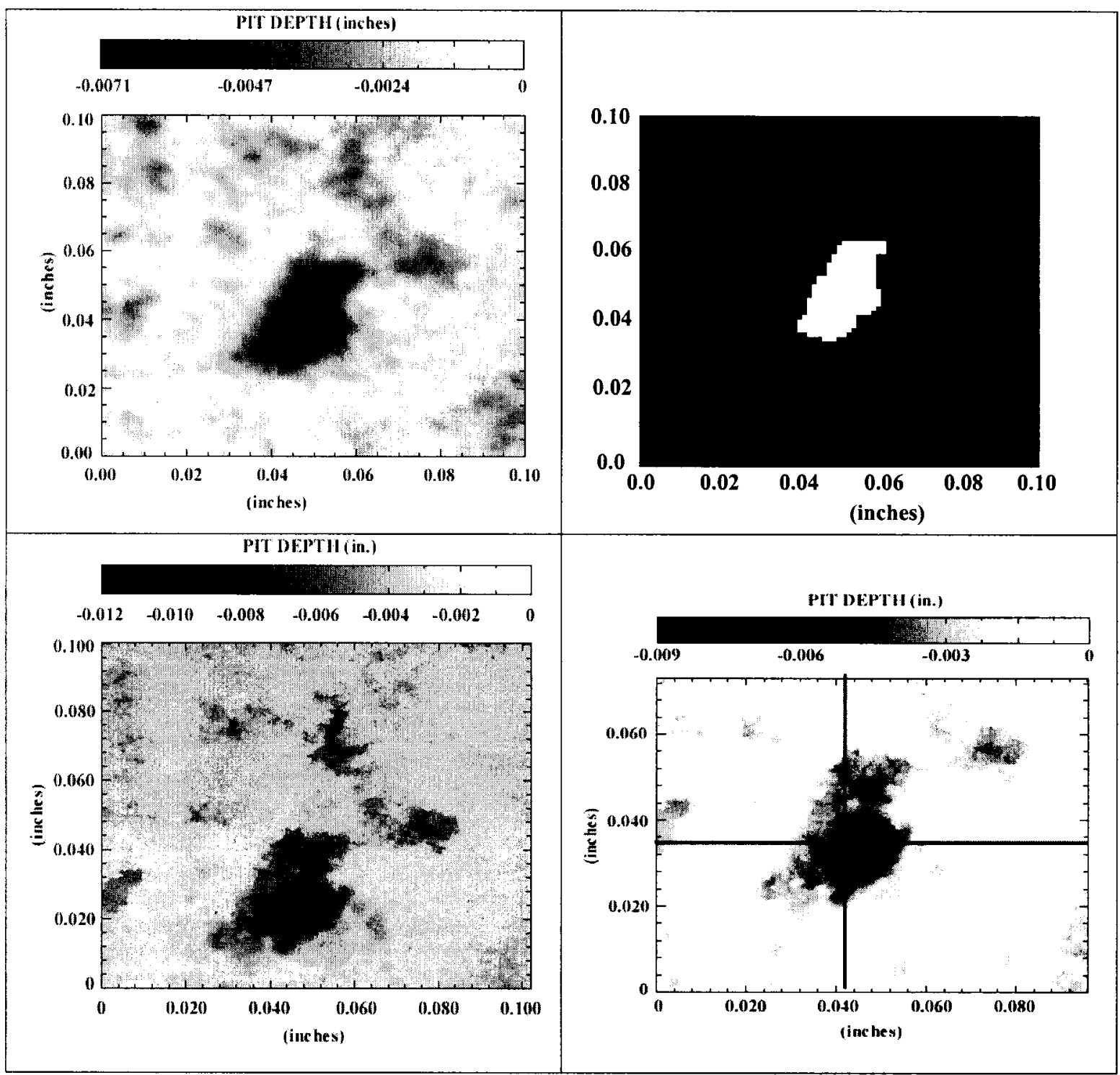

Figure C- 9: Corrosion pit geometry for specimen 037csk E pit 3 (a) DXR image (b) Segmented pit geometry from DXR image analysis (c) Confocal microscope (d) Wyko ${ }^{\circledR}$ optical profiler. 


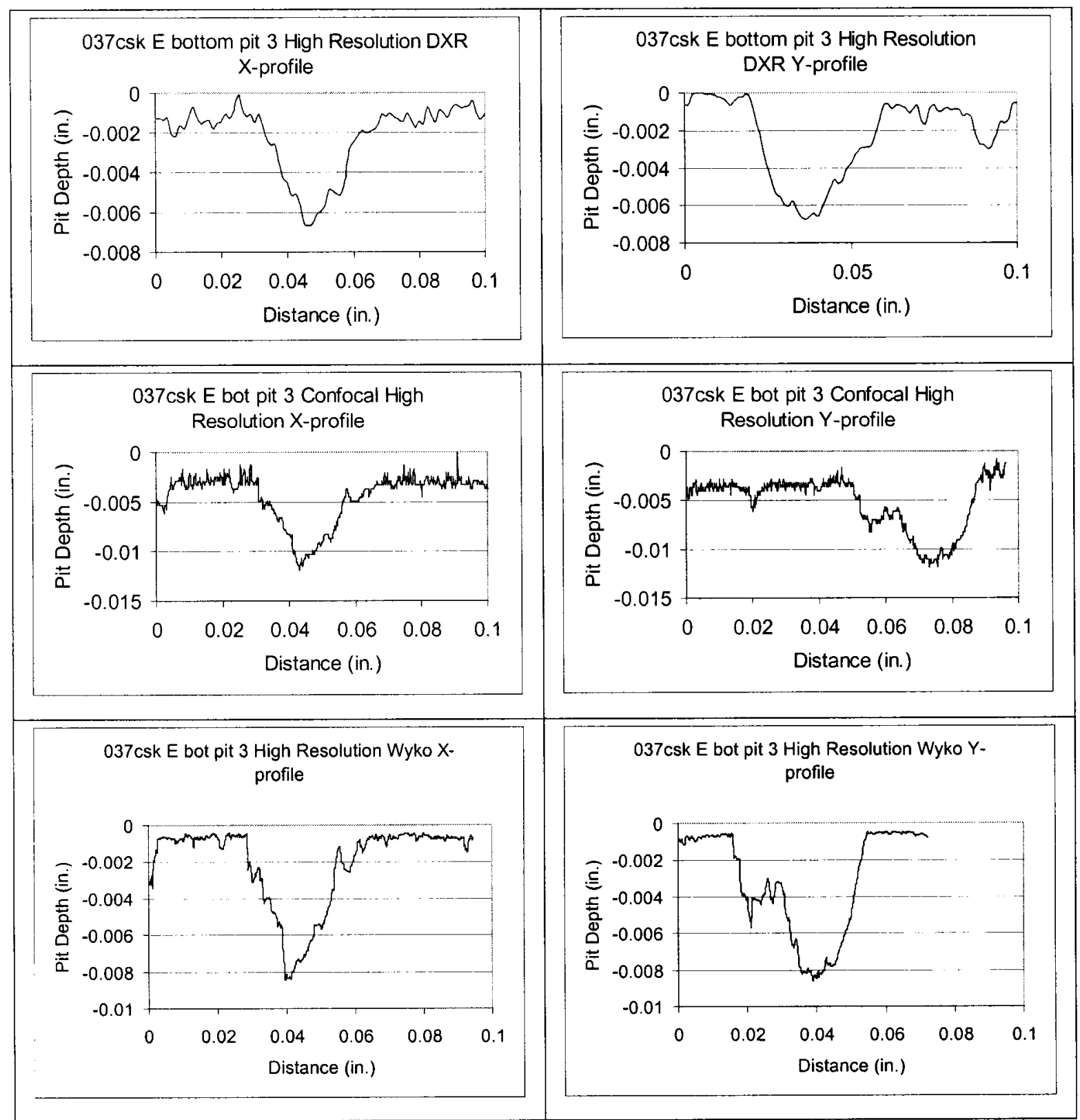

Figure C-10: High-Resolution Corrosion pit geometry line profiles for specimen 037 csk E pit 3. 


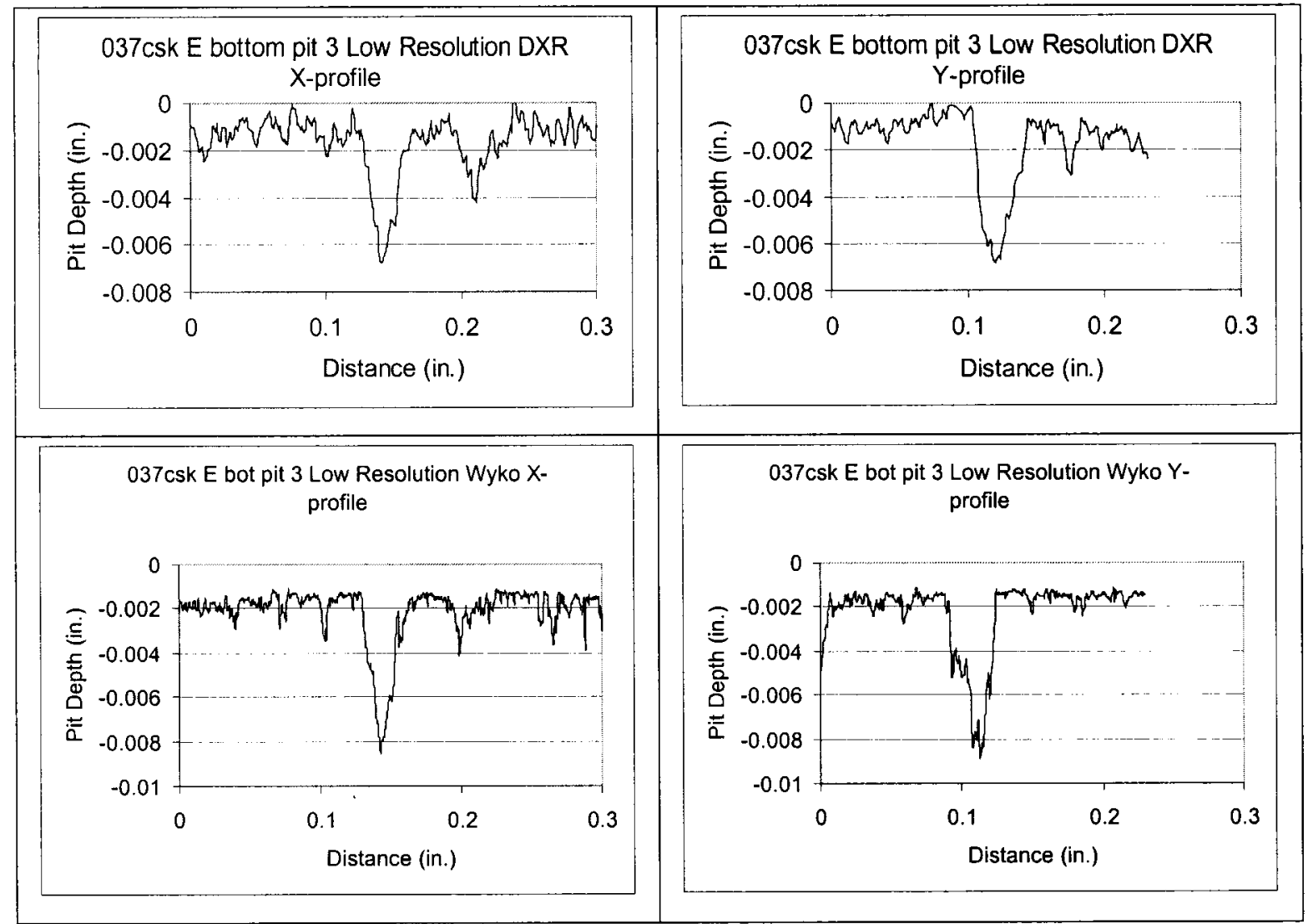

Figure C- 11: Low-Resolution Corrosion pit geometry line profiles for specimen 037csk E pit 3. 


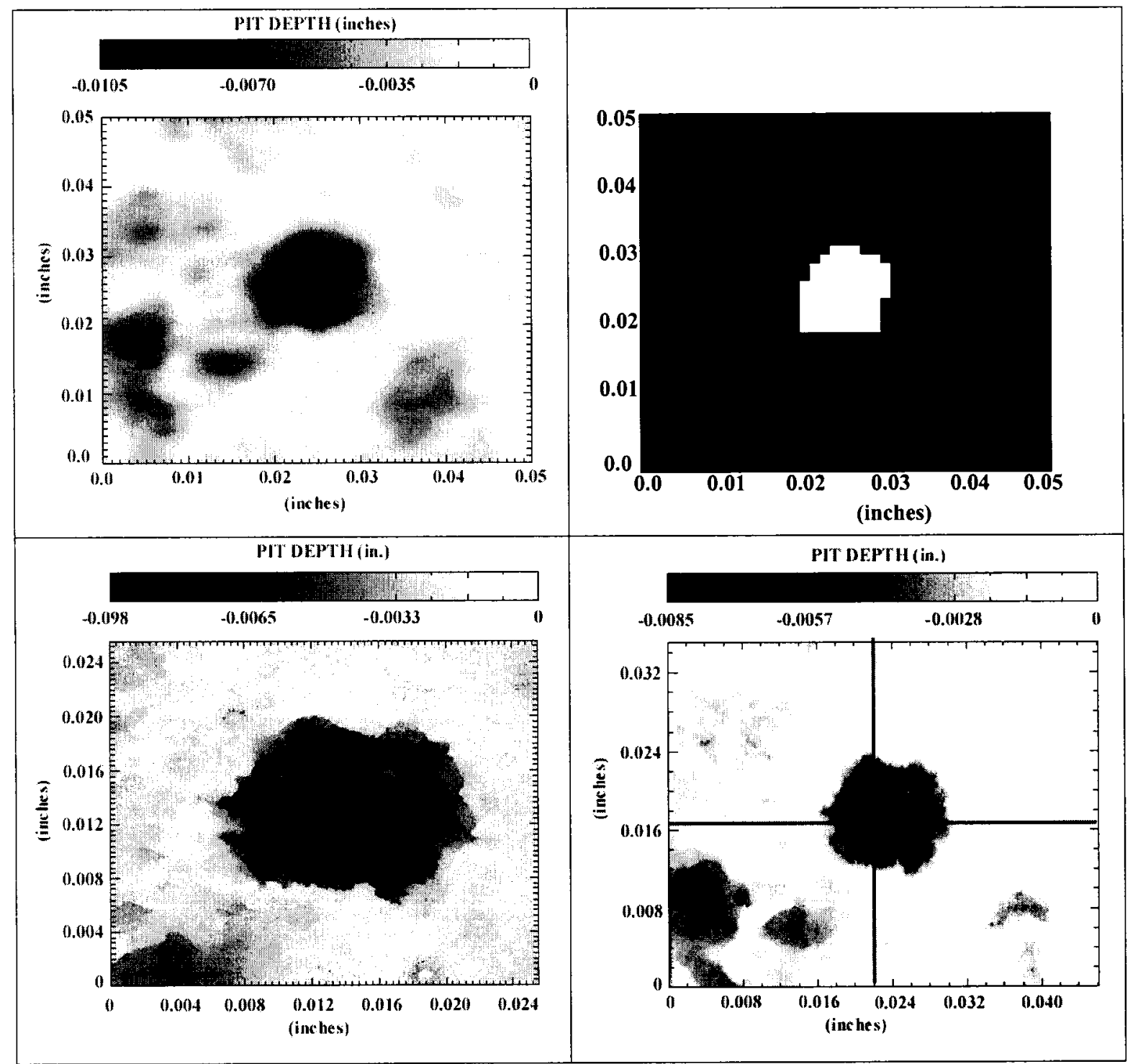

Figure C- 12: Corrosion pit geometry for specimen 049csk L pit 2 (a) DXR image (b) Segmented pit geometry from DXR image analysis (c) Confocal microscope (d) Wyko $^{\circledR}$ optical profiler. 


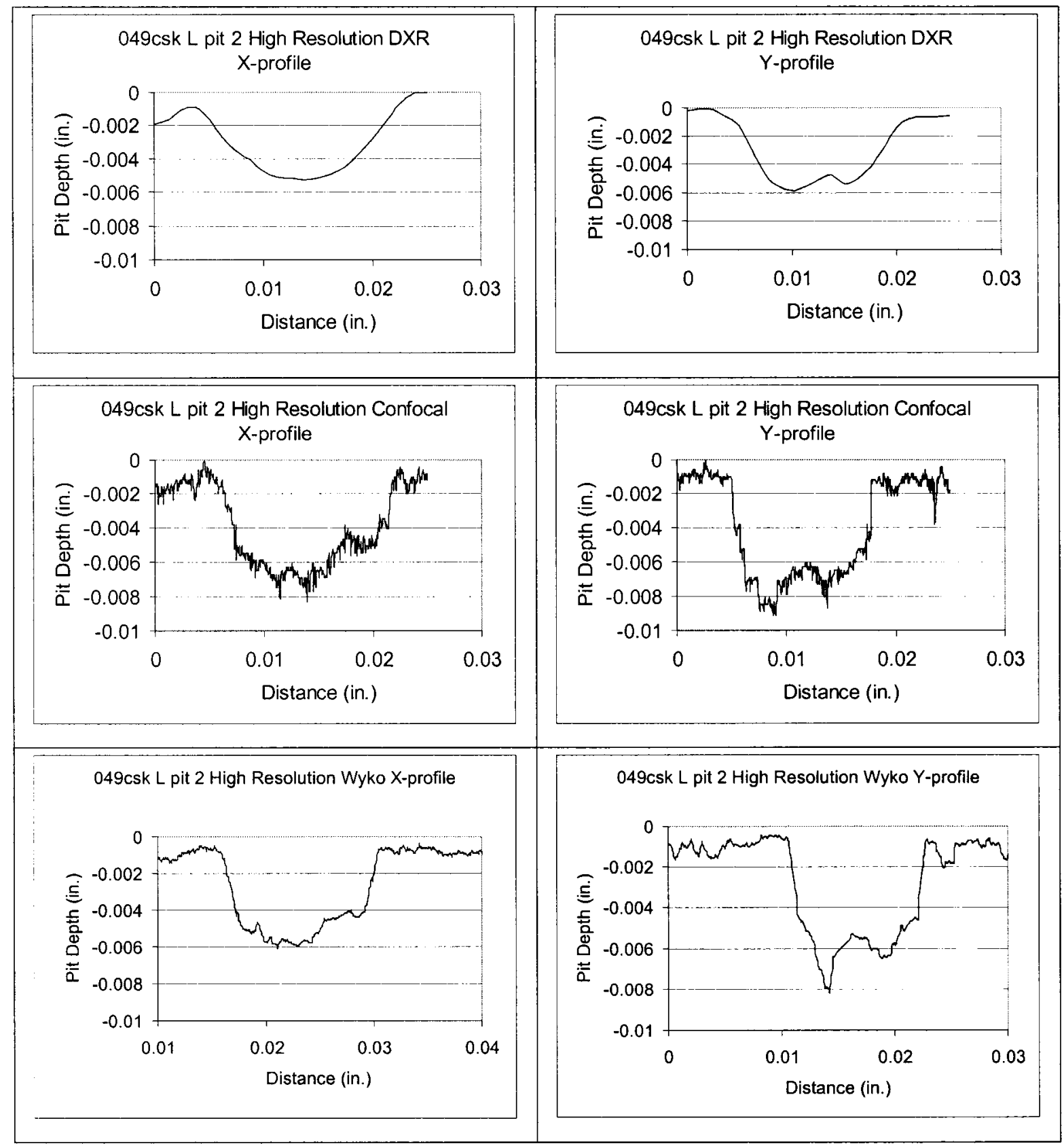

Figure C- 13: High-Resolution Corrosion pit geometry line profiles for specimen 049 csk L pit 2. 


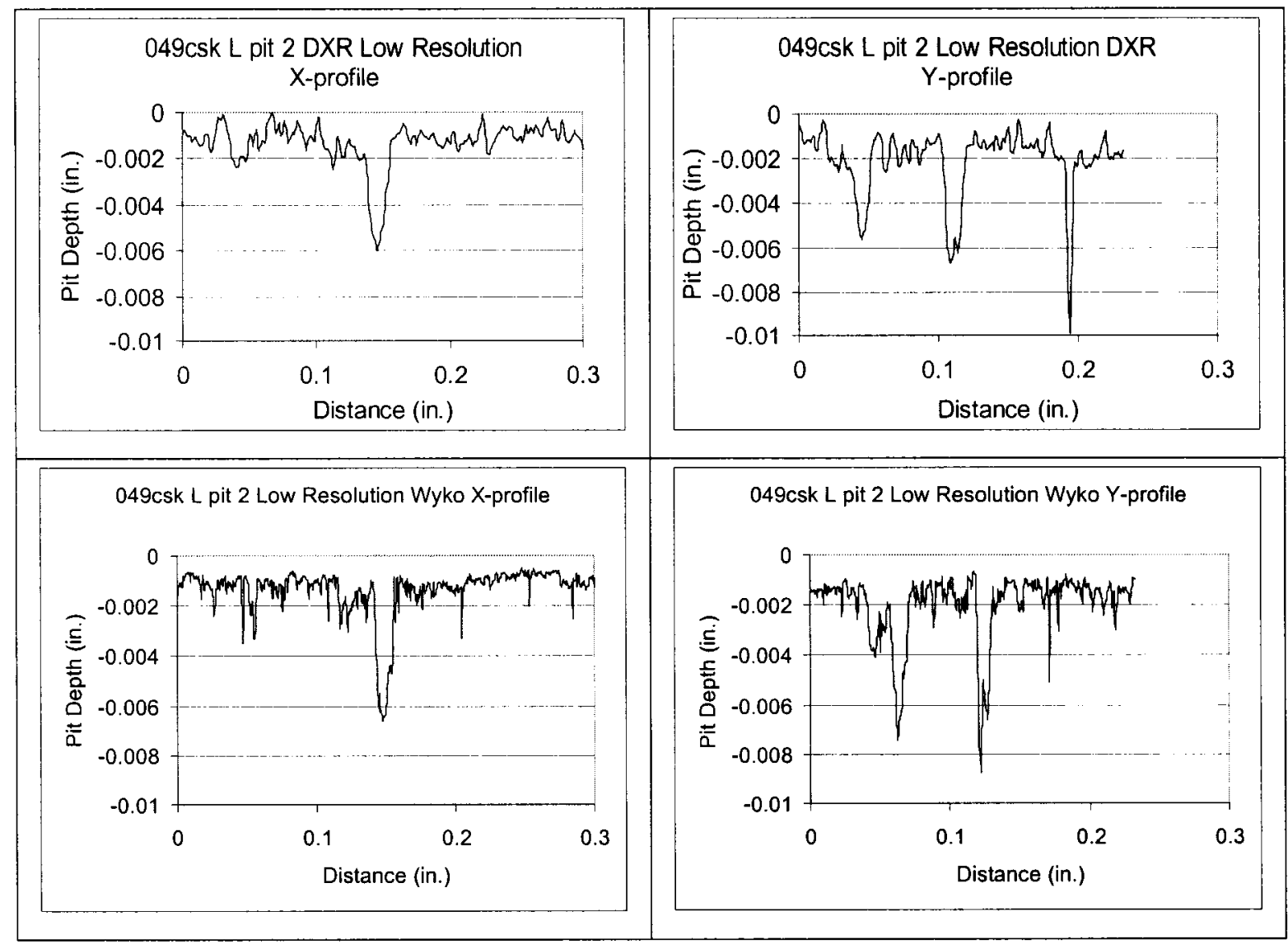

Figure C- 14: Low-Resolution Corrosion pit geometry line profiles for specimen 049 csk L pit 2. 


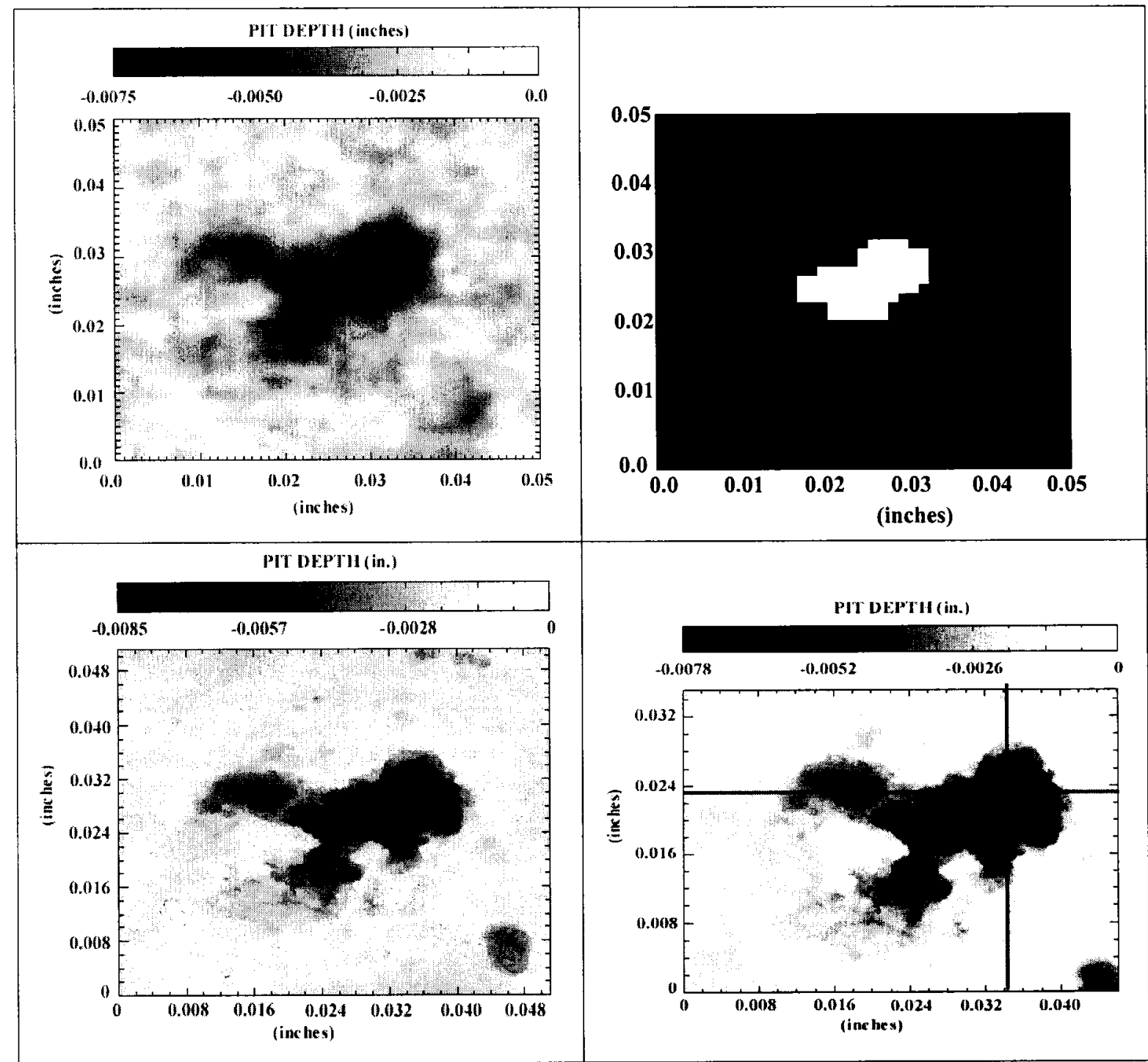

Figure C- 15: Corrosion pit geometry for specimen 049drv L pit 2 (a) DXR image (b) Segmented pit geometry from DXR image analysis (c) Confocal microscope (d) Wyko ${ }^{\mathbb{B}}$ optical profiler. 


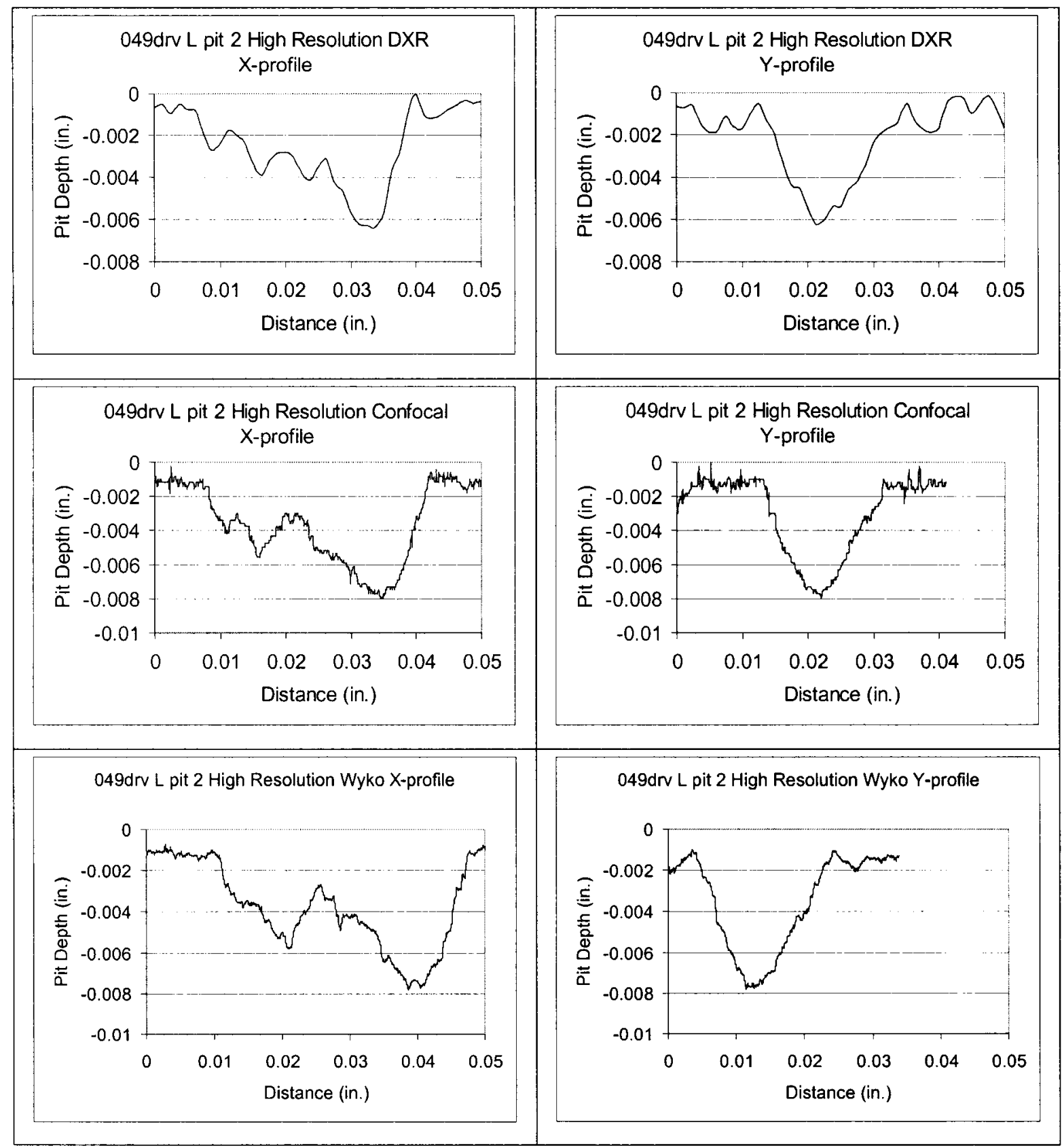

Figure C- 16: High-Resolution Corrosion pit geometry line profiles for specimen 049drv L pit 2. 


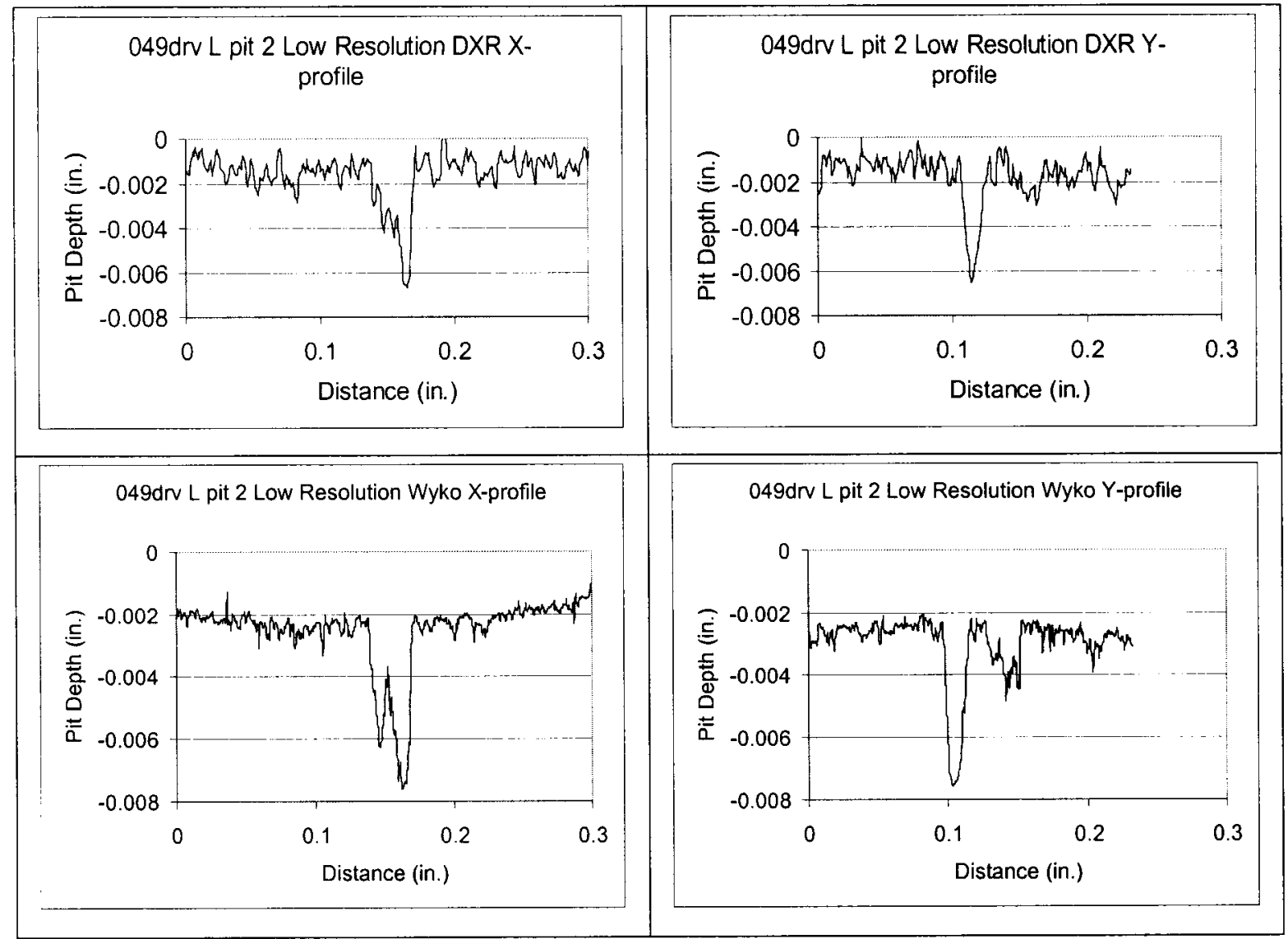

Figure C- 17: Low-Resolution Corrosion pit geometry line profiles for specimen 049drv L pit 2. 


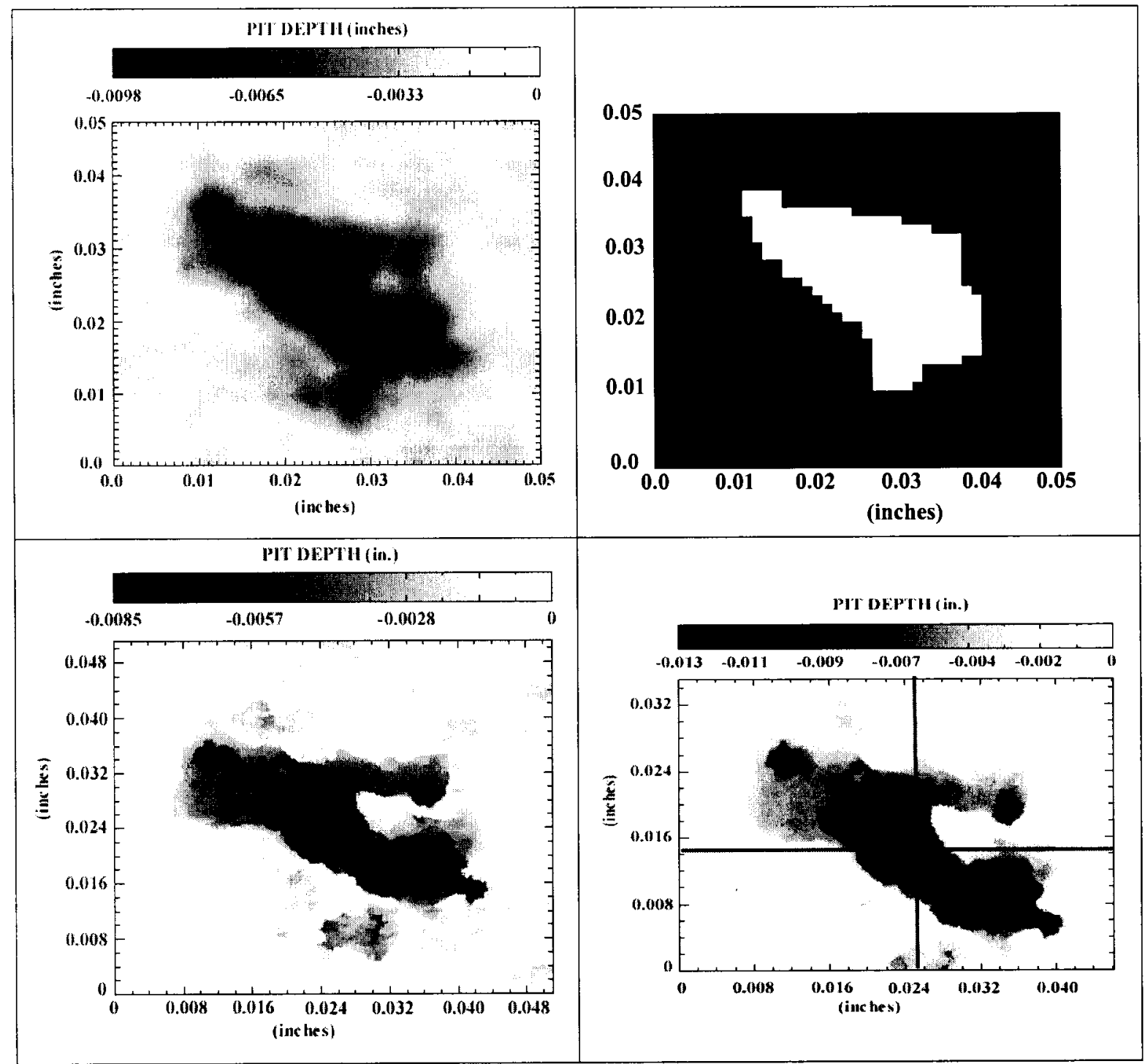

Figure C-18: Corrosion pit geometry for specimen 050csk G pit 1 (a) DXR image (b) Segmented pit geometry from DXR image analysis (c) Confocal microscope (d) Wyko $^{\text {(i) }}$ optical profiler. 


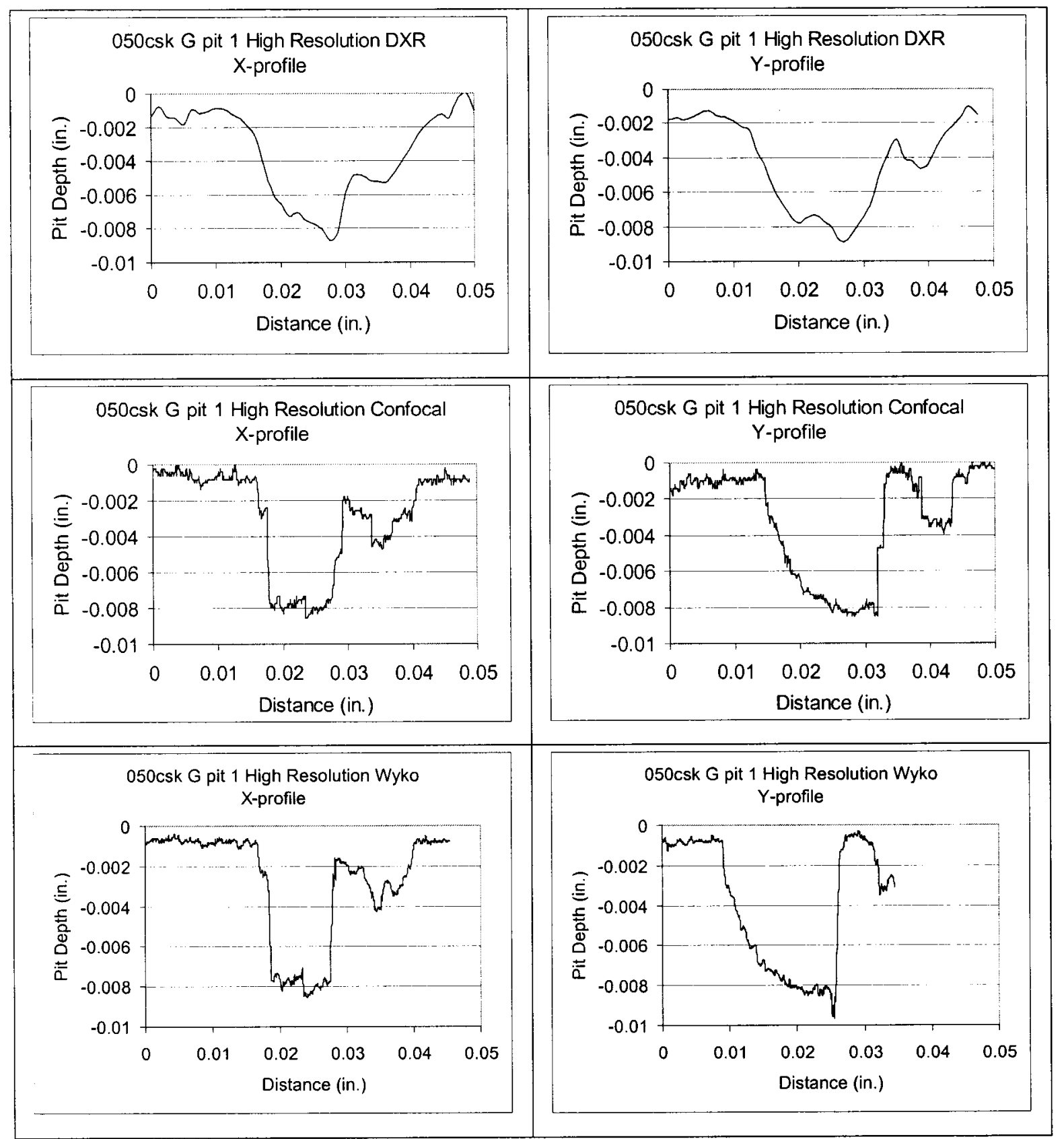

Figure C- 19: High-Resolution Corrosion pit geometry line profiles for specimen 050 csk $G$ pit 1. 


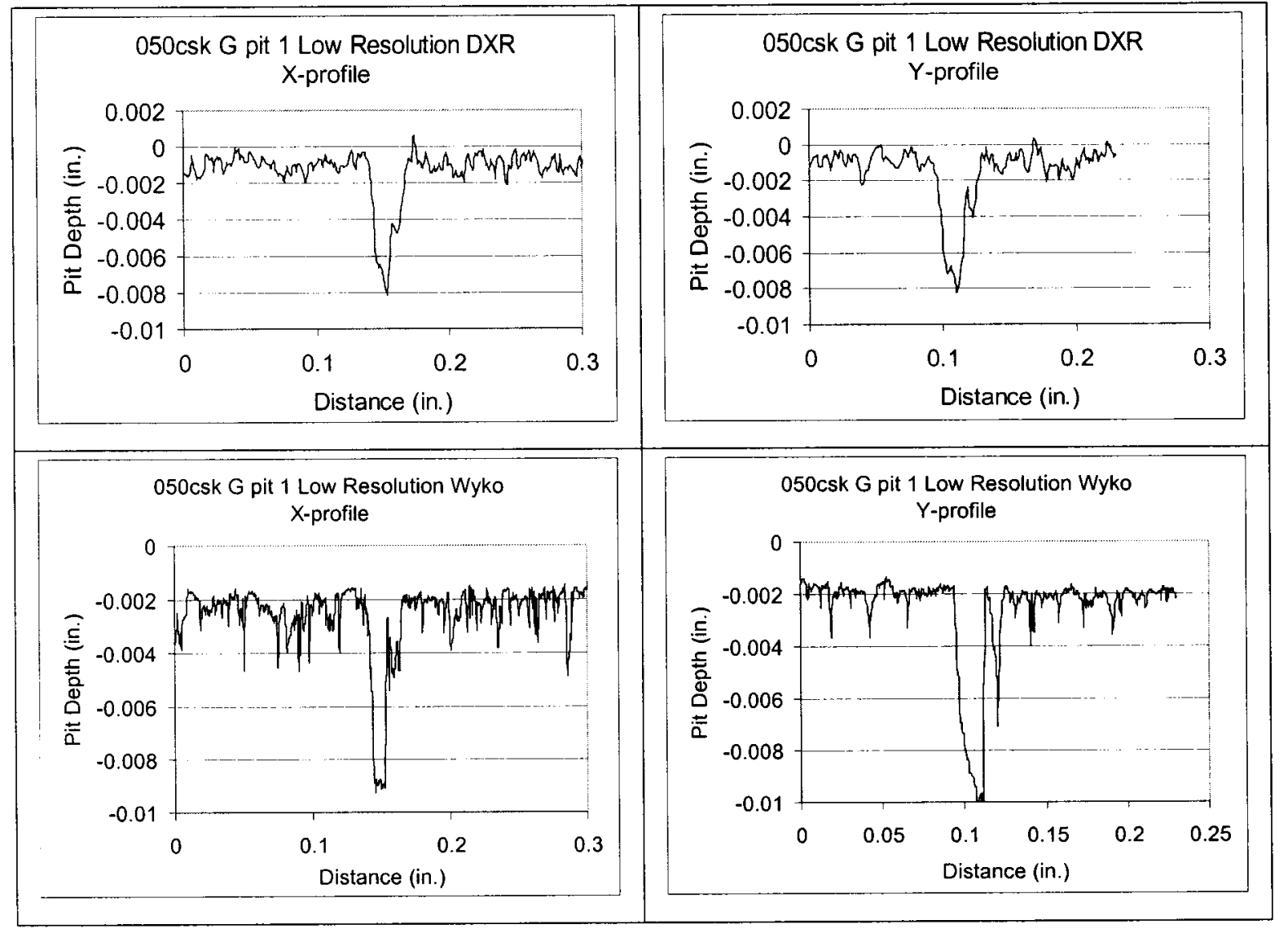

Figure C- 20: Low-Resolution Corrosion pit geometry line profiles for specimen 050 csk G pit 1 . 


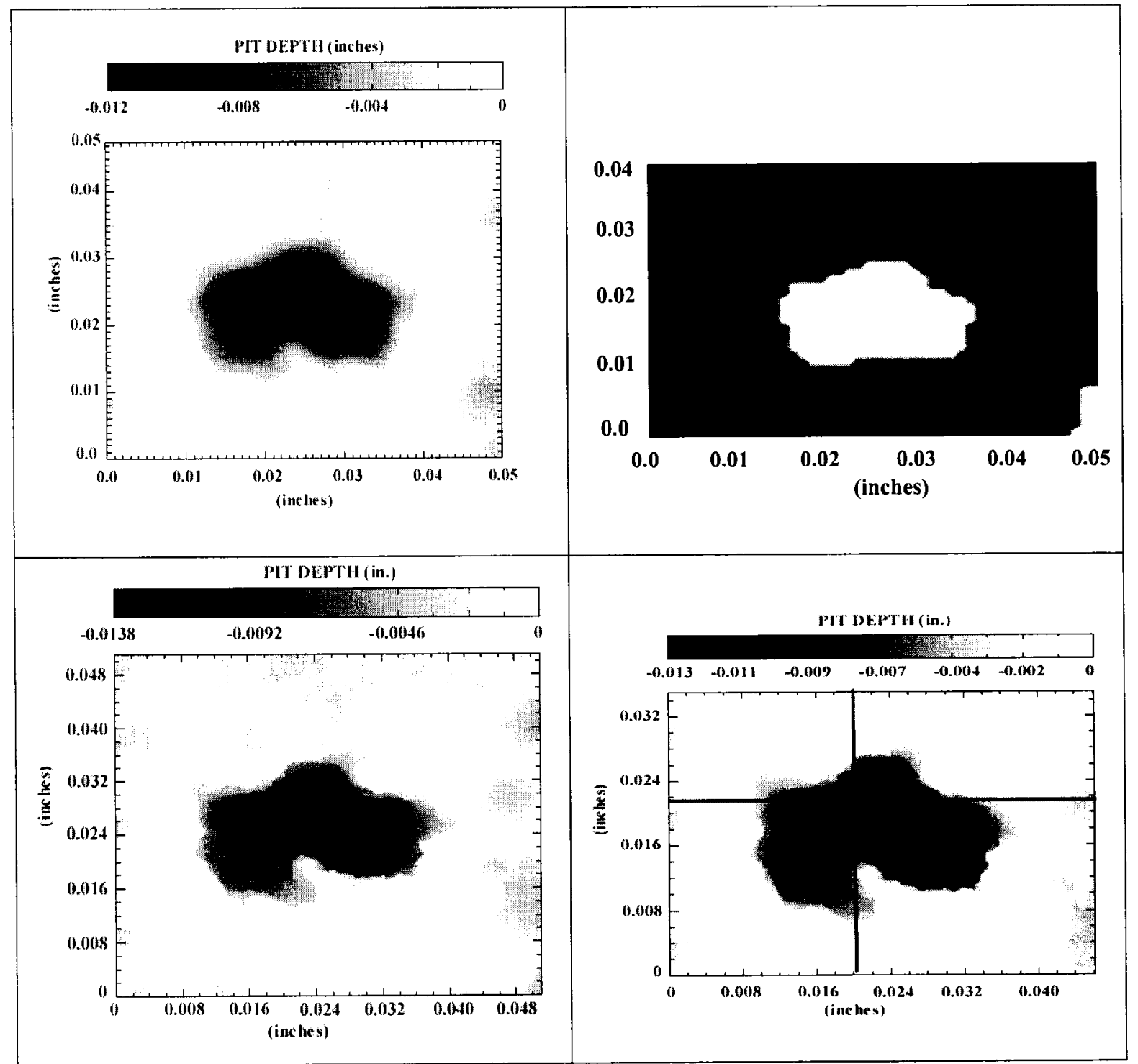

Figure C- 21: Corrosion pit geometry for specimen 050csk G pit 4 (a) DXR image (b) Segmented pit geometry from DXR image analysis (c) Confocal microscope (d) Wyko $^{\text {op }}$ optical profiler. 


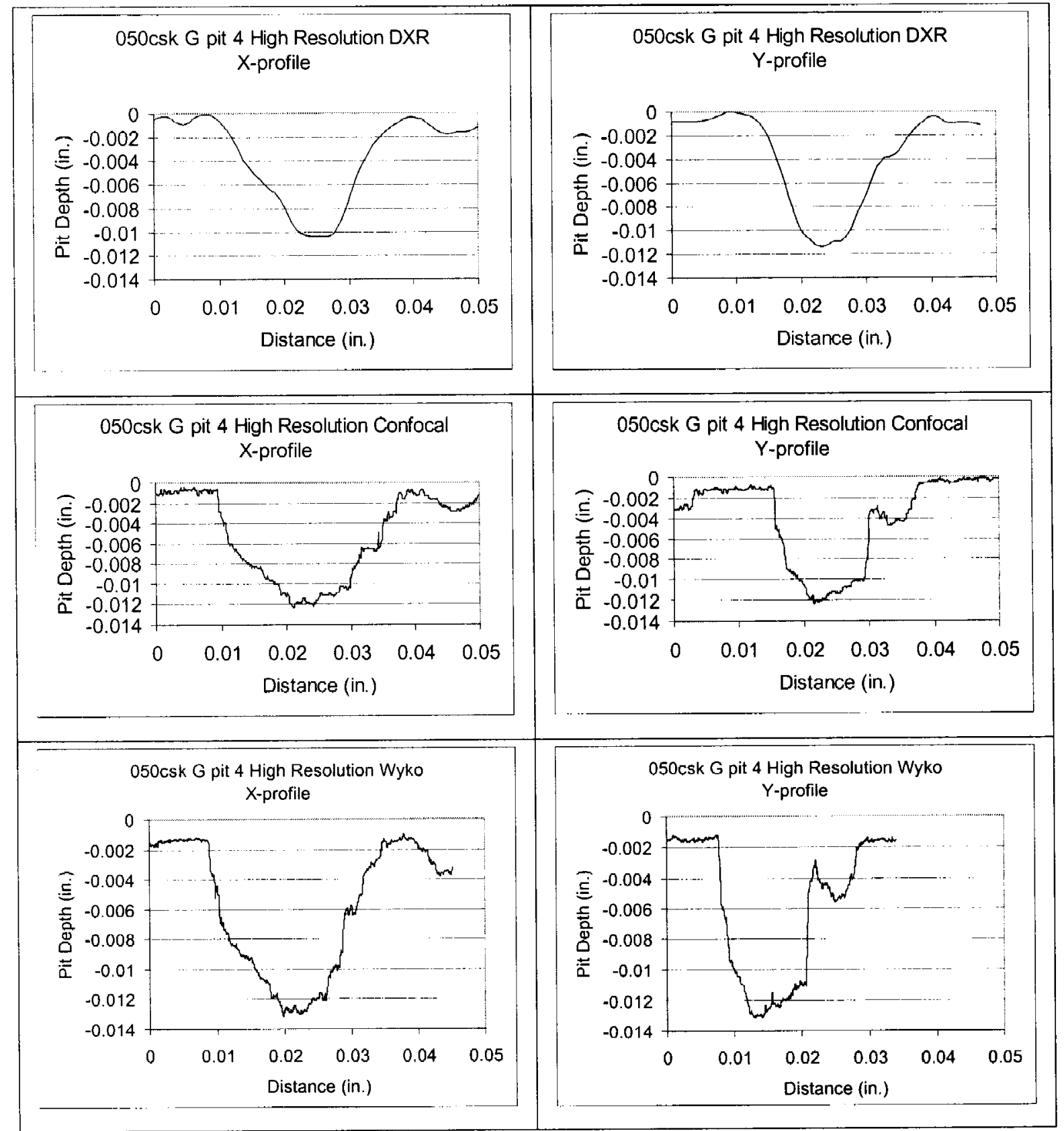

Figure C- 22: High-Resolution Corrosion pit geometry line profiles for specimen 050 csk G pit 4. 


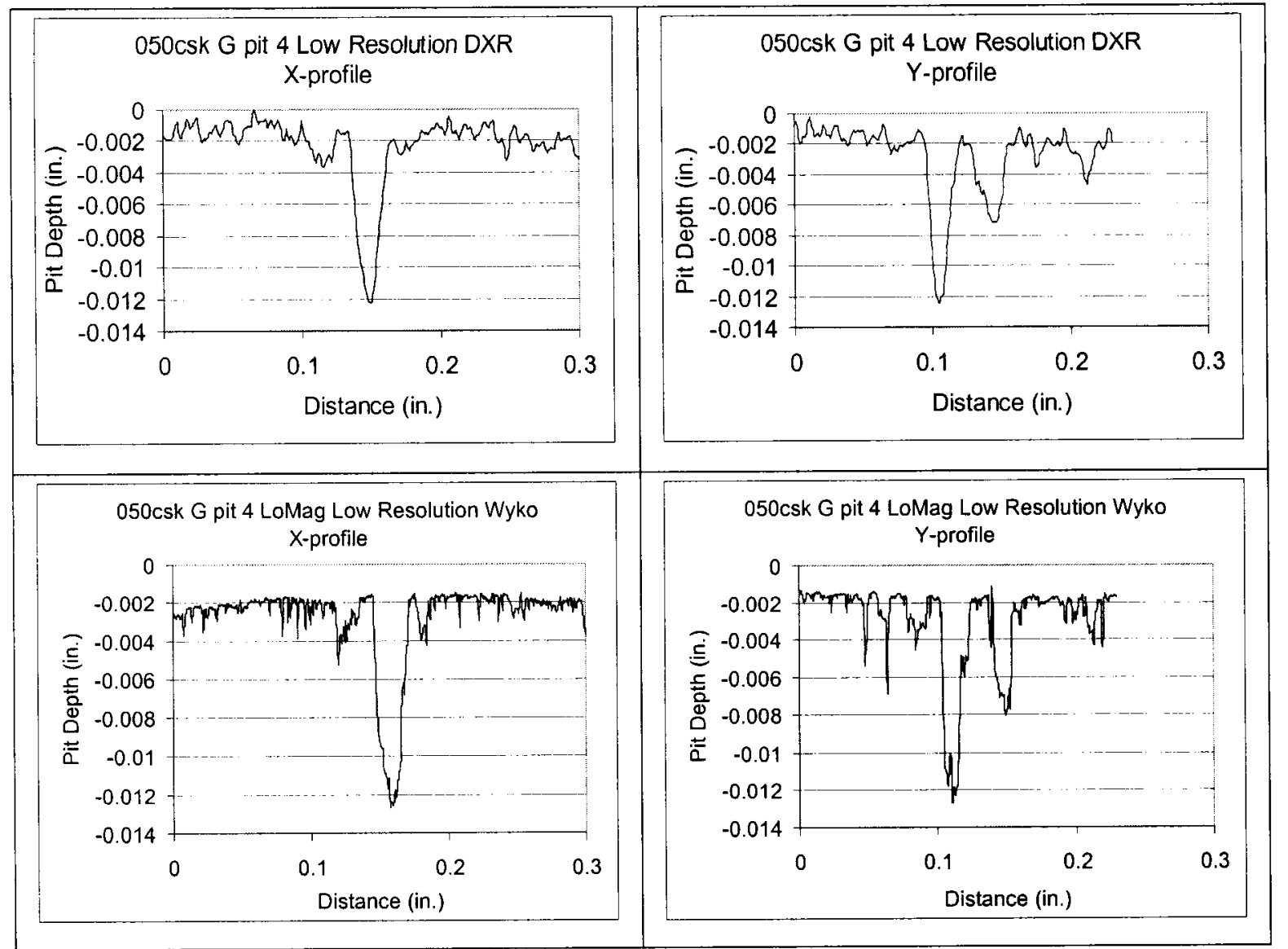

Figure C- 23: Low-Resolution Corrosion pit geometry line profiles for specimen 050csk $G$ pit 4 . 